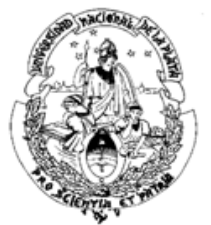

Tesis Doctoral

\title{
Relaciones filogenéticas y biogeográficas de las especies del género Pleurodema (Amphibia: Anura: Leiuperidae)
}

\author{
Daiana Paola Ferraro
}

Director: Dr. Esteban Orlando Lavilla Co-director: Prof. J orge Daniel Williams

Facultad de Ciencias Naturales y Museo Universidad Nacional de La Plata 
A mi amado compañero, Ariel

A quienes representan una luz en nuestras vidas, Candela y Guadalupe (jen camino!) 


\section{Agradecimientos}

Les agradezco en primer lugar a mis directores de tesis, Esteban Lavilla y Jorge Williams, por haberme guiado y apoyado a lo largo de estos años. A mi directora de beca, Mercedes Azpelicueta, por haberme ayudado en esta tesis infinidad de veces, corrigiendo minuciosamente las versiones que iba recibiendo.

A Gustavo Carrizo y Julián Faivovich (Museo Argentino de Ciencias Naturales, "B. Rivadavia”, Buenos Aires); Esteban Lavilla, Sonia Kretzschmar y Marta Cánepa (Fundación Miguel Lillo, Tucumán); Flavia Lagiglia y Ricardo Juárez (Museo de Historia Natural de San Rafael, Mendoza), Arley Camargo y Raúl Maneyro (Facultad de Ciencias, Universidad de la República, Montevideo, Uruguay), Pepe Langone, Diego Arrieta y Enrique González (Museo Nacional de Historia Natural y Antropología, Montevideo, Uruguay), Felipe Toledo (Museu de Zoologia "Prof. Dr. Adão José Cardoso, Universidade Estadual de Campinas, Brasil) por permitirme estudiar material bajo su cuidado y ofrecerme espacio físico para trabajar en sus Instituciones.

A Gustavo Carrizo y Julián Faivovich (Museo Argentino de Ciencias Naturales, “B. Rivadavia", Buenos Aires); Marissa Fabrezzi (Museo de Ciencias Naturales, Universidad Nacional de Salta); Marta Patricia Ramírez (Escuela de Biología, Universidad Industrial de Santander, Bucaramanga, Colombia), Hussam Zaher (Museo de Zoología de la Universidad de Sâo Paulo, Brasil) y Esteban Lavilla (Fundación Miguel Lillo) por facilitarme valioso material en calidad de préstamo para realizar preparaciones osteológicas.

Muy especialmente agradezco a J ulián Faivovich por interesarse en mi trabajo desde que me conoció, por ser crítico y objetivo, por aportarme ideas, bibliografía, conocimientos y todo lo estuvo a su alcance para mejorar mi trabajo.

A Raúl Maneyro, por enviarme fotografías de las preparaciones osteológicas de Pleurodema aff. bibroni. A José Enrique Gonzalez Fernandez (Museo Nacional de Ciencias Naturales, Madrid, España), Franz Tiedemann (Naturhistorisches Museum Wien, Vienna, Austria), por enviarme fotografías de materiales tipo depositados en las colecciones bajo su cuidado.

A Diego Baldo y su familia; J orge Baldo y Yanina Arzamendia; Mónica Barg y su familia; Sebastián Barrionuevo y su familia; Néstor Basso; Darío Cardozo; Dolores Casagranda; Sabrina Clavijos, Andrea y Verónica Dallagnol; Ricardo Juárez e Inés Aguer; Agustín y Soledad de Tilcara y Liliana Ferrari porque me abrieron las puertas de sus casas durante diversos viajes. 
A Leandro Alcalde, Diego Baldo, Néstor Basso, Igor Berkunsky, Boris Blotto, Claudio Borteiro, Ricardo Buff, Darío Cardozo, Cecilia Diminich, Manuel Gontero Fourcade, Julián Faivovich, Adriana Jerez, Federico Kacoliris, Francisco Kolenc, Cecilia Kopuchian, Liliana Ferrari, Pepe Langone, Fernando Lobo, M. Inés Martínez Oliver, Gabriela Perotti, Silvia Moro, Laura Nicoli, Diego Nuñez, Silvana Peiretti, Martín Pereyra, Laurita Ponssa, Sergio Rosset, Gustavo Scrocchi, Cristian Tomatis y Carmen Úbeda por facilitarme bibliografía, responder varias inquietudes en diferentes momentos de este trabajo y/o alcanzarme material desde sus instituciones. Muy especialmente a Ricardo Buff, que infinidad de veces me facilitó bibliografía desinteresadamente. A Boris Blotto, Darío Podestá, Francisco Kolenc y Julián Valetti por brindarme algunas de las fotos que ilustran esta tesis. A Cristina Machado por su ayuda en la traducción del alemán.

En la etapa final de esta tesis fue inmejorable el apoyo y compañía de los "chicos" de la División Herpetología del MACN: Boris Blotto, Martín Pereyra, Laura Nicoli, Sebastián Barrionuevo, Andrés Brunetti, Andrés Sheikman, Carlos Taboada y Francisco Solá. Todos ellos en mayor o menor medida me dieron opiniones, sugerencias, críticas iy hasta apoyo moral!; especialmente quiero agradecerles todas las discusiones en relación a la codificación de caracteres, uso del TNT, etc. Especialmente estoy agradecida a Cecilia Kopuchian (MACN), quien me ayudó en aspectos cladísticos, siempre con excelente predisposición y paciencia. Todos ellos dispusieron generosamente de su tiempo y de sus conocimientos. A J uan Manuel Díaz Gómez y Mariano Donato por la desinteresada y cordial ayuda en los análisis biogeográficos. A Diego Baldo, Martín Pereyra, Cristian Tomatis y Sergio Rosset por las sugerencias sobre los caracteres de citogenética.

A Diego Baldo, Mónica Barg, Boris Blotto, Claudio Borteiro, Andrés Brunetti, Darío Cardozo, Francisco Kolenc, Erika Kubisch, Marcelo Tedros, Martín Pereyra y Sergio Rosset por haber sido excelentes compañeros de campañas, con los cuales recorrí hermosos lugares de nuestro país, descubriendo la naturaleza a cada paso.

Agradezco especialmente a Julián, Diego, Sergio, Boris y Laura, por ser inagotables apoyos morales a lo largo de este trabajo (tan necesario en algunas etapas), además de haber estado siempre dispuestos a discutir ideas. 
A la Dirección General de Medio Ambiente y Desarrollo Sustentable (Provincia de La Rioja), Secretaría de Medio Ambiente y Desarrollo Sustentable (Provincia de Salta), Dirección de Recursos Naturales y Suelos (Provincia de Tucumán), Dirección Provincial de Recursos Naturales y Medio Ambiente (Provincia de J ujuy), Dirección de Ambiente (Provincia de Córdoba), Departamento de Flora y Fauna Silvestre (Provincia de Buenos Aires), Secretaria de Estado de Producción (Provincia de Río Negro), Dirección de Fauna y Flora Silvestres (Provincia de Chubut) y Delegación Regional Patagonia y Delegación Regional Centro de la Administración de Parques Nacionales por los permisos de colecta e investigación otorgados que hicieron posible la realización del presente trabajo.

A la Universidad Nacional de La Plata y al Consejo Nacional de Investigaciones Científicas y Técnicas (CONICET) por brindarme las Becas Doctorales que posibilitaron este estudio. A la Universidad Nacional de La Plata (Resoluciones № 68/ 07 y 1299/ 08) por los subsidios de investigación otorgados y a Idea Wild (EE.UU.) por los equipamientos provistos.

Desde lo personal, quiero agradecer a mis padres, que desde siempre me han criado con libertad para elegir (y equivocarme), siendo un ejemplo de amor a lo largo de los años. A mi mamá también por cuidar de Cande y ayudarme siempre en todo lo que estuviera a su alcance, estando atenta hasta en los más mínimos detalles. Hago extensivo el agradecimiento a mi hermano y su familia, porque todos ellos siempre creyeron en mí y confiaron en el camino que elegí. A mi hermosa sobrina, Loli, por haber venido al mundo a irradiar dulzura, simpatía y amor. Por la paciencia, la compañía, el aguante, la ayuda económica y todo lo que hace a una familia, les agradezco infinitamente.

A la familia de Ariel: Liliana, Soledad y María, por abrirme las puertas de su corazón, por el apoyo constante y por cuidar de Cande las veces que el tiempo apremiaba.

A mis amigas del alma, que me acompañaron desde mi más temprana decisión por estudiar biología. Emi, por ser mi hermana del alma; Angi, por su irónica frescura y por estar siempre; Maie, por su compañía inquebrantable; Cari, por recordarme que siempre hay que luchar por lo que debe ser defendido. A todas ellas, por escucharme largas tardes de mate hablar de ranas, informes, becas, viajes, etc. A las entrañables amigas que me dio la profesión: Vani, Mae, Malala, Lau y Mag, por ser todas y cada una personas admirables, dulces y compañeras. A todas ellas, por permitirme 
conocerlas y tenerlas de amigas, por siempre oficiar de "oído" a todas las vicisitudes de la profesión. Y además, cada una me dejó entrar en otros espacios de sus vidas. Vani, por compartir no sólo cuestiones laborales si no por haber conversado miles de veces de pañales, chupetes, noches sin dormir, etc. Mae, por entrar un poco más en mi mundo a través del folclore y divertirnos en muchas peñas. Malala, por su apoyo en todo momento. Lauri, por su simpatía inagotable, y también por sus consejos de mamá. Mag, por intentar siempre planes para romper la rutina. Y también otros amigos ganados a través de esta profesión: Sergio, Diego, Boris y Lauch, quienes siempre, desde que los conocí, se convirtieron en fuente de consulta constante, y algo mejor aún: en entrañables amigos.

A Lucas, quien a pesar de la distancia siempre tuvo un lugar especial en mi vida. Por su particular sentido del humor, por no entender muy bien qué hago pero igual estar siempre ahí. Siempre.

Un párrafo aparte merece mi gran compañero en este camino. Ariel, con su infinita paciencia, me ha enseñado a disfrutar la vida de otra manera y a hacer las cosas con amor y entrega; me ayuda a ser más fiel a mí misma tolerando e incentivando cada una de mis nuevas inquietudes. Es la persona que más estoicamente ha escuchado y acompañado mis momentos de mayor desazón, siempre dándome apoyo y palabras de aliento con su mayor dulzura y amor, apuntalándome siempre en mi camino, nuestro camino. No sólo me ha ayudado escuchándome sobre todos y cada uno de mis proyectos en Pleurodema, o leyendo textos en inglés y portugués, sino que también ha sacrificado vacaciones acompañándome en las campañas. Y como no podía ser de otra manera, de esta unión ha venido al mundo Candela, que no deja de sorprendernos día a día con su crecimiento, con sus risas, sus bailes, sus palabras, su alegría tan pura y regocijante y todo el amor que tiene para dar. Por ser tan dulce, hermosa, cariñosa y alegre es una luz que guía nuestros corazones y hace que la vida cobre más sentido, otro sentido. $Y$ no conformes con esta belleza, está en camino otra belleza, Guadalupe, quien tolera los nervios y apuros del final de la tesis, acompañándome día a día con sus suaves pataditas. Sin ellos tres, nada sería igual de hermoso. 


\section{Resumen en español \\ Resumen en inglés}

Introducción.

I. Síntesis histórica del género Pleurodema

II. Ubicación taxonómica del género Pleurodema

III. El género Pleurodema como modelo de estudio

IV. Análisis filogenético

V. Análisis biogeográfico

VI. Objetivos

Materiales y Métodos.

I. Morfología externa

II. Morfometría

III. Osteología

IV. Biología reproductiva

V. Análisis filogenético

v.i. Selección de taxones

v.ii. Grupo interno

v.iii. Grupo externo

v.iv. Selección y codificación de caracteres

v.v. Matriz de datos

v. vi. Pesos iguales y pesado de caracteres

v. vii. Estrategias de búsqueda

v. viii. Medidas de soporte

v.ix. Análisis cladístico excluyendo especies poliploides

VI. Análisis biogeográfico

Capítulo I. Morfología externa

Capítulo II. Morfometría

Capítulo III. Osteología 66

Capítulo IV. Biología reproductiva 88

Capítulo V. Análisis filogenético 96

5.1. Caracteres seleccionados

5.1.1. Caracteres exo-morfológicos

5.1.2. Caracteres osteológicos

5.1.3. Caracteres reproductivos

5.1.4. Caracteres sexuales secundarios

5.1.5. Caracteres de anatomía interna de órganos blandos

5.1.6. Caracteres citogenéticos

5. 1.7. Caracteres larvales

5.1.8. Caracteres musculares

5.2. Análisis cladístico

5.3. Discusión de las relaciones filogenéticas de Pleurodema

5.4. Análisis cladístico excluyendo las especies poliploides

Capítulo VI. Análisis biogeográfico

6.1. Distribución de las especies de Pleurodema 
6.2. Distribución de los grupos externos

6.3. Reconstrucción del área ancestral de Pleurodema según Optimización de Fitch (Ronquist 1994)

6.4. Reconstrucción de las distribuciones ancestrales de Pleurodema según Análisis de Dispersión-Vicarianza (DIVA, Ronquist 1997)

6.5. Discusión de los análisis biogeográficos de Pleurodema

Conclusiones generales 164

Apéndice de material examinado 166

Bibliografía 


\section{Resumen}

Pleurodema (Anura: Leiuperidae) es un género de anuros neotropical que incluye 14 especies reconocidas, distribuidas desde Panamá hasta el extremo austral de América del Sur. Este género resulta una unidad de estudio muy interesante porque presenta especies polimórficas (e.g. Pleurodema thaul, Pleurodema bufoninum) y especies crípticas, diferentes modalidades de amplexo y de oviposición, diferentes niveles de ploidía, etc. Al presente, no existe ningún análisis cladístico que sustente su monofilia ni proponga una hipótesis de relaciones entre sus especies.

En el presente estudio se presenta, en primer lugar, una revisión histórica de las especies que incluye Pleurodema y de las relaciones que se han postulado a lo largo de su historia taxonómica. Luego, se realiza una descripción de la morfología externa de cada especie.

Para abordar problemática de las especies crípticas (e.g. Pleurodema borelliiPleurodema cinereum, Pleurodema kriegi-Pleurodema bibroni, Pleurodema guayapae-Pleurodema nebulosum) se realizaron análisis en base a 27 medidas morfométricas. Los resultados obtenidos mediante Análisis de Componentes Principales no permiten identificar variables que inequívocamente posibiliten la diferenciación de cada par de especies crípticas.

La osteología frecuentemente es usada en estudios filogenéticos basados en morfología. En consecuencia, se ofrece una descripción detallada de la osteología de cada especie. Luego, se brinda una síntesis de los conocimientos sobre la biología reproductiva de cada especie.

De la información obtenida de observaciones propias, sumada a datos bibliográficos, se construyó una matriz de datos para realizar el análisis filogenético de Pleurodema. La matriz incluyó, dentro del grupo interno, a las 14 especies de Pleurodema reconocidas más una entidad relacionada con Pleurodema bibroni pero aún no descripta formalmente. Las 19 especies que conformaron el grupo externos incluyeron 13 Leiuperidae, 2 Leptodactylidae, 3 Cycloramphidae y 1 Cerathoprhyidae, este último usado para enraizar el árbol (un total de 34 terminales). La matriz incluyó 125 caracteres, 84 binarios y 41 multiestado. Los caracteres provienen de las siguientes fuentes de información: 0-18 de morfología externa de adultos, 19-89 de osteología, 90-100 de biología reproductiva y caracteres sexuales secundarios, 101-102 de citogenética, 103-119 de morfología larval y 110- 
124 de musculatura. El análisis filogenético se realizó con pesos iguales y bajo pesos implicados (con valores de $k$ entre 4 y 10). Las medidas se soporte calculadas corresponden a Soporte absoluto de Bremer, Soporte relativo de Bremer, "Parsimony jackknifing" y "Bootstrapping" para el análisis bajo pesos iguales y "Symmetric resampling" $(\mathrm{P}=0,33)$ para el análisis bajo pesos implicados. En ambos análisis filogenéticos Pleurodema incluye a Somuncuria somuncurensis anidada en su interior. En los análisis con pesos implicados Somuncuria somuncurensis resultó ser la especie hermana de Pleurodema bufoninum, mientras que en los análisis bajo pesos resultó ser la especie basal. En consecuencia, se sugiere el cambio de género de Somuncuria somuncurensis, correspondiendo designarla Pleurodema somuncurensis comb. nov. Por otro lado, la posición filogenética de Pleurodema fuscomaculatum, especie recientemente transferida desde el género Physalaemus, no ha podido ser corroborada debido a la escasa información existente sobre la misma, en especial aquélla referida a los caracteres diagnósticos de Pleurodema. Por último, Se reconoce a Pleurodema borellii y Pleurodema cinereum como dos especies válidas en base a caracteres osteológicos y larvales.

Finalmente, se realizó un Análisis Biogeográfico con el fin de conocer la posible área ancestral de Pleurodema y los eventos que generaron su distribución actual. De acuerdo con el método de Optimización de Fitch, el género Pleurodema se habría originado en la Patagonia de Argentina. El Análisis de dispersión-vicarianza (DIVA) explica, mediante una serie de eventos, cómo las especies del género fueron distribuyéndose hacia el norte, alcanzando una amplia distribución en América del Sur. Se describen los eventos que pudieron permitir esta expansión del género. 


\section{Abstract}

Pleurodema (Anura: Leiuperidae) is a neotropical genus of anurans which includes 14 recognized species distributed from Panama to southern South America. This genus presents interesting particularities, like polymorphic species (e.g., Pleurodema thaul, Pleurodema bufoninum) and cryptic species, different patterns of oviposition and amplexus, etc. At present, no cladistic analysis supporting its monophyly or proposing a relationship hypothesis between these species has been performed.

Firstly, the present study shows an historical review of Pleurodema species and the relationships that have been postulated along its taxonomic history. Secondly, a description of external morphology of each species is provided.

To address the problem of cryptic species (e.g., Pleurodema borelliiPleurodema cinereum, Pleurodema kriegi-Pleurodema bibroni, Pleurodema guayapae-Pleurodema nebulosum) analyses based on 27 morphometric measures were performed. Results obtained by Principal Component Analysis did not identify variables which unequivocally differentiate each pair of cryptic species.

Osteological information frequently is used in phylogenetic studies based on morphology. Therefore, a detailed osteological description of each species is provided. Also, a synthesis on reproductive biology knowledge of each species is presented.

The data matrix for phylogenetic analysis of Pleurodema included personal observations as well as data taken from literature. The ingroup included the 14 recognized species of Pleurodema and another taxa related to Pleurodema bibroni, but not yet formally described. The outgroup (19 species) included 13 Leiuperidae, 2 Leptodactylidae, 3 Cycloramphidae and 1 Cerathoprhyidae; the last one was used to root the tree (total of 34 terminals). The matrix included 84 binary and 41 multistate characters (total $=125$ ). The characters were sorted as follow: 0-18 exo-morphology, 19-89 adult osteology, 900-100 reproductive biology and secondary sexual characters, 101-102 cytogenetics, 103-119 larval morphology, and 110-124 muscle. Phylogenetic analyses were performed with equal weights and implied weights ( $k$ values $=4-10$ ). Support measures calculated included absolute Bremer support, relative Bremer support, Parsimony jackknifing, and Bootstrapping for equal weights analysis, and Symmetric resampling $(P=0.33)$ for implied weights. In all phylogenetic analyses Pleurodema includes Somuncuria somuncurensis nested in it. In implied weights analyses Somuncuria somuncurensis was the sister species of Pleurodema bufoninum, whereas in the equal weights analysis it was the basal species. Therefore, it is 
suggested to transfer Somuncuria somuncurensis to Pleurodema, corresponding Pleurodema somuncurensis comb. nov. By the other hand, phylogenetic position of de Pleurodema fuscomaculatum, a species recently transferred from genus Physalaemus, could not be corroborated because of the large amount of missing data; especially those referred to diagnostic characters. Finally, I propose to recognize Pleurodema borellii and Pleurodema cinereum as two valid species based on both osteological and larval characters.

Finally, a Biogeographic analysis was performed to reconstruct both the ancestral range distribution of Pleurodema and the events which generated its present distribution. According to Fitch optimization, the genus Pleurodema would have originated in the Patagonia of Argentina. Dispersion-Vicariance Analysis (DIVA) explains, through a series of events, how species of the genus were distributed to the north, reaching a wide distribution in South America. Events related to genus expansion are described. 


\section{INTRODUCCIÓN}

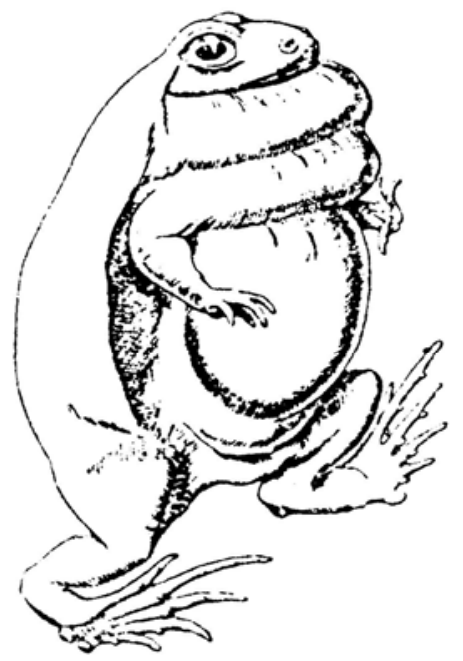

Tomado de Nieden (1923) 


\section{Síntesis histórica del género Pleurodema}

Dentro del género Pleurodema, actualmente se reconocen 14 especies: Pleurodema bibroni, P. borellii, P. bufoninum, P. brachyops, P. cinereum, P. cordobae, P. diplolister, P. fuscomaculatum, P. kriegi, P. guayapae, P. marmoratum, P. nebulosum, P. thaul y P. tucumanum.

La primera descripción correspondiente a una especie actualmente asignada al género Pleurodema, Pleurodema thaul, tiene una historia taxonómica conflictiva. Molina (1782), en su obra Saggio sulla storia naturale del Chili, describió dos "anfibios acuáticos", indicando que "...Gli acquatici sono di due spece, I’Arunco, Rana Arunco (*), e il Thaul, Rana Lutea $\left(2^{*}\right) . . . "$; luego ofreció una breve descripción morfológica de ambos. Además, las dos llamadas refieren a una breve descripción a pie de página:

“...(*) Rana corpore verrucoso, pedibus palmatis..."

“...(2*) Rana corpore verrucoso luteo, pedibus subpalmatis..."

La obra de Molina es pionera en describir especies animales de Chile usando el sistema binomial de Linneo (Stuardo 2007), además de describir las primeras especies de anfibios de ese país (Klappenbach \& Langone 1992). Existe una segunda edición de la obra de Molina, publicada en Bolonia (al igual que la primera) de 1810. De acuerdo con Stuardo (2007), la primera y única traducción de la obra de Molina (1782) al español es de 1788 y corresponde al español Domingo J. de Arquellada Mendoza, habiendo sido titulada "Compendio de la historia geográfica, natural y civil del Reyno de Chile. Primera parte, que abraza la historia geográfica y natural" (véase Molina 1788). Además, la obra de Molina (1782) tiene dos re-ediciones en español, además de traducciones al francés, inglés y alemán (Stuardo 2007).

Gmelin (1789) citó Rana Arunco y Rana lutea para Chile, ofreciendo la siguiente descripción para Rana lutea: “...R. corpore luteo, pedibus omnis subpalmatis. Molina hist. nat. Chil. p. 190. Habitat in aquis regni Chilensis, esculentae habitu, at multo minor. Ultimi digitorum articuli liberi...".

Schneider (1799), en su obra Historiae Amphibiorum, incluyó las especies de Molina bajo el género Bufo: Bufo Arunco y Bufo Thaul. Schneider (1799) claramente asigna Bufo Thaul a Molina, pero incurre en el error de confundir el nombre vernáculo "Thaul" con el específico Rana lutea al caracterizar la especie. El autor hace referencia a un material depositado en el Museum Huttuini (№ 120). Este ejemplar corresponde a Rana papillosa, incluida en un catálogo de venta de los 
ejemplares del Mus. Hutt. publicado de manera anónima y sin fecha (aunque atribuido a Huttuyn, 1786). Sin embargo, cabe destacar que todos los nombres contenidos en ese catálogo fueron considerados inválidos por la International Commision of Zoological nomenclature (Opinion 380 - J anuary 24th, 1956).

Daudin (1802) citó a Rana arunco y Rana thaul. La descripción que ofreció para Rana thaul es “...Rana flava, verrucosa. Caract. Phys. Beaucoup plus petite que ele grenouille verte, forme presque semblable, peau jaune, couverte de verrues, pieds demi-palmés...". Daudin (1802) asignó Rana thaul a Molina, reafirmando el error de Schneider (1799).

Daudin (1803) volvió a mencionar a Rana thaul, ofreciendo la misma descripción que en su obra anterior, agregando: “...Cette espèce est nommée thaul par les habitans d'Arunco, selon Molina, qui l'a trouvée dans les eaux du Chili. Schneider soupçonne qu' elle est indiquéedans la collection d' Houttuyn, no 120, sous le nom de grenouille papilleuse. Elle est entièrement jaunâtre, tachetée de noir, et couverte de papilles ou des verrues dessus tout le dos...". Daudin (1803) comienza la sinonimia de la especie indicando:

Rana lutea Gmelin, Syst. pat. p 1050, o 21.

Rana thaul Molina, Hist. Nat. du Chili, Appendix.

Posiblemente, Daudin utilizó en sus dos obras la traducción al francés de la obra de Molina (1782), realizada por M. Gruvel en 1789 y titulada Essai sur I'Histoire Naturelle du Chili (ver Stuardo 2007). Esto se desprende del modo en que Daudin (1802) abrevia el título de la obra de Molina en la sinonimia de Rana thaul: ...Molina. Hist. Nat. du Chili, App...".

Merrem (1820) incluyó en su catálogo a Bufo Thaul, comenzando la lista sinonímica de la siguiente forma:

Rana lutea. Der Thaul. Molina Chili S. 190. 306.

Lesson (1826) describe el material recolectado por integrantes de la tripulación del buque La Coquille. Curiosamente, en la página 6 menciona: “...Nous ne vimes point le thaul (Rana lutea) de Molina, ni son pallum (Lacerta paluma, Mol. ${ }^{2}$ )...". Sin embargo, más adelante en la misma obra, al describir las especies halladas, redescribe: Bufo arunco Schn.? (lámina VII, figura 5) y Bufo thaul, Merrem.?? (lámina VII, figura 6). Los ejemplares de Bufo thaul provenían de “...ville de Penco, située au fond de la baie de la Concepcion au Chili")... “; además el autor destacó que “...C'est avec regret que nous conservons dans cette description de nom de bufo thaul de Molina...". Lesson (1826) señaló que las descripciones realizadas por Molina de la fauna de Chile no eran buenas. Sin embargo es contradictorio al mencionar a la especie de Molina, Ilamándola primero Rana lutea y luego Bufo thaul. Además, en el 
encabezado de Bufo thaul, Lesson (1826: 64) asigna la especie a Merrem con interrogantes, cuando en el texto claramente asigna la autoría a Molina. A pesar de todo este conflicto, la mayoría de los autores consideran que Lesson (1826) es el autor esta especie (e.g., Duellman \& Veloso 1977; Cei 1980a; Frost 2009).

Tschudi (1838) describió el género Pleurodema para separar el género Cystignathus Wagler de aquellas formas que poseían glándulas lumbares, además describió Pleurodema bibroni.

Duméril \& Bibron (1841) describieron Bufo chilensis (nombre inválido por ser homónimo reciente de Bufo chilensis Tschudi, 1838) incluyendo en su sinonimia, con interrogantes, a Rana thaul Molina (y sus subsecuentes usos), Bufo cinctus Wied., Bufo spinulosus Wiegm., Bufo chilensis Tschudi y Bufo spinulosus Tschudi. También mencionaron que el Bufo thaul citado por Lesson (1826) se corresponde con Bufo chilensis, dado que ellos revisaron cuidadosamente el material traído por el buque La Coquille y depositado en el Museo Nacional de París. Finalmente, comentaron que Rana thaul de Molina también podría corresponderse con Bufo chilensis. Además, Duméril \& Bibron (1841) transfirieron Pleurodema bibroni Tschudi al género Cystignathus, considerando el material proveniente de Chile conespecífico con el taxón de Tschudi. De este modo, comenzó una larga confusión entre la especie de Uruguay y sur de Brasil (actualmente P. bibroni) y la de Chile y sur de Argentina (actualmente P. thaul), con lo cual la historia sinonímica de ambas especies se entremezcla.

Gay (1848) reconoció al género Cystignathus Wagler incluyendo en su sinonimia a Pleurodema Tschudi, entre otros géneros. Realizó una descripción de Cystignathus Bibronii Dumeril \& Bibron (incluyendo en su sinonimia a Pleurodema Bibronii Tschudi y Bombinator ocellatus), y señaló que se encuentra en las provincias centrales de Chile (e.g. Valparaíso), y no fuera del país hasta ese momento.

Girard (1853), al dividir el género Cystignathus (en el sentido usado por Duméril \& Bibron 1841) incluyó en el género Pleurodema, entre otras especies, a P. arunco (Bufo arunco, Schn.) y P. bibroni Tsch. (C. bibroni, Dum. y B.).

Girard (1858) incluye Bufo thaul Lesson en la familia Bufonidae, destacando que la historia taxonómica de esta especie es muy dificultosa de resolver. Toda la descripción que realiza y las figuras de la lámina $V$ parecen referir a una especie de Rhinella dado que describe, por ejemplo, glándulas parotoideas moderadas y pies palmados, dos caracteres que no posee Pleurodema thaul. Esto es realmente Ilamativo porque el autor reconoce que las descripciones y figuras de Bufo thaul y Bufo arunco de Lesson (1826) están intercambiadas por un error editorial, sin 
embargo, en la sinonimia de Bufo thaul refiere a la lámina VII, fig. 6 de Lesson (1826). Además, Girard (1858) parece haber utilizado la traducción al español de la obra de Molina. La sinonimia de Bufo thaul incluye:

Bufo thaul, Less. Voy. Coq. Zool. II, I. 1830, 63, PI. VII, fig. 6 (nec Rana thaul Molina, Hist. De Chile, I, 1788, 194-TsCH. Faun. Peruan. Herp. 1845, 19

Bufo chilensis, Dum. \& B. Erp. gén. VIII, 1841, 678 (In part.)

Por otro lado, la descripción de Girard (1858) de Pleurodema bibroni está basada en material de Valparaíso, Chile, por lo cual corresponde a la de la especie actualmente llamada Pleurodema thaul. Su sinonimia incluye:

Pleurodema bibroni, TSCH. In Mém. Soc. Sc. nat. Neuch. II, 1838, 85- GRD. Proc.

Acad. Nat. ci. Philad. VI, 1853, 420.

Bombinator ocellatus, Mus. Leyde.

Cystignathus bibroni, Dum. \& B. Erp. gén. VIII, 1841, 410.

Bufo arunco LeSS, Zoo. Voy. Coq. II, i, 1830, 64. Pl. vii, fig. 5.

Pleurodema arunco GrD. Proc. Acad. Nat. ci. Philad. VI, 1853, 420.

Como puede apreciarse, Girard (1858) siguió el criterio de Duméril \& Bibron (1841) al considerar Pleurodema bibroni Tschudi conespecífica con Bufo arunco. Sin embargo, ninguna de estas dos especies estudiadas por el autor (Bufo thaul y Pleurodema bibroni) refiere a la especie de Molina, hecho explícitamente establecido cuando señala "nec Rana thaul Molina".

Günther (1858) incluyó a Pleurodema darwini Bell en la sinonimia de Pleurodema bibroni Tschudi, considerando tres variedades para esta última especie: variedad A para Maldonado, Chile y América del Sur; variedad B para Venezuela y variedad $C$ para Chile y América del Sur. Esta acción, junto con la identificación conespecífica de material chileno con P. bibroni Tschudi realizada por Duméril \& Bibron (1841), acarreó grandes confusiones taxonómicas durante más de un siglo.

Steindachner (1867), en su obra sobre la expedición de la Fragata Novara, incluyó en la sinonima de Bufo spinulosus Wiegmann a los siguientes taxones: "...Bufo chilensis Tsch. - Bufo thaul Less., Girard - Phryne chilensis Fitz. Ausb...".

Weyenberg (1876) citó para la fauna argentina, entre otras especies, a Bufo luteus Gm. Esta acción implica dos cosas, que el autor transfirió la especie de género y que la asignó a Gmelin (1789; ver en Lavilla [1992] apartado de Bufo spinulosus spinulosus).

Boulenger (1882) reconoció un amplio género Paludicola (en el cual incluyó como sinómimo a Pleurodema, entre otros) que incluía varias especies, entre ellas Paludicola bibroni Tschudi. En su sinonimia incluyó a P. darwini Bell (siguiendo el criterio de Günther 1858) y también a poblaciones chilenas. 
Berg (1896) reconoce Paludicola bibroni (D.B.) Blrg. como especie válida. Incluye en su sinonimia Bufo thaul Garnot \& Lesson (1830), indican que “... El Bufo thaul de Garnot y Lesson, es sin duda la Paludicola Bibroni (D.B.) de Blgr., pero seguramente no la problemática Rana Thaul ó Rana lutea de Molina...". Además, Berg (1896) considera que Pleurodema bibroni Tschudi 1838 es un nomen nudum. En la misma, más adelante, Berg (1896) reconoce Bufo spinulosus Wiegm. como especie válida, destacando: “... Es sin duda un lapsus calami que el Sr. Boulenger atribuye el Bufo thaul Garn. Less. como sinónimo al Bufo spinulosus Wiegm.; lo es indudablemente el Bufo arunco, mientras que el Bufo thaul Garn. Less. [?? = Bufo thaul (Mol.) Schneid.] forma parte de la sinonimia de Paludicola Bibroni (D.B.) Blgr...."

Philippi (1902) se refirió al tipo de Pleurodema bibroni Tschudi, señalando que “...considero como tipo de esta especie el animal figurado por Bibron en la lámina citada (Dum. et Bibron, Herpetol gener. T. VIII p. 410. tab. 87 fig 2 et 2a)...". El autor concluyó que bajo Pleurodema bibroni habría más de una especie.

Nieden (1923: 114) incluye a Rana arunco Molina 1782 (y sus subsecuentes usos) y Bufo thaul sensu Girard (1858:88) en la sinonima de Rhinella spinulosa (como Bufo spinulosus), ambos con interrogantes. Además, Nieden (1923: 494) reconoce Pleurodema bibroni Tschudi 1830 como especie válida, incluyendo a Bufo thaul Lesson (non Schenider 1799) y sus subsecuentes usos dentro de su sinonimia. El autor indica que la especie habita Chile.

Cei (1962a) mencionó un dato interesante, previamente destacado por Girard (1858): a raíz de un error tipográfico en la leyenda de la lámina VII de la obra de Lesson (1826), las imágenes correspondientes a Bufo thaul y Bufo arunco están cambiadas. Lesson refiere a la lámina VII, figura 5 para Bufo arunco, y a la lámina VII, figura 6 para Bufo thaul; sin embargo, Cei aclara que la figura 5 representa una Pleurodema thaul y la figura 6 Bufo arunco. Por último, Cei (1962a) sugirió que la localidad tipo de Pleurodema thaul (Ilamándola Pleurodema bibroni) sería "...Chile (Penco, Concepción)...".

Es finalmente Donoso-Barros (1969b) quien aclara -parcialmente- la historia taxonómica de las especies de Pleurodema largamente confundidas: P. bibroni, referida hasta ese momento para Chile, y P. darwini, mencionada hasta ese momento para Uruguay. El autor estableció que:

- Lesson (1826) describió Bufo thaul, nombre que debe darse a la especie de Chile, transferida al género Pleurodema. 
- Tschudi (1838) es el autor del género Pleurodema y de la especie tipo, Pleurodema bibroni, proveniente de Montevideo, Uruguay.

- Duméril \& Bibron (1841) utilizaron el nombre Pleurodema bibroni para referirse a material de Chile obtenido por C. Gay, lo cual es erróneo.

- $\quad$ El nombre de la especie que describió Bell (1843), Pleurodema darwini (para Maldonado, cerca de Montevideo, Uruguay), no debía emplearse más para las poblaciones chilenas.

De acuerdo con Frost (2009), la lista sinonímica de Rhinella spinulosa comienza así:

Rana Iutea Molina, 1782, Saggio Stor. Nat. Chili: 216. Types: Not designated or known to exist. Type locality: "Chili". Synonymy by Daudin, 1803 "An. XI", Hist. Nat. Gen. Part. Rept., 8: 136; Lavilla, 1994 "1992", Acta Zool. Lilloana, 42: 67. Nomen oblitum.

Bufo thaul Schneider, 1799, Hist. Amph. Nat.: 227. Type(s): including "Museum Huttuini no. 120", current location unknown. Type locality: "Chilenses". Likely an error for Rana lutea Molina, 1782, who provided the name "il Thaul" as a common name for his Rana lutea. This error followed by Daudin, 1802 "An. XI", Hist. Nat. Rain. Gren. Crap., Quarto: 69, and Duméril and Bibron, 1841, Erp. Gen., 8: 672. Steindachner, 1867, Reise Österreichischen Fregatte Novara, Zool.: 42, also considered it a synonym of Bufo spinulosus. A primary homonym of Bufo thaul Lesson, 1826 (= Pleurodema thaul).

De lo anteriormente expuesto deben destacarse las siguientes apreciaciones: a) Molina no describió Rana thaul; hasta 1799 "thaul" era solamente un nombre vernáculo aplicado a Rana lutea Molina 1782; b) Lesson (1826) no es el autor del nombre Bufo thaul como indica Donoso-Barros (1969b), si no que Schneider (1799) es el verdadero y primer autor de dicha combinación. La utilización de esta combinación no debiera considerarse un error como sugiere Frost (2009), porque se trata de un sinónimo reciente de Rana lutea Molina 1782; c) Frost (2009) considera a Rana lutea como un nomen oblitum; d) Pleurodema bibroni Tschudi 1838 no es un nomen nudum como sugirió Berg (1896) e) A diferencia de lo expresado por Frost (2009), la página 672 de la obra de Duméril \& Bibron (1841) abarca parte de la sinonimia de Bufo vulgaris Laurenti (que va de la página 671 a 673), y no se menciona a Bufo thaul en esa lista; f) la especie descrita por Molina (1782) como Rana arunco es considerada una especie válida, Rhinella arunco (Molina, 1782).

El artículo 23 del Código Internacional de Nomenclatura Zoológica (ICZN Internacional Comission on Zoological Nomenclature 1999) regula el Principio de Prioridad. De acuerdo con el artículo 23.9.1, el uso de un nombre previo debe mantenerse si se cumplen dos condiciones: 
23.9.1.1. El sinónimo u homónimo senior no ha sido usado como un nombre válido después de 1899, y

23.9.1.2. El sinónimo u homónimo junior ha sido usado para un taxón particular como su nombre presumiblemente válido en al menos 25 trabajos publicados por al menos 10 autores en los 50 años inmediatamente precedentes y engloban una envergadura no menor a 10 años.

De acuerdo a nuestros conocimientos, podemos concluir que:

- Rana lutea Molina 1782 es un nombre binomial creado por Molina (1782; versión original en italiano) y utilizado para un anfibio de Chile Ilamado vulgarmente "thaul". El nombre Rana lutea fue luego usado por Gmelin (1789); pero ambas obras son anteriores a 1899,

- Rana thaul es una combinación utilizada por primera vez por Schneider (1799) y repetida posteriormente por varios autores. La descripción de Schneider (1799) está basada en la obra de Molina (1782), con lo cual se convierte en un sinónimo objetivo (Artículo 61.3.4),

- Considerando entonces que se cumplen las dos condiciones del Artículo 23.9.1, concluimos que Rana lutea Molina 1782 es un nomen oblitum (i.e. nombre más antiguo pero inválido) y Rana thaul Schneider (1799) es el nomen protectum (i.e. nombre más reciente pero válido) (Artículo 23.9.2).

- Finalmente, la combinación correcta de la especie es Pleurodema thaul (Schneider 1799).

A continuación, sigue la historia taxonómica del género y sus especies. Wagler (1830), dentro del Orden Ranae, incluyó a dos familias: Aglossae y Phaneroglossae. Dentro de esta última, describió el género Cystignathus: “...Caput magnum, ovatum, rostro convexo; digiti scelidum antipedumque semplice, terete, scelidum elongati basi vix membrana connexi, antici breves toto liberi, secundus eorum omnium minimus; tympanum conspicuum; dentes maxillae et palati, mandibulae nulli; lingua libera pone furcata, antice solum mento affixa, antrorsum jaculatoria; corpus breve, torosum. (Vesica aerea (maris) utrinque prope oris angulum nascente.) America. ...". Incluyó dentro del género Cystignathus varias especies de Rana. El autor también describió el género Paludicola dentro de la familia Phaneroglossae: “...Habitus Ranae, dentes nulli; tympanum latens; lingua oblonga, integra, vix margine postico sublibera; digiti palmae plantaeque liberi; ossicula bina plana, ovata, margine libera infra metatarsum. (America.) ...". Incluyó dentro del género Paludicola una sola especie, Bufo albifrons Spix. 
Tschudi (1838) describió el género Pleurodema (Ranæ, familia Bombinatores) con el objetivo de separar el género Cystignathus Wagler de aquellas formas que poseían glándulas lumbares (pág. 47), señalando: “...Ausgezeichnet ist dieses Genus durch die Lage der Ohrdrüsen, die, ich möchte sagen, ganz nach hinten gerückt sind, und dadurch, wenn sie auch keine andere physiologische Bedeutung haben, dennoch auf einem andern Namen Anspruch machen müssen. Sie liegen jederseits in der Lendengegend, sind gross, oval, erbsenförmig. Der Habitus dieses Thieres nähert sich schon ziemlich dem der Kröten, auch sind die Zehen frei. Gaumen und Oberkieferzähne sind vorhanden. Hr. d'Orbigny brachte es in mehrern Exemplaren von Monte-Video nach Paris...". El autor agregó más adelante (pág. 84): “...Caput breve; rostrum obtusum, rotundum; verticem convexum; linguam subcordatum, pone liberam; dentes palatinos et maxillares; tympanum latens; digitos palmarum plantarumque toto liberos, Iongos, teretes; duos callos lateral es scelidum metatarsi. In utroque abdominis latere magnam, oblongam glandulam. Patria: America merid. (Monte-Video.)...". Finalmente, Tschudi (1838) describió Pleuroderma bibroni (terra typica "America merid. (Monte-Video)" [Uruguay]), en base a material trasladado a París por D'Orbigny. El epíteto genérico difiere en una letra (una " $r$ ") con el nombre usado al describir el género, observación realizada por Méhelÿ (1904) (err. typ.). Pleurodema bibroni es la especie tipo designada por monotipía. Ortiz \& Lescure (1989) destacaron que el único ejemplar colectado D’Orbigny en la región del Plata y depositado en el Muséum National d'Histoire Naturelle, Francia, es el MNHNP 4501, designándolo entonces lectotipo. Según Frost (2009), habría varios sintipos en el MNHNP no hallados aún; además, el ejemplar depositado en el Rijksmuseum van Naturlijke Historie, Holanda, bajo el número RMNH 2277 habría sido el referido por Tschudi (1838: 85) como "..Syn. Bombinator ocellatus Mus. Lugd. ...", única especie que el autor incluyó en la sinonimia de Pleurodema bibroni (M.S. Hoogmoed en Frost 1985). Este ejemplar correspondería a Pleurodema thaul, y fue recolectado en Valparaíso [Chile] por C. Gaudichaud (Gassó Miracle et al. 2007). Sin embargo, Bombinator ocellatus es un nombre por al menos dos razones: (1) la primera mención del nombre no estuvo acompañada por una descripción (nomen nudum) y (2) fue publicado en sinonimia (art. 11.6, ICZN 1999).

Duméril \& Bibron (1841) incluyeron dentro de la familia Cystignathi a los géneros Leptodactylus Fitzinger; Cystignathus, Crinia y Pleurodema Tschudi y Doriphorus Weise. Describieron el género Leiuperus, diferenciándolo básicamente de Cystignathus porque carece de dientes en el paladar (=dientes vomerinos), pero lo relacionan con la familia Cystignathi por su estructura general. Describieron la 
especie Leiuperus marmoratus (terra typica "Amerique du Sud, Potosi" [Bolivia]), en base a dos ej emplares transportados por D'Orbigny. Dos sintipos están depositados en el Muséum National d'Histoire Naturelle, Francia (MNHNP 760, 2 especímenes) (Guibé 1950 en Frost 2009).

Además, Duméril \& Bibron (1841) transfirieron Pleurodema Bibroni Tschudi al género Cystignathus (pág. 410), pero cometieron el error de basarse en material proveniente de Chile (pág. 411). Señalaron, entre otros caracteres, la presencia de dientes vomerinos en dos grupos y de glándulas en los flancos. Los autores consideraron que la especie no debía estar en el género Pleurodema Tschudi (familia Bombinatores) sino en el género Cystignathus debido a que comparte con este último similitudes en la conformación de las apófisis sacras de la IX vértebra, los dientes vomerinos, y la presencia de glándulas en los flancos.

Bell (1843) expresó su acuerdo respecto a la idea de Tschudi de separar del género Cystignathus aquellas especies que poseían glándula lumbar. Describió tres especies en base a material que le proporcionara Charles Darwin obtenido durante su viaje en el HMS Beagle: Pleurodema darwini (terra typica "Madonado, near the mouth of the river La Plata" [Uruguay]); P. elegans (terra typica "Valparaiso, Valdivia and Archipielago de Chiloé", [Chile]) y P. bufoninum (terra typica "Port Desire, in Patagonia, and high up of the river Santa Cruz" [Argentina]). Además, dentro del género Leiuperus, Bell (1843) describió Leiuperus salarius (terra typica "Port Desire" [Argentina]). Los sintipos de Pleurodema darwini estarían depositados en el British Museum, Inglaterra (BM 1947.2.17.84) (Frost 2009).

Tschudi (1845) señaló la presencia de Leiuperus marmoratus y Leiuperus viridis (Fam. Alytae) para la fauna peruana. El autor incluyó dentro de la sinonimia de Leiuperus al género Chianopelas, el cual fuera descrito por él mismo en un manuscrito de 1839. En dicho manuscrito, Tschudi, había descrito Chianopelas maculatus y Chianopelas viridis, sinónimos de Leiuperus marmoratus y Leiuperus viridis, respectivamente, según la obra posterior del autor (Tschudi 1845). De acuerdo con Frost (2009), Chianopelas es un sinómino de Pleurodema, lo cual es incorrecto porque Chianopelas es un "nombre no disponible", ya que fue publicado en sinonimia (Art. 11.6 del ICZN 1999).

D'orbignyi (1847) citó Leiuperus marmoratus para los alrededores de Montevideo, Uruguay, particularmente para “...las charcas situadas en medio de las dunas del fondo de la bahía...". La única especie conocida de Pleurodema para Uruguay es $P$. bibroni, aunque en la figuras 1-4 no puede apreciarse la presencia de glándulas lumbares. 
Gay (1848) realizó una división de los anuros. Dentro del grupo Cistignato incluyó al género Cystignathus Wagler. En la sinonimia de Cystignathus incluye a los géneros Cystignathus Wagler, Leptodactylus Fitzinger, Cystignathus Tschudi, Crinia Tschudi, Pleurodema Tschudi y Doriphorus Weise. Ofreció una caracterización de Cystignathus Bibronii Dumeril \& Bibron (incluyendo en su sinonimia a Pleurodema Bibronii Tschudi y Bombinator ocellatus), y señaló que se encuentra en las provincias centrales de Chile (e.g. Valparaíso), y no fuera del país hasta ese momento.

Girard (1853) se basó en la estructura de los dientes vomerinos, el tímpano y la lengua, para subdvidir el género Cystignathus, siguiendo el criterio de Duméril \& Bibron (1841). Pleurodema quedó entonces definido por poseer dientes vomerinos en dos grupos oblongos entre las coanas, lengua subcircular, tímpano indistinto, pies sin membrana o con membrana marginal rudimentaria, piel con pústulas o granos y a veces glándulas lumbares. Girard (1853) incluyó en el género Pleurodema a P. arunco (Bufo arunco, Schn.); P. bibroni Tsch. (C. bibroni, Dum. y B.), P. bufonium, Bell; P. darwini, Bell; P. elegans, Bell y P. nodosa (C. nodosus, Dum. y B.).

Günther (1858) incluyó dentro del género Leiuperus a L. marmoratus y L. salarius, el autor señaló que el espécimen de L. salarius probablemente sea un juvenil de P. bufonium (enmienda injustificada del epíteto específico). Además, incluyó dentro del género Pleurodema a P. labyrinthicum, P. bufonium y P. bibroni, considerando tres variedades para esta última especie: variedad A para Maldonado, Chile y América del Sur; variedad B para Venezuela y variedad C para Chile y América del Sur.

Burmeister (1861) describió Leiuperus nebulosus (terra typica "Mendoza" [Argentina]). El ejemplar tipo es una hembra y está depositado en el Berlin Museum, Alemania (BM 7374) (Boulenger 1887). Además citó, entre otras especies, a Bufo thaul.

Cope (1862), en su trabajo de exploración de los ríos Paraná, Paraguay, Bermejo y Uruguay, citó Pleurodema biligonigera con un ejemplar que posee glándulas lumbares negras. Cope sugirió que, considerando que P. biligonigera es una especie descripta como carente de glándulas lumbares y dientes vomerinos, el ejemplar hallado en la expedición podría corresponder a alguna de las formas de P. bibroni propuestas por Günther (1858).

Steindachner (1863) describió Pleurodema elegans (terra typica "Lachen bei Forte do Rio branco", [Colombia]), homónimo primario del taxón descrito por Bell (1843). También describió el género Eupemphix y la especie E. nattereri. 
Steindachner (1864) describió Eupemphix fuscomaculatum. El ejemplar tipo es una hembra y está depositado en el Naturhistoriches Museum Wien, Viena, Austria (NHMW 4316) (Häupl \& Tiedemann 1978; Nascimento et al. 2006).

Cope (1865) propuso una clasificación de los Batrachia en tres Series o Subórdenes:

Bufoniformia: sin dientes; diapófisis sacras dilatadas; sin manubrio esternal; esternón con o sin arcos cartilaginosos;

Arcifera: con dientes; diapófisis sacras dilatadas o cilíndricas; con o sin manubrio esternal; coracoides y epicoracoides divergentes y conectados por un arco cartilaginoso longitudinal, el de un lado superpuesto al del otro;

- Raniformia: con dientes; diapófisis sacras cilíndricas; esternón con la siguientes estructura: los ejes de los coracoides y epicoracoides son paralelos, no divergentes, sus extremos distales están separados sólo por tejido cartilaginoso interpuesto, extremos de los epicoracoides descansando sobre los coracoides, coracoides con extremos dilatado, sin cartílagos arciformes, siempre con manubrio, usualmente con xifisternón óseo y estiliforme.

Cope (1865) incluyó al género Engystoma en la familia Engystomidae y al género Paludicola en la familia Bufonidae (suborden Bufoniformia). Incluyó al género Pleurodema dentro de la familia Cystignathidae (Suborden Arcifera), la cual caracterizó por poseer diapófisis sacras cilíndricas; vértebras procélicas; metacarpales externos generalmente unidos, raramente libres; falanges terminales continuas, uniformemente cónicas o con procesos terminales divergentes definidos 0 rudimentarios; manubrio débil, cartilaginoso o fibro-cartilaginoso proximalmente y oído perfectamente desarrollado. Dentro de la familia Cystignathidae, Cope describió dos grupos, A y B, diferenciados por varias características osteológicas. El grupo B, donde incluye Pleurodema, está caracterizado por poseer metacarpales externos generalmente unidos; fontanela frontoparietal (al menos en la mitad de los géneros); siete géneros con dilataciones en las falanges. Definió los géneros Pleurodema, Gomphobates y Liuperus por poseer pies libres, falanges terminales simples; fontanela frontoparietal; lámina superior del etmoides más o menos expandida anteriormente; xifisternón cartilaginoso soportado por un estilo o placa basal fibrocartilaginoso; manubrio ancho. Finalmente diferenció al género Pleurodema de los dos anteriormente mencionados por poseer la siguiente combinación de caracteres: glándulas inguinales, dientes vomerinos, ausencia de tubérculo tarsal y lengua redondeada. 
Hensel (1867) citó Pleurodema Darwinii para Montevideo, señalando que había algunas diferencias con Pleurodema bibroni Tschudi. El autor también destacó que la especie de Tschudi habría sido traída de Montevideo, mientras que el material estudiado por Duméril \& Bibron (también llamado P. bibroni) provenía de Chile.

Cope (1868) describió el género Lystris diferenciándolo de Pleurodema por la presencia de dos tubérculos metatarsales con forma de pala (ambos incluidos en la tribu Pleurodemæ), de Gomphobates por presentar fontanela frontoparietal y dientes vomerinos, y de Eupemphix por presentar dentición bien desarrollada tanto en juveniles como en adultos. Estableció que las tribus Pleurodemæ y Cystignathi podrían estar cercanamente emparentadas. Transfirió Euphemphix fuscomaculatum al género Lystris. También describió la especie Lystris brachyops (terra typica "Magdalena River, New Grenada" [Colombia], Schulte Buckow col.). Cinco sintipos están depositados en The Academy of Natural Sciences of Philadelphia, Estados Unidos (ANSP 2260-2264) (Malnate 1971; La Marca 1992).

Peters (1870) describió Cystignathus diplolistris (terra typica "Ceára" [Brasil]) en base a tres ejemplares. Dos sintipos están depositados en el Zürcher MuseumsBahn, Alemania (ZMB 6952, dos ejemplares) (Bauer et al. 1995).

Jiménez de la Espada (1875) realizó una detallada re-descripción de Pleurodema bibroni (actualmente P. thaul) señalando variaciones en ejemplares de algunas localidades de Chile. Luego describió Pleurodema granulosum en base a dos hembras (terra typica "Montevideo" [Uruguay], Regal. por el Sr. Gibert). Dos sintipos están depositados en el Museo Nacional de Ciencias Naturales, España (MNCN 16851686) (Curador J. E. Gonzalez Fernandez, com. pers.). Finalmente, Jiménez de la Espada señaló afinidades entre P. bibroni y P. granulosum, considerando la necesidad de analizar más material para establecer el estatus de las mismas. El autor incluyó al género Pleurodema dentro de la familia Cystignathidae.

Jiménez de la Espada (1875) hizo una redescripción de Engystomops y Engystomops petersi (Fam. Bufonidae), taxones que él mismo había descrito anteriormente. El autor consideró que la osteología de E. petersi era afín a la del género Pleurodema, por lo cual propone que E. petersi es un taxón que relaciona las familias Cystignathidae y Bufonidae.

Peters (1877) describió Pleurodema Saschi (terra typica "San Fernando de Apure" [Venezuela]), incluyendo en su sinonimia a Pleurodema bibroni en el sentido de la variedad B de Günther (1858). El holotipo está depositado en el Zürcher Museums-Bahn, Alemania (ZMB 9094) (Bauer et al. 1995). 
Cope (1877) describió Pleurodema cinereum en base a un ejemplar (terra typica “Juliaca, 12.500 pies. No. 137", [Perú]). El holotipo estaría depositado presumiblemente en The Academy of Natural Sciences of Philadephia 0 en el Philadelphia Museum de Estados Unidos, pero no ha sido localizado (Frost 2009).

Boulenger (1882) en su gran obra de Batracios, dividió al grupo en dos subordenes: Phaneroglossa (tubos de Eustaquio separados; con lengua) y Aglossa (tubos de Eustaquio unidos en un solo hueso, ostium pharyngium; sin lengua). E suborden Phaneroglossa fue dividido en dos Series: Firmisternia (coracoides firmemente unidos por un único cartílago epicoracoides; precoracoides, cuando existe, descansando con su extremidad distal sobre el coracoides, o conectado con este último por el cartílago epicoracoideo) y Arcifera (coracoides y precoracoides conectados por un arco cartilaginoso [el epicoracoides], uno de los epicoracoides está superpuesto al del otro lado). Finalmente, la Seria Arcifera la dividió en ocho familias, incluyendo, por ejemplo, Cystignathidae (con dientes en la quijada superior; diapófisis de las vértebras sacras cilíndricas o levemente dilatadas), y Bufonidae (sin dientes en la quijada superior; diapófisis de las vértebras sacras dilatadas, géneros Engystomops y Eupemphix, entre otros).

De acuerdo con Boulenger (1882), la familia Cystignathidae se caracteriza por tener los metatarsales externos unidos o incompletamente separados y el esternón con un estilo óseo. La familia contiene los géneros Edalorhina, Paludicola, Leptodactylus, Plectromantis, Limnomedusa e Hylorina.

Boulenger (1882) incluyó en la sinonimia del género Paludicola Wagler 1830 a Pleurodema Tschudi 1838, Cystignathus Duméril \& Bibron 1841, Leiuperus Duméril \& Bibron 1841, Gomphobates Reinhardt \& Lütken, 1862, Eupemphix Steindachner 1863 y Lystris Cope, 1868. De esta forma, concibió un extenso género formado por un gran número de especies. Luego caracterizó al género Paludicola por poseer pupila horizontal, tímpano indistinto u oculto y dientes vomerinos, cuando presentes, entre las coanas. El autor incluyó dentro del género Paludicola a las especies Paludicola bufonia, P. bibronii, P. brachyops, P. cinerea, P. fuscomaculata, P. diplolistris, P. biligonigera, P. albifrons, P. kröyeri, P. henselii, P. marmorata, P. verrucosa, P. sagittifera, P. falcipes, P. nitida y P. mexicana. Cabe destacar que Boulenger (1882) consideró que Paludicola bibroni Tschudi incluía en su sinonimia P. darwini Bell y también a las poblaciones chilenas que mencionaron otros autores, siguiendo el mismo criterio que había establecido previamente Günther (1858). Este acto continuó la confusión taxonómica, ya que las obras de Boulenguer fueron muy influyentes en la literatura herpetológica posterior. Se utilizó el nombre P. bibroni 
Tschudi para las poblaciones de Chile (y sur de Argentina) y P. darwini Bell para las poblaciones de Uruguay (y sur de Brasil). Esta situación recién fue aclarada por Donoso-Barros (1969b).

Boulenger (1887) transfirió Leiuperus nebulosus al género Paludicola y señaló que el tipo es una hembra y está depositado en el Museo de Berlín (№ 7374). Además, estableció que la especie citada por Burmeister (1861: 532) como Liuperus marmoratus es sinónimo de Paludicola fuscomaculata.

Boulenger (1888) señaló que el género Eupemphix difiere del género Paludicola en la ausencia de dientes. Además, consideró que el género Engystomops J iménez de la Espada es sinónimo de Eupemphix Steindachner.

Peracca (1895) describió Paludicola borellii en base a un ejemplar (terra typica "Tucumán, Argentina"). Dos sintipos están depositados en el Museo Regionale Di Scienze Naturali, Italia (MZUT An449, An446) (Frost 2009). El ejemplar MZUT An449 fue designado lectotipo (Gavetti \& Andreone 1993 en Frost 2009). Peracca (1895) además incluyó, dentro del género Paludicola, a P. fuscomaculata, P. signifera, P. gracilis y $P$. falcipes.

Cope (1890) describió Paludicola frenata en base a un ejemplar (terra typica "Lota" [Chile]). Parker (1927) consideró que probablemente se tratara de un ejemplar aberrante de la especie polimórfica Pleurodema bibroni (actualmente P. thaul).

Philippi (1902) describió Pleurodema montevidense y Liuperus calcaratus (terra typica de ambos taxones "Montevideo" [Uruguay]), ambas especies fueron referidas a Physalaemus gracilis por Klappenbach (1968).

Además, describió una gran cantidad de especies dentro del género Pleurodema: Pleurodema andina (terra typica "andibus provinciae Valdivia et Andibus provinciae Cautin" [Chile]); P. fusca (terra typica "Valdivia" [Chile]); P. coquimbensis (terra typica "la Serena" [Chile]); P. bibroni var. grandis; P. glandulosa (terra typica "Concepcion" [Chile]); P. andicola (terra typica "Cordillera de la prov. de Cautin" [Chile]); P. plebeya (terra typica "Coquimbo" [Chile]); P. Iongipes (terra typica "Valdivia" [Chile]); P. carbonaria (terra typica "Valdivia" [Chile]); P. aspera (terra typica "provincia Aconcagua" [Chile]); P. phryniscoides (localidad tipo no establecida) y P. verrucosa (terra typica "Valdivia" [Chile]). Todas estas entidades fueron consideradas sinónimos junior de Pleurodema bibroni por Cei (1958a), autor que estudió las láminas originales de Philippi. Además, Cei (1958a) estableció que los ejemplares representados en las láminas de Philippi como Pleurodema bibroni breviceps y Pleurodema elegans, también son sinónimos de Pleurodema bibroni. Cei 
(1958a) consideró que dos de las especies descritas por Philippi (1902), Pleurodema belli (terra typica "Valdivia" [Chile]) y P. pseudophryne (terra typica "insulis Chonos" [Chile]), debían examinarse mejor cuando hubiera más ejemplares recolectados en las respectivas localidades tipo.

Méhelÿ (1904), en su trabajo de batracios de Paraguay, consideró que la forma del esternón y la presencia de dientes vomerinos eran caracteres suficientemente relevantes para diferenciar géneros, y estableció que las especies con dientes vomerinos y estilo esternal óseo simple correspondían al género Pleurodema ( $P$. bibroni y P. brachyops), y aquéllas sin dientes vomerinos y con estilo esternal óseo bifurcado, al género Paludicola ( $P$. signifera y $P$. fuscomaculata). También caracterizó a Eupemphix nattereri, especie que no asignó a ninguno de los dos géneros mencionados precedentemente, aunque posee las características de Paludicola.

Andersson (1906), en su obra de batracios colectados en Bolivia, Argentina y Perú en expediciones de principios del siglo XX, señaló haber hallado Paludicola fuscomaculata en Tatarenda (chaco boliviano) y en Casabindo, Jujuy (puna argentina). Luego describió Paludicola alpina en base a dos ejemplares, probablemente machos (terra typica "Casabindo, Puna de J ujuy, Andes of Argentina, 3500 m", October 1901, E. Nordrnskiöld col.). El autor sugirió que esta nueva especie podría ser afín a Paludicola cinerea o a Paludicola brachyops.

Andersson (1908) (en Andersson 1938) incluyó a Paludicola alpina en la sinonimia de Paludicola borellii. Sin embargo, el mismo autor, consideró más tarde que ese criterio era incorrecto, basándose en una muestra más grande proveniente de Chiripa y Eucaliptos (próximo al Lago Titicaca, a unos 3.000-4.000 m s.n.m.), y concluyó que P. borellii y P. alpina son dos especies diferentes claramente diferenciables en base a caracteres morfológicos (Andersson 1938). El autor también sugirió que Paludicola alpina podría ser conespecífica con Paludicola cinerea, dado que son dos especies andinas, pero que, al estar esta última especie tan pobremente definida, no podía realizar comparaciones definitivas (Andersson 1938). El autor también comparó P. alpina con Paludicola brachyops, estableciendo que son dos especies distintas, y con Paludicola elegans Steindachner, considerando que podrían ser especies cercanas. Finalmente, el autor destacó que no es posible separar a Pleurodema Tschudi de Paludicola Wagler por la presencia o ausencia de dientes vomerinos, por lo cual considera que debe utilizarse Paludicola Wagler por principio de prioridad. 
Fernández \& Fernández (1921), en su clásica obra de reproducción de batracios argentinos, consideraron que Paludicola alpina Andersson es un sinónimo de Paludicola cinerea Cope, y que las variaciones encontradas se deben a variaciones entre individuos (afirmación que realizan desconociendo la obra de Andersson 1908; ver comentarios en Fernández 1927). A pesar de haber diferencias en los tubérculos metatarsales, Fernández (1927) concluyó que el material citado por Fernández \& Fernández (1921) como Paludicola cinerea corresponde a P. borellii.

Noble (1922) dividió el orden Salientia en cuatro Subórdenes. Uno de ellos, Procœla, incluye Bufonidæ, Hylidæ y Brachycephalidæ. Según el autor, no hay caracteres útiles para diferenciar Bufonidæ de Leptodactylidæ, por lo cual decide fusionarlos en una sola familia (Bufonidæ) y considerar a los Leptodactylidae como "bufónidos dentados". Define, entonces, a la familia Bufonidæ por poseer cintura pectoral arcífera, diapófisis sacras cilíndricas o dilatadas, 8 vértebras presacras y falanges terminales simples o en forma de T. El autor describió variaciones en tendones de los miembros posteriores entre Pleurodema bibronii (que posee el complejo de tendones típico de Bufonidae, menos especializado) y P. cinerea, P. brachyops y $P$. marmorata, que poseen una estructura tendinosa más especializada.

Ruthven (1922) citó Pleurodema brachyops y Pleurodema pusilla (= Pseudopaludicola pusilla actualmente) para La Sierra de Santa Marta, Colombia.

Nieden (1923) siguió la propuesta de Méhelÿ (1904), incluyendo 12 especies dentro del género Pleurodema; además transfirió las especies de Edalorhina a Pleurodema. El autor incluyó dentro del género Pleurodema las siguientes especies: P. diplolistris, P. frenata, P. bufonina, P. alpina, P. bibroni, P. darwinii, P. borellii, P. cinerea, P. nasuta, P. perezi y P. buckleyi. También incluyó, con interrogantes, a Pleurodema biligonigera y a 14 especies descritas por Philippi (1902).

Müller (1926) describió Paludicola kriegi en base a un ejemplar hembra (terra typica "Sierra Grande von Cordoba, Provinz Cordoba, Argentinien" Dr. H. Krieg leg., 1924) y depositó el material tipo en el Zoologisches Sammlung des Bayerischen Staates, Alemania (ZSM 138/1925); sin embargo, este espécimen se encuentra perdido (Glaw \& Franzen 2006). Valetti et al. (2009) designaron neotipo al espécimen FML 20460, hembra adulta, proveniente de "near La Posta (3136'46" S, 64ำ52'29" W, aproximately 2151 m.s.n.m. ), Pampa de Achala, provincia de Córdoba, Argentina".

Miranda-Ribeiro (1926), en su trabajo sobre Anuros de Brasil, dividió a la familia Paludicolidae en dos grupos: 
-Sin dientes maxilares: géneros Eupemphix y Engystomops (aspecto bufonoide, diseño dorsal en forma de flecha invertida, diferenciados porque el primero tiene mayores dimensiones y el diseño dorsal de flechas más irregular).

-Con dientes maxilares: los géneros Pleurodema (aspecto ceratofrinoide, coloración variada, estilo esternal simple, incluye P. brachyops y P. diplolistris) y Paludicola (aspecto leptodactiloide, coloración elegantemente ornamental, dorso con un diseño similar al símbolo $\Omega$, estilo esternal con forma de áncora).

Parker (1927) realizó una revisión de los géneros sudamericanos Paludicola, Physalaemus y Pleurodema, analizando en varios casos ejemplares tipo, tratando de generar grupos naturales. El autor propuso 36 especies válidas divididas en tres géneros, Pseudopaludicola, Physalaemus y Pleurodema caracterizados de la siguiente forma:

- Pseudopaludicola: sin dientes vomerinos; vómer sin proceso dirigido hacia atrás; esternón elongado, cartilaginoso o calcificado; falanges terminales simples 0 en forma de $\mathrm{T}$; dígitos, a veces, con leves dilataciones terminales; cuadradoyugal pequeño, que no alcanza el maxilar; un tubérculo bajo el antebrazo.

- Physalaemus: sin dientes vomerinos; vómer con proceso dirigido hacia atrás; esternón con estilo óseo; falanges terminales simples; dígitos no dilatados terminales; cuadradoyugal alcanzando hacia adelante el maxilar; sin tubérculo bajo el antebrazo.

- Pleurodema: con o sin dientes vomerinos; vómer con proceso dirigido hacia atrás; esternón con estilo óseo; falanges terminales simples; dígitos no dilatados terminales; cuadradoyugal ausente; sin tubérculo bajo el antebrazo.

En síntesis, según la propuesta de Parker (1927), Pseudopaludicola se diferencia por la presencia de un tubérculo antebraquial, y Physalaemus se diferencia de Pleurodema por la presencia de cuadradoyugal. El autor consideró que Pleurodema es más basal que Physalaemus por poseer dientes vomerinos (estado de carácter que considera basal); aunque aclara que no puede considerarse ancestral a Physalaemus porque la ausencia de cuadradoyugal es un carácter derivado. Concluyó que ambos géneros quizás surgieron como linajes paralelos de un stock ancestral de leptodactílidos. Parker (1927), además, describió Pleurodema tucumana (terra typica "Tapia, Tucumán, Argentina, 2300 feet") y depositó el material tipo en el British Museum of Natural History, Inglaterra (BMNH 1902.7.29.75).

Parker (1927) propuso 13 especies válidas para el género Pleurodema: P. illota, P. bufonina, P. cinerea (incluyendo en la sinonimia a P. borellii, P. alpina y $P$. kriegi), P. bibroni [= P. thaul], P. brachyops, P. diplolistris, P. darwinii [= P. 
bibroni], P. sagittifer [= P. marmorata], P. marmorata, P. mexicana [= Eleutherodactylus mexicanus], P. verrucosa [ $=$ P. thaul] y P. nebulosa.

Noble (1931) definió a la subfamilia Leptodactylinae (Fam. Bufonidae) por poseer esternón óseo angosto, incluyendo a los géneros Leptodactylus, Physalaemus, Eumpemphix y Pleurodema, entre otros. Consideró que el género más basal es Physalaemus, por poseer el estilo óseo más ancho, y que derivaría directamente del género Borborocoetes (Bufonidae, Pseudinae en la clasificación del autor). Estableció que Physalaemus difiere de Pleurodema por poseer cuadradoyugal y de Eupemphix por poseer dientes maxilares, entre otros caracteres. Concluyó que todos los géneros de Leptodactylinae son sólo pequeñas modificaciones de los miembros del stock de Physalaemus.

Freiberg (1942) en su enumeración de Batracios de Argentina, listó nueve especies dentro del género Pleurodema (Fam. Leptodactylidae, Subfam. Leptodactylinae): P. illota, P. tucumana, P. bufonina, P. cinerea, P. alpina, P. bibroni, P. darwini (para Uruguay), P. marmorata y P. nebulosa.

Dunn (1944) en su trabajo de revisión de la herpetofauna colombiana, señala que existen dos especies del género Pleurodema en Colombia: Pleurodema brachyops (en el área cálida de valle del Río Magdalena y en la región de Santa Marta) y "Pleurodema marmorata (= P. sagittifer de "Colombia")", aclarando que no se conoce con certeza el estatus taxonómico de esta última especie.

Schmidt (1954), en su obra sobre los anfibios de su expedición a Chile, registró dos especies: Pleurodema bibroni (Departamentos de Llanquihue y Chiloé) y Pleurodema plebeya (Departamento Coquimbo). Esta última especie fue descrita por Philippi (1902) para La Serena (localidad muy próxima a Coquimbo). Schmidt (1954) consideró que los dos ejemplares macho de Coquimbo corresponderían a P. plebeya. Descartó que correspondan a P. coquimbensis Philippi, dado que esta especie tiene un tubérculo tibiotarsal según Philippi. Lamentablemente, no se recuperaron figuras de ninguna de estas dos especies de Philippi (Cei 1958a). Finalmente, Schmidt (1954) ofreció una redescripción del taxón.

Cei (1956c), en su lista de Batracios de Argentina, reconoció ocho taxones dentro del género Pleurodema (Fam. Leptodactylidae): P. cinerea con dos subespecies, ( $P$. cinerea cinerea y P. cinerea alpina); P. illota, P. tucumana, P. marmorata, P. nebulosa, P. bibroni y P. thaul.

Vellard (1960) revisó las especies de Pleurodema de los Andes de Perú. El autor señaló que tres especies fueron descritas para esta región: Pleurodema marmorata (Dumeril \& Bibron, 1841); Pleurodema viridis (Tschudi, 1845) y Pleurodema cinerea 
Cope 1877. El autor señaló que el único carácter común a todas las especies andinas peruano-bolivianas es la ausencia de cuadradoyugal, y estableció que pueden reconocerse dos grupos andinos: uno de ellos, habitante de los andes peruanobolivianos, incluye a P. cinerea, y se caracteriza por poseer mayor tamaño, glándulas lumbares muy desarrolladas, dientes vomerinos casi siempre presentes, tímpano visible, estilo esternal osificado y bifurcado en la base y xifisternón escotado. A este primer grupo corresponden también P. bufoninum y P. thaul (el autor estudió sólo material de Chile de estas especies).

Al segundo grupo, que habita los Andes de Perú entre los 2.500-3.000 m s.n.m. y los 5.000 m s.n.m., el autor asignó tres subespecies: Pleurodema marmorata marmorata (de la región del Lago Titicaca), P. m. viridis (de las regiones a 4.0005.000 m s.n.m. del Valle de Andaychagua, Lago J unín, Abra de la Capylla y Laguna de Capyllacocha) y una subespecie nueva, P. marmorata infuscata (de la región del Cerro Pasco), diferenciable de P. m. viridis fundamentalmente por el manchado de su vientre. Este grupo, altamente variable, se caracteriza por poseer menor tamaño que $P$. cinerea, ausencia de glándulas lumbares; ausencia (casi siempre) de dientes vomerinos; tímpano generalmente visible; estilo esternal no bifurcado, terminado en forma roma en adultos y xifisternón entero, semilunar o en forma de áncora. El autor destaca el hallazgo de ejemplares integradantes entre P. m. infuscata y P. m. viridis en la región del Lago J unín.

Barrio (1964a) describió Pleurodema guayapae en base al holotipo (CENAI 175) y once paratipos (CENAI 176-183 y 242-243) (terra typica "Guayapa (Establecimiento Santa Rosa), próximo a Patquía, La Rioja, Argentina" A. Barrio col. 15/ enero/ 1964). Algunos paratipos tienen datos de colecta diferentes a los del holotipo.

Gorham (1966 en Duellman \& Veloso 1977) reconoció 11 especies dentro del género Pleurodema.

Gallardo (1968a) propuso a P. borellii como una especie válida y distinta de P. cinerea, diferenciable por la forma del esternón y xifisternón, longitud hocicocloaca, reborde cutáneo en pie, tamaño de la glándula lumbar, entre otros caracteres. Esta posición es la que se mantiene hasta el presente, a pesar de no haber evidencia conclusiva. El autor también sugirió que P. kriegi Müller (de Pampa de Achala) es sinónimo de P. darwini Bell (de Uruguay).

- Donoso-Barros (1969b) presentó, en un corto pero trascendente artículo, una importante aclaración taxonómica referida a especies largamente confundidas del género Pleurodema: P. bibroni, referida para Chile y P. darwini, mencionada para Uruguay (ver detalle en la página 6 del presente trabajo). Sintéticamente, 
Pleurodema bibroni Tschudi es el nombre de la especie tipo, proveniente de Uruguay, y Pleurodema thaul (Lesson) es el nombre de las poblaciones chilenas. Donoso-Barros (1969b) además aclara que el material tipo de Pleurodema bibroni ya no se encuentra en el Museo de Neuchâtel, Suiza.

Barrio \& Rinaldi de Chieri (1970) no reconocieron a P. borellii como una especie válida, sino que consideraron que las variaciones sugeridas por Gallardo (1968a) podían explicarse dentro de la variación intraespecífica de P. cinerea. Dentro de Pleurodema cinerea identificaron dos subespecies, P. c. cinerea (Horcomolle [Tucumán] y Libertador San Martín [Jujuy] en Argentina; Sucre y Chuquisaca en Bolivia) y P. c. alpina (Abralaite, Jujuy, Argentina).

Lynch (1971), en su clásica obra de revisión de Leptodactyloidea, definió a la subfamilia Leptodactylinae por poseer estilo esternal óseo, como previamente lo había diagnosticado Noble (1931), agregando 18 caracteres más revisados por él. El autor incluyó 10 géneros neotropicales en Leptodactylinae. Sin embargo, considerando la variabilidad de los integrantes de esta familia, Lynch sugirió que podría ser polifilética. A diferencia de la propuesta de Noble (1931), Lynch consideró al género Pleurodema como el más basal del stock de leptodactylinos, debido a su forma generalizada, la estructura de la cintura pectoral, el esqueleto y las larvas. Al mismo tiempo, el autor señaló que el género no posee cuadradoyugal, hecho que consideró como un carácter derivado. El autor destacó que Pleurodema tiene afinidades morfológicas y osteológicas con el género Eupsophus (las especies que Lynch incluyó en Eupsophus, actualmente se distribuyen en Alsodes, Eupsophus y Phrynopus). Lynch (1971) realizó una diagnosis de cada género de Leptodactyloides en base a 50 caracteres morfológicos, osteológicos y reproductivos, reconociendo 10 especies dentro del género Pleurodema: P. bibroni [= P. thaul], P. brachyops, P. bufonina, P. cinerea (incluyendo en la sinonimia a P. borellii, P. alpina y P. kriegi), P. darwini [= P. bibroni], P. diplolistris, P. guayapae, P. marmorata, P. nebulosa y P. tucumana.

Heyer (1975) Ilevó a cabo un análisis entre los géneros de la familia Leptodactylidae (sensu Lynch 1971). Pleurodema resultó anidada con Batrachyla, Batrachophrynus, Eupsophus y Telmatobius en dos cladogramas, y con Physalaemus en un tercer árbol. El autor concluyó que no hay evidencias para preferir una u otra hipótesis. Finalmente, Heyer (1975) señaló que el género Pleurodema podría ser polifilético, debido a la distribución geográfica discontinua y a los diferentes modos reproductivos de sus especies. 
Duellman \& Veloso (1977) propusieron el primer esquema evolutivo de las especies del género Pleurodema. Los autores analizaron una serie de caracteres osteológicos, exomorfológicos, reproductivos y citogenéticos de las 12 especies de Pleurodema reconocidas al momento, proponiendo el siguiente agrupamiento:

1 - P. marmorata

2 - P. diplolistris +P. guayapae +P. nebulosa +P. tucumana

3 - P. thaul (de Chile central y sur de Argentina)

4 - P. bufonina +P. thaul (del sur de Chile)

5 - P. brachyops + P. borellii + P. cinerea

6 - P. bibroni +P. kriegi

Duellman \& Veloso (1977) compararon Pleurodema con Alsodes nodosus, un taxón entonces incluido en Telmatobiini con 22 cromosomas metacéntricos y submetacéntricos, al igual que todas las especies de Pleurodema (exceptuando las dos especies poliploides conocidas al momento, P. bibroni y P. kriegi). A pesar de poseer constricciones secundarias en diferentes pares cromosómicos, los autores propusieron que Pleurodema derivó independientemente de un stock de Eupsophus, especialmente relacionado con $E$. roseus $(2 n=30, N F=46)$. También sugieren que $2 n$ $=22$ es el número de cromosomas basal de los entonces Leptodactylinae.

Duellman \& Veloso (1977) también señalaron que Pleurodema es intermedio entre Telmatobiini y Leptodactylinae en varios caracteres (e.g. estilo esternal, larva, amplexo, cuadradoyugal), dado que comparte algunos estados de carácter con uno u otro grupo y, al mismo tiempo, se diferencia de ambos en otros. Considerando que $2 \mathrm{n}$ = 22 sería el número cromosómico basal de los Leptodactylinos y que tanto Pleurodema como Leptodactylus, entre otros, realizan sus puestas en nidos de espuma, los autores establecieron que Pleurodema es un ancestro ideal para la subfamilia... a no ser por la ausencia de cuadradoyugal, un carácter derivado que Pleurodema comparte con Pseudopaludicola.

Finalmente, Duellman \& Veloso (1977) propusieron un esquema biogeográfico del origen del género y su diversificación en América del Sur (Fig. 1A). Sugirieron el origen del género durante el Oligoceno (unos 37-38 M.a.), evolucionando conjuntamente con los eventos climáticos ocurridos durante el Terciario (desecación gradual del extremo sur del continente, elevación de los Andes, restricción de los bosques australes y expansión de la Paleoflora Chaco-terciaria). Del Oligoceno se conocen varios géneros fósiles entonces incluidos en Leptodactylidae, como Caudiverbera, Eupsophus y Neoprocela. Los autores propusieron que el stock 
primitivo de Pleurodema se dispersaba por los bosques australes del sur de América del Sur, y un grupo perdió las glándulas lumbares mientras que otro las mantuvo.

Durante el Mioceno, el grupo "sin glándulas" originó dos linajes que se reproducían por nidos de espuma. Uno de los linajes dio origen a P. marmorata en las planicies de la Puna, y el otro linaje volvió a dividirse dando origen, por un lado, a P. diplolistris, y por otro, a un stock de Pleurodema que se diversificó en el monte centro-occidental de Argentina. Este último stock, durante el Plioceno, originó dos linajes, por un lado P. tucumana, y por otro, P. guayapae y P. nebulosa; estas dos últimas especies divergen muy recientemente (Pleistoceno).

Por otro lado, el grupo "con glándulas", se divide en dos linajes durante el Mioceno: de acuerdo con su modo de reproducción, un linaje se dividió en especies reproducidas por masas y otras por cordones, mientras el otro linaje adquiere reproducción por nido de espuma.

El linaje que se reproduce por masas da origen a las poblaciones de $P$. thaul de Sur de Argentina y Chile Central; el linaje que se reproduce por cordones, da origen a $P$. thaul de Sur de Chile y a P. bufonina. Finalmente, el linaje que se reproduce por nidos de espuma origina, durante el Plioceno, a P. brachyops y a otro linaje. Este otro linaje ha originado, durante el Pleistoceno, a P. borellii y P. cinerea por un lado, y a P. kiegi y P. bibroni por otro.

Duellman \& Veloso (1977) concluyeron que la radiación adaptativa de Pleurodema involucró las modificaciones en su biología reproductiva en respuesta a ambientes xéricos, en concordancia con la dispersión de la Paleoflora chaqueña y el retroceso de los bosques australes de Notophagus. El comienzo de la radiación fue en el Oligoceno, siendo la mayoría de las especiaciones a través de vicarianza. Finalmente, propusieron que la condición poliploide de P. bibroni y P. kriegi se originó por autopoliploidía, a diferencia de la propuesta de Barrio \& Rinaldi de Chieri (1970).

Barrio (1977) propone un esquema de relaciones entre las especies con glándula lumbar de Pleurodema. El autor sugiere una bifurcación en dos linajes, uno que se reproduce mediante de nidos de espuma y otros sin nidos de espuma; en el último linaje el autor sugiere una afinidad entre $P$. thaul y las especies tetraploides (P. bibroni y P. kriegi), basándose en similitudes en morfología externa, canto de anuncio y ausencia de nidos de espuma como modalidad reproductiva (Fig. 1B).

Lynch (1978) consideró que Somuncuria somuncurensis (Cei) es una especie intermedia entre el género Atelognathus (Telmatobinae, con quien comparte 
hábitat) y Pleurodema (Leptodactylinae, con quien comparte similitudes en morfología craneana y esternal y en cariotipo).

Duellman (1993) estableció que el género Pleurodema es neutro, sin ofrecer justificaciones, y reconoció 8 especies dentro del mismo: P. bibroni, P. bufoninum, P. cinereum, P. diplolister, P. guayapae, P. marmoratum, P. nebulosum y P. tucumanum. Por su parte, Frost (2009), señaló que de acuerdo el artículo 30.1.2.a del (ICZN Internacional Comission on Zoological Nomenclature 1999), Pleurodema ("side-band") retiene su género en griego, el cual es neutro.

Nascimento et al. (2005) realizaron un estudio fenético y propusieron un nuevo arreglo del género Physalaemus en 7 grupos de especies. Además, Eupemphix fue revalidado para incluir E. nattereri, mientras que Engystomops fue revalidado para incluir las especies que Lynch (1970) asignó al grupo pustulosus de Physalaemus. Estos dos géneros, Eupemphix y Engystomops, habían sido incluidos por Lynch (1970) en la sinonimia de Physalaemus. Poteriormente, y en concordancia con su propuesta previa, Nascimento et al. (2006) transfirieron Physalaemus fuscomaculatum (Steindachner, 1864) al género Pleurodema estableciendo que el material tipo posee dientes vomerinos, los cuales están ausentes en Physalaemus (véase diagnosis de Physalaemus en Nascimento et al. 2005). Sin embargo, mencionaron que esta nueva combinación propuesta debe ser evaluada mediante un análisis de presencia/ausencia de dientes vomerinos en todos los géneros y especies de la familia Leiuperidae (Nascimento et al. 2006).

Recientemente Valetti et al. (2009) describieron Pleurodema cordobae, en base al holotipo (FML 20490) y nueve paratipos (FML 20484-20489, 20491-20492) (terra typica Estancia Los Tabaquillos (32²3'58.4" S, 64ํ5'35.1" W, approximately 2105 m elevation), Sierra de Comechingones, Córdoba province, Argentina, A. L. Martino y J . A. Valetti. cols. 5/febrero/2006). Pleurodema cordobae es una especie críptica con Pleurodema kriegi, pero se diferencia de ésta por poseer un complemento cromosómico octoploide.

\section{Ubicación taxonómica del género Pleurodema}

Desde la década de 1940 hubo consenso entre los autores en considerar que Pleurodema forma parte de la familia Leptodactylidae, habiendo sido considerado como uno de los géneros más basales dentro de la subfamilia Leptodactylinae (Lynch 1971). 
Sin embargo, hace tiempo hay evidencias de la condición para- o polifilética de Leptodactylidae (e.g. , Lynch 1971; Ford \& Cannatella 1993; Ruvinsky \& Maxson 1996; Haas 2003; Darst \& Cannatella 2004; Faivovich et al. 2005; Correa et al. 2006; Frost et al. 2006; Grant et al. 2006). Haas (2003) realizó un análisis filogenético de Anura basado en caracteres de morfología larval y de adultos, y concluyó que Leptodactylidae es un taxón parafilético (Fig. 2). Darst \& Cannatella (2004) realizaron un análisis basado en ADN mitocondrial, donde Leptodactylidae resultó ser un taxón polifilético en el análisis de parsimonia ( 5 clados del árbol conformando la familia), y parafilético en los análisis de máxima verosimilitud y bayesianos ( 2 clados conformando la familia); sin embargo, Leptodactylinae resultó monofilético. Faivovich et al. (2005) realizaron una revisión sistemática de Hylidae en base a caracteres moleculares de ADN mitocondrial y nuclear, y Leptodactylidae resultó parafilético. Frost et al. (2006) realizaron una filogenia de todos anfibios vivientes basada fundamentalmente en caracteres moleculares, y con el fin de obtener clados monofiléticos, dividieron la familia Leptodactylidae en varias nuevas familias: Batrachophrynidae, Leptodactylidae, Ceratophryidae y Cycloramphidae (Fig. 3). Finalmente, Grant et al. (2006), en su análisis de Dendrobatidae, propusieron un nuevo cambio en la familia Leptodactylidae, conformando la mayor diferencia entre su trabajo y el de Frost et al. (2006). Grant et al. (2006) propusieron dividir Leptodactylidae en Leptodactylidae y Leiuperidae (Fig. 4). La familia Leuperidae Bonaparte, 1850 resultó el taxón hermano de Bufonidae + Hylodidae + Dendrobatoidea, e incluye 7 géneros: Edalorhina Jiménez de la Espada, 1871 (2 spp.), Engystomops Jiménez de la Espada, 1872 (7 spp.), Eupemphix Steindachner, 1863 (1 sp.), Physalaemus Fitzinger, 1826 (41 spp.), Pleurodema Tschudi, 1838 (13 spp.), Pseudopaludicola Miranda-Ribeiro, 1926 (12 spp.), Somuncuria Lynch, 1978 (1 sp.).

Lourenço et al. (2008) realizaron un análisis filogenético basado en genes ribosomales con el objetivo de explorar las relaciones interespecíficas de las especies de Paratelmatobius y Scythrophrys, dos géneros de la Selva atlántica de Brasil. Estos dos géneros fueron incluidos en Leptodactylidae sensu Lynch (1971), Frost et al. (2006) y Grant et al. (2006), aunque con diferente arreglo de los géneros que componen la familia (vid supra). Los autores incluyeron representantes de todos los géneros de Leiuperidae excepto Somuncuria, y sus resultados sugieren que la familia no es monofilética, dado que Pseudopaludicola resulta ser el género hermano de Leptodactylus, clado a su vez hermano de Paratelmatobius + Scythrophrys (Fig. 5). 


\section{El género Pleurodema como modelo de estudio}

Las especies incluidas en el género Pleurodema muestran particularidades desde varios puntos de vista: génetico (poliplodía), morfológico (especies crípticas, polimórficas, presencia de glándulas lumbares en varias especies), osteológico (presencia de estados de carácter considerados derivados y otros basales), reproductivo (especies que no realizan vocalizaciones, diferentes modalidades de amplexo y puesta) y geográfico (especies de puna, sierras, estepa, bosques, zonas xéricas, entre otros). Además, se han descrito formas híbridas.

Teniendo en cuenta todos estos aspectos, no es sorprendente que no haya acuerdo entre diferentes autores sobre las especies válidas que constituyen el género Pleurodema, habiéndose generado numerosas discrepancias taxonómicas a lo largo de la historia del taxón. Considerando las discontinuidades en la distribución geográfica y los modos de vida, Heyer (1975) sugirió que se trataría de un género polifilético.

A continuación, se listan las especies incluidas en el género Pleurodema, indicando brevemente sus particularidades. Caracterísitcas de la biología reproductiva de las especies pueden encontrarse en el Capítulo IV, mientras que detalles de su distribución geográfica pueden encontrarse en el Capítulo VI.

Existe un complejo de especies crípticas y poliploides en el género Pleurodema, dentro del cual tres especies son reconocidas y otra forma restaría describirse. Pleurodema bibroni (Fig. 6 A-B) y P. kriegi (Fig. 6 C-D) comparten la característica de ser las únicas especies del género tetraploides $(2 n=4 x=44)$.

Parker (1927) incluyó P. kriegi dentro de la sinonimia de P. cinereum; criterio seguido por Freiberg (1942). Sin embargo, Gallardo (1968a) la sinonimizó con la forma uruguaya P. briboni, especie que, a su vez, había sido incluida en la sinonimia de Pleurodema thaul (Cei 1962a). Posteriormente, Donoso-Barros (1969b) estableció que P. bibroni es una especie válida para Uruguay. (Barrio \& Rinaldi de Chieri 1970; Veloso et al. 1973b; Schmid et al. 1993). Laurent (1975) halló diferencias biométricas estadísticamente significativas entre las poblaciones argentinas y uruguayas. Barrio (1977), contemplando las diferencias ecológicas entre las poblaciones argentinas y uruguayas, propuso que se trata de “...dos especies incipientes en el concepto de Mayr..."

Los individuos actualmente asignados a P. bibroni que habitan el sur de Brasil han sido señalados como pertenecientes a una especie diferente, de ploidía aún desconocida, en base a diferencias fundamentalmente morfométricas (véase 
Camargo et al. 2005). A lo largo del presente trabajo el material proveniente del sur de Brasil será referida como Pleurodema aff. bibroni (Fig. 6 E).

Recientemente, ha sido descripta Pleurodema cordobae (Fig. 6 F), especie críptica con P. kriegi y P. bibroni, pero diferenciable por su condición octoploide $(2 n=8 x=88)$ (Valetti et al. 2009). Ningún mecanismo ha sido sugerido para explicar esta condición.

Pleurodema cinereum (Fig. 7 A-B) y P. borellii (Fig. 7 C-D) son un par de especies crípticas cuya identidad ha sido cuestionada. Algunos autores se inclinaron por la sinonimia de P. cinereum y P. borellii (Parker 1927; Barrio \& Rinaldi de Chieri 1970; de la Riva 1990; McLister et al. 1991), en tanto otros las consideran especies válidas, alegando una diferenciación en los ambientes que ocupa cada una (Gallardo 1968a; 1987; Duellman \& Veloso 1977; Cei 1980a; Lavilla 1992; Straneck et al. 1993; Ferrari 1992). Ninguno de estos estudios incluyó material de las respectivas localidades tipo, lo cual sería necesario para definir la identidad taxonómica de estas entidades. Ferrari (1992) estudió material de ambas especies desde el punto de vista morfométrico y osteológico, hallando ciertas diferencias entre ambas. Para una discusión de su estatus taxonómico véase Ferraro \& Casagranda (2009).

Pleurodema brachyops es una especie abundante con una característica coloración rojiza en las zonas ocultas de los fémures (Fig. 7 E). Se registraron comportamientos aposemáticos en esta especie (Martins 1989). El modo en el cual estos animales cavadores salen a la superficie de la tierra fue descripto por Staton \& Dixon (1977).

Pleurodema marmoratum es una especie polimórfica (Vellard 1960; Sinsch 1986) (Fig. 7 F) que habita la puna entre Perú y el norte de Argentina y Chile. En nuestro país existen muy pocos registros de la especie (veáse Ferraro \& Casagranda 2009), pero parece ser muy abundante en Bolivia, alcanzando altitudes de hasta 5.400 m s.n.m. (Tarifa et al. 2007; Seimon et al. 2007).

Pleurodema bufoninum (Fig. 8 A-B) es una especie polimórfica con una alta resistencia a habitar ambientes esteparios (Cei 1980a). Se registraron comportamientos aposemáticos en esta especie (Cei 1980a). 
Pleurodema diplolister (Fig. 8 C) es una especie restringida al noreste de Brasil, al área conocida como Caatingas. Esta especie posee un característico tubérculo tarsal, condición única dentro del género Pleurodema.

Pleurodema fuscomaculatum (Fig. 8 D) fue recientemente transferida al género Pleurodema por Nascimento et al. (2006), básicamente por poseer dientes vomerinos, los cuales está ausentes en el género en el cual estaba ubicada (Physalaemus). Muy poca información existe sobre esta especie (véase Cei 1990); Amaral et al. (2000) realizaron un análisis citogenético de tres especies de Physalaemus, entre las que incluyeron una muestra de 20 ejemplares de Cáceres (estado de Mato Grosso, Brasil; localidad tipo de la especie) asignados a Physalaemus fuscomaculatus, aunque probablemente corresponda a material de Physamaemus marmoratus (véase Nascimento et al. 2006).

Pleurodema guayapae, P. nebulosum y P. tucumanum (Figs. 8 E; 9 A-D) son tres especies muy cercanas entre sí, que conforman un grupo especializado que ha perdido las glándulas lumbares y los dientes vomerinos y posee un hocico muy corto, además de tener la capacidad de vivir en ambientes desérticos y salobres (Cei 1980a). Barrio (1964a) describió híbridos entre P. guayapae y P. nebulosum. Cei (1979) describió larvas albinas y caníbales en P. nebulosum, y más tarde detalló el mecanismo de regulación osmótica de esta especie, capacidad que le permite habitar ambientes salobres (Cei 1980a).

Pleurodema thaul es una especie de elevado polimorfismo y amplia distribución geográfica (Cei \& Capurro 1957; Cei 1958b) (Fig. 8 E-F; 10 A). Su gran variabilidad morfológica influyó para que Duellman \& Veloso (1977) indicaran que bajo esta nómina podría reconocerse más de una especie, y describieron tres morfotipos: Argentina Sur, Chile Sur, y Chile Central. Rosset et al. (2001) realizaron un análisis morfométrico concluyendo que no es posible distinguir los citados morfotipos (véase Capítulo II). Fueron registrados especimenes albinos (Capurro 1953; Ortiz \& Hermosilla 1991). Se registraron comportamientos aposemáticos en esta especie (Cei 1962; Kolenc et al. 2009).

Un punto interesante para evaluar en un contexto filogenético es el surgimiento de especies poliploides. La poliploidía es la condición por la cual un organismo posee más de un conjunto de complemento cromosómico (White 1954). Este fenómeno de 
mutación cromosómica puede ocurrir de dos formas: por autopoliploidía (más de una copia del mismo complemento cromosómico) o alopoliploidía (más de dos copias de complemento cromosómico surgidas por hibridación). Stebbins (1950 en Marble 2004) sugirió que los autopoliploides podían ser más frecuentes que los alopoloides; además propuso que podían diferenciase por las figuras que forman durante la meiosis: los autopoliploides formarían figuras multivalentes y los alopoliploides figuras bivalentes. Por su parte, King (1990) sugirió que la formación de multivalentes no refleja necesariamente la absoluta homología de los genomas involucrados (i.e. origen autopoliploide). Además, considera que la variabilidad citogenética observada puede reflejar diferencias en los ancestros diploides y que los tetraploides pueden haber tenido un origen independiente por hibridación de diferentes citotipos. En síntesis, la formación de figuras multivalentes no resulta ser evidencia concluyente sobre el origen alo- o autopoliploide de especies poliploides.

Conocer si el origen de un linaje poliploide ocurrió por alo- o auto poliploidía es de crucial importancia en análisis filogenéticos. Si un linaje surge por alopoliploidía (i.e. por hibridación) las relaciones filogenéticas no podrían ser correctamente establecidas mediante un análisis cladístico convencional, y los eventos de evolución reticulada perjudicarían las reconstrucciones filogenéticas (Chenuil et al.1999).

Al presente, conocemos tres niveles de ploidía en Pleurodema: especies diploides, especies tetraploides (P. bibroni y P. kriegi) y una especie octoploide (P. cordobae). Dos propuestas han sido sugeridas en la literatura respecto al origen del par de especies tetraploides: por autopoliploidía con posterior diploidización (Duellmn \& Veloso 1977) o bien mediante alopoliploidía, ya que no se han hallado figuras tetravalentes durante la meiois (Barrio \& Rinaldi de Chieri 1970; Barrio 1977). En relación a $\mathrm{P}$. cordobae, no se ha sugerido qué evento pudo originar s u condición octoploide.

En síntesis, si bien no tenemos certeza respecto a los mecanismos que dieron origen a la poliploidía en Pleurodema, en el presente trabajo se contemplará el posible origen híbrido de P. kriegi y P. bibroni (i.e. por alopoliploidía) y, en consecuencia, se realizará un análisis filogenético excluyendo las especies poliploides.

\section{Análisis filogenético}

En los últimos años, varios trabajos se han enfocado a esclarecer las relaciones filogenéticos de anuros a distintos niveles taxonómicos (e.g. Hay et al. 1995; Pramuk et al. 2001; Darst \& Cannatella 2004; Evans et al. 2004; Faivovich 2002; Faivovich et 
al. 2004; Faivovich et al. 2005; Correa et al. 2006; Frost et al. 2006; Grant et al. 2006). Muchas de estas hipótesis filogenéticas están sustentadas en evidencia molecular, con lo cual los clados propuestos carecen de diagnosis morfológicas. En consecuencia, conocer la variabilidad morfológica de los taxones supragenéricos propuestos en las filogenias que sustentan la taxonomía vigente (Frost 2009) permitirá robustecer dichas hipótesis.

Las especies de Pleurodema han sido relacionadas con las especies actualmente incluidas en Engystomops, Eupemphix, Physalaemus y Pseudopaludicola desde el comienzo mismo de las descripciones de las primeras especies en los siglos XVII, XVIII y XIX, como así también y en varias de las obras más influyentes del siglo XX relacionadas a este grupo de anuros neotropicales (Parker 1927; Heyer 1975; Lynch 1971); sin embargo, estos trabajos no se basaban en análisis filogenéticos que sustenten las relaciones propuestas. Durante el desarrollo del presente trabajo de tesis, se publicaron varios estudios filogenéticos (basados fundamentalmente en evidencia molecular), los cuales, a pesar de tener otros objetivos y alcances, han esbozado las relaciones de parentesco de Pleurodema con otros géneros neotropicales (Faivovich et al. 2005; Frost et al. 2006; Grant et al. 2006) e imponiendo la revalidación de Leiuperidae como taxón monofilético que incluye a Pleurodema y seis géneros más (Grant et al. 2006). Estos estudios han ofrecido una valiosa hipótesis de la ubicación de Pleurodema dentro de reconstrucciones filogenéticas, pero han usado siempre una sola especie del género (P. brachyops).

La sistemática filogenética fue fundamentalmente difundida por Hennig (1968) a mitad del siglo pasado, alcanzando gran trascendencia en la década de 1970. Este autor propuso que las observaciones de características en los organismos permitirían realizar filogenias que representaran las relaciones de los taxones en estudio, dado que la filogenia es la principal causa de similitudes y diferencias entre organismos. En este sentido, una filogenia explica por ancestralidad común la presencia de caracteres compartidos. Precisamente, el criterio de parsimonia sugiere seleccionar, entre las hipótesis posibles, aquellas que expliquen por ancestralidad común la mayor cantidad de similitudes observadas (i.e. el menor número de homoplasias). En este contexto, se estudiaron caracteres morfológicos, osteológicos, reproductivos, citogenéticos, larvales y de musculatura de las especies del género Pleurodema y de los grupos externos seleccionados, con el fin de realizar un análisis filogenético que permita evaluar la monofilia del género.

\section{Análisis biogeográfico}


La Biogeografía histórica se ocupa de explicar cómo los procesos que suceden a escalas de millones de años (e.g. procesos evolutivos, procesos tectónicos, etc.) afectan los patrones de distribución geográfica de los seres vivos. Biológica e históricamente las relaciones filogenéticas entre los taxones y su distribución geográfica se hallan íntimamente ligadas. En los cladogramas resultantes de la aplicación del cladismo, puede obtenerse información sobre la historia de la distribución de los organismos, y sobre las relaciones entre las áreas geográficas que ellos ocupan (Crisci et al. 2000). Uno de los dogmas principales de la Biogeografía es determinar los centros de orígenes de las especies; sin embargo, ha sido demostrado que son difíciles de determinar con precisión y que la búsqueda de dichos centros produce resultados muchas veces improbables o espúreos (Bremer, 1992).

En el presente estudio, una vez obtenida una hipótesis de relaciones filogenéticas de las especies de Pleurodema, se aplicaron dos metodologías: (Optimización de Fitch que tiene por objetivo conocer el área ancestral del género Pleurodema, y Análisis de dispersión-vicarianza; con el fin de reconstruir los eventos biogeográficos que generaron la distribución actual de las especies de Pleurodema.

\section{Objetivos}

Los objetivos propuestos en el presente trabajo fueron:

- Describir y analizar la variabilidad inter e intraespecífica en morfología externa, morfometría, osteología, aspectos reproductivos, citogenética y morfología larval de las especies del género Pleurodema;

- Realizar análisis morfométricos de las especies crípticas del género Pleurodema (P. borellii - P. cinereum; P. bibroni - P. kriegi y P. guayapae - P. nebulosum), con el fin de explorar las posibles variables que permitan discriminar las especies entre sí;

- Realizar un análisis filogenético del género Pleurodema a fin de poner a prueba su monofilia;

- En base al análisis filogenético, aportar evidencia sobre el estatus taxonómico del par de especies crípticas Pleurodema borellii y Pleurodema cinereum;

- Evaluar el impacto de especies poliploides -con posible origen híbrido- en el análisis filogenético;

- Mediante un análisis biogeográfico, reconstruir el área ancestral del antecesor del género Pleurodema y conocer los posibles eventos biogeográficos que afectaron la distribución de las especies del género. 


\section{Hipótesis}

El género Pleurodema es un taxón monofilético sustentado por sinapomorfías exomorfológicas, osteológicas, citogenéticas, reproductivas, de morfología larval y/ o de caracteres musculares. 


\section{MATERIALESY MÉTODOS}

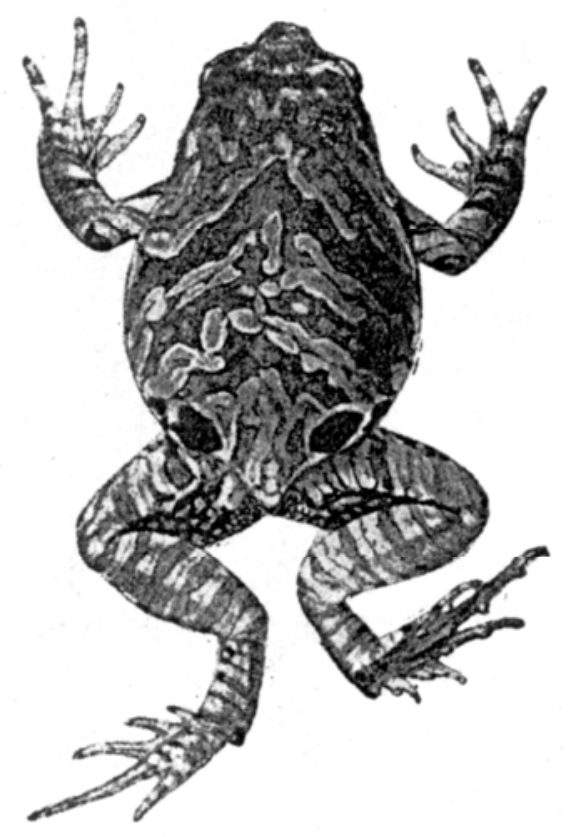

Tomado de Miranda Ribeiro (1926) 
El material utilizado en el presente estudio fue provisto por colecciones herpetológicas de Argentina y del extranjero, como así también coleccionado durante viajes de campo realizados en el país.

\section{Material examinado de colecciones}

Todo el material disponible de Pleurodema depositado en las principales colecciones herpetologías del país fue estudiado. En el Apéndice de material examinado se detallan aquellos especimenes empleados en estudios particulares (morfometría, morfología externa, anatomía interna, osteología).

\section{Morfología externa}

Las observaciones de caracteres morfológicos externos se realizaron bajo lupa binocular, examinándose, en todos los casos que fue posible, un mínimo de 15 ejemplares adultos por especie. Se siguió la nomenclatura utilizada por Savage \& Heyer (1967), Duellman (1970) y Myers \& Duellman (1982).

\section{Morfometría}

Se han registrado 27 medidas morfométricas exosomáticas tomadas en un mínimo de 30 machos y 30 hembras (siempre que fuera posible) de las siguientes especies: Pleurodema bibroni, P. borellii, P. bufoninum, P. cinereum, P. guayapae, P. kriegi, P. nebulosum, P. thaul y P. tucumanum. Los machos se diferenciaron de las hembras según sus caracteres sexuales secundarios (e.g. zona gular pigmentada y/o callosidades nupciales en dedo I y tubérculo metacarpal interno). De las especies $\mathrm{P}$. brachyops, P. cordobae, P. diplolister y P. marmoratum se hallaron pocos ejemplares en colecciones, mientras que de Pleurodema aff. bibroni y $P$. fuscomaculatum no hay material en colecciones de Argentina; en consecuencia, no se efectuaron análisis estadísticos para estas especies.

Todas las medidas fueron tomadas con calibre digital de precisión $\pm 0.01 \mathrm{~mm}$, bajo lupa binocular, sobre el lado derecho del cuerpo de cada individuo, a menos que las condiciones de preservación o la presencia de teratologías lo impidieran. Las medidas tomadas fueron (Fig. 10 C-E): LT (longitud total, longitud hocico-cloaca); NH (distancia entre el extremo del hocico y el borde anterior de la narina); AC (ancho de la cabeza tomado a la altura de las comisuras bucales); LC (longitud de la cabeza, distancia entre el extremo del hocico y la comisura bucal); 0 (longitud del ojo); Ti (longitud del tímpano); PS (longitud dorso-ventral del párpado superior); DO 
(distancia entre los bordes internos de los ojos); NO (distancia narina-ojo, distancia entre el borde posterior de la narina y el borde anterior del ojo); H (hocico, distancia entre el extremo del hocico y el borde anterior del ojo); DN (distancia entre los bordes internos de las narinas); OT (distancia entre el borde posterior del ojo y el borde anterior del tímpano); OB (distancia entre el borde inferior del ojo y el labio superior); F (longitud del fémur); T (longitud de la tibia); Tr (longitud del tarso, distancia entre la articulación tibio tarsal y el extremo proximal del tubérculo metatarsal interno); P (longitud del pie, distancia entre extremo proximal del tubérculo metatarsal interno y el extremo del dedo IV); LMTe (longitud del tubérculo metatarsal externo); LMTi (longitud del tubérculo metatarsal interno); B (longitud del brazo, distancia entre la articulación del húmero con el cuerpo y la articulación humeral-radioulnar); AB (longitud del antebrazo distancia entre el codo y el extremo proximal tubérculo metatarsal externo); $\mathbf{M}$ (longitud de la mano, distancia entre extremo proximal del tubérculo metatarsal externo y el extremo del dedo IV); LMCe (longitud del tubérculo metacarpal externo); LMCi (longitud del tubérculo metacarpal interno); LL (longitud de la glándula lumbar); DmL (distancia menor entre glándulas lumbares); y AL (ancho de glándula lumbar).

Se obtuvieron estadísticos descriptivos para todas las especies consideradas, independientemente para machos y hembras (número de ejemplares, promedio, rango y desvío estándar). Se realizó un Test de Student para probar si hay diferencias significativas en la longitud total en machos y hembras de las especies consideradas.

Las variables morfométricas fueron analizadas mediante métodos multivariados. Se efectuó un Análisis de Componentes Principales (ACP) para cada par de especies crípticas (e.g., Pleurodema borellii-P. cinereum, P. bibroni-P. kriegi y P. guayapaeP. nebulosum), independientemente en machos y hembras. El ACP se efectuó a partir de una matriz de varianza-covarianza, con los datos transformados a logaritmo natural, a fin de homogeneizar la magnitud de las variables morfométricas (Rosset et al. 2001). El objetivo del ACP es clarificar las relaciones entre las variables y dividir la variabilidad total de todos los caracteres en un número limitado de nuevas variables no correlacionadas (Wiley 1981). Para el par de especies Pleurodema guayapae-P. nebulosum no se consideraron tres variables: longitud hocico-narina (por poseer las narinas ubicadas en el extremo del hocico) y aquéllas relacionadas a las glándulas lumbares (por carecer de estas estructuras). Además, para este par de especies y para $P$. bibroni-P. kriegi tampoco se consideraron las variables longitud del tímpano y distancia entre el borde posterior del ojo y el borde anterior del 
tímpano, dado que algunos ejemplares de P. bibroni y todos los ejemplares de P. guayapae carecen de manifestaciones externas de la membrana timpánica.

\section{Osteología}

Los ejemplares analizados para estudios osteológicos, todos adultos, fueron tratados mediante la técnica de tinción diferencial propuesta por Wassersug (1976), según la cual el cartílago se tiñe de azul con Azul alcian, el hueso de rojo con Alizarina, y el músculo queda diáfano por acción del Hidróxido de Potasio.

Las observaciones fueron realizadas bajo lupa binocular y las ilustraciones fueron llevadas a cabo con la ayuda de una cámara clara anexada a la lupa. La nomenclatura utilizada en las descripciones sigue a diferentes autores según la parte esqueletaria examinada: osteología general y nomenclatura de los forámenes craneanos (Trueb 1973; 1993; Duellman \& Trueb 1994), osteología craneana (Jurgens 1971; Roček 1989), aparato hiolaríngeo (Trewavas 1933), fórmula falangeal (Alberch \& Gale 1985, quienes establecen que, en la evolución de los anuros, se pierde el dedo I), morfología carpal (Fabrezi 1992; Fabrezi \& Alberch 1996; Fabrezi \& Barg 2001) y morfología tarsal (Fabrezi 1993).

Se ha descripto el esqueleto completo de una especie, Pleurodema thaul, porque es de la que se cuenta con mayor número de ejemplares teñidos en colecciones. Para el resto de las especies, se destacan las principales diferencias con respecto al esqueleto de $P$. thaul. Además, para cada especie, se destacan las variaciones intraespecíficas más relevantes en cada estructura.

No se cuenta con información osteológica de Pleurodema cordobae ni de Pleurodema fuscomaculatum; la información sobre Pleurodema aff. bibroni está basada en fotografías de los ejemplares MCN 6617 (macho) y MCN 6620 (hembra) gentilmente cedidas por R. Maneyro.

\section{Biología reproductiva}

Se realizaron diferentes viajes de campaña hacia zonas de Argentina con diferentes ambientes con la intención de recolectar todas las especies que habitan el territorio nacional: puna (ambiente de $P$. cinereum), región altoandina ( $P$. marmoratum), selva pedemontana (P. borellii), pastizales de altura del ámbito chaqueño austral ( $P$. kriegi), región chaqueña y de monte (P. guayapae, P. nebulosum y $P$. tucumanum), bosques andino-patagónicos ( $P$. thaul) y estepa patagónica (P. bufoninum). 


\section{Análisis filogenético}

A continuación se describen las etapas seguidas para la realización del análisis filogenético del género Pleurodema.

\section{v.i. Selección de taxones}

Para generar un test riguroso de la monofilia del género Pleurodema, se seleccionaron todas las especies contenidas en él así como representantes de géneros cercanamente emparentados, considerando las hipótesis filogenéticas de Frost et al. (2006) y Grant et al. (2006) y teniendo en cuenta la variabilidad morfológica a representar. Se detallan a continuación:

\section{v.ii. Grupo interno}

Leiuperidae: Pleurodema bibroni, P. aff. bibroni, P. borellii, P. brachyops, P. bufoninum, P. cinereum, P. cordobae, P. diplolister, P. fuscomaculatum, P. guayapae, P. kriegi, P. marmoratum, P. nebulosum, P. thaul y P. tucumanum.

Para P. fuscomaculatum existen muchas entradas faltantes, dado que existen muy pocos registros en la literartura: la descripción original (Steindachner 1863) y una muestra proveniente de Paraguay de fines de siglo XIX (Cei 1990). Los ejemplares identificados como Physalaemus fuscomaculatus en estudios citogenéticos (Amaral et al. 2000), probablemente correspondan a Physalaemus marmoratus (véase Nascimento et al. 2006).

Finalmente, no se cuentan con datos de osteología, morfología larval, ni musculatura de $P$. cordobae, especie recientemente descripta.

\section{v.iii. Grupo externo}

Leiuperidae: Physalaemus albonotatus (Steindachner 1864), Physalaemus biligonigerus (Cope 1861), Physalaemus cuqui Lobo 1993, Physalaemus cuvieri Fitzinger 1826, Physalaemus fernandezae (Müller 1926), Physalaemus henselii (Peters 1872) y Physalaemus santafecinus Barrio 1965. Engystomops pustulosus (Cope 1864). Eupemphix nattereri Steindachner 1863. Somuncuria somuncurensis (Cei 1969). Pseudopaludicola boliviana Parker 1927, Pseudopaludicola falcipes (Hensel 1867) y Pseudopaludicola mystacalis (Cope 1887).

Los géneros actualmente reconocidos Physalaemus, Eupemphix y Engystomops incluyen un gran conjunto de especies neotropicales que oviponen en nidos de espuma. Todas las especies de estos géneros fueron incluidos en Physalaemus por Lynch (1970) argumentando que no existían evidencias para separar las especies en 
los tres géneros. El autor ofrece una descripción del género y propone el ordenamiento en cuatro grupos de especies: biligonigerus (4 especies), pustulosus (7 especies) signiferus (5 especies) y cuvieri (18 especies). Cannatella \& Duellman (1984) propusieron la monofilia para el grupo pustulosus de Physalaemus, sugiriendo cuatro sinapomorfías morfológicas: piel con tubérculos; presencia de glándula paratoidea; presencia de glándula elíptica en los flancos del cuerpo y proceso dentígero del vómer delgado.

Cuando se diseñó la selección de grupos externos del presente trabajo, se seleccionó al menos un representante de cada grupo de especies de Physalaemus propuesto por Lynch (1970), considerando las afinidades entre Pleurodema y Physalaemus señaladas previamente en la Introducción. Durante el transcurso del presente estudio, se publicó el trabajo de Nascimento et al. (2005), quienes proponen un ordenamiento fenético de Physalaemus, revalidando Eupemphix para incluir a Eupemphix nattereri (género monotípico) y Engystomops para incluir a las 7 especies del grupo pustulosus de Lynch (1970). Para más detalle de la historia nomenclatorial de estos taxones véase Lynch (1970) y Nascimento et al. (2005).

El género Pseudopaludicola fue recuperado como monofilético por Lobo (1995) en su análisis filogenético, dado que las especies que lo componen comparten tres sinapomorfías: tubérculo hipertrofiado presente en la cara posterior del antebrazo; procesos alares (aquí llamados procesos anterolaterales) del hioides muy expandidos e indiferenciados de la placa hioidea y epicoracoides muy angostos, no superpuestos o apenas superpuestos. Con respecto a P. falcipes, se han registrado diferentes niveles de ploidía (ver caracteres 101-102 del Capítulo V). En consecuencia, y al no contar con material de la localidad tipo para todos los sets de caracteres examinados (Provinz S. Pedro do Rio Grande do Sul -Brasil-, Hensel 1867) se emplearon sólo ejemplares de Uruguay, ya que fue posible revisar ejemplares para morfología externa y osteología, además de contar con datos de citogenética y morfología larval de dichas poblaciones. Hasta tanto una revisión taxonómica permita conocer el estatus de las diferentes poblaciones, la información incluida respecto a esta especie se basa en material de Uruguay.

\section{Leptodactylidae:}

Leptodactylus latinasus Jiménez de la Espada 1875 y Leptodactylus ocellatus (Linnaeus 1758).

Heyer (1969a) ofrece una diagnosis de Leptodactylus en base a siete caracteres morfológicos: tímpano diferenciado; pies sin membranas o con membranas 
vestigiales; dientes maxilares y vomerinos presentes; vómer sin proyección posterior; mesosternón con estilo óseo y falanges terminales en forma de garra.

Ponssa (2008) realizó un análisis filogenético del grupo fuscus del género Leptodactylus, hallando que todas las especies de Leptodactylus incluidas conforman un grupo monofilético sustentado por cinco sinapomorfías: margen posterior de los frontoparietales derecho, entre 8 y 13 dientes vomerinos, vómeres y palatinos superpuestos, rama ótica del escamoso del mismo ancho que la rama zigomática y xifisternón trapezoidal o semicircular.

Cycloramphidae: Alsodes gargola Gallardo 1970, Eupsophus calcaratus (Günther 1881) y Odontophrynus americanus (Duméril and Bibron 1841).

Los géneros Alsodes, Eupsohpus y Odontophrynus estaban incluidos en Leptodactylidae, Telmatobiinae pero en diferentes tribus sensu Lynch (1971; 1978; véase tabla 2 del presente trabajo). Recientes propuestas sugieren que estos géneros están cercanamente emparentados conformando, junto con otros géneros, la familia Cycloramphidae (Frost et al. 2006; Grant et al. 2006, aunque véanse diferencias en el contenido total de la familia).

Odontophryus americanus incluye un complejo de especies diploides y poliploides (Rosset et al. 2006). Hasta tanto se establezca el estatus específico de las poblaciones que componen este complejo, se ha optado por incluir material procedente de la provincia de Buenos Aires, posible localidad tipo de la especie (véanse comentarios para la especie en Frost 2009). Una revisión de la distribución geográfica de este complejo de especies se encuentra en Rosset et al. (2006).

Ceratophryidae: Batrachyla leptopus Bell 1843.

Batrachyla estaba incluida en la subfamilia Telmatobiinae de acuerdo a la clasificación de Lynch $(1971 ; 1978)$ y Heyer (1975). Frost et al. (2006) y Grant et al. (2006) hallaron en sus análisis filogenéticos que este género está cercanamente emparentado a Atelgnathus. Estos dos géneros resultan anidados con Telmatobious, Ceratophrys, Chacophrys y Lepidobatrachus, constituyendo la familia Ceratophryidae. Sin embargo, los resultados de la filogenia de los Telmatobius (grupo “meridional”) propuesta por Barrionuevo (2009) no sustentan una relación muy cercana de Batrachyla con Ceratophrys+Chacophrys.

Batrachyla leptopus se empleó para enraizar el árbol. 
Tabla 2. Propuestas taxonómicas de diferentes géneros de "Leptodactylidae" mencionadas en el texto (sólo se incluyen los géneros citados en el texto).

\begin{tabular}{|c|c|}
\hline $\begin{array}{l}\text { Lynch (1971) } \\
\text { Telmatobiinae }\end{array}$ & $\begin{array}{l}\text { Lynch (1978) } \\
\text { Telmatobinae }\end{array}$ \\
\hline Telmatobiini & Batrachylini \\
\hline Caudiverbera & Batrachyla \\
\hline Telmatobufo & Thoropa \\
\hline Telmatobius & Cayptocephalellini \\
\hline Batrachrophrynus & Caudiverbera \\
\hline † Neoprocela & Telmatobufo \\
\hline Alsodini & Telmatobiini \\
\hline Eupsophus & Alsodes \\
\hline Hylorina & Atelognathus \\
\hline Batrachyla & Batrachrophrynus \\
\hline \multirow[t]{2}{*}{ Thoropa } & Eupsophus \\
\hline & Hylorina \\
\hline Odontophyinini & Insuetophrynus \\
\hline Odontophrynus & Limnomedusa \\
\hline Proceratophrys & Somuncuria \\
\hline & Telmatobius \\
\hline \multicolumn{2}{|l|}{ Leptodactylinae } \\
\hline Pleurodema & Frost et al. (2006) \\
\hline Limnomedusa & Cycloramphidae \\
\hline Hydrolaetare & Alsodes \\
\hline Edalorhina & Crossodactylus \\
\hline Lithodytes & Cycloramphus \\
\hline Physalaemus & Eupsophus \\
\hline Paratelmatobius & Hylodes \\
\hline Pseudopaludicola & Hylorina \\
\hline Leptodactylus & Limnomedusa \\
\hline \multirow[t]{3}{*}{ Barycholos } & Megalosia \\
\hline & Odontophrynus \\
\hline & Proceratoprhys \\
\hline Heyer (1975) & Rhinoderma \\
\hline \multicolumn{2}{|l|}{ Telmatobiinae } \\
\hline Batrachrophrynus & Ceratophryidae \\
\hline Batrachyla & Atelognathus \\
\hline Caudiverbera & Batrachyla \\
\hline Eupsophus & Ceratophrys \\
\hline Hylorina & Chacophrys \\
\hline Insuetophrynus & Lepidobatrachus \\
\hline \multirow{2}{*}{\multicolumn{2}{|c|}{$\begin{array}{l}\text { Telmatobius } \\
\text { Telmatobufo }\end{array}$}} \\
\hline & \\
\hline & Batrachophrynidae \\
\hline & Batrachophrynus \\
\hline & $\begin{array}{l}\text { Caudiverbera } \\
\text { Telmatobufo }\end{array}$ \\
\hline
\end{tabular}




\section{v.iv. Selección y codificación de caracteres}

Los caracteres seleccionados proceden de observaciones propias (siempre que fuera posible) y de la literatura. Los sets de caracteres utilizados corresponden a morfología externa (Capítulo I), osteología (Capítulo III), variables reproductivas (Capítulo IV), caracteres sexuales secundarios, caracteres cromosómicos, caracteres de morfología larval y caracteres miológicos. La nomenclatura de morfología larval sigue a Altig \& McDiarmid (1999).

La codificación de los caracteres seleccionados puede ser definida como la unión entre las observaciones y las explicaciones, y se espera que se obtengan estados de carácter homólogos, independientes y no-redundantes (Strong \& Lipscomb 1999). Los caracteres han sido definidos, en su gran mayoría, siguiendo la codificación reductiva o "reductive coding” (Wilkinson 1995), la cual permite que cada variable se mantenga separadamente como una potencial sinapomorfía para ser puesta a prueba (Kitching et al. 1998). La otra forma de codificar los caracteres es la codificación combinada o “composite coding” (Wilkinson 1995), la cual produce un único carácter multiestado. Debe tenerse en cuenta que la selección de cada uno de los modos de codificación debe depender del balance entre el conocimiento previo sobre las variables a codificar y la independencia entre los caracteres que se construyen, evaluando si covarían o no (Wilkinson 1995).

La determinación de los estados de carácter implica una hipótesis de homología primaria (De Pinna 1991; Hawkins et al. 1997), dado que tiene implícito el concepto de ancestralidad común. Las hipótesis primarias, basadas en las observaciones sobre los organismos, serán luego contrastadas con el análisis filogenético y, en caso de comprobarse que esa similitud observada corresponde a ancestralidad común (i.e., no son caracteres homoplásicos), se constituyen en homologías secundarias (De Pinna 1991).

\section{v.v. Matriz de datos}

La matriz de datos se construyó en el programa WINCLADA (Nixon 1999) e incluye 34 taxones (descriptos en la sección previa) y 125 caracteres, 84 de los cuales son binarios y 41 multiestado. Los caracteres incorporados al análisis se listaron de la siguiente forma: 0-18 de morfología externa de adultos, 19-89 de osteología, 90100de biología reproductiva y caracteres sexuales secundarios, 101-102 de citogenética, 103-119 de morfología larval y 110-124 de musculatura. Los caracteres multiestado 49, 63 y 100 fueron considerados aditivos dado que se identificó un ordenamiento gradual en los estados de carácter observados. 
Una vez construida la matriz de datos, el análisis filogenético se realizó siguiendo el criterio de optimalidad de parsimonia (Farris 1983) utilizando el programa T.N.T. (Goloboff et al. 2003b).

\section{v.vi.Pesos iguales y pesado de caracteres}

La matriz de datos fue analizada siguiendo dos criterios: asignando a todos los caracteres el mismo y también asignándoles pesos diferentes.

La primera propuesta de pesados de caracteres ("Pesados sucesivos") postulaba que era posible incrementar la eficiencia de las reconstrucciones filogenéticas pesando diferencialmente los caracteres de acuerdo a su grado de correlación con las relaciones cladísticas del grupo en estudio (Farris 1969). Más recientemente, Goloboff (1993) destacó algunas falencias de este procedimiento y sugirió el método de "Pesos implicados". Este método permite asignar un peso a los caracteres ("fit") durante las búsquedas, considerando que usualmente, en análisis filogenéticos, algunos caracteres tienen mucha homoplasia mientras que otros son perfectamente jerárquicos (Goloboff 1993). El "fit" de los caracteres depende de una función de cóncava decreciente, la cual es: Fit $=\mathbf{k} /(\mathbf{k}+\mathbf{E S i})$, donde $\mathbf{k}$ es la constante de concavidad y ESi representa la cantidad de pasos extras para un carácter dado. A mayores valores de concavidad (i.e. menores valores de $\mathbf{k}$,) más peso se asigna a los caracteres con homoplasia (Goloboff 1993). Si bien el programa TNT (Goloboff et al. 2003b) permite asignar a la constante $\mathbf{k}$ valores entre 1 y 100 (siendo 3 el valor por defecto), en el presente análisis se exploraron los valores de k entre 4 y 10.

\section{v.vii. Estrategias de búsqueda}

Se emplearon las mismas estrategias de búsqueda tanto para el análisis bajo pesos iguales como para el análisis bajo pesos implicados; en este último caso, se exploró un rango de valores de la constante $\mathbf{k}$ (4-10) con el fin de evaluar la sensibilidad de los clados obtenidos a los diferentes valores de peso (Goloboff 1993).

Existen dos tipos de estrategias de búsqueda: a) búsquedas exactas, cuando se cuenta con un número relativamente bajo de taxones y es posible evaluar todas las topologías posibles; b) búsquedas heurísticas, aplicables cuando el número de taxones empleados hace prohibitiva la primera modalidad. En el presente trabajo se realizaron búsquedas heurísticas. Las búsquedas crean un árbol de Wagner inicial (Farris 1969) a partir del cual se van adicionando secuencias de taxones en la posición en la cual se incremente lo menos posible la longitud. Luego, los árboles obtenidos fueron sometidos a permutación de ramas mediante el método "Tree- 
bisection and reconnection" (TBR); este procedimiento corta una rama del árbol y la re-enraiza en todas las raíces posibles, con el fin de aproximarse gradualmente a los árboles más cortos, calculando en cada corte la longitud que se va obteniendo. Se extendió la memoria del programa para que pueda guardar hasta 10000 árboles. Cada búsqueda incluyó 1000 secuencias de adición y se permitió guardar 10 árboles en cada una. La idea de incorporar múltiples secuencias de adición se relaciona con la posibilidad de disminuir la probabilidad de "caer" en las “islas de árboles", término acunado por Maddison (1991). Las islas son conjuntos de árboles separados por reacomodamientos; entonces, al emplear múltiples secuencias de adición existen más posibilidades de hallar todas las topologías máximamente parsimoniosas posibles. Finalmente, si más de un árbol máximamemente parsimonioso fue obtenido, se realizó un consenso estricto.

La optimización de los caracteres en las ramas de los cladogramas se realizó con el programa Winclada (Nixon 1999).

\section{v.viii. Medidas de soporte}

Las medidas de soporte permiten conocer el grado en que se ajustan los caracteres a los clados obtenidos, es decir, contemplan la cantidad de caracteres que apoyan (i.e. sinapomorfías) y que contradicen (i.e. homoplasias) cada clado. De este modo se puede tener una idea sobre cómo podrían ser afectados los resultados ante la adición de nuevos caracteres (Goloboff 1998).

Existen varias medidas de soporte. El Soporte de Bremer (Bremer 1988; definido formalmente en Bremer 1994) consiste en evaluar cuántos pasos extra son necesarios para que el árbol máximamente parsimonioso colapse. El soporte absoluto de Bremer mide el conjunto total de evidencia a favor de un grupo; mientras que el soporte relativo de Bremer (Goloboff \& Farris 2001) mide la tasa entre la evidencia favorable y desfavorable.

Por otro lado, existen medidas de re-muestreo de la matriz de datos. Existe un acuerdo general en considerar que los re-muestreos reflejan el grado de soporte de la evidencia disponible, i.e. de la matriz de datos analizada (Ramírez 2005 y trabajos allí citados), más que la probabilidad de recuperar un grupo monofilético, como originariamente sugirió Felsenstein (1985). Sin embargo, también debe señalarse que existen opiniones encontradas respecto a sus usos e interpretaciones [véase Grant \& Kluge (2003) contra Ramírez (2005)].

“Parsimony jackknifing” (Farris et al. 1996) consiste en cortar una determinada proporción de la matriz y re-analizarla, a fin de evaluar el grado de resistencia de la 
topología obtenida frente a este re-muestreo. En el "Bootstrapping" (Felsenstein 1985), cada re-muestreo consiste en una nueva matriz de datos con los mismos terminales, pero con algunos de los caracteres originales duplicados y otros eliminados, con el fin de evaluar el desempeño de cada carácter como si hubiera evolucionado independientemente de los otros según un proceso estocástico pero en concordancia con una medida de ramas y una filogenia determinadas.

A pesar de ser extensamente usados, "Parsimony jackknifing" y “Bootstrapping” pueden causar algunos resultados ilógicos cuando son utilizados con caracteres con diferentes pesos (Goloboff et al. 2003a). La influencia de los pesos (o matrices de costo) puede ser eliminada si el re-muestreo es hecho de modo que la probabilidad de aumentar el peso de un carácter sea igual a la probabilidad de disminuirlo. El método "Symmetric resampling" propuesto por Goloboff et al. (2003a) considera estos argumentos y puede ser utilizado bajo pesos sucesivos, pesos implicados y matrices de costo. Además, considera el problema de la frecuencia con la cual los grupos están presentes o son contradictorios (esta diferencia de frecuencias es llamada GC por su sigla en inglés, “Group present/Contradicted”). La diferencia de frecuencias GC adopta valores entre -1 y 1 , indicando $-1,0$ y 1 máxima contradicción, indiferencia y máximo soporte, respectivamente (Goloboff et al. 2003a). En los cladogramas obtenidos, los valores de contradicción (i.e. negativos) se observan como valores entre corchetes por defecto del programa.

En consecuencia, y de acuerdo a lo discutido, se calcularon las siguientes medidas de soporte: Soporte absoluto de Bremer, Soporte relativo de Bremer, "Parsimony jackknifing" y "Bootstrapping" para el análisis bajo pesos iguales y "Symmetric resampling" ( $P=0,33)$ para el análisis bajo pesos implicados. Para calcular las medidas de soporte se amplió la memoria del programa para permitirle guardar hasta 50000 árboles, mientras que el número de réplicas en cada caso fue de 1000.

Finalmente se calcularon tres parámetros: Longitud del árbol (número total de pasos para una topología determinada), Índice de consistencia, IC (Kluge \& Farris 1969) e Índice de de retención, IR (Farris 1989; Farris 1990). El IC está definido como $\mathbf{M}$ / $\mathbf{S}$, donde $\mathbf{M}$ es la sumatoria de todos los valores de $\mathbf{m}$ ( $\mathbf{m}$ es el número mínimo de pasos que un carácter presenta en cada cladograma) y $\mathbf{S}$ la sumatoria de todos los valores de $\mathbf{s}$ (s es el mínimo número de pasos que un carácter presenta en un cladograma en particular). El IR está definido como G - S / G - M, donde G es la sumatoria de todos los valores de $\mathbf{g}$ (g representa el máximo número de pasos que un carácter puede tener en cualquier cladograma). Los dos índices varían entre 0 y 1 , 
acercándose a 1 cuanto menos homoplasia exista. Para el cálculo de ambos índices se empleó el archivo stats.run en el programa TNT.

\section{v.ix. Análisis cladístico excluyendo especies poliploides}

La presencia de especies poliploides de origen híbrido (i.e. por alopoliploidía) dificulta las recontrucciones filogenéticas, dado que impican en modelo de evolución reticulada que no contemplan los métodos estándares de análisis cladísticos Chenuil et al. 1998). A pesar de que no hay pruebas concluyentes, se ha sugerido que Pleurodema bibroni y Pleurodema kriegi se han originado por alopoliploidía, dado que no forman figuras tetravalentes en la meiosis. En consecuencia, y para evaluar el impacto de posibles especies poliploides de origen híbrido, se ha analizado la matriz de datos excluyendo a P. bibroni, P. kriegi, P. aff. bibroni (de ploidía desconocida pero posiblemente poliploide por sus similitudes con P. bibroni) y P. cordobae (octoploide). Además, se ha excluido una especie del grupo externo, Odontophrynus americanus. En el presente trabajo se han incluido poblaciones de Buenos Aires, (Argentina) de esta especie, pero se ha sugerido que podría tratarse de un complejo de especies diploides y tetraploides, no necesariamente con origen autopoliploide para estas últimas (véase Rosset et al. 2006, Lanzone et al. 2009).

\section{Análisis biogeográfico}

Uno de los puntos centrales en la biogeografía es el conocimiento de las áreas ancestrales de linajes monofiléticos. Para determinar dichas áreas, varios métodos fueron desarrollados en las últimas décadas con el fin de evitar los problemas metodológicos y conceptuales que generaba el clásico enfoque de Centros de origen.

Bremer (1992) desarrolló una metodología llamada Análisis de Áreas Ancestrales. El autor definió que todos los grupos monofiléticos poseen un área donde habitó su antecesor común, llamada área ancestral. A diferencia de lo postulado por la escuela de Centro de origen y dispersión, Bremer (1992) destaca que el área ancestral no necesariamente debe estar limitada a un solo lugar, sino que puede corresponder a más de un sitio. De este modo, el autor desarrolló un método que permite determinar la probabilidad relativa de que un área forme parte del área ancestral. A pesar de que el área ancestral puede extenderse a más de un lugar, una limitación indica que la misma no puede ser mayor que el área de los descendientes. El método aplica las optimizaciones de Camin-Sokal ("reverse Camin-Sokal" y "forward Camin-Sokal" parsimony), las cuales no permiten la reversibilidad de los estados. Este aspecto conduce a la mayor crítica al método, dado que serían más 
apropiadas aquellas metodologías que permitieran la reversibilidad de los estados para reconstruir áreas ancestrales (Ronquist 1994).

Ronquist (1994) propuso emplear la Optimización de Fitch, la cual permite la reversibilidad entre los estados. El método se basa en dos premisas: i) el antecesor común poseía una distribución no mayor que cualquiera de sus descendientes, y ii) el grupo bajo análisis es más reciente que cualquier posible evento vicariante ocurrido entre las áreas de endemismo actuales. Este método además contempla la posibilidad de que el ancestro haya habitado más de un área (pero nunca áreas mayores a las de los descendientes), lo que se ha llamado polimorfismo ancestral (Ronquist 1994).

Cuando más de un área resulta ser el área ancestral, se debe calcular una medida de la probabilidad relativa de que el estado ancestral sea alguna de ellas. Este coeficiente se calcula invirtiendo el número de pasos del área y dividiéndolo por el menor número de pasos que presenta un área (Ronquist 1994). Por ejemplo, si los resultados indican que las áreas $A$ y $B$ son probables áreas ancestrales, y $A$ tiene 2 pasos y $B$ tiene 3 , el coeficiente se calcula de la siguiente manera:

Probabilidad de $A$ de ser el área ancestral: $1 / 2 \times 2=1$

Probabilidad de $B$ de ser el área ancestral: $1 / 3 \times 2=0,67$

El área con el coeficiente más alto será la seleccionada como aquella con mayor probabilidad de ser el área ancestral del grupo.

El Análisis de dispersión-vicarianza (DIVA) reconstruye la distribución ancestral de los taxones sobre la base de un modelo biogeográfico simple, factible de aplicar a un sólo taxón (Ronquist 1997). La filogenia sobre la cual se realice la optimización debe corresponder a un árbol completamente dicotómico, definiéndose como unidad de área a las pequeñas unidades habitadas por cada especie, contemplando que cada especie puede habitar una o varias pequeñas unidades (i.e. áreas de endemismo). Por ejemplo, si la especie $X$ habita las áreas $A, B$ y C, la unidad de área de la especie $\left(D_{x}\right)$ puede ser definida como $D_{x}=\{A, B, C\}$.

En el campo de la biogeografía se considera que cuatro eventos pueden ocurrir: vicarianza, duplicación, dispersión y extinción. El DIVA asigna costo cero a los eventos de vicarianza y duplicación, contemplando la especiación alopátrida (subdivisión del área ancestral en dos conjuntos de áreas mutuamente excluyentes) y la especiación alopátrida dentro del área (subdivisión del área ancestral en dos conjuntos de áreas mutuamente excluyentes). Además, el DIVA asigna costo uno a los 
eventos de dispersión (adición de una o más unidades de área a la distribución) y extinción (pérdida de una o más unidades de área a la distribución).

Una vez considerados los costos, se confecciona una matriz de costos tridimensional, dado que el costo de cada evento depende de una combinación particular de las distribuciones de los descendientes. Una vez construida la matriz tridimensional, la optimización se realiza en forma similar a una optimización de matriz de costos ordinaria, i.e. en dos dimensiones (Ronquist 1997). Dos pautas reglamentan el modo de optimización: i) la distribución óptima de un nodo ancestral no puede contener una unidad de área no ocupada por alguno de sus descendientes; y ii) la distribución óptima de un nodo ancestral debe contener al menos una unidad de área de la distribución de cada uno de los dos nodos descendientes (Ronquist 1997).

La definición de las áreas habitadas por el grupo en estudio está basada en el esquema biogeográfico propuesto por Morrone (2001).

De acuerdo con lo discutido precedentemente, dos métodos serán utilizados: Optimización de Fitch (Ronquist 1994), implementada en el programa TNT (Goloboff et al. 2003b) con el objetivo de reconstruir el área del ancestro común más reciente de Pleurodema; y Análisis de dispersión-vicarianza (DIVA; Ronquist 1997), implementado con el programa DIVA 1.1 (Ronquist 1996), con el objetivo de reconstruir la secuencia de eventos que explican la distribución actual del género. 


\section{CAPÍTULO I}

Morfología externa

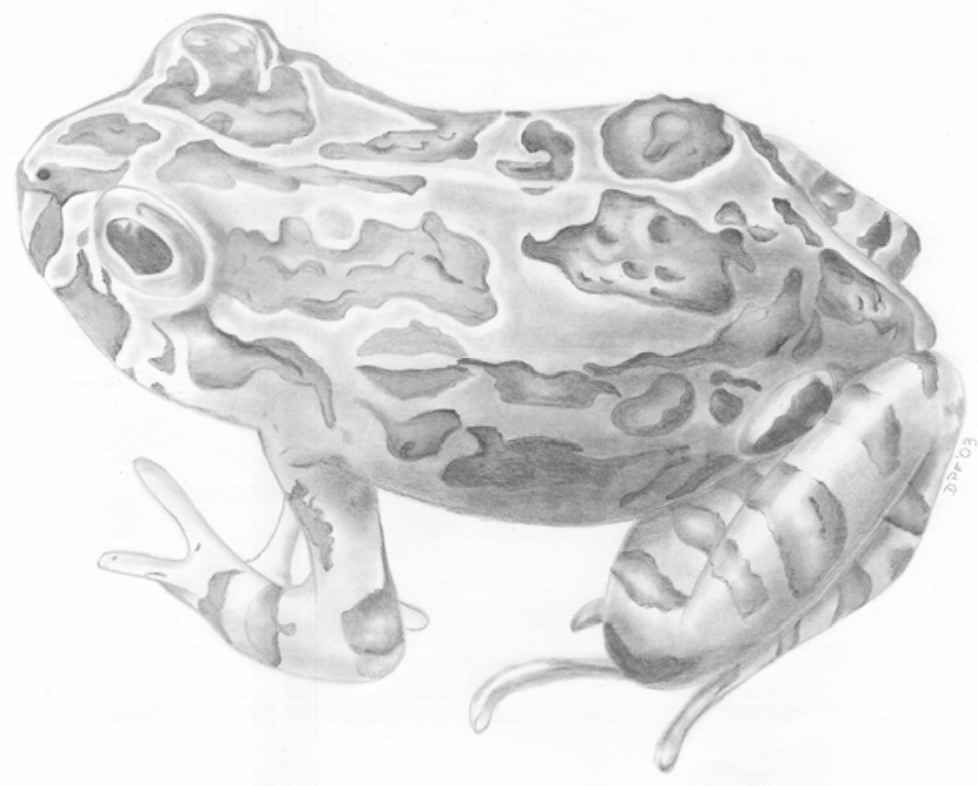


A continuación se describe la morfología externa de las especies del género Pleurodema, excepto de P. fuscomaculatum, dado que no fue posible examinar material.

Pleurodema bibroni: hocico levemente acuminado en vista dorsal, truncado en vista lateral; el hocico sobrepasa la boca; canthus rostralis no diferenciado, redondeado; región loreal plana o levemente cóncava, inclinada; textura del párpado superior levemente verrugosa, pupila redondeada; membrana nictitante translúcida; sin pliegue timpánico pero con una mancha desde el ojo hacia la glándula poscomisural; membrana timpánica ausente y circunferencia del anillo timpánico evidente; glándula poscomisural presente, blanquecina; lengua redondeada; dientes vomerinos ausentes. Glándulas lumbares presentes. Miembros anteriores con dedos redondeados; tubérculo metacarpal interno (TMI) redondeado u ovalado, no queratinizado, penetrando en el dedo II; tubérculo metacarpal externo (TME) ovalado, no queratinizado; tubérculos subarticulares y pequeños palmares presentes; longitud relativa de los dedos $\mid \mathrm{V}>\mathrm{II}>\mathrm{V}>\mathrm{III}$. Miembros posteriores con dedos redondeados; tubérculo metatarsal interno (Tml) ovalado, no queratinizado; tubérculo metatarsal externo (TmE) ovalado, no queratinizado; tubérculos subarticulares presentes; reborde en dedos; longitud relativa de los dedos $|V>|||=V>||>\mid$, pliegue tarsal ausente. Machos con saco bucal simple y subgular; callosidades nupciales en un solo parche en el dedo II.

Patrones de coloración y textura del cuerpo: En líneas generales, dorso marrón pálido, con manchas marrones relativamente simétricas a ambos lados de una delgada línea vertebral (a veces no conspicua), bordeadas de marrón más oscuro; estas manchas muchas veces están conectadas transversalmente (en kriegi, longitudinalmente). En el material conservado, las manchas en P. bibroni a veces se observan mejor definidas que en P. kriegi. En el dorso hay pequeñas pústulas dispersas, marrón claro, bordeadas de marrón oscuro. Desde el ojo nace una línea marrón oscura que pasa por la narina y termina en el borde de la quijada superior (a veces no conspicua). Generalmente una única mancha oscura sobre las glándulas lumbares. Zona dorsal de los miembros posteriores barrada; cada barra es amarronada, bordeada a ambos lados de marrón más oscuro. Miembros anteriores también barrados. La zona de los flancos entre la glándula lumbar y el comienzo del miembro posterior, y la zona oculta de los fémures con manchas marrones oscuras, bien definidas (coloración “flash”). Vientre inmaculado. Machos con región gular marrón oscura.

No se analizaron ejemplares vivos. Descripción basada en CENAI 6155-6163 y 6202-6218. 
Pleurodema aff. bibroni (poblaciones de Rio Grande do Sul, Brasil): Las características exo-morfológicas son muy similares a las descriptas para P. bibroni, por lo tanto, sólo se señalan las variaciones. Hocico levemente acuminado en vista dorsal, acuminado o truncado en vista lateral. Textura del párpado superior verrugosa. Sin mancha conspicua entre el ojo y la glándula poscomisural. En algunos ejemplares se observó un engrosamiento dérmico en la región más proximal del tarso. Machos con saco bucal simple y subgular; callosidades nupciales, si presentes, en dedo II.

Patrones de coloración y textura del cuerpo: En líneas generales, dorso marrón pálido, con manchas marrones poco simétricas bordeadas de marrón más oscuro (en P. bibroni se observó patrón más simétrico), estas manchas muchas veces están conectadas transversalmente; sin delgada línea vertebral. Textura del dorso del cuerpo más verrugosa que en $\mathrm{P}$. bibroni.

No se analizaron ejemplares vivos. Descripción basada en la serie del MCN (véase apéndice de Material examinado).

Pleurodema borellii: hocico levemente acuminado en vista dorsal, redondeado o truncado en vista lateral; el hocico sobrepasa la boca; canthus rostralis redondeado; región loreal levemente cóncava, inclinada; textura del párpado superior levemente verrugosa, pupila redondeada; membrana nictitante translúcida; pliegue timpánico presente que no cubre al tímpano; membrana y anillo timpánico prominentes; glándula poscomisural presente; lengua variable, redondeada, oval o lanceolada; dientes vomerinos presentes, agrupados, divergentes anteriormente, ubicados entre las coanas. Glándulas lumbares presentes. Miembros anteriores con dedos redondeados; TMI ovalado, no queratinizado, penetrando en el dedo II; TME ovalado o redondeado, no queratinizado; tubérculos subarticulares y palmares presentes; a veces reborde en dedos de la mano; longitud relativa de los dedos IV>II>V>III. Miembros posteriores con dedos redondeados; TmI ovalado y comprimido, no queratinizado; TmE ovalado o redondeado, no queratinizado; tubérculos subarticulares, supernumerarios y palmares presentes; reborde en dedos; longitud relativa de los dedos $|V>V>| I|>||>|$; en algunos ejemplares de observa un engrosamiento dérmico en la región más proximal del tarso. Algunos individuos infectados con ácaros. Machos con saco bucal simple y subgular; callosidades nupciales en dos parches, uno en dedo II y otro en tubérculo metacarpal interno.

Patrones de coloración y textura del cuerpo en vida: En líneas generales, dorso generalmente verrugoso, marrón claro, con pequeñas manchas anaranjadas $\mathrm{y} / \mathrm{o}$ marrón más oscuras, presentando una W intraescapular generalmente conspicua; a 
veces una delgada línea vertebral. Desde el ojo nace una línea marrón oscura que pasa por la narina y termina en el borde de la quijada superior; luego hay un número variable de barras en el labio superior, desde las narinas hasta el tímpano. Generalmente una mancha más oscura rodeada de un reborde blanquecino sobre las glándulas lumbares. Zona dorsal de los miembros anteriores y posteriores barrada; cada barra es marrón, bordeada a ambos lados de marrón más oscuro. Glándulas lumbares con una o varias manchas oscuras. Zona de los flancos entre la glándula lumbar y el comienzo del miembro posterior, y la zona oculta de los fémures es violácea en los ejemplares de Tucumán y amarillo-anaranjada en los ejemplares de Jujuy. Dorso con pequeñas pústulas. Vientre liso e inmaculado, en algunos ejemplares los flancos presentan un fino puntillado. Ojo con pupila redonda, negra con reborde dorado; iris dorado, con reticulados cobrizos. Machos con región gular amarronada.

Coloración en vida basada en 3 ejemplares de Yerba Buena, Tucumán (MLP A. 39093911) y 2 ejemplares de El Carmen, Jujuy (MLP A. 4748-4749).

Pleurodema brachyops: hocico levemente acuminado en vistas dorsal y truncado en vista lateral; el hocico sobrepasa la boca; canthus rostralis redondeado; región loreal levemente cóncava, inclinada; textura del párpado superior levemente verrugosa, pupila redondeada; membrana nictitante translúcida; pliegue supratimpánico corto; membrana y anillo timpánico prominentes; sin glándula poscomisural ni parotoidea; lengua generalmente ovalada y entera; dientes vomerinos presentes. Glándulas lumbares presentes. Miembros anteriores con dedos redondeados; TMI y TME ovalados, no queratinizados; tubérculos subarticulares presentes; longitud relativa de los dedos IV $>$ V $\geq I I>I I I$. Miembros posteriores con dedos redondeados; Tml ovalado, comprimido, a veces queratinizado; TmE ovalado, a veces queratinizado; tubérculos subarticulares presentes; reborde en dedos; longitud relativa de los dedos $I V>I I|V|>\mid I>I$, engrosamiento dérmico en el borde cantal del tarso. No se observaron ejemplares infectados con ácaros. Machos con saco bucal simple y subgular; callosidades nupciales en dos parches, uno en dedo II y otro en TMI.

Patrones de coloración y textura del cuerpo: dorso liso, con coloración marrón relativamente uniforme, sobre el cual se destacan manchas marrón oscuro que guardan cierta simetría. Hay una delgada línea blancuzca desde el urostilo hasta la región escapular o hasta el hocico. Una barra a la altura de cada narina (desde los ojos hasta el hocico) y otra debajo de cada ojo en el labio superior. Zona de los flancos, entre la región lumbar y el comienzo del miembro posterior con manchas 
marrones oscuras. Región oculta de los fémures sin de pigmentación, exceptuando la región circundante a la cloaca (a veces hay algunas pequeñas manchitas). Las manchas se van dispersando hacia los flancos del cuerpo, alcanzando la región de los miembros anteriores. Glándulas lumbares marrón oscuras o negruscas con pequeñas pintas blanquecinas. Región dorsal de miembros anteriores y posteriores barrada. Vientre inmaculado y liso. Machos con saco gular marrón oscuro.

No se analizaron ejemplares vivos. Descripción basada en: CENAI 3158-3159, 8780-8785 y UIS-A 098 y 1543.

Pleurodema bufoninum: hocico redondeado o levemente acuminado en vista dorsal, redondeado en vista lateral; el hocico sobrepasa la boca; canthus rostralis no diferenciado, redondeado; región loreal plana o levemente cóncava, inclinada; textura del párpado superior levemente verrugosa, pupila redondeada; membrana nictitante translúcida; pliegue timpánico corto, sobre el tímpano o apenas sobrepasándolo posteriormente; membrana timpánica ausente y circunferencia del anillo timpánico evidente; glándulas poscomisural y paratoidea presentes, a veces fusionadas; lengua generalmente redondeada y entera; dientes vomerinos presentes. Glándulas lumbares presentes. Miembros anteriores con dedos redondeados; TMI ovalado, no queratinizado, comprimido, penetrando en el dedo II; TME redondeado, ovalado o lanceolado, no queratinizado, no comprimido; tubérculos subarticulares, supernumerarios y palmares presentes; reborde en dedos; longitud relativa de los dedos $I V>I I \geq V>I I I$. Miembros posteriores con dedos redondeados; Tml ovalado, no queratinizado; TmE redondeado u ovalado, no queratinizado, comprimido; tubérculos subarticulares supernumerarios y palmares presentes; reborde en dedos; longitud relativa de los dedos $|V>V>|||>||>\mid$; pliegue tarsal presente. Algunos ejemplares infectados con ácaros. Machos sin saco bucal, con callosidades nupciales en dedo II y TMI.

Patrones de coloración y textura del cuerpo en vida: dorso de coloración muy variable, en líneas generales con fondo blanquecino o pardo, y manchas en diferentes gamas de marrones; a veces con machas grandes oscuras, y pequeñas manchas en su interior más claras, que mantienen una cierta simetría a cada lado del cuerpo; otras veces con manchas irregulares oscuras; con o sin línea vertebral. En general, cuando no hay línea vertebral, se observa una línea más clara, a la altura de la unión de las supraescápulas. Coloración de las glándulas lumbares similar a la del resto del cuerpo. Piel dorsal lisa o con pequeños gránulos en baja densidad. Zona dorsal de los miembros anteriores y posteriores barrada o con manchas más bien ocelares, de contorno irregular, cada barra o mancha ocelar es marrón, y está 
bordeada a ambos lados de marrón más oscuro. Vientre inmaculado. Ojo con pupila redonda, negra con reborde dorado; iris dorado, con reticulados negros, con una concentración de pigmento en los bordes anterior y posterior del mismo. Machos con región gular amarronada.

Coloración en vida basada en cuatro ejemplares del Cruce de la RN 40 y Arroyo Pilcaniyeu, Río Negro (MLP A. 4033-4036); un ejemplar de cruce de la RN 40 y Arroyo El Porteño, Río Negro (MLP A. 4048); un ejemplar del Cruce de la RN 23 y Río Pichi Leufú, Río Negro (MLP A. 4005) y un ejemplar de Puerto Deseado, Santa Cruz (MLP A. 4747).

Pleurodema cinereum: hocico redondeado o levemente acuminado en vista dorsal, acuminado o truncado en vista lateral; el hocico sobrepasa la boca; canthus rostralis redondeado; región loreal levemente cóncava, inclinada; textura del párpado superior levemente verrugosa, pupila redondeada; membrana nictitante translúcida; pliegue timpánico presente que no cubre al tímpano; membrana y anillo timpánico prominentes; glándula poscomisural presente; lengua variable, redondeada, oval o lanceolada; dientes vomerinos presentes, agrupados, divergentes anteriormente, ubicados entre las coanas. Glándulas lumbares presentes. Miembros anteriores con dedos redondeados; TMI ovalado, no queratinizado, penetrando en el dedo II; TME ovalado o redondeado, no queratinizado; tubérculos subarticulares y palmares presentes; a veces reborde en dedos III y IV; longitud relativa de los dedos IV $>$ II $>$ V > III. Miembros posteriores con dedos redondeados; Tml ovalado y comprimido, no queratinizado; TmE ovalado, no queratinizado; tubérculos subarticulares y palmares presentes; reborde en dedos; longitud relativa de los dedos $\mid \mathrm{V}>\mathrm{III}>\mathrm{V}>\mathrm{II}>\mathrm{I}$; en algunos ejemplares de observa un engrosamiento dérmico en la región tarsal, en otros un pliegue tarsal conspicuo; membrana interdigital basal. Machos con saco bucal simple y subgular; callosidades nupciales en dedo II y TMI.

Patrones de coloración y textura del cuerpo en vida: Muy similar a P. borellii. En líneas generales, dorso verrugoso, marrón claro, con pequeñas manchas marrón más oscuras, presentando una $\mathrm{W}$ intraescapular generalmente conspicua; a veces una delgada línea vertebral. Desde el ojo nace una línea marrón oscura que pasa por la narina y termina en el borde de la quijada superior; luego hay un número variable de barras en el labio superior, desde las narinas hasta el tímpano. Sobre las glándulas lumbares generalmente hay una mancha más oscura rodeada de un reborde blanquecino. Zona dorsal de los miembros anteriores y posteriores barrada; cada barra es marrón, bordeada a ambos lados de marrón más oscuro. Zona de los flancos entre la glándula lumbar y el comienzo del miembro posterior, y la zona oculta de los fémures, es blanquecina en los ejemplares de Casabindo y proximidades, y amarillo- 
anaranjada en los ejemplares de La Intermedia. Vientre inmaculado. Ojo con pupila redonda, negra con reborde dorado, iris dorado, con reticulados cobrizos. Machos con región gular amarronada.

Coloración en vida basada en cuatro ejemplares de Casabindo, Jujuy (MLP A. 47544757); un ejemplar de RP 11, camino a Casabindo, Jujuy (MLP A. 4753); tres ejemplares de Juella, Jujuy (MLP A. 4676-4578) y tres ejemplares de La Intermedia, Jujuy (MLP A. 4095-4096 y 4758).

Pleurodema cordobae: hocico levemente acuminado en vista dorsal, redondeado en vista lateral; el hocico sobrepasa la boca; canthus rostralis no diferenciado, redondeado; región loreal plana o levemente cóncava, inclinada; textura del párpado superior levemente verrugosa, pupila redondeada; membrana nictitante translúcida; sin pliegue timpánico; membrana timpánica ausente y circunferencia del anillo timpánico evidente; glándula poscomisural presente; lengua generalmente redondeada y entera; dientes vomerinos ausentes. Glándulas lumbares presentes. Miembros anteriores con dedos redondeados; TMI ovalado, no queratinizado, penetrando en el dedo II; TME ovalado, no queratinizado; tubérculos subarticulares y pequeños palmares presentes; longitud relativa de los dedos IV $>$ V $>$ II $>$ III. Miembros posteriores con dedos redondeados; Tml y TmE ovalados, no queratinizados; tubérculos subarticulares presentes; reborde en dedos; longitud relativa de los dedos $|\mathrm{V}>||||\mathrm{V}>||>|$, sin pliegue tarsal. No se analizaron machos.

Patrones de coloración y textura del cuerpo en vida: En líneas generales, dorso marrón pálido, con manchas relativamente simétricas a ambos lados de una delgada línea vertebral (a veces no conspicua) verde musgo, bordeadas de verde más oscuro. En el dorso hay pequeñas pústulas dispersas, amarillas bordeadas de negro; en los flancos son amarillas. Desde el ojo nace una línea marrón oscura que pasa por la narina y termina en el borde de la quijada superior. Glándula postcomisural amarillenta. Sobre las glándulas lumbares generalmente hay una mancha más oscura, flanqueada por otras manchas blancuzcas o amarillentas, anterior y posteriomente. Zona dorsal de los miembros posteriores barrada; cada barra es verde-amarronado o verde musgo, bordeada a ambos lados de verde o marrón más oscuro. Miembros anteriores con un barrado menos conspicuo. La zona de los flancos entre la glándula lumbar y el comienzo del miembro posterior y la zona oculta de los fémures tiene manchas negras y rojizas (coloración "flash"). Vientre inmaculado. Ojo con pupila redonda, negra con reborde dorado; iris dorado, con reticulados negros.

Coloración en vida basada en dos ejemplares de Sierra de Comechingones, Córdoba (MACN 39911-39912). 
Pleurodema diplolister: hocico acuminado en vista dorsal, levemente truncado en vista lateral; el hocico sobrepasa la boca; canthus rostralis no diferenciado; región loreal levemente cóncava, inclinada; narinas muy próximas al hocico; textura del párpado lisa, pupila redondeada; membrana nictitante translúcida; pliegue timpánico presente que no cubre al tímpano; tímpano con membrana y anillo timpánicos prominentes; glándula poscomisural ausente; lengua lanceolada; dientes vomerinos presentes, alineados, divergentes anteriormente, ubicados entre las coanas. Glándulas lumbares ausentes. Pliegues gular y discoidal presentes. Miembros anteriores con dedos redondeados; TMI ovalado, no queratinizado, penetrando en el dedo II; TME ovalado, no queratinizado; tubérculos subarticulares y palmares presentes; longitud relativa de los dedos $I V>I I \geq I I \mid>V$. Miembros posteriores con dedos redondeados; Tml y TmE ovalados, comprimidos, a veces queratinizados; tubérculos subarticulares y palmares presentes; tubérculo tarsal presente, próximo a la articulación entre estilo y zeugopodio; reborde en dedos y membrana interdigital basal; longitud relativa de los dedos $|V>|||>V>||>I$, engrosamiendo dérmico en el borde cantal del tarso. No se observaron ejemplares infectados por ácaros. Machos con saco bucal simple y subgular; callosidades nupciales en dedo II y TMI.

Patrones de coloración y textura del cuerpo: dorso con coloración marrón claro, sobre el cual se destacan manchas marrón oscuro que guardan cierta simetría. En un ejemplar hay una delgada línea blancuzca desde el urostilo hasta la región escapular. Hay una barra a la altura de cada narina (desde los ojos hasta el hocico) y otra debajo de cada ojo en el labio superior. Los flancos del cuerpo poseen manchas irregulares. Región dorsal de miembros anteriores y posteriores barrada. Dorso liso. Vientre inmaculado y liso.

No se analizaron ejemplares vivos. Descripción basada en: CENAI 8773-8775, 1100311004 y MZUSP 38280, 38291.

Pleurodema guayapae: hocico truncado en vistas dorsal y lateral; el hocico sobrepasa la boca; canthus rostralis no diferenciado; región loreal plana, vertical; narinas en el extremo del hocico; textura del párpado superior lisa, pupila redondeada; membrana nictitante translúcida; pliegue timpánico presente, aunque poco conspicuo; membrana timpánica ausente; glándula poscomisural presente; lengua redondeada; dientes vomerinos ausentes. Glándulas lumbares ausentes. Debajo de la cloaca se observan dos pliegues cutáneos. Pliegue discoidal presente. Miembros anteriores con dedos redondeados; TMI redondeado, no queratinizado, penetrando en el dedo II; TME ovalado o con forma levemente de corazón, no 
queratinizado; pequeños tubérculos palmares; longitud relativa de los dedos IV $>$ II $>$ V > III. Miembros posteriores con dedos redondeados; Tml ovalado, comprimido, a veces queratinizado; TmE ovalado, comprimido, no queratinizado; pocos tubérculos subarticulares, generalmente sólo en la base de los dedos; reborde en dedos; longitud relativa de los dedos $|V>|||>V>I|>|$, pliegue tarsal ausente. Machos con saco bucal simple y subgular; callosidades nupciales en dedo II y TMI (a veces no se han observado, probablemente por el estado de preservación de los ejemplares).

Patrones de coloración y textura del cuerpo: dorso con coloración marrón claro marmolada con marrón más oscuro, con pequeñas manchitas ocelares negras dispersas en el dorso, recordando vagamente "forma de 8" (sin unirse dorsal ni ventralmente; menos definido que en P. nebulosum). En algunos ejemplares hay manchas entre los ojos y en el hocico. Las manchas se van dispersando hacia los flancos del cuerpo, donde son más pequeñas y menos numerosas. Miembros anteriores marrón claro, a veces con pequeñas manchas marrón oscuro; lo mismo se observa en los miembros posteriores, pero sin formar un barrado conspicuo. Dorso liso. Vientre inmaculado y liso. Machos con región gular amarronada.

No se analizaron ejemplares vivos. Descripción basada en: CENAI 7253 a 7260.

Pleurodema kriegi: hocico levemente acuminado en vista dorsal, redondeado en vista lateral; el hocico sobrepasa la boca; canthus rostralis no diferenciado, redondeado; región loreal plana o levemente cóncava, inclinada; textura del párpado superior levemente verrugosa, pupila redondeada; membrana nictitante translúcida; con pliegue timpánico tenue; membrana y anillo timpánico con diferentes grados de reducción; glándula poscomisural presente; lengua generalmente redondeada y entera; dientes vomerinos ausentes. Glándulas lumbares presentes. Miembros anteriores con dedos redondeados; TMI ovalado, no queratinizado, comprimido, penetrando en el dedo II; TME ovalado, no queratinizado, comprimido; tubérculos subarticulares y pequeños palmares presentes; reborde a veces en dedo IV; longitud relativa de los dedos IV $>$ V $>$ II $>$ III. Miembros posteriores con dedos redondeados; TmI ovalado, no queratinizado; TmE ovalado, no queratinizado; tubérculos subarticulares presentes; reborde en dedos; longitud relativa de los dedos $I V>I I I \geq V>I \mid>I$, sin pliegue tarsal. Muchos ejemplares infectados con ácaros. Machos con saco bucal simple y subgular; callosidades nupciales en un solo parche en el dedo II.

Patrones de coloración y textura del cuerpo en vida: En líneas generales, dorso marrón pálido, con manchas relativamente simétricas a ambos lados de una delgada línea vertebral (a veces no conspicua) verde musgo, bordeadas de verde más oscuro. 
En el dorso hay pequeñas pústulas dispersas, amarillas bordeadas de negro; en los flancos son amarillas. Desde el ojo nace una línea marrón oscura que pasa por la narina y termina en el borde de la quijada superior. Glándula postcomisural amarillenta. Sobre las glándulas lumbares generalmente hay una mancha más oscura, flanqueada por otras manchas blancuzcas o amarillentas, anterior y posteriomente. Zona dorsal de los miembros posteriores barrada; cada barra es verde-amarronado o verde musgo, bordeada a ambos lados de verde o marrón más oscuro. Miembros anteriores con un barrado menos conspicuo. La zona de los flancos entre la glándula lumbar y el comienzo del miembro posterior, y la zona oculta de los fémures tiene manchas negras y rojizas (coloración "flash"). Vientre inmaculado o con pequeñas motas marrones. Ojo con pupila redonda, negra con reborde dorado; iris dorado, con reticulados negros. Machos con región gular verde musgo, algunas zonas amarillentas.

Coloración en vida basada en dos ejemplares de Pampa de Achala, Córdoba (MLP A. 3528-3529) y dos ejemplares del Parque Nacional Quebrada del Condorito, Córdoba (MLP A. 4759-4760).

Pleurodema marmoratum: hocico redondeado en vistas dorsal y lateral; el hocico sobrepasa la boca; canthus rostralis redondeado; región loreal levemente cóncava, inclinada; textura del párpado superior levemente verrugosa, pupila redondeada; membrana nictitante translúcida; con pliegue supratimpánico; membrana timpánica ausente y circunferencia del anillo timpánico evidente; glándula poscomisural presente, blanquecina; lengua generalmente ovalada y entera; dientes vomerinos ausentes. Pliegue discoidal presente, a veces interrumpido en la unión de los brazos al cuerpo. Glándulas lumbares ausentes. Miembros anteriores con dedos redondeados; TMI ovalado, no queratinizado, comprimido; TME redondeado, no queratinizado, comprimido; tubérculos subarticulares presentes; longitud relativa de los dedos IV >V $\geq$ II $>$ III. Miembros posteriores con dedos redondeados; Tml ovalado, no queratinizado; TmE ovalado, no queratinizado; tubérculos subarticulares presentes; reborde en dedos; longitud relativa de los dedos $|\mathrm{V}>| \mathrm{II} \geq \mathrm{V}>\mathrm{I}|>|$, pliegue tarsal presente. Pocos ejemplares infectados con ácaros. Machos con saco bucal poco conspicuo, doble y lateral; callosidades nupciales en un solo parche en el dedo II.

Patrones de coloración y textura del dorso: Dorso con manchas ocelares irregulares, marrones, con rebordes marrón oscuro. A veces se diferencia una línea vertebral, de acuerdo a la forma que tomen las manchas ocelares. Generalmente hay una mancha marrón triangular entre los ojos. Banda oscura desde el hocico hasta los ojos, atraviesa el tímpano (debajo del pliegue supratimpánico) hasta el brazo. Las manchas pueden coincidir o no con pliegues glandulares alargados antero- 
posteriormente $\mathrm{y} / \mathrm{o}$ con pústulas sobresalientes. Vientre inmaculado y liso; en algunos ejemplares se observaron puntos blanquecinos desde los flancos hacia el centro del abdomen, donde van disminuyendo en cantidad hasta desaparecer.

No se analizaron ejemplares vivos. Descripción basada en dos ejemplares de $\mathrm{El}$ Quemado, Abra de Pives, Jujuy (lote FML 3757), cuatro ejemplares de Mina El Aguilar, Jujuy (FML 2406 y lote de tres ejemplares FML 3300), un ejemplar de Laguna Leandro, Jujuy (FML 2784), diescisiete ejemplares de Mina El Gigante, Jujuy (lote de seis ejemplares FML 2830 y lote de once ejemplares FML 2804) y un ejemplar de Laguna Cañuma, Ulla Ulla, Bolivia (FML 5226).

Pleurodema nebulosum: hocico truncado en vistas dorsal y lateral; el hocico sobrepasa la boca; canthus rostralis no diferenciado; región loreal plana, vertical; narinas en el extremo del hocico; textura del párpado lisa, pupila redondeada; membrana nictitante translúcida; pliegue timpánico presente; membrana timpánica presente; glándula poscomisural presente; lengua redondeada; dientes vomerinos ausentes. Glándulas lumbares ausentes. Debajo de la cloaca se observan dos pliegues cutáneos. Pliegue discoidal presente. Miembros anteriores con dedos redondeados; TMI redondeado, no queratinizado, penetrando en el dedo II; ME ovalado o con forma levemente de corazón, no queratinizado; tubérculos subarticulares, generalmente en la base de los dedos; longitud relativa de los dedos IV $>||>V>I I I$. Miembros posteriores con dedos redondeados; Tml y TmE ovalados, comprimidos, a veces queratinizados; extremos de los dedos a veces queratinizados (especialmente dedos II y III); pocos tubérculos subarticulares, generalmente sólo en la base de los dedos; reborde en dedos; longitud relativa de los dedos $|V>I| I>V>I \mid>I$, pliegue tarsal ausente. Machos con saco bucal simple y subgular; callosidades nupciales en dos parches, uno en dedo II y otro en el tubérculo metacarpal.

Patrones de coloración y textura del cuerpo: dorso con coloración gris plomiza o marrón clara marmolada con marrón más oscuro. En algunos ejemplares hay pequeñas manchitas ocelares negras dispersas en el dorso, recordando vagamente una "forma de 8" (sin unirse dorsal ni ventralmente); en otros individuos hay manchas formando un patrón más irregular. En algunos ejemplares hay manchas entre los ojos y en el hocico. Las manchas se van dispersando hacia los flancos del cuerpo, donde son más pequeñas, y confluyen, a veces, con pequeñas verrugas. Piel dorsal lisa. Miembros anteriores grises o marrón claro, a veces con pequeñas manchas marrón oscuro; lo mismo se observa en los miembros posteriores, pero sin formar un barrado conspicuo. Vientre inmaculado y liso. Machos con región gular amarronada. 
No se analizaron ejemplares vivos. Descripción basada en: lote CENAI 228, MACN 3874838774 y MACN 38993-38996.

Pleurodema thaul: hocico redondeado en vistas dorsal y lateral; el hocico sobrepasa la boca; canthus rostralis no diferenciado, redondeado; región loreal levemente cóncava, inclinada; textura del párpado superior lisa o levemente verrugosa, pupila redondeada; membrana nictitante translúcida; pliegue timpánico presente aunque difuso, que cubre el tímpano; membrana timpánica ausente y circunferencia del anillo timpánico evidente; glándula poscomisural presente; lengua redondeada y levemente escotada; dientes vomerinos presentes, en líneas divergentes anteriormente, ubicados entre y por detrás de las coanas. Característica mancha oscura alargada en el labio superior. Textura dorsal verrugosa. Glándulas lumbares presentes. Miembros anteriores con dedos redondeados; TMI ovalado, no queratinizado, comprimido, penetrando en el dedo II; TME ovalado o lanceolado, no queratinizado, comprimido; tubérculos subarticulares y pequeños palmares presentes; leve reborde cutáneo en los dedos; longitud relativa de los dedos IV $>$ V $\geq$ II $>$ III. Miembros posteriores con dedos redondeados; Tml ovalado, no queratinizado; TmE redondeado, no queratinizado; tubérculos subarticulares presentes, a veces tubérculos palmares; reborde en dedos; longitud relativa de los dedos IV>III>V>II>I; pliegue tarsal presente. Machos con saco bucal simple y subgular; callosidades nupciales en dedo II y TMI.

Patrones de coloración y textura del cuerpo en vida: dorso verrugoso, de coloración muy variable, en líneas generales con fondo marrón o pardo, con machas marrones, verdes, cobrizas, rojizas, generalmente con cierta simetría bilateral en el manchado; con o sin línea vertebral. En todo el dorso se destaca una suave coloración iridiscente. Desde el ojo nace una línea marrón oscura que pasa por la narina y termina en el borde de la quijada superior; otra mancha que acompaña al pliegue timpánico; y luego, característicamente, una mancha alargada en el borde del labio superior. Sobre las glándulas lumbares generalmente hay una mancha oscura limitada por márgenes más claros. Piel dorsal con pequeños gránulos en baja densidad. Zona dorsal de los miembros anteriores y posteriores barrada, cada barra es de un color marrón bastante uniforme. Vientre inmaculado. Ojo con pupila redonda, negra con reborde dorado; iris cobrizo, con reticulados negros, con una concentración de pigmento en los bordes anterior y posterior del mismo. Machos con región gular verdoso-amarronada.

Coloración en vida basada en dos ejemplares del Parque Nacional Lago Puelo (MLP A. 4070-4071). 
Pleurodema tucumanum: hocico truncado en vistas dorsal y lateral; el hocico sobrepasa la boca; canthus rostralis redondeado; región loreal levemente cóncava, inclinada; textura del párpado superior levemente verrugosa, pupila redondeada; membrana nictitante translúcida; con pliegue supratimpánico corto; membrana y anillo timpánico poco prominentes; sin glándula poscomisural ni parotoidea; lengua generalmente ovalada y entera; dientes vomerinos presentes. Pliegue abdominal. Glándulas lumbares ausentes. Miembros anteriores con dedos redondeados; TMI ovalado, no queratinizado; TME ovalado, no queratinizado; tubérculos subarticulares presentes; longitud relativa de los dedos IV $>$ V $\geq I I>I I I$. Miembros posteriores con dedos redondeados; Tml ovalado, comprimido, a veces queratinizado; TmE ovalado, a veces queratinizado; tubérculos subarticulares presentes; reborde en dedos; longitud relativa de los dedos $|\mathrm{V}>| \mathrm{I}|\geq V>||>|$, presencia de un engrosamiento dérmico en el borde cantal del tarso, pero sólo en algunos ejemplares, en otros no se observó ninguna estructura tarsal. No se observaron ejemplares infectados con ácaros. Machos con saco bucal simple y subgular; callosidades nupciales en dedo II y TMI.

Patrones de coloración y textura del cuerpo en vida: dorso con coloración gris o marrón claro uniforme, con pequeñas manchitas ocelares negras dispersas en el dorso, recordando vagamente una forma de X. La zona de los flancos, entre la región lumbar y el comienzo del miembro posterior, y la zona oculta de los fémures tiene manchas marrones oscuras. Manchas dispersas hacia los flancos del cuerpo, donde son más pequeñas. Dorso liso. Vientre inmaculado y liso. Ojo con pupila redonda, negra; iris marrón, volviéndose más amarillento al rodear la pupila, con una concentración de pigmento en los bordes anterior, posterior, dorsal y ventral del mismo. Machos con región gular amarronada.

Coloración en vida basada en catorce ejemplares, MLP A. 3852-3856, 3889-3903 y 47214724 de Establecimiento Santa Rosa, RN 150, km 11, próximo a Patquía, La Rioja.

Los caracteres 0-19 y 97-99 del análisis filogenético surgieron de la información presentada en este capítulo. 


\section{CAPÍTULO II}

Morfometría

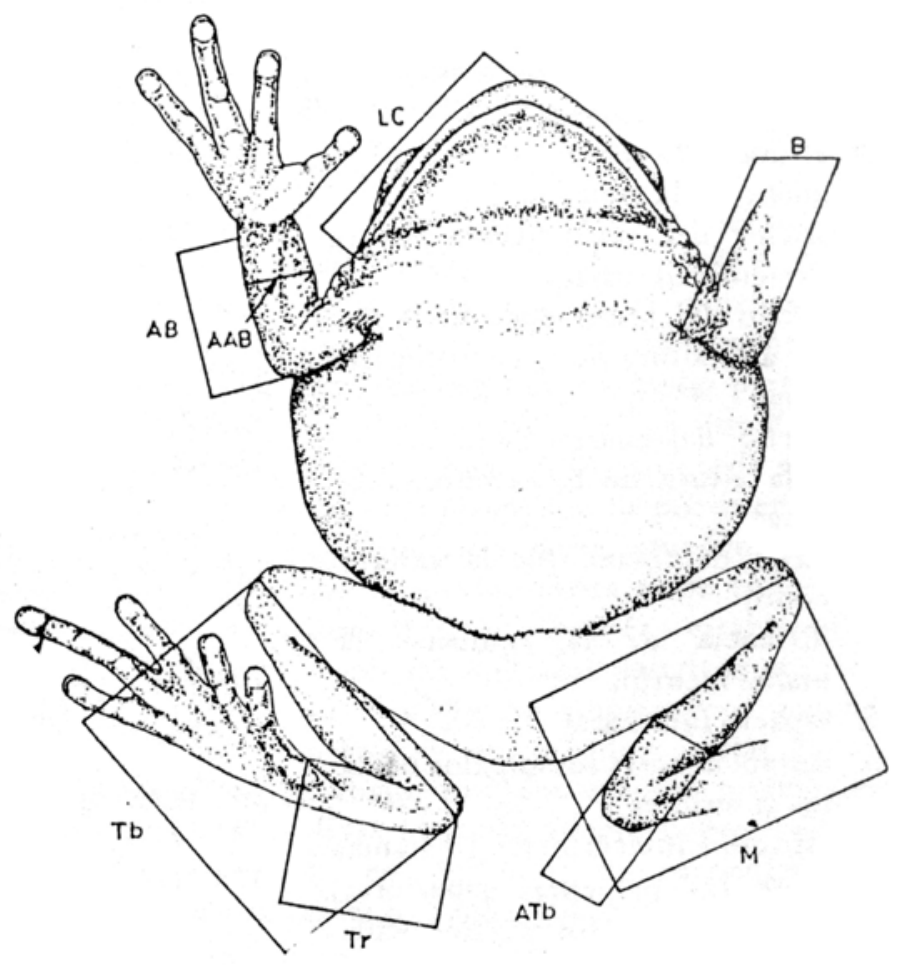

Tomado de Laurent (1984) 


\section{Estadística descriptiva}

En la tabla 1 se muestran estadísticos descriptivos (número de ejemplares, promedio, rango y desvío estándar) para todas las especies consideradas.

Tabla 1. Estadísticos descriptivos de las variables morfométricas estudiadas en las especies de Pleurodema. Véanse abreviaciones de las variables en la sección Materiales y Métodos. Todas las medidas expresadas en milímetros. D. E. = Desvío Estándar.

\begin{tabular}{l|llllll} 
& \multicolumn{3}{l}{ P. borellii, Hembras $(\mathbf{N}=\mathbf{3 6})$} & \multicolumn{3}{l}{ P. borellii, Machos (N = 68) } \\
\hline LT & Promedio Rango & D. E. & Promedio & Rango & D. E. \\
N-H & 42,54 & $34,73-50,96$ & 4,11 & 39,20 & $33,19-46,04$ & 3,15 \\
AC & 3,71 & $3,04-4,48$ & 0,38 & 3,56 & $2,91-4,53$ & 0,32 \\
LC & 15,90 & $13,04-19,02$ & 1,52 & 15,37 & $11,20-18,54$ & 1,39 \\
O & 12,24 & $10,07-15,11$ & 1,04 & 11,74 & $9,58-14,16$ & 0,95 \\
Ti & 4,70 & $3,61-5,82$ & 0,50 & 4,50 & $3,62-5,53$ & 0,42 \\
PS & 2,23 & $1,42-3,09$ & 0,38 & 2,14 & $1,20-3,93$ & 0,45 \\
DO & 3,87 & $3,05-4,61$ & 0,44 & 3,74 & $2,87-5,02$ & 0,54 \\
NO & 6,88 & $5,87-8,49$ & 0,62 & 6,66 & $5,45-8,03$ & 0,52 \\
H & 3,53 & $2,67-4,52$ & 0,36 & 3,46 & $2,84-4,21$ & 0,32 \\
DN & 6,17 & $5,12-7,68$ & 0,64 & 5,93 & $4,57-7,82$ & 0,67 \\
OT & 3,16 & $2,58-3,72$ & 0,29 & 3,04 & $2,15-3,51$ & 0,26 \\
OB & 1,78 & $1,20-2,53$ & 0,28 & 1,68 & $1,18-2,52$ & 0,29 \\
F & 2,73 & $1,90-3,57$ & 0,38 & 2,54 & $1,91-3,24$ & 0,31 \\
T & 19,15 & $16,68-22,47$ & 1,47 & 18,37 & $15,59-21,43$ & 1,41 \\
Tr & 19,41 & $16,75-22,41$ & 1,45 & 18,41 & $15,53-21,33$ & 1,46 \\
Pie & 9,27 & $7,66-11,19$ & 0,84 & 8,87 & $7,25-10,11$ & 0,67 \\
LTMe & 21,39 & $16,96-25,69$ & 2,14 & 20,38 & $16,85-23,69$ & 1,50 \\
LTMi & 2,00 & $1,35-2,53$ & 0,25 & 1,79 & $1,22-2,66$ & 0,29 \\
B & 2,14 & $1,40-2,73$ & 0,28 & 1,99 & $1,48-2,82$ & 0,29 \\
AB & 7,74 & $6,20-9,57$ & 1,02 & 7,11 & $5,29-8,73$ & 0,68 \\
Mano & 9,52 & $7,96-11,43$ & 0,94 & 9,00 & $7,48-10,45$ & 0,69 \\
LMCe & 11,65 & $9,70-13,40$ & 0,95 & 10,92 & $9,10-13,34$ & 0,96 \\
LTMi & 2,17 & $1,65-2,62$ & 0,28 & 2,11 & $1,47-3,02$ & 0,30 \\
LL & 2,13 & $1,64-2,60$ & 0,23 & 2,26 & $1,67-2,82$ & 0,25 \\
AL & 7,99 & $5,41-11,29$ & 1,20 & 7,12 & $5,13-10,46$ & 1,19 \\
DmL & 4,68 & $3,10-6,68$ & 0,98 & 4,11 & $2,72-6,23$ & 0,73 \\
& 10,96 & $7,23-14,91$ & 2,07 & 9,52 & $7,30-12,80$ & 1,16 \\
& & & & & &
\end{tabular}

\begin{tabular}{l|llllll} 
& \multicolumn{3}{l}{ P. cinereum, Hembras $(\mathbf{N}=\mathbf{1 9})$} & \multicolumn{3}{l}{ P. cinereum, Machos (N = 63) } \\
\hline & Promedio Rango & D. E. & Promedio & Rango & D. E. \\
LT & 38,89 & $29,95-43,59$ & 3,88 & 37,28 & $31,25-43,73$ & 3,05 \\
N-H & 3,30 & $2,88-3,81$ & 0,29 & 3,19 & $1,79-3,90$ & 0,33 \\
AC & 14,18 & $11,01-16,74$ & 1,60 & 14,33 & $10,74-16,94$ & 1,27 \\
LC & 10,63 & $8,19-12,34$ & 1,06 & 10,74 & $8,39-13,07$ & 1,12 \\
$\mathbf{~ O}$ & 3,93 & $3,12-4,79$ & 0,47 & 4,26 & $3,38-5,33$ & 0,45 \\
Ti & 1,90 & $1,42-2,70$ & 0,37 & 2,07 & $1,39-3,93$ & 0,44 \\
PS & 3,71 & $3,03-4,32$ & 0,36 & 3,57 & $2,01-4,65$ & 0,49 \\
DO & 6,33 & $5,33-7,66$ & 0,60 & 6,32 & $5,44-8,03$ & 0,55 \\
NO & 3,25 & $2,69-4,04$ & 0,37 & 3,22 & $2,67-3,86$ & 0,29 \\
H & 5,61 & $4,53-6,49$ & 0,56 & 5,42 & $4,62-6,47$ & 0,45 \\
DN & 2,49 & $1,36-3,30$ & 0,57 & 2,86 & $1,99-3,62$ & 0,29 \\
OT & 2,01 & $1,30-3,07$ & 0,58 & 1,68 & $1,13-2,40$ & 0,25 \\
OB & 2,60 & $2,11-3,27$ & 0,32 & 2,48 & $1,86-3,44$ & 0,31 \\
F & 16,81 & $11,30-19,27$ & 1,97 & 17,05 & $13,47-19,77$ & 1,32 \\
T & 16,67 & $14,03-19,01$ & 1,47 & 16,96 & $14,14-20,13$ & 1,25 \\
Tr & 7,79 & $5,33-9,38$ & 1,16 & 8,52 & $6,78-11,32$ & 1,01 \\
Pie & 18,21 & $12,12-21,32$ & 2,21 & 18,98 & $17,09-22,54$ & 1,42
\end{tabular}




\begin{tabular}{l|llllll} 
LTMe & 1,74 & $1,38-2,08$ & 0,22 & 1,67 & $1,19-2,29$ & 0,24 \\
LTMi & 2,00 & $1,42-2,82$ & 0,33 & 1,91 & $1,18-2,48$ & 0,23 \\
B & 6,32 & $4,78-7,61$ & 0,70 & 6,77 & $4,73-9,88$ & 1,00 \\
AB & 8,03 & $5,98-9,28$ & 0,85 & 8,56 & $6,64-10,44$ & 0,96 \\
Mano & 9,93 & $7,87-11,52$ & 1,02 & 9,90 & $8,47-12,57$ & 0,95 \\
LMCe & 1,92 & $1,49-2,31$ & 0,21 & 1,95 & $1,47-2,67$ & 0,26 \\
LTMi & 1,91 & $1,53-2,28$ & 0,21 & 2,02 & $1,36-2,64$ & 0,29 \\
LL & 6,45 & $3,71-8,18$ & 1,17 & 6,15 & $3,70-8,56$ & 0,98 \\
AL & 4,01 & $2,79-5,41$ & 0,73 & 3,56 & $2,11-5,40$ & 0,61 \\
DmL & 10,50 & $7,70-14,26$ & 1,69 & 9,27 & $7,05-13,10$ & 1,33
\end{tabular}

P. bibroni, Hembras ( $\mathbf{N}=33$ )

\begin{tabular}{l|llllll} 
& \multicolumn{3}{l}{ P. bibroni, Hembras (N = 33) } & \multicolumn{4}{c}{ P. bibroni, Machos (N = 30) } \\
\hline & Promedio & Rango & D. E. & Promedio Rango & D.E. \\
LT & 32,07 & $28,29-46,21$ & 3,60 & 32,97 & $29,03-38,38$ & 2,56 \\
N-H & 2,70 & $2,19-3,67$ & 0,31 & 2,77 & $1,45-3,51$ & 0,39 \\
AC & 11,69 & $9,55-16,15$ & 1,45 & 12,44 & $11,16-15,14$ & 1,19 \\
LC & 8,46 & $6,60-12,09$ & 1,20 & 8,99 & $7,97-10,66$ & 0,75 \\
O & 3,45 & $2,63-4,24$ & 0,38 & 3,47 & $2,65-4,28$ & 0,37 \\
PS & 2,51 & $2,02-4,39$ & 0,51 & 2,54 & $1,69-3,37$ & 0,33 \\
DO & 5,65 & $5,09-6,85$ & 0,39 & 5,77 & $5,13-6,81$ & 0,38 \\
NO & 2,89 & $2,40-3,90$ & 0,33 & 2,90 & $2,32-3,44$ & 0,24 \\
H & 4,92 & $4,14-6,74$ & 0,54 & 5,01 & $3,19-5,76$ & 0,49 \\
DN & 2,09 & $1,77-2,61$ & 0,19 & 2,10 & $1,65-2,61$ & 0,21 \\
OB & 2,09 & $1,81-2,89$ & 0,25 & 2,19 & $1,76-2,66$ & 0,24 \\
F & 13,26 & $11,26-18,12$ & 1,33 & 14,10 & $12,06-17,65$ & 1,42 \\
T & 14,33 & $12,40-18,37$ & 1,17 & 14,96 & $12,51-17,23$ & 1,34 \\
Tr & 6,53 & $5,43-9,21$ & 0,79 & 6,61 & $5,29-7,91$ & 0,69 \\
Pie & 14,94 & $12,18-20,02$ & 1,55 & 15,88 & $13,74-18,70$ & 1,45 \\
LTMe & 1,46 & $1,11-1,91$ & 0,17 & 1,59 & $1,19-2,07$ & 0,22 \\
LTMi & 1,22 & $1,01-2,01$ & 0,18 & 1,39 & $0,98-1,94$ & 0,25 \\
B & 4,83 & $3,60-6,45$ & 0,78 & 5,20 & $4,02-6,70$ & 0,75 \\
AB & 7,07 & $5,83-9,91$ & 0,83 & 7,75 & $6,37-9,15$ & 0,69 \\
Mano & 9,00 & $7,50-11,11$ & 0,88 & 9,23 & $7,11-11,41$ & 0,97 \\
LMCe & 1,39 & $1,12-1,91$ & 0,19 & 1,58 & $1,07-2,05$ & 0,25 \\
LMCi & 1,30 & $0,94-1,67$ & 0,22 & 1,58 & $0,95-2,06$ & 0,27 \\
LL & 5,32 & $4,10-8,32$ & 0,87 & 5,85 & $4,29-7,35$ & 0,69 \\
AL & 3,37 & $2,64-4,92$ & 0,46 & 3,72 & $3,00-4,83$ & 0,44 \\
DmL & 8,71 & $6,72-13,01$ & 1,29 & 8,72 & $6,64-11,51$ & 1,04
\end{tabular}

P. kriegi, Hembras ( $\mathbf{N}=\mathbf{3 0}$ )

\begin{tabular}{|c|c|c|c|c|c|c|}
\hline \\
\hline LT & $\begin{array}{l}\text { Promedio } \\
35,26\end{array}$ & $\begin{array}{l}\text { Rango } \\
30,60-40,35\end{array}$ & $\begin{array}{l}\text { D. E. } \\
2.56\end{array}$ & $\begin{array}{l}\text { Promedio } \\
31,37\end{array}$ & $\begin{array}{l}\text { Rango } \\
28,00-35,58\end{array}$ & $\begin{array}{l}\text { D. E. } \\
2.11\end{array}$ \\
\hline N-H & 3,11 & $2,77-3,44$ & 0,20 & 2,95 & $2,42-3,30$ & 0,22 \\
\hline AC & 13,11 & $10,39-14,93$ & 1,03 & 12,47 & $10,93-14,10$ & 0,82 \\
\hline LC & 9,22 & $7,46-10,42$ & 0,75 & 8,83 & $7,41-10,16$ & 0,65 \\
\hline 0 & 3,68 & $2,89-4,72$ & 0,42 & 3,51 & $2,79-4,11$ & 0,37 \\
\hline PS & 2,93 & $1,97-3,48$ & 0,33 & 2,72 & $2,17-3,54$ & 0,30 \\
\hline DO & 5,89 & $5,34-6,55$ & 0,36 & 5,70 & $4,80-6,44$ & 0,38 \\
\hline NO & 3,17 & $2,68-3,94$ & 0,29 & 2,89 & $2,44-4,47$ & 0,38 \\
\hline H & 5,09 & $4,40-6,19$ & 0,47 & 4,67 & $4,20-5,32$ & 0,32 \\
\hline DN & 2,16 & $1,83-2,51$ & 0,16 & 1,98 & $1,71-2,35$ & 0,16 \\
\hline OB & 2,45 & $1,91-3,09$ & 0,25 & 2,17 & $1,63-2,73$ & 0,27 \\
\hline $\mathbf{F}$ & 15,04 & $12,51-17,00$ & 1,26 & 13,83 & $12,01-16,37$ & 0,91 \\
\hline $\mathbf{T}$ & 15,77 & $13,40-17,27$ & 0,95 & 14,51 & $13,06-15,85$ & 0,82 \\
\hline $\operatorname{Tr}$ & 7,13 & $6,48-8,01$ & 0,41 & 6,60 & $5,50-7,32$ & 0,44 \\
\hline Pie & 16,47 & $14,99-18,18$ & 0,90 & 15,46 & $13,47-16,92$ & 0,90 \\
\hline LTMe & 1,51 & $1,18-1,73$ & 0,14 & 1,45 & $1,11-1,82$ & 0,21 \\
\hline LTMi & 1,36 & $1,10-1,59$ & 0,12 & 1,31 & $1,02-1,73$ & 0,17 \\
\hline B & 5,99 & $5,12-7,18$ & 0,54 & 5,67 & $4,12-7,16$ & 0,72 \\
\hline
\end{tabular}




\begin{tabular}{l|llllll} 
AB & 7,97 & $6,29-9,14$ & 0,60 & 7,17 & $5,39-8,16$ & 0,60 \\
Mano & 9,47 & $8,38-10,87$ & 0,64 & 8,73 & $7,06-9,77$ & 0,63 \\
LMCe & 1,66 & $1,23-2,19$ & 0,22 & 1,56 & $1,14-2,04$ & 0,22 \\
LMCi & 1,40 & $0,92-1,78$ & 0,21 & 1,48 & $1,00-1,75$ & 0,18 \\
LL & 5,06 & $4,05-6,87$ & 0,71 & 5,02 & $3,53-6,16$ & 0,63 \\
AL & 2,85 & $2,09-3,98$ & 0,52 & 2,85 & $1,97-4,67$ & 0,50 \\
DmL & 10,63 & $7,25-12,78$ & 1,10 & 9,09 & $6,96-11,07$ & 1,13
\end{tabular}

\begin{tabular}{l|llllll} 
& \multicolumn{3}{l}{ P. guayapae, Hembras (N = 15) } & \multicolumn{3}{l}{ P. guaya pae, Machos (N = 15) } \\
\hline & Promedio & Rango & D. E. & Promedio & Rango & D. E. \\
LT & 36,01 & $31,81-42,00$ & 3,39 & 33,50 & $29,85-37,11$ & 2,49 \\
AC & 13,72 & $11,76-16,48$ & 1,31 & 13,33 & $11,09-15,67$ & 1,24 \\
LC & 9,14 & $7,72-11,34$ & 0,94 & 8,71 & $7,50-9,59$ & 0,59 \\
O & 4,40 & $3,95-5,01$ & 0,38 & 4,20 & $3,16-4,82$ & 0,51 \\
PS & 4,00 & $3,18-4,59$ & 0,40 & 3,85 & $3,20-4,61$ & 0,44 \\
DO & 7,04 & $6,20-7,86$ & 0,47 & 7,00 & $6,32-7,74$ & 0,46 \\
NO & 3,16 & $2,59-3,68$ & 0,25 & 3,04 & $2,52-3,41$ & 0,30 \\
H & 4,31 & $3,83-4,83$ & 0,25 & 4,31 & $3,82-4,91$ & 0,32 \\
DN & 2,42 & $2,09-2,73$ & 0,18 & 2,37 & $1,76-2,72$ & 0,25 \\
OB & 2,14 & $1,85-2,48$ & 0,18 & 2,19 & $1,62-2,56$ & 0,27 \\
F & 14,04 & $11,68-17,60$ & 1,53 & 14,15 & $11,65-15,88$ & 1,26 \\
T & 12,51 & $10,57-14,191,00$ & 12,70 & $10,77-13,81$ & 1,01 \\
Tr & 5,91 & $4,24-7,20$ & 0,80 & 6,06 & $4,74-6,76$ & 0,56 \\
Pie & 13,64 & $11,78-14,91$ & 0,75 & 13,40 & $11,21-16,07$ & 1,41 \\
LMTe & 1,49 & $1,30-1,74$ & 0,16 & 1,44 & $1,13-1,79$ & 0,20 \\
LMTi & 2,35 & $1,97-3,22$ & 0,39 & 2,13 & $1,91-2,48$ & 0,16 \\
B & 4,82 & $3,65-6,25$ & 0,57 & 4,86 & $3,81-5,98$ & 0,68 \\
AB & 6,80 & $6,14-7,62$ & 0,46 & 6,67 & $5,32-8,66$ & 0,95 \\
Mano & 8,42 & $7,45-9,46$ & 0,66 & 8,40 & $7,42-9,74$ & 0,67 \\
LMCe & 2,18 & $1,58-2,45$ & 0,23 & 2,15 & $1,78-2,53$ & 0,21 \\
LMCi & 1,79 & $1,56-2,30$ & 0,18 & 1,68 & $1,35-1,85$ & 0,13
\end{tabular}

\begin{tabular}{|c|c|c|c|c|c|c|}
\hline & P. nebulos & m, Hembras (N & = 29) & P. nebulos & um, Machos (N & $=40)$ \\
\hline & Promedio & Rango & D. E. & Promedio & Rango & D. E. \\
\hline LT & 39,33 & $32,20-46,49$ & 3,82 & 36,72 & $31,42-41,42$ & 2,31 \\
\hline AC & 16,00 & $13,66-18,01$ & 0,96 & 14,89 & $13,23-17,61$ & 0,99 \\
\hline LC & 10,83 & $8,58-15,57$ & 1,34 & 10,00 & $8,58-12,56$ & 0,73 \\
\hline 0 & 4,55 & $3,86-5,55$ & 0,41 & 4,35 & $3,83-5,19$ & 0,30 \\
\hline PS & 4,60 & $3,99-5,52$ & 0,43 & 4,25 & $3,35-5,34$ & 0,40 \\
\hline DO & 7,64 & $5,78-8,91$ & 0,70 & 7,28 & $5,99-7,88$ & 0,37 \\
\hline NO & 3,47 & $2,67-4,21$ & 0,43 & 3,22 & $2,65-3,85$ & 0,32 \\
\hline H & 5,09 & $4,01-5,91$ & 0,46 & 4,67 & $3,95-5,42$ & 0,32 \\
\hline DN & 2,9 & $2,27-3,91$ & 0,36 & 2, & $2,21-3,21$ & 0,24 \\
\hline OB & 2, & $1,39-3,33$ & 0,41 & 2, & $1,75-3,49$ & 0,41 \\
\hline $\mathbf{F}$ & 16,59 & $13,23-18,99$ & 1,64 & 15,43 & $12,83-18,31$ & 1,43 \\
\hline $\mathbf{T}$ & 14,82 & $11,33-17,83$ & 1,44 & 13,85 & $12,18-15,78$ & 0,93 \\
\hline $\operatorname{Tr}$ & 7,01 & $5,55-8,59$ & 0,87 & 6,65 & $5,31-8,30$ & 0,73 \\
\hline Pie & 16,44 & $13,62-19,42$ & 1,45 & 15,35 & $13,50-17,94$ & 1,07 \\
\hline LMTe & 1,91 & $1,12-2,38$ & 0,26 & 1,80 & $1,42-2,30$ & 0,19 \\
\hline LMTi & 2,42 & $1,94-2,90$ & 0,25 & 2,23 & $1,82-3,12$ & 0,29 \\
\hline B & 550 & $4,04-7,17$ & 0,73 & 5,39 & $4,25-6,75$ & 0,63 \\
\hline AB & 7,65 & $6,19-9,39$ & 0,70 & 7,12 & $6,08-8,62$ & 0,61 \\
\hline Mano & 9,83 & $8,14-11,28$ & 0,81 & 9,37 & $7,45-10,83$ & 0,73 \\
\hline LMCe & 2,7 & $1,97-3,49$ & 0,36 & 2,10 & $1,73-2,65$ & 0,23 \\
\hline LMCi & 2,12 & $1,62-2,76$ & 0,28 & 2,34 & $1,32-3,80$ & 0,44 \\
\hline & P. bufor & min & $=3 c$ & P. bu & (ii) & $=30)$ \\
\hline & Promedio & Rango & D. E. & Promedio & Rango & D. E. \\
\hline LI & 41,85 & $31,85-53,05$ & 5,45 & 36,17 & $29,20-43,87$ & 3,60 \\
\hline $\mathrm{N}-\mathrm{H}$ & 3,93 & $2,67-4,76$ & 0,42 & 3,43 & $2,77-3,91$ & 0,32 \\
\hline
\end{tabular}




$\begin{array}{lllllll}\text { AC } & 16,20 & 12,27-18,77 & 1,73 & 14,07 & 11,33-17,73 & 1,30 \\ \text { LC } & 11,85 & 8,54-13,98 & 1,35 & 10,60 & 8,41-13,75 & 1,09 \\ \mathbf{~} & 4,21 & 2,95-5,91 & 0,59 & 3,88 & 2,74-5,15 & 0,49 \\ \text { PS } & 3,73 & 2,97-4,66 & 0,44 & 3,35 & 2,30-3,85 & 0,38 \\ \text { DO } & 6,66 & 5,60-7,72 & 0,53 & 6,19 & 4,81-7,76 & 0,58 \\ \text { NO } & 3,36 & 2,67-3,90 & 0,36 & 3,10 & 2,49-3,92 & 0,35 \\ \text { H } & 6,63 & 5,21-8,19 & 0,71 & 6,05 & 4,59-7,26 & 0,66 \\ \text { DN } & 2,73 & 2,26-3,16 & 0,24 & 2,57 & 2,01-3,05 & 0,23 \\ \text { OB } & 3,19 & 2,32-3,91 & 0,47 & 2,87 & 2,25-3,71 & 0,30 \\ \text { F } & 18,55 & 14,38-22,32 & 2,21 & 16,46 & 13,28-20,14 & 1,70 \\ \text { T } & 18,09 & 13,66-21,72 & 2,24 & 16,34 & 12,50-19,58 & 1,81 \\ \text { Tr } & 9,17 & 7,01-10,99 & 1,07 & 8,10 & 6,89-10,39 & 0,74 \\ \text { Pie } & 21,55 & 15,66-25,26 & 2,40 & 19,34 & 15,51-23,60 & 1,98 \\ \text { LTMe } & 1,96 & 1,30-3,02 & 0,36 & 1,68 & 1,33-2,09 & 0,18 \\ \text { LTMi } & 2,40 & 1,64-3,04 & 0,41 & 2,07 & 1,67-2,65 & 0,23 \\ \text { B } & 6,45 & 4,59-7,71 & 0,74 & 5,96 & 4,78-7,77 & 0,76 \\ \text { AB } & 8,87 & 6,57-10,64 & 1,01 & 8,17 & 6,76-9,66 & 0,78 \\ \text { Mano } & 11,43 & 8,50-12,91 & 1,10 & 10,35 & 8,90-12,50 & 0,94 \\ \text { LMCe } & 2,15 & 1,54-2,69 & 0,26 & 1,92 & 1,50-2,40 & 0,24 \\ \text { LMCi } & 2,38 & 1,81-2,94 & 0,26 & 2,39 & 1,85-2,92 & 0,26 \\ \text { LL } & 12,18 & 8,17-21,68 & 2,76 & 10,41 & 7,99-13,07 & 1,53 \\ \text { AL } & 6,78 & 4,53-12,22 & 1,76 & 5,90 & 4,38-8,48 & 1,15 \\ \text { DmL } & 8,21 & 5,03-10,89 & 1,49 & 6,61 & 3,43-9,20 & 1,32 \\ & & & & & & \end{array}$

P. thaul, Hembras ( $=33) \quad$ P. thaul, Machos $(\mathrm{N}=33)$

\begin{tabular}{l|llllll}
\hline & Promedio & Rango & D. E. & \multicolumn{3}{l}{ Promedio Rango } \\
LT & 43,31 & $29,97-56,70$ & 5,59 & 32,27 & $26,88-40,16$ & D. E. \\
NH & 3,74 & $2,18-4,58$ & 0,59 & 2,99 & $1,98-3,78$ & 0,41 \\
AC & 15,16 & $11,27-18,99$ & 1,80 & 11,70 & $9,17-14,16$ & 1,09 \\
LC & 11,65 & $8,42-14,86$ & 1,63 & 9,26 & $7,96-10,95$ & 0,77 \\
O & 4,29 & $3,27-5,48$ & 0,56 & 3,66 & $2,86-4,73$ & 0,41 \\
PS & 3,67 & $2,55-4,95$ & 0,50 & 2,73 & $1,86-3,87$ & 0,44 \\
DO & 6,62 & $4,71-7,71$ & 0,71 & 5,18 & $4,02-5,90$ & 0,46 \\
NO & 3,38 & $2,07-4,28$ & 0,42 & 2,79 & $2,17-3,27$ & 0,27 \\
H & 6,33 & $4,02-7,88$ & 0,81 & 5,05 & $2,30-6,31$ & 0,72 \\
DN & 2,69 & $1,86-3,34$ & 0,35 & 2,24 & $1,87-2,60$ & 0,16 \\
OB & 2,71 & $1,70-3,53$ & 0,41 & 2,07 & $1,41-2,85$ & 0,32 \\
F & 18,86 & $13,19-22,60$ & 2,76 & 14,29 & $11,39-16,90$ & 1,55 \\
T & 19,18 & $14,10-23,12$ & 2,52 & 15,06 & $11,67-17,30$ & 1,42 \\
Tr & 9,71 & $6,37-12,06$ & 1,67 & 7,28 & $1,80-8,76$ & 1,19 \\
Pie & 23,25 & $16,94-27,73$ & 2,80 & 18,10 & $14,78-20,98$ & 1,63 \\
LMTe & 1,72 & $1,13-2,76$ & 0,33 & 1,34 & $0,78-2,39$ & 0,35 \\
LTMi & 2,34 & $1,64-3,07$ & 0,39 & 2,20 & $1,01-17,00$ & 2,68 \\
B & 7,19 & $4,18-9,11$ & 1,15 & 6,01 & $3,88-7,47$ & 0,76 \\
AB & 9,43 & $6,67-11,32$ & 1,16 & 7,30 & $5,82-9,15$ & 0,70 \\
Mano & 11,93 & $7,53-14,06$ & 1,47 & 9,64 & $7,82-11,38$ & 0,85 \\
LMCe & 2,06 & $1,35-2,60$ & 0,30 & 1,55 & $0,71-2,09$ & 0,28 \\
LMCi & 2,35 & $1,39-3,11$ & 0,40 & 2,19 & $1,41-2,71$ & 0,31 \\
LL & 6,24 & $3,51-9,66$ & 1,37 & 4,93 & $2,74-6,83$ & 0,92 \\
AL & 3,76 & $1,90-6,60$ & 0,85 & 2,68 & $1,67-3,69$ & 0,51 \\
DmL & 12,39 & $8,82-17,61$ & 2,38 & 8,17 & $6,39-10,74$ & 1,20
\end{tabular}

\begin{tabular}{l|llllll} 
& \multicolumn{3}{l}{ P. tucumanum, Hembras $(\mathbf{N}=\mathbf{1 1})$} & \multicolumn{3}{c}{ P. tucumanum, Machos (N = 25) } \\
\hline & Promedio & Rango & D. E. & Promedio & Rango & D. E. \\
LT & 36,04 & $31,67-40,47$ & 2,94 & 33,98 & $29,73-39,14$ & 2,01 \\
N-H & 3,17 & $2,46-5,61$ & 0,87 & 2,84 & $1,81-3,44$ & 0,40 \\
AC & 14,43 & $12,88-15,87$ & 0,89 & 14,19 & $12,75-17,84$ & 1,13 \\
LC & 10,60 & $9,49-12,15$ & 0,74 & 10,03 & $8,69-11,54$ & 0,71 \\
$\mathbf{O}$ & 3,36 & $1,06-4,34$ & 0,92 & 3,94 & $3,36-4,60$ & 0,32 \\
Ti & 1,85 & $1,06-2,46$ & 0,43 & 1,95 & $1,48-2,73$ & 0,26
\end{tabular}




\begin{tabular}{l|llllll} 
PS & 3,67 & $3,21-4,25$ & 0,31 & 3,50 & $2,92-4,18$ & 0,33 \\
DO & 6,66 & $5,88-7,44$ & 0,43 & 6,28 & $5,65-7,10$ & 0,38 \\
NO & 2,83 & $2,29-3,18$ & 0,23 & 2,71 & $2,41-3,11$ & 0,18 \\
H & 5,27 & $4,80-5,69$ & 0,27 & 5,17 & $4,54-5,55$ & 0,28 \\
DN & 2,62 & $2,41-3,03$ & 0,20 & 2,57 & $2,20-3,16$ & 0,19 \\
OT & 1,62 & $1,40-1,90$ & 0,17 & 1,50 & $1,10-1,95$ & 0,20 \\
OB & 2,13 & $1,76-2,64$ & 0,29 & 1,94 & $1,57-2,47$ & 0,20 \\
F & 14,78 & $13,54-16,98$ & 0,98 & 14,23 & $12,38-17,10$ & 1,12 \\
T & 14,54 & $13,43-16,71$ & 0,91 & 13,95 & $12,16-15,61$ & 0,74 \\
Tr & 7,21 & $6,12-8,21$ & 0,66 & 6,75 & $5,68-8,24$ & 0,59 \\
Pie & 15,10 & $13,83-16,51$ & 0,84 & 14,50 & $12,28-16,99$ & 0,84 \\
LMTe & 1,82 & $1,10-2,20$ & 0,30 & 1,81 & $1,53-2,09$ & 0,17 \\
LMTi & 2,09 & $1,89-2,41$ & 0,18 & 1,94 & $1,51-2,32$ & 0,22 \\
B & 5,12 & $4,23-6,77$ & 0,79 & 4,78 & $3,94-5,91$ & 0,50 \\
AB & 6,86 & $6,15-8,15$ & 0,58 & 6,53 & $5,64-7,41$ & 0,40 \\
Mano & 9,31 & $8,72-10,41$ & 0,56 & 8,76 & $7,63-9,89$ & 0,49 \\
LMCe & 2,28 & $1,95-2,69$ & 0,19 & 2,07 & $1,68-2,46$ & 0,18 \\
LMCi & 1,75 & $1,53-1,91$ & 0,13 & 1,96 & $1,65-2,32$ & 0,20
\end{tabular}

Los resultados de los Test de Student indican que existen diferencias significativas en la variable longitud total para Pleurodema borellii, P. bufoninum, P. guayapae, P. kriegi, P. nebulosum, P. thaul y P. tucumanum, siendo las hembras mayores que los machos $(p<0,05)$. Las diferencias no fueron significativas para $P$. bibroni y P. cinereum. Cabe aclarar que, para P. cinereum, se pudo medir un bajo número de hembras, debido a las condiciones de preservación de los ejemplares en colecciones.

\section{Análisis de componentes principales}

Pleurodema guayapae - P. nebulosum. El ACP de los machos explica, mediante los tres primeros componentes, el 70,30\% de la variabilidad morfométrica. Las variables de mayor peso son: para el Factor 1, longitud del tubérculo metacarpal interno, longitud del tubérculo metatarsal externo y distancia ojo-labio superior; para el Factor 2, longitud del tubérculo metacarpal interno, longitud del fémur y longitud del tubérculo metatarsal externo; y para el Factor 3, distancia ojo-labio superior, longitud del tubérculo metacarpal interno y longitud del tarso (Fig. 11).

El ACP de las hembras de P. guayapae y P. nebulosum explica, mediante los tres primeros componentes, el 75,1 \% de la variabilidad morfométrica. Las variables de mayor peso son: para el Factor 1, longitud del tubérculo metacarpal externo, distancia ojo-labio superior y longitud del tubérculo metatarsal externo; para el Factor 2, longitud del tarso, longitud del brazo y longitud del fémur; y para el Factor 3 , longitud del tubérculo metatarsal externo, distancia ojo-labio superior y longitud del brazo (Fig. 12). 
Tanto en el caso de los machos como en el de las hembras, las variables que se repiten en los ordenamientos son las longitudes de los tubérculos metacarpal interno y metatarsal externo, las longitudes de los miembros (tarso, brazo, fémur) y la distancia oj o-labio.

A pesar de que, tanto en machos como en hembras, se aprecia cierto ordenamiento de cada especie en los distintos gráficos, no es posible diferenciar claramente las nubes de puntos.

Pleurodema borellii - P. cinereum. El ACP de los machos explica, mediante los tres primeros componentes, el $49,4 \%$ de la variabilidad morfométrica. Las variables de mayor peso son: para el Factor 1, longitud del tímpano, longitud del brazo y longitud del tubérculo metacarpal interno; para el Factor 2, ancho de la glándula lumbar, longitud del tímpano y longitud del tubérculo metacarpal interno; para el Factor 3, longitud del tubérculo metatarsal externo, longitud del párpado superior y distancia ojo-tímpano.

En los gráficos basados en ej emplares macho, no es posible separar claramente las nubes de puntos correspondientes a ambas especies (Fig. 13).

El ACP de las hembras de P. borellii y P. cinereum explica, mediante los tres primeros componentes, el $64,8 \%$ de la variabilidad morfométrica. Las variables de mayor peso son: para el Factor 1, longitud de la glándula lumbar, ancho de la glándula lumbar y longitud del tímpano; para el Factor 2, distancia ojo-tímpano, distancia entre narinas y longitud del tímpano; y para el Factor 3, longitud de la glándula lumbar, longitud del brazo y distancia entre narinas.

En el primer gráfico (Componente 1 vs. 2), cuatro ej emplares son agrupados por el Componente 2, los cuales corresponden a ejemplares de P. cinereum de La Quiaca, J uj uy (Fig. 14).

Tanto en el caso de los machos como de las hembras, las variables que se repiten en los ordenamientos son las longitudes de la glándula lumbar, longitud del tímpano, longitud del tubérculo metatarsal externo, distancia ojo-tímpano.

Pleurodema bibroni - P. kriegi. El ACP de los machos explica, mediante los tres primeros componentes, el $62,0 \%$ de la variabilidad morfométrica. Las variables de mayor peso son: para el Factor 1, longitud del tubérculo metatarsal interno, longitud del tubérculo metacarpal externo y longitud del tubérculo metacarpal interno; para el Factor 2, ancho de glándula lumbar, longitud de la glándula lumbar y longitud del 
brazo; y para el Factor 3, longitud del tubérculo metatarsal externo, longitud del párpado superior y longitud del tubérculo metacarpal interno (Fig. 15).

El ACP de las hembras P. bibroni y P. kriegi explica, mediante los tres primeros componentes, el 68,5\% de la variabilidad morfométrica. Las variables de mayor peso son: para el Factor 1, Iongitud del brazo, Iongitud del tubérculo metacarpal externo y distancia menor entre glándulas lumbares; para el Factor 2, ancho de glándula lumbar, longitud de la glándula lumbar y distancia ojo-labio superior; y para el Factor 3, longitud del párpado superior, ancho de glándula lumbar y longitud del tubérculo metacarpal interno (Fig. 16).

Tanto en el caso de los machos como de las hembras, las variables que se repiten en los ordenamientos longitud de los tubérculos metatarsales y metacarpales, longitudes de la glándula lumbar, longitud del brazo y longitud del párpado superior.

A pesar de que, tanto en machos como en hembras, se aprecia cierto ordenamiento de cada especie en los distintos gráficos, no es posible diferenciar claramente las nubes de puntos.

Los Análisis de Componentes Principales de varianza-covarianza realizados en los tres pares de especies crípticas del género permitieron encontrar variables que se repiten en los ordenamientos tanto de machos como de hembras. En P. guayapae - P. nebulosum, las variables que se repiten en los ordenamientos son longitud de los tubérculos metacarpal interno y metatarsal externo, las longitudes de los miembros (tarso, brazo, fémur) y distancia ojo-labio; en P. borelii - P. cinereum, las longitudes de la glándula lumbar y longitud del tímpano y, finalmente, en P. bibroni - P. kriegi, longitud de los tubérculos metatarsales y metacarpales, longitudes de la glándula lumbar, del brazo y del párpado superior.

Barrio (1964a) señaló que P. nebulosum se diferencia de P. guayapae por la longitud relativa de sus miembros posteriores y de $P$. tucumanum por su menor longitud en los miembros posteriores. Sin embargo, los valores indicados por el autor para P. nebulosum y P. guayapae son muy similares entre sí, y no realizó análisis estadísticos para probar esta consideración. En el presente trabajo, la longitud del tarso y la longitud del fémur fueron dos de las variables que mejor permitieron explicar la variabilidad morfométrica en P. nebulosum y P. guayapae. Laurent (1969) realizó un análisis morfométrico entre este par de especies crípticas, hallando diferencias significativas pero no diagnósticas. Sin embargo, sus resultados no son comparables con los aquí presentados, dado que no se midieron las mismas variables. Por su parte, de la Riva \& Gonzalez (1998) señalaron que, en la única población de P. 
guayapae del chaco boreal de Bolivia (Departamento de Santa Cruz), los machos alcanzan valores de longitud hocico-cloaca muy similares a los de las hembras.

Los valores morfométricos de longitud hocico-cloaca para $P$. borellii y $P$. cinereum (incluyendo P. alpina) aportados por Fernández \& Fernández (1921) y Gallardo (1968a) coinciden con los aportados en el presente trabajo.

Los valores morfométricos de longitud hocico-cloaca para P. kriegi señalados por Gallardo (1968a) coinciden con los obtenidos en el presente trabajo. Por su parte, Laurent (1975) realizó un análisis morfométrico entre P. kriegi y P. bibroni, hallando que la longitud del tubérculo metatarsal externo, la distancia entre narinas, la distancia entre narina y boca y la longitud de la glándula lumbar son mayores en $\mathrm{P}$. bibroni, mientras que la longitud del tubérculo carpal interno, el ancho del párpado superior y la distancia menor entre las glándulas lumbares eran mayores en P. kriegi (sólo se mencionaron las medidas significativas que también fueron tomadas en el presente trabajo).

Cei (1958b) analizó la variación en tamaño y proporciones corporales de poblaciones de $P$. thaul de Chile. El autor determinó que existe un aumento del tamaño corporal y de las glándulas lumbares hacia el sur (por mencionar sólo algunas variables), y caracterizó a tres grandes grupos: las poblaciones del norte (desde el valle de Copiapó hasta el sur de Coquimbo), las poblaciones del centro del país (Santiago, Lo Valdés) y las poblaciones del sur del país (Aysén), destacando el alto grado de polimorfismo que presenta esta especie. Duellman \& Veloso (1977) propusieron que $P$. thaul incluye, por lo menos, tres morfotipos que difieren en proporciones, coloración, citogenética, amplexo y modo de puesta, denominándolos Argentina Sur, Chile Sur y Chile Central, en función de su distribución geográfica. Rosset et al. (2001) realizaron un estudio morfométrico y de morfología esternal utilizando material de Argentina y Chile, con el fin de comprobar si existen diferencias entre estos tres morfotipos, concluyendo que no es posible realizar ordenaciones de los ejemplares en función de su distribución geográfica. Por su parte, Díaz-Páez \& Ortiz (2001) demostraron que existe dimorfismo sexual en la longitud hocico-cloaca de $P$. thaul.

A pesar de haberse descrito especies crípticas y polimórficas dentro del género Pleurodema, no ha sido posible, en los análisis aquí presentados, ofrecer variables que permitan diferenciar discretamente las diferentes especies o razas geográficas. 


\section{CAPÍTULO III Osteología}

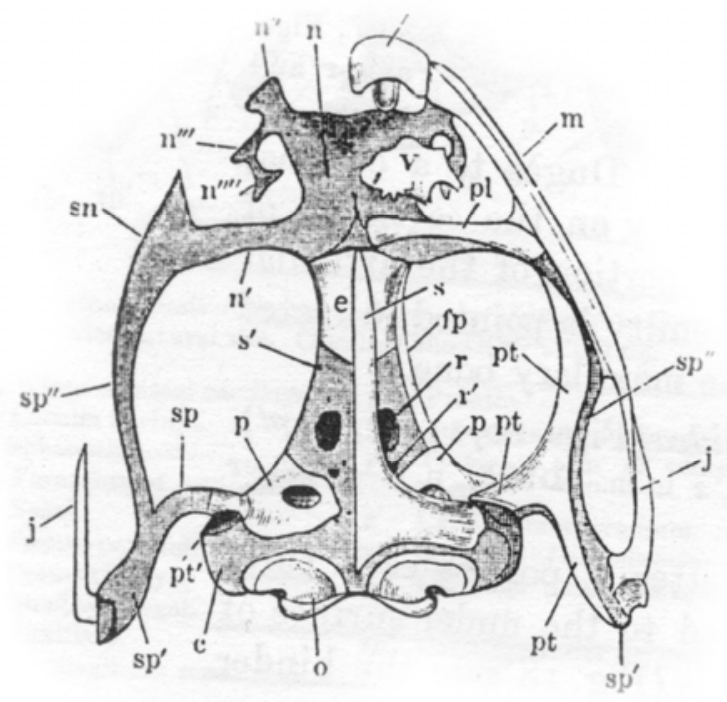

Tomado de Eckert (1889) 
Se describe la osteología de Pleurodema thaul ( $₫$ CENAI 3617). Variaciones de los ejemplares đô CENAI 1527-5, 1952, 3617, 4107, 8826, MACN 9092; q $q$ CENAI 3619, MACN 11648, 11649, 28703, 32118; ejemplares sin datos de sexo MACN 28701, 28702, 28703, 29214. Para cada estructura descripta se indican las variaciones intraespecíficas entre corchetes. Luego se compara con la osteología de las restantes especies del género.

\section{Cráneo (Figs. 17; 18 A)}

Cráneo apenas más ancho que largo (índice cefálico 0,96).

Exocráneo

Frontoparietales alargados, separados en toda su extensión, posteriormente se ensanchan pero sin contactar el uno con el otro [sí contactan en MACN 29214], márgenes mediales subparalelos, irregulares en los dos tercios posteriores. Fenestra frontoparietal expuesta. Márgenes anteriores de los frontoparietales yuxtapuestos con el esfenoetmoides, extendiéndose hasta un punto algo posterior al margen anterior de las órbitas. Márgenes posteriores de los frontoparietales superpuestos levemente con exoccipitales. Lámina perperdicularis desarrollada. [Se observaron conjuntos de orificios en la región dorso y latero-posterior en los frontoparietales de algunos ejemplares]. Sin reborde supraorbital.

Nasales claviformes. Los márgenes anteriores cubren la parte posterior del tectum nasi, los procesos maxilares poseen los extremos libres en punta. No contactan entre sí, con el esfenoetmoides ni con la pars facialis del maxilar.

Paraesfenoides con forma de $\mathrm{T}$ invertida. Proceso cultriforme con extremo anterior irregular; contacta con los palatinos; cubre la mitad del esfenoetmoides. Procesos alares dirigidos levemente hacia atrás [perpendiculares en MACN 11648]; extremos distales ensanchados; no contactan con la rama media del pterigoides. Proceso posterior que no alcanza el foramen magnum, con límites difusos respecto al solum synoticum, el cual se observa en el borde posterior del piso craneano.

Palatinos laminares, delgados y edéntulos. Extremos mediales en contacto con el esfenoetmoides, posteriormente a la posición de los vómeres. Extremos externos ensanchados, contactando con la superficie interna de la pars palatina del maxilar y con la rama anterior del pterigoides.

Vómeres. Porción anterior dirigida hacia la articulación entre premaxilar y maxilar. Proceso precoanal en punta [ramificado en MACN 9092, 11648, 11649, 28701, 28702, 32114, CENAI 1952, 3619, 4107, 8826], expandido hacia el maxilar; delimitando el borde anterior de la coana. Proceso postcoanal triangular dirigido hacia el interior de la coana y delimitando su borde medial. Sin proceso posterior. 
Procesos dentígeros ubicados en dirección anterolateral-posteromedial [o alineados perpendicularmente al eje axial MACN 9092, 11648, 32118, CENAI 1527-8], con 3 dientes [2-6 dientes]. El vómer cubre el solum nasi, y no contacta con el esfenoetmoides.

Premaxilares separados medialmente. Proceso alar largo, con forma de media luna, convexo medialmente y cóncavo lateralmente; dirigido posterodorsalmente. Pars dentalis con 11-12 dientes cónicos [7-12 dientes]. Pars palatina laminar, con margen libre, irregular. Proceso palatino triangular orientado posteriormente, extremo libre dirigido hacia el proceso palatino opuesto, sin contactarlo.

Maxilar separado de la pars facialis del premaxilar por tejido conectivo denso. La pars dentalis lleva 34-39 dientes ubicados en casi toda la extensión del maxilar [20-40 dientes; en general alrededor de 30]. La pars palatina es delgada y contacta con la rama anterior del pterigoides. La pars facialis es una lámina ancha que se va afinando posteriormente; no contacta con los nasales.

Cuadradoyugal ausente y cuadrado presente. Arcada maxilar incompleta (sensu Lehr \& Trueb 2007).

Escamoso triradiado. La rama zigomática está bien desarrollada, ensanchada en el plano axial y curvada con respecto al plano sagital, no contacta con la arcada maxilar. La rama ótica, más larga que la zigomática, posee márgenes irregulares y está girada con respecto a su propio eje; el extremo distal se ensancha en el plano sagital; contacta con la crista parótica a través de la porción cartilaginosa de ésta. La rama ventral es la más larga y está dirigida posteroventralmente.

Pterigoides triradiado. La rama anterior es la más larga, alcanzado el plano anteorbitario hasta el nivel de los palatinos. La rama media contacta con el proótico a través de una zona ligamentosa o similar (no teñida con alizarina ni azul de alcian). La rama posterior contacta con la rama ventral del escamoso.

Mandíbula. Cada hemimandíbula está formada por el mentomeckeliano, el dentario y el angular, estando unidas entre sí por ligamento. Cartílagos de Meckel largos y cilíndricos. Mentomeckelianos óseos. Dentario recubriendo el Cartílago de Meckel, en la superficie anterior y labial. Angular recubriendo el Cartílago de Meckel en su superficie lingual y posteriormente labial; proceso coronoides redondeado. Articulación cráneo-mandibular posterior al margen anterior (cefálico) de las alas del paraesfenoides.

\section{Endocráneo}

Esfenoetmoides, hueso impar que forma un anillo completo osificado. En vista dorsal, el margen anterior es triangular y no contacta con los nasales; los 
bordes laterales constituyen los márgenes internos de las órbitas; y el margen posterior es cóncavo y está cubierto parcialmente por los frontoparietales, constituyéndose en el borde anterior de la fenestra frontoparietal. En vista ventral, el margen anterior alcanza el plano anteorbitario pero no alcanza vómeres, no posee proyecciones; el margen posterior es cóncavo y está parcialmente cubierto por el paraesfenoides. Pared lateral recta [o irregular]. Crista supraorbital desarrollada. Foramen orbitonasal presente.

Proóticos y exoccipitales fusionados en un complejo otoccipital, el cual protege las cápsulas óticas y la parte posterior del neurocráneo [proóticos y exoccipitales independientes en MACN 28701, 32118]. Complejos otoccipitales, tanto dorsal como ventralmente, sin contacto medial. Crestas epióticas de las cápsulas óticas desarrolladas. Proóticos rodeando parcialmente la salida del foramen proótico [(salida del nervio trigémino (V) y nervio facial (VII)]; esta condición fue definida por Lobo (1996) para algunas especies de Physalaemus y Eupemphix; los forámenes proóticos quedan de todos modos “cerrados" porque el orbitoesfenoides completa el límite medial [en los ejemplares CENAI 1527-5, CENAI 8826 y MACN 32118 los forámenes proóticos están completamente rodeado por el hueso homónimo]. Además se observan los forámenes óptico (anterior) y oculo-motor (medial) perforando el orbitoesfenoides. Exoccipitales perforados por dos forámenes, el más lateral posee una tabicación interna y corresponde a la salida del nervio perilinfático inferior, mientras que el foramen medial corresponde a la salida del lo nervio yugular. Cóndilos occipitales semilunares, intermedios tipos II según Lynch (1971), flanqueando lateralmente el foramen magnum, extendiéndose dorsalmente hasta la mitad del mismo. Los márgenes del foramen magnum están incompletamente osificados dorsal y ventralmente.

Esqueleto hiolaríngeo (Fig. 18 B). Hioides subcuadrangular, cartilaginoso. Seno hiogloso pronunciado, en forma de U. Hiales alargados, naciendo en los márgenes anterolaterales del hioides; contactan con el neurocráneo al nivel de la articulación de la rama media del pterigoides con las cápsulas óticas, por delante de la columela. Cada hial presenta un pequeño proceso anteromedial [falta en CENAI 1527-8]. Procesos anterolaterales ensanchados distalmente. Procesos posterolaterales delgados en toda su extensión. Procesos posteromediales osificados con base ensanchada y extremos distales cartilaginosos. Unión cóncava entre la placa hial y los procesos posteromediales [procesos posterolaterales de la placa hiodea bifurcados con la rama interna es más corta en MACN 28703].

Laringe formada por dos cartílagos aritenoides y un cartílago cricoideo. Los 
aritenoides son semiovalados y, en vista dorsal, la porción más cefálica de sus bordes mediales se proyecta constituyendo una prominencia dorsal. El cricoides es un anillo completo; en vista dorsal presenta los procesos esofágico (triangular), articular, lateral y muscular; en vista ventral, se observa un proceso cardíaco bilobulado [o simple] y dos proceso bronquiales que superan el proceso esofágico del anillo cricoideo. En vista lateral, los procesos bronquiales tienen posición subparalela a los procesos posteromediales del hioides [en MACN 28703 son curvos].

Oído medio (Fig. 19 A) Opérculo oval, mineralizado. Columela formada por una placa ósea y expandida (proximal) y un estilo óseo (distal) dirigido dorsalmente en su extremo distal [con una proyección cuadrangular ventral en todo el resto de los ejemplares examinados, llamada proceso caudal según Mason (2006)]. La columela, en vista dorsal, se extiende perpendicular al eje axial. Extracolumela cartilaginosa y oval, con una proyección ahusada dirigida hacia el opérculo. Anillo timpánico incompleto, piriforme, faltando la porción superior.

\section{Esqueleto postcraneano}

Esqueleto axial (Fig. 19 B)

Columna formada por ocho vértebras presacras procélicas, vértebra sacra y urostilo. Atlas con sus arcos neurales imbricados con los de la vértebra II [excepto en MACN 29214]. Las vértebras presacras II a VIII poseen arcos neurales no imbricados; procesos transversos con porciones distales cartilaginosas. Expansión de los procesos transversos en orden decreciente: III $>$ IV $>$ II $>$ V = VI = VII > VIII [variable, en forma general podría expresarse como III $>$ II (ó IV) $\geq \mathrm{IV}$ (ó II) $>\mathrm{V} \geq \mathrm{VI} \geq \mathrm{VII} \geq \mathrm{VIII}$. Orientación de los procesos transversos con respecto al eje longitudinal: II, VII y VIII hacia adelante; III, IV y V hacia atrás y VI perpendicular [variable la posición del proceso III]. Vértebra sacra con diapófisis levemente dilatadas, dirigidas posteriormente. Articulación sacro-coccígea bicondilar. Urostilo con cresta longitudinal dorsal desarrollada en $3 / 4$ de su extensión, adelgazada hacia el extremo caudal. Porción distal cartilaginosa. Procesos transversos ausentes. [En la columna vertebral es donde se encontraron mayor cantidad de anomalías, a saber: columna vertebral formada por 7 vértebras presacras, atlas fusionado con la vértebra II (MACN 29214). Columna formada por 8 vértebras presacras, vértebra sacra, y una vértebra posterior, cuya apófisis transversa derecha es corta y no contacta con ningún hueso, mientras que la izquierda contacta con el ilion (CENAl 1952). Columna formada por 8 vértebras presacras, vértebra sacra, y una vértebra posterior, cuya apófisis transversa izquierda es corta y no contacta con ningún hueso, mientras que la derecha contacta 
con el ilion (MACN 32118). Columna formada por nueve vértebras presacras, la novena vértebra presacra presenta la apófisis sacra derecha, y la vértebra sacra presenta la apófisis sacra izquierda (MACN 28702)].

\section{Esqueleto apendicular}

Cintura pectoral (Fig. 20 A) de tipo arcífera. Epicoracoides mineralizados, superpuestos entre sí medialmente, cuernos del epicoracoides desarrollados. Omoesternón cartilaginoso, porción proximal alargada y delgada; porción distal ensanchada. Clavículas bien desarrolladas, arqueadas, no contactan entre sí; ensanchadas distalmente; unidas sindesmóticamente con la pars acromialis de la escápula. Coracoides oblicuos respecto al eje axial; ensanchados distalmente, unidos sindesmóticamente con la pars glenoidalis de la escápula. Pars acromialis y pars glenoidalis separadas formando dos superficies de articulación independientes. Escápulas con porción proximal formando las articulaciones con clavícula y coracoides; porción distal ensanchada. Supraescápulas con porción proximal fuertemente mineralizada; porción distal ensanchada, cartilaginosa, con una pequeña proyección en forma de gancho dirigida hacia el eje axial. Cleitros óseos, extendiéndose en el margen anterior de la supraescápula. Fenestra mayor ovalada, eje antero-posterior menor que el eje lateral. Esternón formado por mesosternón y xifisternón. Mesosternón óseo, ensanchado en ambos extremos; articula proximalmente con los epicoracoides, mediante una zona cartilaginosa y distalmente con el xifisternón. Xifisternón cartilaginoso y bifurcado.

Cintura pélvica (Fig. 20 B). Iliones con cresta dorsal y prominencia dorsal desarrolladas; expansión acetabular ventral poco expandida; zona preacetabular poco desarrollada. Alcanzan las apófisis sacras [o las sobrepasan]. Isquion osificado, con un reborde cartilaginoso en el contacto con los iliones. Pubis calcificado en la mayor parte de su extensión [a veces permanece cartilaginoso]. Fosa acetabular perforada.

Miembro anterior (Fig. 21 A). Húmero con cresta deltoidea desarrollada en la mitad proximal de la diáfisis; cresta lateralis y cresta medialis desarrolladas en su mitad distal. Epicóndilo lateral desarrollado. Radio-ulna con porción distal más ancha; proceso oleocraneano bien desarrollado. Carpales correspondientes con la morfología "C" de Fabrezi (1992), formada por seis elementos: ulnar, carpal distal 54-3; carpal distal 2, radial, elemento y y elemento proximal del prepollex. Prepollex formado por 3 elementos distales [ó 4]. Se observó un elemento sesamoideo en el carpo. Cuatro metacarpales. Fórmula falangeal 2-2-3-3. 
Miembro posterior (Fig. 21 B). Fémur y tibio-fíbula prácticamente del mismo largo, se observa un elemento sesamoideo en la articulación entre ambos. Tibial y fibular fusionados distalmente. Tarsales representados por tarsal distal 2-3, tarsal distal 1 y elemento $\mathrm{Y}$, tal como ha sido descripto por Fabrezi (1993, para P. cinereum). Prehallux formado por 3 elementos [ó 4, 5, 6]. Se observaron elementos sesamoideos en las articulaciones fémur/tibio-fíbula y tibio-fíbula/tibial-fíbular y en el tarso. Cinco Metatarsales. Fórmula falangeal 2-2-3-4-3.

\section{Pleurodema kriegi}

Descripción basada en el ejemplar $\widehat{~}$ CENAI 5170; sólo se describen las diferencias con P. thaul. Variaciones con los especimenes $q$ ㅇ CENAI 5169 y MLP A. 4728 indicadas entre corchetes.

Exocráneo. Frontoparietales con márgenes mediales irregulares en toda su extensión; sin contactar entre sí [contactando en su extremo posterior en CENAI 5169]. Nasales trapezoidales. Paraesfenoides con extremo anterior en punta, procesos alares perpendiculares. Los palatinos contactan con el pterigoides pero no con la pars dentalis del maxilar. Vómeres con porción anterior en punta [redondeada en CENAI 5169]; proceso precoanal en punta; proceso postcoanal dirigido dorsalmente; proceso posterior desarrollado sin contactar el esfenoetmoides; sin proceso dentígero, aunque con un reborde protruido. Premaxilares con pars dentalis con unos 10-11 dientes. Maxilar en contacto con premaxilar pero no con palatinos ni pterigoides [sí contacta con palatinos en CENAI 5169]; pars dentalis con unos 28-30 dientes. Cuadradoyugal ausente y cuadrado presente. Escamoso con ramas zigomática y ótica alineadas en vista dorsal. Pterigoides con rama anterior que no contacta con los palatinos [sí contacta con palatinos en CENAI 5169]; rama media que no contacta con el proótico, con una proyección medial ventral que no alcanza el maxilar. Articulación cráneo-mandibular al mismo nivel que el margen cefálico de las alas del paraesfenoides [posterior en CENAI 5169].

Endocráneo. Esfenoetmoides formado por dos elementos que no se unen ni dorsal ni ventralmente; no contacta con nasales ni vómeres; crista supraorbital no desarrollada; ventralmente no alcanza el espacio entre los vómeres; foramen orbitonasal presente [esfenoetmoides formando un anillo completo, con crista supraorbital en CENAI 5169 y MLP A. 4728]. Forámenes óptico y proótico desarrollados; este último rodeado parcialmente por el hueso proótico. Exoccipitales perforados por dos forámenes. Cóndilos occipitales estrechamente separados, tipo II. 
Esqueleto laríngeo. Hioides con procesos anteromediales ensanchados distalmente. Laringe con cricoides con proceso cardíaco redondeado, con procesos musculares, articulares, laterales y bronquiales desarrollados; estos últimos alcanzan el proceso esofágico pterigoides [en CENAI 5169 procesos bronquiales con un segmento óseo; superan el proceso esofágico del cricoides].

Oído medio. Opérculo oval. Columela con proyección ventral como en $\mathrm{P}$. thaul; estilo óseo dirigido dorsalmente en su extremo distal. Extracolumela con proyección hacia el opérculo, anillo timpánico incompleto en su porción dorsal.

Esqueleto postcraneano. Esqueleto axial. Vértebra cervical con cótilos de tipo II. Expansión de los procesos transversos en orden decreciente: III $>$ IV $>$ V $>$ II $=$ $\mathrm{VI}>\mathrm{VII}>\mathrm{VIII}[\mathrm{III}>\mathrm{V}=\mathrm{VI}=\mathrm{VII}=\mathrm{VIII}>\mathrm{II}>\mathrm{IV}$ en CENAI 5169; la II es la vértebra más corta en MLP A. 4728]. Orientación de los procesos respecto al eje longitudinal: II (curvados), III, VI, VII y VIII hacia adelante; IV y V hacia atrás [VIII hacia delante, VI hacia atrás, VII perpendicular en MLP A. 4728]. Vértebra sacra con apófisis levemente dilatadas.

Esqueleto apendicular. Cintura pectoral. Supraescápula sin proyección en forma de gancho [con proyección en CENAI 5169]. Mesosternón ancho en toda su extensión [adelgazado distalmente en CENAI 5169]. Xifiesternón bifurcado. Miembro anterior sin modificaciones. Prepollex formado por 2 elementos distales. Se observaron elementos sesamoideos en vistas dorsal y ventral del carpo. Cintura pélvica sin modificaciones. Se observaron elementos sesamoides en la articulación tibio-fíbula/tibial-fibular y en el tarso. Prehallux formado por 3 elementos [2 en CENAI 5169 y MLP A. 4728].

\section{Pleurodema bibroni}

Descripción basada en el ejemplar $\widehat{O}$ CENAI 6205; sólo se describen las diferencias con P. thaul. Variaciones con el espécimen $\odot$ CENAI 6204 indicadas entre corchetes.

Exocráneo. Frontoparietales con márgenes mediales irregulares en toda su extensión, en la porción posterior se aproximan entre sí hasta casi contactar uno con el otro [contactan en la zona media]. Nasales claviformes con procesos maxilares poco desarrollados. Paraesfenoides con extremo anterior en punta, procesos alares perpendiculares. Los palatinos contactan con la pars dentalis del maxilar y con el pterigoides. Vómeres con porción anterior en punta; proceso precoanal expandido distalmente; proceso postcoanal dirigido dorsalmente; proceso posterior desarrollado sin contactar el esfenoetmoides; sin proceso dentígero. Premaxilares con pars 
dentalis con unos 11-12 dientes. Maxilar en contacto con premaxilar, palatinos y pterigoides; pars dentalis con unos 28-30 dientes [unos 35 dientes]. Cuadradoyugal ausente y cuadrado presente. Escamoso con ramas zigomática y ótica alineadas en vista dorsal. Pterigoides con rama media que no contacta con el proótico [sí contacta. Con una proyección medial ventral que no alcanza el maxilar en CENAI 6204]. Articulación cráneo-mandibular posterior al margen cefálico de las alas del paraesfenoides.

Endocráneo. Esfenoetmoides que no contacta con nasales ni vómeres; crista supraorbital desarrollada; margen anterior en vista dorsal curvado [proyectado] y en vista ventral no proyectado; ventralmente no alcanza el espacio entre los vómeres; foramen orbitonasal presente. Forámenes óptico y proótico desarrollados; este último rodeado parcialmente por el hueso proótico. Exoccipitales perforados por dos forámenes. Cóndilos occipitales estrechamente separados, tipo II.

Esqueleto laríngeo. Hioides con procesos anteromediales redondeados. Laringe con cricoides con proceso cardíaco redondeado, con procesos musculares, articulares y bronquiales desarrollados; estos últimos alcanzan el proceso esofágico [lo sobrepasan].

Oído medio. Opérculo oval. Columela con proyección ventral como en $\mathrm{P}$. thaul; estilo óseo dirigido dorsalmente en su extremo distal. Extracolumela con proyección hacia el opérculo, anillo timpánico incompleto en su porción dorsal.

Esqueleto postcraneano. Esqueleto axial. Vértebra cervical con cótilos de tipo II. Expansión de los procesos transversos en orden decreciente: III > VI = VII = VIII $=\mathrm{V}>\mathrm{IV}>\mathrm{II}$. Orientación de los procesos respecto al eje longitudinal: II (muy curvados), III, VII y VIII hacia adelante; IV, V y VI hacia atrás [VI perpendicular. Procesos transversos III-IV derechos fusionados en la la mitad de su extensión]. Vértebra sacra con apófisis levemente dilatadas.

Esqueleto apendicular. Cintura pectoral. Mesosternón con región distal adelgazada. Xifiesternón bifurcado. Miembro anterior sin modificaciones. Prepollex formado por 2-3 elementos distales. Se observaron elementos sesamoideos en vistas dorsal y ventral del carpo. Cintura pélvica sin modificaciones. Se observaron elementos sesamoides en la articulación tibio-fíbula/tibial-fibular y en el tarso. Prehallux formado por 3 elementos.

\section{Pleurodema bufoninum}

Descripción basada en el ejemplar đ MLP A. 1458 (topotipo); sólo se describen las diferencias con P. thaul. Variaciones con los especímenes $\partial^{\lambda} \partial^{\lambda}$ MLP A. 2077, 4054, 
4061 y $q$ MLP A. 1459 y 2240 indicadas entre corchetes.

Exocráneo. Frontoparietales sin contactar entre sí [contactando en su extremo posterior en MLP A. 1459 y 4061]. Nasales trapezoidales. Paraesfenoides con extremo anterior en punta [extremo irregular en MLP A. 2077], procesos alares dirigidos levemente hacia atrás. Los palatinos no contactan con la pars palatina del maxilar [sí contactan con maxilar en MLP A. 1459 y 2077]. Vómeres con porción anterior ovalada; proceso precoanal expandido distalmente; proceso postcoanal dirigido dorsalmente; proceso posterior desarrollado sin contactar el esfenoetmoides [proceso posterior ausente en MLP A. 2077]; procesos dentígeros ubicados en dirección anterolateral-posteromedial, con 3 dientes [2-5 en el resto; ejemplar MLP A. 2240 con malformación en vómer derecho]. Premaxilares con pars dentalis con unos 11-12 dientes [10-12 en el resto]. Los maxilares no contactan con los pterigoides, pars dentalis con unos 35-37 dientes [entre 34-40 en el resto; ejemplar MLP A. 2240 sin maxilar derecho]. Cuadradoyugal ausente y cuadrado presente. Escamoso con ramas zigomática y ótica alineadas en vista dorsal [curvadas en MLP A. 4054]. Pterigoides con una proyección medial ventral que no alcanza el maxilar; rama media que no contacta con el proótico [sí contacta en MLP A. 4054 y 4061]. Articulación cráneo-mandibular al mismo nivel que el margen cefálico de las alas del paraesfenoides.

Endocráneo. Esfenoetmoides que no contacta con nasales ni vómeres; crista supraorbital no desarrollada [sí desarrollada en MLP A. 2077, 4054 y 4061]; los márgenes anteriores, en vistas dorsal y ventral, no están proyectados; ventralmente no alcanza el espacio entre los vómeres; foramen orbitonasal presente [en MLP A. 4061 el esfenoetmoides es incompleto ventralmente; en MLP A. 2240 el esfenoetmoides, en vista dorsal, con proyección anterior]. Forámenes óptico y proótico desarrollados; este último rodeado totalmente por el hueso proótico [en MLP A. 1459, 2077, 4061 foramen proótico rodeado parcialmente por el hueso homónimo]. Exoccipitales perforados por dos forámenes. Cóndilos occipitales estrechamente separados, tipo II.

Esqueleto laríngeo. Hioides seno hiogloso muy pronunciado, con procesos anterolaterales no ensanchados. Laringe con cricoides con procesos musculares y esofágico; sin proceso laterales, articulares ni bronquiales, no se pudo establecer si hay proceso cardíaco en MLP A. 1458 [en los restantes ejemplares examinados hay, además, proceso cardíaco bilobulado, procesos laterales, articulares y bronquiales. En MLP A. 1459 y 2077 los procesos bronquiales alcanzan el proceso esofágico, mientras que en MLP A. 2240, 4054 y 4061 lo superan]. 
Oído medio. Opérculo oval. Columela con proyección ventral como en $\mathrm{P}$. thaul; estilo óseo dirigido dorsalmente en su extremo distal. Extracolumela con proyección hacia el opérculo, anillo timpánico incompleto en su porción dorsal [en MLP A. 2077 se observó un elemento óseo, de forma arriñonada, en la región ventral de la extracolumela].

Esqueleto postcraneano. Esqueleto axial. Vértebra cervical con cótilos de tipo II. Expansión de los procesos transversos en orden decreciente: III > IV $>$ V $>$ II > $\mathrm{VI}>\mathrm{VII}=\mathrm{VIII}$. Orientación de los procesos respecto al eje longitudinal: II, VII y VIII hacia adelante; III y V hacia atrás y IV y VI perpendicular [en MLP A. 2077 II, III, VII y VIII hacia delante, IV y V hacia atrás y VI perpendicular; en MLP A. 4054 III, IV y V hacia atrás; en MLP A. 4061 III hacia adelante y V perpendicular. En MLP A. 2240 III hacia delante, En MLP A. 1459 III hacia delante, IV y $V$ hacia atrás]. Vértebra sacra con apófisis levemente dilatadas.

Esqueleto apendicular. Cintura pectoral. Mesosternón con región distal adelgazada. Xifiesternón bifurcado. Miembro anterior. Húmero con crista lateralis, crista medialis y crista ventralis en MLP A. 4054. En MLP A. 2240 elementos sesamoides entre húmero y radio-ulna. Prepollex formado por 2-3 elementos distales. Se observaron elementos sesamoideos en vistas dorsal y ventral del carpo. Cintura pélvica con ilion presentando dos pequeñas proyecciones laterales, a modo de procesos vestigiales [en los restantes ejemplares examinados ilion sin proyecciones]. Tarso con elementos sesamoideos [en MLP A. 1459, 2077 y 2240 sesamoides en articulación de tibio-fíbula con tibial-fibular]. Prehallux formado por 3 elementos [en MLP A. 4061 tarsales representados 2 elementos: tarsal distal 2-3 y tarsal distal 1, faltaría el elemento Y].

\section{Pleurodema borellii}

Descripción basada en el ejemplar đ̊ MLP A. 3814 (proveniente de la misma región que la localidad tipo -Tucumán-); sólo se describen las diferencias con $P$. thaul. Variaciones con los especímenes FML 4125 e ILPLA 400 (sin datos de sexo) y $\hat{\sigma}$ MLP A. 2013 indicadas entre corchetes.

Exocráneo. Nasales claviformes [trapezoidales en FML 4125]. Paraesfenoides con extremo anterior en punta, procesos alares dirigidos levemente hacia atrás. Los palatinos no contactan con la pars palatina del maxilar ni con los pterigoides [sí contactan en FML 4125]. Vómeres con porción anterior ensanchada; proceso precoanal con borde irregular; proceso postcoanal dirigido dorsalmente; proceso 
posterior no desarrollado [sí desarrollado, aunque corto, en FML 4125]; procesos dentígeros ubicados en dirección anterolateral-posteromedial con 4 dientes [procesos dentígeros ubicados en perpendicularmente en MLP A. 2013; 3 dientes en FML 4125]. Premaxilares con proceso alar no dirigido hacia atrás [dirigido posteriormente en FML 4125], pars dentalis con unos 11-12 dientes. Maxilar en contacto con el premaxilar, pars dentalis con unos 40 dientes [unos 35 en FML 4125]. Cuadradoyugal ausente y cuadrado presente. Pterigoides con rama anterior que no contacta con los palatinos y rama media que no contacta con el proótico [sí contacta con ambos huesos en FML 4125]. Articulación cráneo-mandibular al mismo nivel que el margen cefálico de las alas del paraesfenoides.

Endocráneo. Esfenoetmoides que no contacta con nasales ni vómeres; crista supraorbital no desarrollada; ventralmente se proyecta anteriormente sin alcanzar el espacio entre los vómeres; foramen orbitonasal presente. Forámenes óptico y proótico desarrollados; este último rodeado parcialmente por el hueso proótico. Exoccipitales perforados por un foramen tabicado. Cóndilos occipitales estrechamente separados, tipo II.

Esqueleto laríngeo. Hioides no observable en MLP A. 3814. Laringe con cricoides con proceso cardíaco unilobulado; procesos musculares, laterales, articulares, esofágico presentes; se observaron pequeñas perforaciones en vista ventral en la región donde nacen los procesos musculares; procesos bronquiales que superan el proceso esofágico del cricoides [lo sobrepasan]. Esqueleto hiolaríngeo faltante en FML 4125.

Oído medio. Opérculo oval. Columela con proyección ventral como en $\mathrm{P}$. thaul; estilo óseo dirigido dorsalmente en su extremo distal. Extracolumela con proyección hacia el opérculo; anillo timpánico incompleto dorsalmente.

Esqueleto postcraneano. Esqueleto axial. Vértebra cervical con cótilos de tipo II. Expansión de los procesos transversos en orden decreciente: III $>\mathrm{IV}>\mathrm{V}>\mathrm{VI}=$ $\mathrm{VII}>\mathrm{VIII}>\mathrm{II}$ [IV $>\mathrm{III}>\mathrm{V}>\mathrm{VI}>\mathrm{II}>\mathrm{VII}>\mathrm{VIII}$ en FML 4125]. Orientación de los procesos transversos con respecto al eje longitudinal: II, VII y VIII hacia adelante; III, IV y V hacia atrás y VI perpendicular [VI hacia atrás en FML 4125]. Vértebra sacra con apófisis levemente dilatadas.

Esqueleto apendicular. Cintura pectoral. Mesosternón con región medial muy adelgazada y extremos ensanchados. Xifiesternón bifurcado. Miembro anterior. Húmero con cresta lateral. Prepollex formado por 2 elementos. Se observaron elementos sesamoideos en el carpo. Cintura pélvica. Isquion óseo en toda su 
extensión con expansión acetabular dorsal. Se observaron elementos sesamoideos en el tarso. Prehallux formado por 3 elementos.

\section{Pleurodema cinereum}

Descripción basada en el ejemplar đ FML 14975 (topotipo); sólo se describen las diferencias con P. thaul. Variaciones con los especimenes 우 FML 14976 y MLP A. 4753 y $\lesssim$ MLP A. 4689 y 4751 indicadas entre corchetes.

Exocráneo. Nasales trapezoidales. Paraesfenoides con extremo anterior levemente en punta, procesos alares perpendiculares [en MLP A. 4751 levemente dirigidos hacia atrás], sin reborde supraorbital. Los palatinos no contactan la pars palatina del maxilar [en MLP A. 4751 sí contactan]; poseen una pequeña proyección en el margen cefálico [ausente en MLP A. 4751 y en 4753]. Vómeres con proceso anterior irregular, proceso postcoanal dirigido dorsalmente, proceso posterior no desarrollado, proceso dentígero ubicados en dirección anterolateral-posteromedial, no se pudo establecer el número de dientes [en MLP A. 4751 y 4753 proceso postcoanal en el mismo plano que el resto del hueso y proceso posterior desarrollado sin contactar con el esfenoetmoides; proceso dentígero con 2 dientes en FML 14976 y MLP A. 4753 y 3 en MLP A. 4751]; sin foramen para la salida de la rama palatina del nervio facial. Premaxilares con pars dentalis con unos 13 dientes [10-15 dientes]. Los maxilares no contactan con premaxilares ni pterigoides [en MLP A. 4751 y 4753 sí contactan con ambos huesos]; pars palatina con unos 27 dientes [alrededor de 30]. Cuadradoyugal ausente y cuadrado presente observado en los ejemplares MLP A. 4751, 4753 y FML 14976. Escamoso con rama zigomática reducida. Pterigoides con rama anterior que alcanza el plano anteorbitario, no contacta con maxilares ni palatinos [en MLP A. 4751 contacta con maxilares; en MLP A. 4753 contactan con ambos huesos]. Articulación cráneo-mandibular al nivel del margen cefálico de las alas del paraesfenoides.

Endocráneo. Esfenoetmoides que no contacta con nasales ni vómeres; crista supraorbital no desarrollada [desarrollada en MLP A. 4751]; ventralmente no posee proyecciones, no alcanza el espacio entre los vómeres; no se pudo establecer la presencia de foramen orbitonasal en FML 14975 y 14976 [en MLP A. 4751 y 4753 foramen presente]. Foramen proótico rodeado parcialmente por el hueso proótico, no se pudo determinar la presencia de foramen óptico en FML 14975. Exoccipitales perforados por dos forámenes. Cóndilos occipitales tipo II.

Esqueleto laríngeo. Hioides con procesos anterolaterales redondeados. Laringe con cricoides con procesos laterales y musculares presentes; procesos 
articulares ausentes; procesos bronquiales que no alcanzan el borde posterior del cricoides [no tiñó correctamente en FML 14976; en MLP A. 4751 y 4753 sobrepasan el límite del proceso esofágico. En FML 14975 no se pudieron visualizar procesos bronquiales, musculares ni cardíaco; en MLP A. 4751 no se pudo visualizar proceso cardíaco; en MLP A. 4753 proceso cardíaco bilobulado].

Oído medio. Opérculo oval. Columela formada por una placa ósea basal y un estilo óseo levemente orientado hacia la región dorsal [orientado transversalmente en el resto del material examinado], proyección ventral presente. Extracolumela sin proyección hacia el opérculo [la membrana timpánica no tiñó correctamente en FML 14976].

Esqueleto postcraneano. Esqueleto axial. Vértebra cervical con cótilos de tipo II. Expansión de los procesos transversos en orden decreciente: III $>$ IV $>$ V $>$ VI = VII > VIII > II. Orientación de los procesos transversos con respecto al eje longitudinal: II, VII y VIII hacia adelante; III, IV y V hacia atrás y VI perpendicular [en MLP A. 4751 III hacia delante; malformación en columna en MLP A. 4753]. Vértebra sacra con apófisis levemente dilatadas.

Esqueleto apendicular. Cintura pectoral. Mesosternón con región medial muy adelgazada y extremos ensanchados [en MLP A. 4751 mesosternón ancho; en MLP A. 4753 mesosternón más delgado distalmente que proximalmente]. Xifiesternón bifurcado. Miembro anterior. Húmero sin crista lateralis [con cresta lateral en MLP A. 4753], con crista medialis y crista ventralis. Prepollex formado por 2 elementos. Se observó un elemento sesamoideo en el carpo. No se pudo establecer la morfología carpal en FML 14975-76. Cintura pélvica. Isquion óseo en toda su extensión con expansión acetabular dorsal. Tarso con elementos sesamoideos. Prehallux formado por 3 elementos.

\section{Pleurodema diplolisiter}

Descripción basada en el ejemplar q MZUSP 38291; sólo se describen las diferencias con P. thaul. Variaciones del espécimen $q$ MZUSP 38280 indicadas entre corchetes.

Exocráneo. Frontoparietales con bordes mediales irregulares, en el tercio posterior contactan entre sí [no contactan]. Fenestra frontoparietal expuesta [expuesta en los $2 / 3$ anteriores]. Nasales con forma de media luna, con los bordes mediales superpuestos al esfenoetmoides. Paraesfenoides con extremo anterior romo, procesos alares perpendiculares. Palatinos contactando con la pars palatina del maxilar; no contactan con el pterigoides. Vómeres con porción anterior con 
extremo en punta; proceso postcoanal dirgido dorsalmente; proceso posterior no desarrollado [proceso posterior presente en contacto con esfenoetmoides]; procesos dentígeros ubicados de forma irregular; con 4 dientes [3]. Premaxilares con proceso alar no dirigido hacia atrás, pars dentalis con unos 13-14 dientes. Maxilar en contacto con el premaxilar, pars dentalis con unos 40 dientes. Cuadradoyugal ausente y cuadrado presente. Escamoso con rama zigomática desarrollada pero corta. Pterigoides con rama anterior que no contacta con maxilar ni palatino; rama media que no contacta con el proótico.

Endocráneo. Esfenoetmoides en contacto con nasales pero no con vómeres [contacta con vómeres]; crista supraorbital desarrollada; ventralmente se proyecta anteriormente hasta sobrepasar el plano formado por el margen anterior de los procesos precoanales del vómeres; foramen orbitonasal presente. Forámenes óptico y proótico desarrollados; este último rodeado totalmente por el hueso proótico. Exoccipitales perforados por dos forámenes. Cóndilos occipitales estrechamente separados, tipo II.

Esqueleto laríngeo. El Hioides no tiño correctamente en ninguno de los dos ejemplares. Laringe con cricoides con proceso cardíaco simple; procesos musculares, laterales, articulares y esofágico presentes; procesos bronquiales dirigidos ventralmente que superan el proceso esofágico del cricoides.

Oído medio. Opérculo oval. Columela con placa ósea basal indiferenciada, estilo óseo curvo, dirigido dorsalmente hacia el extremo distal; sin proyección ventral [con proyección]. Extracolumela con proyección hacia el opérculo; anillo timpánico incompleto dorsalmente.

Esqueleto postcraneano. Esqueleto axial. Vértebra cervical con cótilos de tipo II. Expansión de los procesos transversos en orden decreciente: III $>$ IV $>$ II $>$ V = $\mathrm{VI}>\mathrm{VII}>\mathrm{VIII}$ [los procesos de la vértebra II son los de menor tamaño]. Orientación de los procesos respecto al eje longitudinal: II, VII y VIII hacia adelante; IV y V hacia atrás y III y VI perpendicular. Vértebra sacra con apófisis levemente dilatadas.

Esqueleto apendicular. Cintura pectoral. Mesosternón con región medial adelgazada. Xifiesternón bifurcado. Supraescápula sin proyección en forma de gancho. Miembro anterior. Húmero con crista ventralis; sin crista lateralis ni crista medialis [con crista lateralis]. Prepollex formado por 2 elementos distales. Se observaron elementos sesamoideos en vistas dorsal y ventral del carpo. Cintura pélvica con ilion con expansión acetabular dorsal. Tarso con elementos sesamoideos. Prehallux formado por 3 elementos. 


\section{Pleurodema brachyops}

Descripción basada en el ejemplar đ̂ UIS-A 1543; sólo se describen las diferencias con P. thaul. Variaciones del espécimen $q$ UIS-A 098 indicadas entre corchetes.

Exocráneo. Frontoparietales sin variaciones [en la región posterior contactan entre sí]. Nasales trapezoidales. Paraesfenoides con extremo anterior en punta, procesos alares perpendiculares. Palatinos en contacto con la pars palatina del maxilar [no contactan]. Vómeres con porción anterior con extremo romo; proceso postcoanal dirgido dorsalmente; proceso posterior desarrollado sin contactar el esfenoetmoides [sí contacta]; procesos dentígeros perpendiculares al eje axial [ubicados en dirección anterolateral-posteromedial] con 3 dientes [4]. Premaxilares con proceso alar no dirigido hacia atrás, pars dentalis con unos 13-14 dientes [11-13]. Maxilar en contacto con el premaxilar [sin contactar], pars dentalis con unos 39-41 dientes [37-39]. Cuadradoyugal ausente y cuadrado presente. Escamoso con rama zigomática reducida. Pterigoides con rama media que no contacta con el proótico.

Endocráneo. Esfenoetmoides que no contacta con nasales ni vómeres [sí contacta con vómeres]; crista supraorbital no desarrollada [sí desarrollada]; ventralmente se proyecta anteriormente sin alcanzar el espacio entre los vómeres [sí alcanza el espacio entre los vómeres]; foramen orbitonasal presente. Forámenes óptico y proótico desarrollados; este último rodeado parcialmente por el hueso proótico. Exoccipitales perforados por un foramen tabicado. Cóndilos occipitales estrechamente separados, tipo II.

Esqueleto laríngeo. Hioides con procesos anterolaterales de forma arriñonada. Laringe con cricoides con proceso cardíaco bilobulado; procesos esofágico y articulares presentes; sin proceso lateral ni muscular [con proceso lateral]; procesos bronquiales que alcanzan el proceso esofágico del cricoides [lo sobrepasan].

Oído medio. Opérculo oval. Columela con placa ósea basal indiferenciada, estilo óseo curvo, con su zona media dirigida ventralmente, en forma de " $U$ " poco pronunciada [recta], sin proyección ventral [con proyección]. Extracolumela con proyección hacia el opérculo; anillo timpánico apenas incompleto en su porción antero-dorsal.

Esqueleto postcraneano. Esqueleto axial. Vértebra cervical con cótilos de tipo II. Expansión de los procesos transversos en orden decreciente: IV $>$ III $>$ V $>$ VI > $\mathrm{II}>\mathrm{VII}=\mathrm{VIII}[\mathrm{IV}>\mathrm{V}>\mathrm{III}=\mathrm{VI}>\mathrm{II}=\mathrm{VII}>\mathrm{VIII}$. Orientación de los procesos respecto al eje longitudinal: II, III, VII y VIII hacia adelante; IV y V hacia atrás y VI perpendicular 
[II, III y VIII hacia adelante; IV, V y VI hacia atrás y VII perpendicular]. Vértebra sacra con apófisis levemente dilatadas.

Esqueleto apendicular. Cintura pectoral. Mesosternón con región medial adelgazada. Xifiesternón bifurcado. Supraescápula sin proyección en forma de gancho. Unión posiblemente teratológica entre escápula y supraescápula. Miembro anterior. Húmero sin cresta lateral. Prepollex formado por 2 elementos distales. Se observaron elementos sesamoideos en vistas dorsal y ventral del carpo. Cintura pélvica sin modificaciones. Tarso con elementos sesamoideos. Prehallux formado por 3 elementos.

\section{Pleurodema nebulosum}

Descripción basada en el ejemplar $\widehat{\sigma}$ CENAl 6546; sólo se describen las diferencias con P. thaul. Variaciones del espécimen $\delta$ CENAI 228-5 indicadas entre corchetes.

Exocráneo. Nasales trapezoidales con márgenes posteriores apoyados sobre el esfenoetmoides. Paraesfenoides con extremo anterior levemente irregular [romo], procesos alares perpendiculares, proceso posterior desarrollado prácticamente hasta alcanzar los cóndilos occipitales. Los palatinos no contactan con la pars palatina del maxilar. Vómeres con porción anterior corta y extremo romo; proceso posterior desarrollado contactando el esfenoetmoides; sin proceso dentígero. Premaxilares con proceso alar dirigido hacia adelante [dirigido dorsalmente], pars dentalis con unos 14 [11] dientes. Los maxilares no contactan premaxilares, palatinos ni pterogoides, pars dentalis con unos 27-29 dientes. Cuadradoyugal ausente y cuadrado presente. Escamoso con rama zigomática ausente y rama ótica extremadamente reducida; esta última contacta la crista parótica. Pterigoides con rama anterior que alcanza el plano anteorbitario; la rama posterior no contacta con el proótico. Articulación cráneo-mandibular al mismo nivel que el margen cefálico de las alas del paraesfenoides.

Endocráneo. Esfenoetmoides con margen anterior cubierto por los nasales (vista dorsal) y vómeres (vista ventral); crista supraorbital no desarrollada; ventralmente se proyecta anteriormente hasta alcanzar el espacio entre los vómeres; foramen orbitonasal presente. Forámenes óptico y proótico desarrollados; este último rodeado parcialmente por el hueso proótico. Exoccipitales perforados por un foramen tabicado completamente del lado izquierdo e incompletamente del derecho. Cóndilos occipitales estrechamente separados, intermedio entre los tipos II y III de Lynch (1971), más cercano al tipo III. 
Esqueleto laríngeo. Hioides con hiales sin proceso anteromedial; procesos posterolaterales anchos. Laringe con cricoides con proceso cardíaco bilobulado; procesos musculares, articulares, laterales y esofágico presentes; procesos bronquiales superando el borde posterior del anillo cricoideo.

oído medio. Columela sin placa basal, estilo óseo dirigido perpendicularmente. Extracolumela con proyección ahusada. Anillo timpánico completo.

Esqueleto postcraneano. Esqueleto axial. Vértebra cervical con cótilos intermedios entre tipo II-III de Lynch (1971). Expansión de los procesos transversos en orden decreciente: III $>$ IV $>\mathrm{II}>\mathrm{V}=\mathrm{VI}>\mathrm{VII}>\mathrm{VIII}$. Orientación de los procesos transversos con respecto al eje longitudinal: II, VI (levemente), VII y VIII hacia adelante; IV y $\mathrm{V}$ hacia atrás y VI perpendicular [orientación de los procesos transversos con respecto al eje longitudinal variable: II (levemente), VII y VIII hacia adelante; III, IV y V hacia atrás y VI perpendicular.]. Vértebra sacra con apófisis levemente dilatadas.

Esqueleto apendicular. Cintura pectoral. Mesosternón con región medial muy adelgazada y extremos ensanchados. Xifiesternón doble, levemente mineralizado en la región proximal [mesosternón con el extremo distal bifurcado]. Cintura pélvica. Isquion óseo en toda su extensión, con proyección dorsal. Miembro anterior. Húmero sin cresta lateral. Entre húmero y radio-ulna izquierdos hay un elemento óseo [puede faltar]. Prepollex formado por 3 elementos. Se observó un elemento sesamoideo en el carpo. Miembro posterior. Fémur más largo que tibio-fíbula [cresta posterior, casi ventral en el fémur]. Prehallux formado por 2 elementos. Se observaron elementos sesamoideos en las articulaciones tibio-fíbula/tibial-fibular y en el tarso.

\section{Pleurodema guayapae}

Descripción basada en el ejemplar đ CENAI 2591-20; se destacan las diferencias con P. thaul. Variaciones del espécimen $\widehat{O}$ CENAI 574 indicadas entre corchetes.

Exocráneo. Frontoparietales sin variaciones. Nasales trapezoidales con márgenes posteriores apoyados sobre el esfenoetmoides. Paraesfenoides con extremo anterior trunco, procesos alares perpendiculares, proceso posterior desarrollado prácticamente hasta alcanzar los cóndilos occipitales. Los palatinos no contactan con la pars palatina del maxilar [sí contactan]. Vómeres con porción anterior corta y extremo romo [porción anterior reducida]; proceso postcoanal 
reducido, dirigido dorsalmente [levemente dirigido dorsalmente]; proceso posterior desarrollado en contacto con el esfenoetmoides [proceso posterior reducido, sin contactar con el esfenoetmoides]; sin proceso dentígero; perforado para la salida de la rama palatina del nervio facial. Premaxilares con proceso alar dirigido dorsalmente (sin inclinación), pars dentalis con unos 11-13 dientes [8-9; maxilares superpuestos a los premaxilares]. Los maxilares no contactan con premaxilares, palatinos, ni pterogoides [sí contactan], pars palatina con unos 38 dientes [30]. Cuadradoyugal ausente y cuadrado presente. Escamoso con rama zigomática ausente y rama ótica extremadamente reducida; esta última contacta la crista parótica. Pterigoides con la rama anterior que no alcanza el plano anteorbitario; rama posterior que no contacta con el proótico [sí contacta]. Articulación cráneomandibular al mismo nivel al margen anterior (cefálico) de las alas del paraesfenoides. Cóndilos occipitales tipo II.

Endocráneo. Esfenoetmoides con margen anterior cubierto por los nasales (vista dorsal) y vómeres (vista ventral); ventralmente se proyecta anteriormente hasta alcanzar el espacio entre los vómeres. Foramen orbitonasal desarrollado. Forámenes óptico y proótico desarrollados; este último completamente rodeado por el hueso proótico. Exoccipitales perforados por un foramen tabicado. Cóndilos occipitales estrechamente separados, intermedio entre los tipos II y III de Lynch (1971), más cercano al tipo III.

Esqueleto laríngeo. Hioides con hiales sin proceso anteromedial. Laringe con cricoides con cardíaco bilobulado; procesos musculares, laterales, articulares y esofágico presentes; procesos bronquiales que superan el proceso esofágico del anillo cricoideo [no lo superan, alcanzan su límite].

Oído medio. Columela sin placa basal, estilo óseo dirigido distalmente hacia arriba, con una pequeña curvatura ventral en la mitad de su extensión. Extracolumela con proyección ahusada. Anillo timpánico incompleto, faltando la porción postero-medial.

Esqueleto postcraneano. Esqueleto axial. Vértebra cervical con cótilos intermedios entre tipo II-III de acuerdo con Lynch (1971). Expansión de los procesos transversos en orden decreciente: III $>$ IV $>$ II $>$ V $>$ VI $>$ VII $>$ VIII. Orientación de los procesos transversos con respecto al eje longitudinal: II (muy levemente), III, VI, VII y VIII hacia adelante; IV hacia atrás y $\mathrm{V}$ perpendicular. Vértebra sacra con apófisis levemente dilatadas [proceso transverso izquierdo de la vértebra VIII más corto y sin extremo cartilaginoso; orientación de los procesos transversos con respecto al eje longitudinal: II, III, VI, VII y VIII hacia delante (el proceso de la vértebra VII es más 
bien perpendicular del lado izquierdo); IV y $\mathrm{V}$ hacia atrás].

Esqueleto apendicular. Cintura pectoral. Supraescápulas sin proyección. Mesosternón con región medial muy adelgazada, bifurcado. Xifiesternón doble. Cintura pélvica. Isquion óseo en toda su extensión, con proyección dorsal. Miembro anterior. Húmero sin cresta lateral. Prepollex formado por 3 elementos distales. Entre húmero y radio-ulna y en el carpo hay elementos sesamoideos [pueden faltar]. Miembro posterior. Fémur más largo que tibio-fíbula [fémur una cresta distal, casi ventral]. Prehallux formado por 2 elementos. Se observaron elementos sesamoideos en las articulaciones tibio-fíbula/tibial-fibular y en el tarso.

\section{Pleurodema tucumanum}

Descripción basada en el ejemplar $\lesssim$ MLP A. 4727; se destacan las diferencias con P. thaul. Variaciones del espécimen $\widehat{\alpha}$ MLP A. 1961 y $q$ MLP A. 1960 indicadas entre corchetes.

Exocráneo. Frontoparietales en contacto en la región posterior [en MLP A. 1961-62 no contactan]. Nasales claviformes. Paraesfenoides con extremo anterior romo, procesos alares perpendiculares. Los palatinos contactan con la pars palatina del maxilar pero no con los pterigoides. Vómeres con porción anterior alargada dirigida hacia la zona de unión entre premaxila y maxila; proceso postcoanal en el mismo plano que el resto del hueso; proceso posterior desarrollado en contacto con el esfenoetmoides; con proceso dentígero pero sin dientes (contra Barrio 1964: 474, quien señala la presencia de dientes vomerinos); sin foramen para la salida de la rama palatina del nervio facial. Premaxilares con proceso alar dirigido dorsalmente (sin inclinación), pars dentalis con unos 8-9 dientes [unos 10-11 en MLP A. 1961 y 1962]. Los maxilares contactan con premaxilares, palatinos y pterigoides, pars palatina con unos 24 dientes [unos 30 en MLP A. 1961-62]. Cuadradoyugal ausente y cuadrado presente. Escamoso con rama zigomática desarrollada (corta) y rama ótica reducida pero contactando la crista parótica. Pterigoides con rama anterior que alcanza el plano anteorbitario; rama posterior contactando con el proótico [en MLP A. 1961 no contacta]. Articulación cráneo-mandibular posterior al margen anterior (cefálico) de las alas del paraesfenoides. Cóndilos occipitales tipo II.

Endocráneo. Esfenoetmoides que no contacta con nasales (vista dorsal) pero sí con vómeres vómeres (vista ventral); ventralmente se proyecta anteriormente hasta alcanzar el espacio entre los vómeres [contacta con nasales en MLP A. 196162]. Foramen orbitonasal desarrollado. Forámenes óptico y proótico desarrollados; este último completamente rodeado por el hueso proótico en MLP A. 1961; en el 
resto del material no se pudo determinar el número y posición de los forámenes. Exoccipitales perforados por tres forámenes [dos en MLP A. 1961]. Cóndilos occipitales de tipos II de Lynch (1971).

Esqueleto laríngeo. Hioides con hiales sin proceso anteromedial. Laringe con cricoides con cardíaco simple; procesos musculares, laterales y esofágico presentes; procesos articulares ausentes; procesos bronquiales que no superan el proceso esofágico del anillo cricoideo.

Oído medio. Opérculo oval. Columela formada por una placa ósea basal y un estilo óseo levemente orientado hacia la región dorsal, proyección ventral presente. Extracolumela desarrollada (a diferencia de lo señalado por Barrio 1964: 475) sin proyección hacia el opérculo. Anillo timpánico completo [incompleto en MLP A. 1962].

Esqueleto postcraneano. Esqueleto axial. Vértebra cervical con cótilos intermedios tipo II acuerdo con Lynch (1971). Expansión de los procesos transversos en orden decreciente: III $>$ IV $>$ II $>$ V = VI = VII = VIII. Orientación de los procesos transversos con respecto al eje longitudinal: II, III, VII y VIII hacia adelante; IV, V y VI perpendicular [III (muy levemente), VII y VIII hacia adelante; II y VI perpendicular, IV y V hacia atrás en MLP A. 1961; II, III, VI, VII y VIII hacia delante, IV u V hacia atrás en MLP A. 1962]. Vértebra sacra con apófisis levemente dilatadas, dirigidas posteriormente.

Esqueleto apendicular. Cintura pectoral. Supraescápulas sin proyección. Mesosternón con región medial adelgazada. Xifiesternón bifurcado [doble en MLP A. 1961]. Cintura pélvica. Isquion óseo en toda su extensión, con proyección dorsal. Miembro anterior. Húmero con crista ventralis; sin crista lateralis ni crista medialis. Prepollex formado por 3 elementos distales. Entre húmero y radio-ulna y en el carpo hay elementos sesamoideos. Miembro posterior. Sin variaciones. Prehallux formado por 2 elementos. Se observaron elementos sesamoideos en las articulaciones tibio-fíbula/tibial-fibular y en el tarso.

\section{Pleurodema marmoratum}

Descripción basada en el ejemplar + CENAI 10769; sólo se describen las diferencias con P. thaul.

Exocráneo. Frontoparietales con márgenes mediales irregulares en toda su extensión; sin contactar entre sí. Nasales triangulares, con el esfenoetmoides superpuesto a ellos. Paraesfenoides con extremo anterior en punta, procesos alares levemente dirigidos hacia atrás muy afinados en su unión con el proceso cultriforme. 
Palatinos arqueados, contactan con el pterigoides y con la pars dentalis del maxilar. Vómeres con porción anterior levemente expandida; proceso precoanal en punta; proceso postcoanal en el mismo plano que el resto del hueso; proceso posterior desarrollado, no se pudo establecer si contacta con el esfenoetmoides; sin proceso dentígero. Premaxilares con pars dentalis con unos 10 dientes; procesos palatinos dirigido hacia arriba. Maxilar en contacto con premaxilar, palatinos y pterigoides; pars dentalis con unos 30-32 dientes. Cuadradoyugal ausente y cuadrado presente. Escamoso con ramas zigomática y ótica alineadas en vista dorsal; rama zigomática reducida. Pterigoides con rama anterior contactando con los palatinos; rama media contactando con el proótico. Articulación cráneo-mandibular al mismo nivel que el margen cefálico de las alas del paraesfenoides.

Endocráneo. Esfenoetmoides contactando nasales (no se pudo establecer si contacta con los vómeres); crista supraorbital no desarrollada; ventralmente no alcanza el espacio entre los vómeres; foramen orbitonasal presente. Foramen proótico rodeado parcialmente por el hueso proótico (no se pudo establecer la presencia de foramen óptico). Exoccipitales perforados por dos forámenes. Cóndilos occipitales estrechamente separados, tipo II.

Esqueleto laríngeo. Hioides sin procesos anteromediales. La laringe no tiño correctamente en el ejemplar examinado.

Oído medio. Opérculo oval. Columela con proyección ventral como en $\mathrm{P}$. thaul; estilo óseo dirigido dorsalmente en su extremo distal. Extracolumela sin proyección hacia el opérculo, anillo timpánico incompleto en su porción dorsal.

Esqueleto postcraneano. Esqueleto axial. Vértebra cervical con cótilos de tipo II. Expansión de los procesos transversos en orden decreciente: III $>$ IV $>$ II $>$ V = $\mathrm{VI}=\mathrm{VII}=$ VIII. Orientación de los procesos respecto al eje longitudinal: II, III, VII y VIII hacia adelante; VI perpendicular, IV y $\mathrm{V}$ hacia atrás. Vértebra sacra con apófisis levemente dilatadas.

Esqueleto apendicular. Cintura pectoral. Supraescápula sin proyección en forma de gancho. Mesosternón ensanchado en ambos extremos. Xifiesternón en forma de áncora, cartilaginoso, proximalmente mineralizado. Miembro anterior sin modificaciones. Prepollex formado por 2 elementos distales. Se observaron elementos sesamoideos en vistas dorsal y ventral del carpo. Cintura pélvica sin modificaciones. Se observaron elementos sesamoides en la articulación tibiofíbula/tibial-fibular y en el tarso. Prehallux formado por 3 elementos.

Los caracteres 19-89 del análisis filogenético surgieron de la información 
presentada en este capítulo. 


\section{CAPÍTULO IV}

\section{Biología Reproductiva}

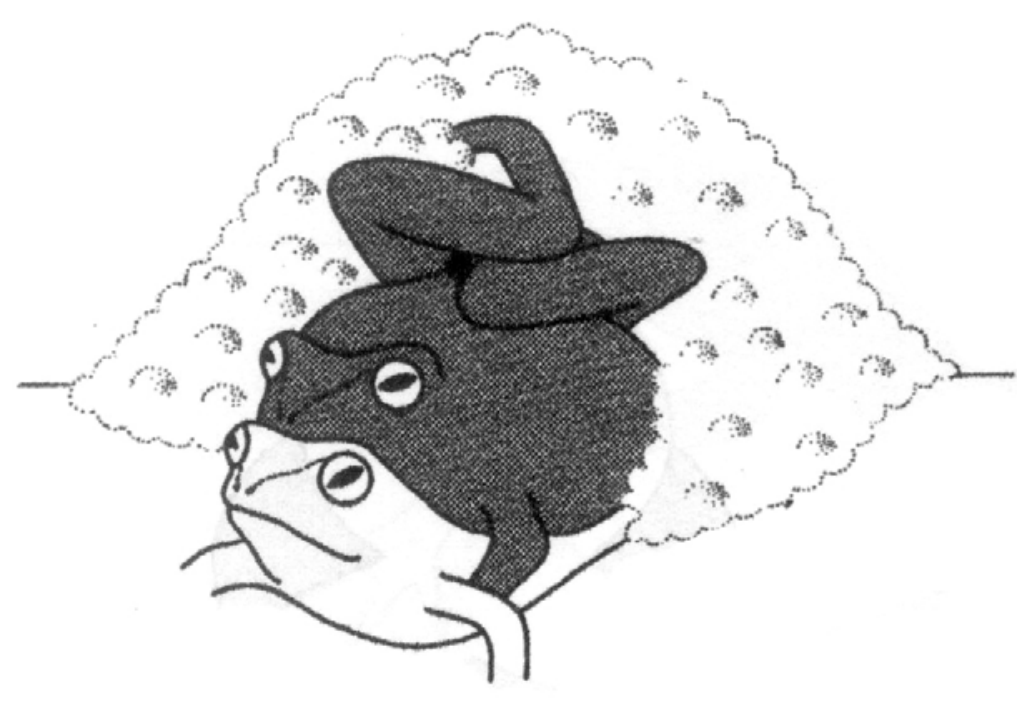

Tomado de Hödl (1990) 
Las especies del género Pleurodema tienen una variedad de modos reproductivos que han Ilamado la atención a lo largo del tiempo. Aquí se presenta una síntesis de los mismos, considerando la bibliografía existente y las observaciones de campo realizadas a lo largo del presente trabajo.

Pleurodema bibroni y P. kriegi poseen amplexo axilar y ponen sus huevos en grupos de 3 a 6, envueltos en una masa gelatinosa común, semiflotante (Barrio 1977). Las puestas son depositadas en cuerpos de agua ocasionales, formados por las lluvias, lejos de arroyos o vertientes (Fig 22 E). Pleurodema bibroni se reproduce en invierno (junio y julio), en tanto $P$. kriegi lo hace en verano (enero y febrero), pero ambas con temperaturas de 5 a $15 \stackrel{\circ}{\circ}$, durante la noche (Barrio 1977). El canto de anuncio de P. kriegi fue analizado por Straneck et al. (1993) y su larva fue descripta por Cei (1980a), mientras que el canto y la larva de P. bibroni fueron descriptos por Kolenc et al. (2009).

Pleurodema borellii fue observada reproduciéndose desde fines de invierno (agosto) en la provincia de Tucumán; el amplexo es axilar, sus huevos son pigmentados (Lavilla, com. pers.) y son puestos en nidos de espuma (Gallardo 1968a; Duellman \& Veloso 1977; Halloy \& Fiaño 2000). El canto de anuncio fue analizado por McLister et al. (1991) en base a ejemplares provenientes de Tucumán y Belén (Catamarca). Straneck et al. (1993) describieron el canto de anuncio en base a un ejemplar de Lagunillas, Rinconada, Jujuy, pero posiblemente corresponda a P. cinereum, dado que el área es de puna. Se observó canibalismo conespecífico en larvas de P. borellii de mayor tamaño sobre otras menores (Halloy \& Fiaño 2000), como así también depredación selectiva de larvas por aves (Crump \& Vaira 1991). Posteriormente Halloy (2006) demostró que las hembras de P. borellii prefieren sitios de oviposición donde haya larvas de pequeño tamaño frente a sitios con larvas de tamaños medianos o grandes, evitando la presencia de competidores y/o depredadores. La larva fue descripta por Cei (1980a), considerándola similar a la de P. cinereum, mientras que su morfología oral fue detallada por Wassersug \& Heyer (1988).

Pleurodema brachyops tiene actividad sexual continua durante todo el año, pone de 3000 a 5000 huevos, despigmentados, en nidos de espuma, y tiene un rápido desarrollo larval (Leon-Ochoa \& Donoso-Barros 1969). El canto de anuncio fue analizado por Duellman \& Veloso (1977). La larva fue descripta por Leon-Ochoa \& Donoso-Barros (1969) y su morfología oral por Wassersug \& Heyer(1988).

Pleurodema bufoninum posee un ciclo de espermatogénesis discontinua, faltando la gametogénesis en las épocas de baja temperatura; este proceso 
probablemente esté regulado genéticamente (Cei 1961; 1962b; Cei \& Codoceo 1957). Se reproduce en primavera-verano y la oviposición y el desarrollo larval ocurren en ambientes temporarios acuáticos lénticos, poco profundos, soleados y con vegetación (Weigandt et al. 2004). Se registró amplexo inguinal (Duellman \& Veloso 1977). Sus huevos, pigmentados, son puestos en tubos de gelatina, habiendo unos 10-40 huevos por tubo, flotando en la superficie del agua; las puestas están formadas por cordones largos $(30-50 \mathrm{~cm})$ o cortos $(9-15 \mathrm{~cm}$ ) (Fernández 1927; Úbeda 1998; Weigandt et al. 2004). Se desconoce su canto de anuncio y probablemente no lo emita (Cei 1980a), pero sí posee canto acompañando a la vibración sexual preventiva (warning vibration) (Cei \& Espina Aguilera 1957). La larva fue descripta por Fernández (1927), Úbeda (1998) y Weigandt et al. (2004) y su morfología oral por Wassersug \& Heyer (1988).

Pleurodema cinereum vocaliza en la puna argentina flotando en el agua, durante toda la época de lluvias (Cei 1980a); fue hallada en la puna de Jujuy cantando a pleno día o de noche, siempre en charcos asociados a matorrales de tola (Parastrephia sp.; obs. pers.) (Fig. 22 A). En la puna peruano-boliviana comienzan a reproducirse a fines de primavera y principios de verano (Vellard 1960). Sus huevos, pigmentados, son puestos en nidos de espuma (Fernández \& Fernández 1921). Se observaron puestas comunales formadas por 6 y 9 parejas en amplexo simultáneamente en la puna de Bolivia, siempre asociadas a vegetación (Agostini et al. 2007). El canto de anuncio fue analizado por Duellman \& Veloso (1977), McLister et al. (1991) y Márquez et al. (1995). La larva fue descripta por Fernández \& Fernández (1921) y Cei (1980a) y su morfología oral por Wassersug \& Heyer (1988).

Pleurodema cordobae fue observada cantado desde diciembre a marzo, reproduciéndose en charcas semi-temporarias con vegetación en los bordes. Los machos cantan flotando en la superficie del agua cerca de los bordes de la charca; mientras que los huevos son depositados en masas semi-sumergidas y adheridas a la vegetación. El amplexo es axilar (Valetti et al. 2009). La información brindada por Ávila et al. (1999) para Pleurodema kriegi posiblemente también corresponda P. cordobae, dado que está basada en ejemplares de Sierra de Comechingones. Ávila et al. (1999) indica que la especie desarrolla su actividad al crepúsculo, y se halla en afloramientos rocosos y áreas periacuáticas, seleccionando estas últimas para su reproducción. Los machos cantan flotando, y la puesta sería, presumiblemente, una masa flotante adherida a vegetación flotante de áreas inundables (mallines), con huevos en grupos de 10 ó 20; las larvas fueron recolectadas en la confluencia de mallines y arroyos. 
Pleurodema diplolister vocaliza flotando en el agua, hallándose con mayor frecuencia en charcos temporales de tamaño medio; el amplexo es axilar, y sus huevos, pigmentados, son puestos en nidos de espuma (Carvalho \& Bailey 1948; Peixoto 1982; Hödl 1992; Cardoso \& Arzabe 1993; Arzabe 1999). Se observaron puestas comunales formadas por hasta 15 parejas en amplexo simultáneamente (Hödl 1992; Arzabe 1999). El canto de anuncio fue analizado por Hödl (1992) y Cardoso \& Arzabe (1993). La larva fue descripta por Peixoto (1982). Se observó canibalismo conespecífico en larvas (Cardoso \& Arzabe 1993).

Pleurodema guayapae y $P$. nebulosum ponen sus huevos pigmentados en nidos de espuma en charcos temporarios salobres (Fernández 1927; Barrio 1964b; di Tada et al. 1976). El amplexo es axilar (Duellman \& Veloso 1977). Los cantos de anuncio fueron analizados por Barrio (1964a) y Straneck et al. (1993). Pleurodema nebulosum puede reproducirse y emitir su canto de anuncio aún de día (Cei 1956c); además, fueron registradas larvas albinas y caníbales (Cei 1979). La larva de P. guayapae fue descripta por Cei (1980a); mientras que la de P. nebulosum por Fernández (1927), Gallardo (1965) y Cei (1980a). La morfología oral de P. nebulosum fue estudiada por Wassersug \& Heyer (1988).

Pleurodema marmoratum emite su canto de anuncio desde el borde de los charcos, posee amplexo axilar y coloca los huevos en masas en el agua (Duellman \& Veloso 1977). Cei (1962a) mencionó que los machos poseen dos sacos vocales poco visibles. El canto de anuncio fue analizado por Duellman \& Veloso (1977). La larva fue descripta por Cei (1980a).

Pleurodema thaul fue observada reproduciéndose en Chile desde julio (en el norte) o agosto (en el centro) por Cei (1962a), mientras que Díaz et al. (1987) registraron su reproducción desde septiembre a diciembre en el centro de Chile. En poblaciones argentinas se observó un período reproductivo que ocurre desde la primavera hasta principios del verano (octubre a diciembre) (Úbeda 1998). Cei (1980a) sugirió que el período reproductivo ocurre irregularmente durante todo el año, incluso en invierno. Díaz-Páez \& Ortiz (2001) demostraron que posee un ciclo sexual parcialmente continuo; el ciclo femenino tiene dos curvas, una a principio de otoño y otra a fines de invierno; en tanto el ciclo masculino tiene lugar durante casi todo el año. Machos y hembras emiten canto acompañando a la vibración sexual preventiva (Cei \& Espina Aguilera 1957; Penna \& Veloso 1982). El canto de anuncio fue analizado por Barrio (1977) y Duellman \& Veloso (1977). Se registró amplexo axilar para las poblaciones de Chile Central y Sur de Argentina, e inguinal para las del sur de Chile (Duellman \& Veloso 1977). Las puestas observadas en Chile están 
formadas por masas gelatinosas sueltas en el agua, entre la vegetación, conteniendo unos 400-500 huevos pigmentados (Cei 1962a). Duellman \& Veloso (1977) describieron que las poblaciones del sur de Chile colocan sus puestas en cordones gelatinosos, en tanto el resto de las poblaciones de Chile Central y Argentina depositan los huevos en masas en el agua. Úbeda (1998) registró puestas en cordones gelatinosos enroscados a la vegetación palustre. La ovipostura en cordón se enrosca en la vegetación palustre a poca profundidad y luego se hidrata paulatinamente adhiriéndose, quedando con aspecto de una ovipostura en masa (Úbeda, com. pers.); probablemente a esto se deba que algunos autores describieron las puestas en forma de masa de huevos. La larva fue descripta por Cei (1962a; 1980a) y úbeda (1998).

Pleurodema tucumanum se reproduce a partir de noviembre en el norte de Córdoba (Martori et al. 1994). De acuerdo con Martori et al. (1994), P. tucumanum ovipone mediante nidos ovoides, en forma de plato, de unos $20-25 \mathrm{~cm}$ de diámetro, constituidos por una matriz gelatinosa donde se ubican los agrupamientos de huevos pigmentados en un solo plano; sin embargo, Cei (1956c), Barrio (1964a; 1977) y Perotti (1994; 1997) sostienen que ovipone mediante nidos de espuma, aunque sin indicar cómo identificaron las puestas. El canto de anuncio fue analizado por Barrio (1964a), McLister et al. (1991) y Straneck et al. (1993) (Fig 22 B). La larva fue descripta por Cei (1980a).

No se conocen datos de la reproducción de Pleurodema aff. bibroni (taxón de Rio Grande do Sul, Brasil, véase Camargo et al. 2005) ni de P. fuscomaculatum.

Dentro de los modos reproductivos de los anuros, el más generalizado incluye realizar las puestas en el agua (Duellman \& Trueb 1994). Sin embargo, en varios grupos de anuros se han registrado modos reproductivos que tienden a separar los primeros estadios de desarrollo de la masa de agua, siendo la construcción de nidos de espuma un ejemplo de esta condición. La modalidad de puesta en nidos de espuma ha evolucionado paralelamente en varios linajes de anuros, habiéndose hallado casos, con diferentes variantes (e.g., flotando en el agua, en tierra o en árboles), en las familias Racophoridae (asiática), Hyperoliidae (africana), Limnodynastidae (australiana y africana), Leptodactylidae y Leiuperidae (centro y sudamericanas) (Hödl 1986; 1990; Duellman \& Trueb 1994). En general, en el momento de la puesta, salen de las vías genitales de las hembras óvulos y secreciones glandulares de tipo albuminoide que, por batimiento activo, se transforman en la espuma que englobará a la puesta. Heyer (1969b) consideró que esta modalidad permite que los huevos queden protegidos de la acción de 
potenciales depredadores acuáticos y de la desecación propia de los ambientes que habitan, aunque no impide su depredación por parte de larvas de insectos voladores, especialmente dípteros (Villa et al. 1982).

La construcción de los nidos documentada en algunos Leiupéridos y Leptodactílidos sudamericanos indica que los machos baten la espuma con sus patas traseras, mientras se mantienen en amplexo axilar con las hembras (Heyer \& Rand 1977; Hödl 1990; 1992) (Fig. 22 D). La forma de construcción del nido es la mayor diferencia entre los Leiuperidae y Leptodactylidae sudamericanos y los Limnodynastidae australianos, dado que en estos últimos las hembras, en amplexo inguinal, baten con los miembros anteriores generando una corriente de burbujas, las cuales pasan por debajo de su cuerpo y son atrapadas por el mucus que contiene los huevos (Martin 1970). Dentro de las formas neotropicales, se ha descripto un movimiento lateral, como de "limpia-parabrisas" ("wiping motion") en Leptodactylus pentadactylus (Heyer \& Rand 1977), en tanto que movimientos rotacionales de la tibia y el tarso, perpendiculares al eje axial ("kicking motion"), han sido observados en Physalaemus y Pleurodema (Hödl 1990; 1992). Heyer (1975) consideró que la evolución de los nidos de espuma en "Leptodactylinae" (actualmente los géneros de esta subfamilia están ubicados en Leiuperidae y Leptodactylidae) fue de vital importancia para el éxito en la colonización de savanas durante el levantamiento de los Andes en el Mioceno.

Diversos autores han tratado de interpretar la función adaptativa de la modalidad de puesta en nidos de espuma, pero varios de ellos analizan este fenómeno de forma parcial, incluyendo a las especies de ambientes más áridos, cuando no sólo especies de ambientes xéricos se reproducen mediante nidos de espuma (e.g. Pleurodema borellii se reproduce en ambientes tales como selva pedemontana). A continuación se mencionan algunas de estas interpretaciones.

Se ha destacado en la literatura la presencia de melanóforos en huevos puestos en nidos de espuma, siendo muy probable que los huevos expuestos a la luz solar posean algún grado de pigmentación (Salthe \& Duellman 1977). Se ha sugerido que podría funcionar como un escudo protector frente a la acción de luz ultravioleta (Heyer 1969b). Para cinco de las seis especies de Pleurodema que colocan nidos de espuma se han descripto huevos pigmentados (P. borellii, P. cinereum, P. diplolister, P. guayapae y P. nebulosum), en tanto se ha mencionado que en P. brachyops son blancos, lo cual los convertiría en crípticos dentro de la masa de espuma (LeonOchoa \& Donoso-Barros 1969). Por otro lado, en algunas de estas especies la tasa de desarrollo larval es muy rápida, durando, en condiciones de laboratorio, 16-19 días 
(Peixoto 1982) y 33 (Cardoso \& Arzabe 1993) para P. diplolister y 28-30 para P. brachyops (Leon-Ochoa \& Donoso-Barros 1969). Se ha sugerido que la puesta en nidos de espuma y el rápido desarrollo podrían favorecer la conquista de formaciones abiertas, evitar la desecación (la parte interna del nido permanece húmeda) y disminuir la depredación por parte de otros organismos acuáticos, insectos aéreos y/ o larvas de la misma u otras especies (Heyer 1969b; Heyer et al. 1975; Martin 1970; Crump 1983; Downie 1988; 1990; 1993; Hödl 1990; 1992; Duellman \& Trueb 1994; Menin \& Giaretta 2003). Hödl (1990; 1992) comprobó, en P. diplolister y Physalaemus ephippifer, que al retirar huevos de los nidos de espuma, éstos eran rápidamente comidos por larvas conespecíficas. Por su parte, Halloy \& Fiaño (2000) demostraron que existe canibalismo en larvas de P. borellii y Cardoso \& Arzabe (1993) en P. diplolister; estos últimos autores sugirieron que este fenómeno podría estar relacionado a la escasez de alimento en los ambientes de reproducción que utilizan estas especies.

Salthe \& Duellman (1977) sugirieron que podría existir una tendencia, en las especies con modos reproductivos desarrollados en tierra, de poner huevos más grandes (con mayor vitelo) y en menor cantidad. Esta apreciación no ha sido probada en Pleurodema, dado que sólo hay información disponible sobre el número de huevos por puesta, y no sobre su tamaño; e.g., 3.000-5.000 huevos en P. brachyops (LeonOchoa \& Donoso-Barros 1969), 400-500 en P. thaul (Cei 1962a), 500-750 (Hödl 1992) ó 950 (Cardoso \& Arzabe 1993) en P. diplolister, 1277 (promedio) en P. borellii (Halloy $\&$ Fiaño 2000) y 300-3.000 en P. bufoninum (Weigandt et al. 2004).

Se han sugerido varias ventajas adaptativas en relación a las puestas en nidos de espuma comunales: i) generar un efecto de "manada egoísta", donde los individuos tienen menos probabilidades de ser depredados (Hamilton 1971 en Hödl 1992); ii) mejorar la termorregulación, dado que al aumentar la proporción masa/ superficie se incrementa la inercia térmica, de modo que los embriones de las masas más centrales se desarrollarían más rápidamente (Dobkin \& Gettinger 1985); iii) disminuir la depredación sobre los embriones (Menin \& Giaretta 2003); v) reducir la mortalidad de embriones o larvas gracias a ofrecerles protección frente a desecación y/ o depredación (Ryan 1985 en Giaretta \& Menin 2004; Zina 2006).

Sin embargo, hay varios puntos que restan ser aclarados respecto a este modo de ovispostura. Por un lado, sería interesante analizar cuándo estas especies ponen sus puestas en forma comunal, dado que se comprobó que es una propiedad facultativa en Physalamemus ephippifer (Hödl 1990) y Physalamemus marmoratus (Giaretta \& Menin 2004, citan la especie como Physalaemus cf. fuscomaculatus, pero 
su identidad correcta es Physalaemus marmoratus, Giaretta com. pers.). Esta capacidad podría estar relacionada con la forma/tamaño y el patrón de distribución de la vegetación de la charca (Giaretta \& Menin 2004). Por otro lado, especies que habitan zonas extremadamente frías (e.g. Lithobates sylvaticus, que habita Estados Unidos y Canadá) también ovipone en nidos de espuma comunales (Seale 1982); en consecuencia, las explicaciones globales relacionadas a evitar la desecación no se aplican a todos los casos.

En síntesis, en la literatura existen varias interpretaciones funcionales respecto al modo de reproducción mediante nidos de espuma ( $y$, cuando ocurren, a las puestas en nidos comunales); sin embargo, estos estudios no incluyen la totalidad de condiciones bajo las cuales los linajes de anuros desarrollaron esta modalidad reproductiva, sin olvidar que ésta ha sido tan exitosa como otras que se consideran más basales, como la puesta de huevos en ambientes lénticos.

Por su parte, las modalidades de reproducción de las dos especies de distribución más austral de Pleurodema también tienen sus particularidades, siendo influenciadas por condiciones ambientales. Pleurodema bufoninum tiene un patrón de reproducción estacional, comenzando su reproducción más tardíamente a mayores latitudes -en el norte de la Patagonia argentina se hallaron larvas a fines de diciembre y en el sur a fines de enero- (Weigandt et al. 2004). Además, la metamorfosis es más lenta que en especies de ambientes xéricos, durando entre $30 \mathrm{y}$ 45 días (Weigandt et al. 2004). Pleurodema thaul posee un ciclo sexual parcialmente continuo, siendo influenciado principalmente por el ciclo de temperatura anual y las Iluvias; en consecuencia, el ciclo reproductivo comienza cuando la temperatura decrece y las Iluvias aumentan (Díaz-Páez \& Ortiz 2001).

Es necesario realizar estudios que confirmen los modos de oviposición de las especies del género Pleurodema que presentan dudas (e.g., P. thaul, P. marmoratum) y determinar el modo de construcción de la puesta. Además, sería propicio establecer si todas las especies que construyen nidos de espuma pueden, potencialmente, realizar puestas comunales, interpretando las puestas comunales como un fenómeno donde se observen varias parejas oviponiendo sincronizadamente en el mismo sector de la charca, de modo de diferenciar una situación de falta de espacios propicios de reproducción respecto de un comportamiento simultáneo de varias parejas en amplexo.

Hasta donde sabemos, dentro de la familia Leiuperidae todas las especies de los géneros Edalorhina, Engystomops, Eupemphix y Physalaemus oviponen en nidos de 
espuma (Lynch 1971; Duellman \& Morales 1990; Schlüter 1990; Nascimento et al. 2005). Pseudopaludicola deposita los huevos individualmente o en pequeños grupos en el fondo de los charcos o adheridos a vegetación (Barrio 1953; Lynch 1970) y sus envolturas se pueden adherir entre sí sólo si varios huevos están muy cerca (Barrio 1953); posiblemente, por la misma razón que la expuesta para P. bufoninum, Basso (1990) describió que las puestas de P. falcipes están constituidas por masas gelatinosas adheridas a plantas de la orilla de pantanos o zanjas, sumergidas en el agua. Finalmente, Somuncuria coloca una masa gelatinosa fija a la porción sumergida de la vegetación emergente del cauce (Diminich 2006). De los siete géneros incluidos en la familia Leiuperidae, Pleurodema es el único que tiene más de una modalidad reproductiva, donde los huevos son depositados en (a) nidos de espuma, (b) cordones (flotantes o adheridos a vegetación) y (d) masa gelatinosa (flotantes o adheridos a vegetación). De todas estas modalidades, los nidos de espuma y los cordones adheridos a vegetación han sido observados en otros Leiupéridos, mientras que las modalidades restantes serían propias del género Pleurodema, de acuerdo al conocimiento actual.

Los caracteres 90-96 del análisis filogenético surgieron de la información presentada en este capítulo. 


\section{CAPÍTULO V}

\section{Análisis filogenético}

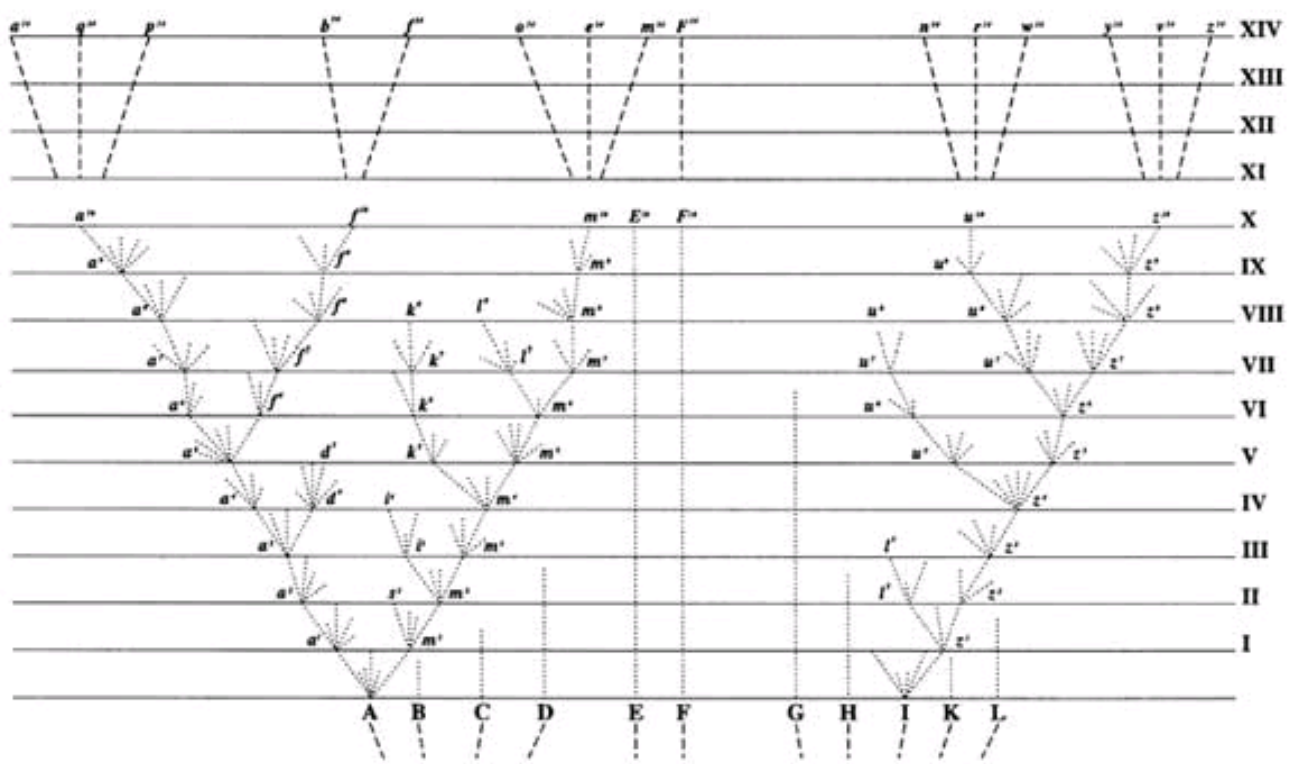

Tomado de Darwin (1859). (Única figura que ilustra "El origen de las especies...") 


\subsection{Caracteres seleccionados}

La siguiente lista de caracteres con la codificación correspondiente fue utilizada para llevar a cabo el estudio filogenético de las especies del género Pleurodema. Cuando se encontraron discrepancias con las descripciones previas de la literatura, se realizó un comentario para el carácter correspondiente.

\subsubsection{Caracteres exo-morfológicos}

(0) Posición de las narinas

0 : Entre el hocico y el ojo

1: En el extremo del hocico

\section{(1) Membrana timpánica (Fig. 23)}

0: Membrana timpánica diferenciable como una porción de piel más adelgazada

1: Membrana timpánica reducida, siendo diferenciable sólo su porción ventral

2: Membrana timpánica ausente; la piel de la región auditiva no presenta diferencias con la del resto del flanco del cuerpo

\section{(2) Pliegue supratimpánico (Fig. 23)}

0 : ausente

1: presente

(3) Glándula postcomisural (Fig. 23)

0 : ausente

1: presente

\section{(4) Glándula parotoidea (Fig. 23)}

0 : ausente

1: presente

Cannatella \& Duellman (1984) propusieron que una de las sinapomorfías del grupo pustulosus del género Physalaemus (actualmente género Engystomops sensu Nascimento et al. 2005) es la presencia de una glándula parotoidea desarrollada. Esta condición fue hallada, además, en Pleurodema bufoninum.

\section{(5) Tubérculo antebraquial}

0 : ausente

1: presente 
Lobo (1995, carácter 2) estableció que una de las sinapomorfías de Pseudopaludicola es el antebrazo con tubérculo hipertrofiado, carácter observado en las especies del género incluidas en el presente análisis. Originariamente, este carácter fue uno de los empleados en la diagnosis del género (Miranda-Ribeiro 1926).

(6) Glándulas en la zona sacra del cuerpo (Fig. 23)

0: Glándulas ausentes

\section{1: Glándulas presentes}

Dentro de la familia Leiuperidae, cuatro de los siete géneros poseen un par de macroglándulas dorsolaterales en la región sacra del cuerpo (Edalorhina, Pleurodema, Physalaemus y Somuncuria). Si bien no está claramente establecida su función, estas glándulas podrían estar relacionadas con mecanismos de defensa (Toledo \& Jared 1995; Toledo et al. 1996), dado que se ha observado que los individuos, al ser molestados, levantan los cuartos traseros del cuerpo, descienden la cabeza y exponen las glándulas. Este carácter hace referencia a la manifestación externa (i.e. macroscópica) de los acúmulos de glándulas granulosas, dado que en especies de Pleurodema carentes de glándulas prominentes se han detectado acúmulos de glándulas granulosas en la piel de la región lumbar (Mangione \& Lavilla 2004).

\section{(7) Posición de las glándulas en la zona sacra del cuerpo (Fig. 23)}

0: Glándulas de posición inguinal (cuando el animal está en reposo, las glándulas quedan parcialmente ocultas por los miembros posteriores)

1: Glándulas de posición lumbar (cuando el animal está en reposo, las glándulas quedan totalmente visibles)

\section{(8) Coloración de las glándulas sacras (Fig. 23)}

0 : Del mismo color que el dorso

1: Con una mancha oscura central

2: Con una mancha oscura y pequeñas pústulas blancas

(9) Reborde cutáneo en los dedos del miembro posterior (Fig. 24)

0 : ausente

1: presente

(10) Desarrollo de estructuras cutáneas en el tarso (Fig. 24) 
$0:$ Ausencia de pliegue tarsal

1: Presencia de pliegue tarsal

En algunas especies se observa en el tarso un pliegue tarsal bien conspicuo (e.g., Leptodactylus ocellatus), en tanto en otras, el engrosamiento dérmico es más débil (e.g., Pleurodema kriegi). Dado que el gradiente entre un pliegue "poco" o "muy" desarrollado no es claramente discernible, he optado por considerar sólo la presencia de algún tipo de engrosamiento dérmico en el borde cantal del tarso.

\section{(11) Tubérculo metatarsal interno (Fig. 24)}

0 : No comprimido

1: Comprimido

\section{(12) Tubérculo tarsal (Fig. 24)}

0 : ausente

1: presente

(13) Patrón de coloración dorsal en la región intraescapular (Fig. 25)

0: Región intraescapular con el mismo diseño de coloración que el resto de la región dorsal

1: Región intraescapular con manchas oscuras en forma de W

(14) Patrón de coloración dorsal: Línea vertebral bien definida (Figs. 9 E-F; 25)

0 : ausente

1: presente

(15) Patrón de coloración en zona oculta de los fémures en animales vivos (Fig. 23, 25)

0 : Coloración similar a la de los flancos del cuerpo

1: Coloración parda

2: Coloración amarillo-anaranjada

3: Coloración violácea

4: Coloración rojiza (“coloración flash”)

(16) Patrón de coloración en el labio superior (Fig. 9 E-F, 23) 
0: Labio superior sin un diseño de pigmentación particular, sin manchas o con manchas irregulares

1: Labio superior con varias barras verticales

2: Labio superior con una banda oscura en sentido antero-posterior

\section{(17) Textura de la piel de la región dorsal (Fig. 25)}

0: Piel dorsal lisa

1: Piel dorsal con pequeños gránulos

2: Piel dorsal con verrugas y tubérculos

3: Piel dorsal con pliegues glandulares longitudinales

Cannatella \& Duellman (1984) propusieron que una de las sinapomorfías del grupo pustulosus del género Physalaemus (actualmente género Engystomops sensu Nascimento et al. 2005) es la piel dorsal con verrugas y tubérculos. Esta condición no fue hallada en ninguna otra especie de Leiuperidae utilizada en el presente análisis, aunque en Odontophrynus americanus se consideró el mismo estado.

\section{(18) Reborde cutáneo en la abertura de la cloaca (Fig. 24)}

0 : ausente

1: presente

Lynch (1971) describió que Pleurodema nebulosum poseía un "fimbriated anal flap" no observado en ninguna otra especie. Esta estructura también la observé en Pleurodema guayapae (especie no examinada por Lynch).

\subsubsection{Caracteres osteológicos}

Los caracteres de este set de datos han sido ordenados de modo que faciliten su comparación. Se listan los caracteres de cráneo (en vistas anterior, dorsal, ventral, lateral y posterior), esqueleto axial y esqueleto apendicular.

\section{Vista anterior del cráneo}

\section{(19) Forma del borde libre de los procesos alares del maxilar}

0 : Procesos alares con borde libre indiviso

1: Procesos alares con borde libre bifurcado

\section{Vista dorsal del cráneo}

(20) Forma de los nasales (Fig. 26)

0 : En forma de media luna 
1: Claviformes, con el proceso maxilar afinado

2: Romboidales (bordes medial y lateral con sus extremos anteriores confluyentes)

\section{3: Triangulares}

Como indicó Scott (2005), este carácter es generalmente difícil de codificar y, siguiendo el criterio de la autora, sólo se ha considerado la forma del hueso y no su orientación.

\section{(21) Distancia entre los márgenes mediales de los nasales (Fig. 26)}

0 : Márgenes mediales separados

1: Márgenes mediales próximos entre sí, alineados, en algunos casos contiguos

Lynch (1971), en la diagnosis de Pleurodema, describió los nasales en contacto. En el material examinado del género nunca observé esta condición, dado que los nasales están siempre separados entre sí.

\section{(22) Relación entre nasales y esfenoetmoides (Fig. 26)}

0: Nasales no superpuestos al esfenoetmoides

1: Nasales superpuestos al esfenoetmoides

2: Esfenoetmoides superpuesto a los nasales

Lynch (1971), en la diagnosis de Pleurodema, señala que el esfenoetmoides se desarrolla superando el borde posterior de los nasales. De acuerdo con Scott (2005, carácter 62) este carácter podría estar influenciado por el grado de desarrollo de los especimenes; de todos modos, en la codificación de caracteres sólo utilicé ejemplares adultos. Dentro de los grupos interno y externo observé que el esfenoetmoides en algunos casos supera el borde posterior de los nasales y en otros casos no.

En el caso de Pleurodema marmoratum, observé que es el hueso esfenoetmoides es el que se superpone a los nasales.

\section{(23) Crista supraorbitalis del esfenoetmoides (Fig. 26)}

0: Presente

1: Ausente

La crista supraorbitalis (Jurgens 1971) es una pequeña saliencia del esfenoetmoides que se proyecta sobre la órbita.

(24) Bordes externos de los frontoparietales (Fig. 27) 
0 : Convergentes en su porción anterior

1: Paralelos o subparalelos en su porción anterior

\section{(25) Forma de los frontoparietales (Figs. 27-28)}

0: Frontoparietales con sus bordes mediales separados, sin contactar entre sí, fenestra frontoparietal subyacente totalmente expuesta (ocasionalmente puede existir una zona de contacto medial entre los frontoparietales, pero si ocurre es posterior a la fenestra)

1: Frontoparietales con sus bordes mediales separados, contactando entre sí irregularmente; fenestra frontoparietal subyacente parcialmente expuesta, debido al contacto irregular de los frontoparietales (e.g. CENAI 6204 P. bibroni)

2: Frontoparietales con sus bordes mediales paralelos y alineados en toda su extensión; fenestra frontoparietal subyacente expuesta a través de una fontanela frontoparietal angosta (e.g. FML 1281 macho de P. cuqui; MZUSP 38280, P. diplolistris)

3. Frontoparietales con sus bordes mediales paralelos y en contacto medial en toda su extensión; fenestra frontoparietal y fontanela frontoparietal no expuestas

4: Frontoparietales cuya porción más cefálica presente los bordes mediales subparalelos, separados entre sí y de ancho regular; en tanto la porción parietal está fusionada medialmente; fenestra frontoparietal expuesta (B. leptopus, CENAI 1830)

En los anuros actuales, el cerebro está protegido por una caja craneana (endocráneo) que permanece abierta dorsalmente anterior al tectum synoticum, conformando la fenestra frontoparietal. Los frontoparietales son huesos dérmicos, elongados en sentido rostro-caudal, que forman gran parte del exocráneo posterior a las órbitas. Cuando los frontoparietales no entran en contacto medial, queda delimitada la fontanela frontoparietal (Roček1980). En síntesis: se entiende por fenestra frontoparietal a la abertura a nivel endocondral y fontanela frontoparietal a aquella formada entre huesos dérmicos (contra Trueb 1973: 74, 89).

Lynch (1971), en la diagnosis de Pleurodema, indica fontanela frontoparietal larga. En algunas especies del grupo externo los frontoparietales tienen sus márgenes mediales alineados en toda su extensión (e.g. Engystomops pustulosus), condición considerada por varios autores como "fontanela frontoparietal no expuesta" (Nascimento et al. 2005). En Physalaemus observé el estado 2 en todas las especies excepto en $\mathrm{P}$. fernandezae y $\mathrm{P}$. henselii, que poseen estado 0 . Estas observaciones no 
coinciden con las de Lynch (1970), quien describe ausencia de fontanela en todo el género, pero están en acuerdo con Nascimento et al. (2005), quienes describen fontanela presente en ambas especies (aunque sin cuantificar el grado de exposición). Lobo (1992) y Nascimento et al. (2005) definen fontanela ausente en P. cuqui (como P. albonotatus en Lobo 1992) y P. cuvieri; en el presente trabajo considero que la fenestra está expuesta en toda la extensión de los frontoparietales, aunque sea angosta y notablemente diferente de la observada en de otras especies, e.g. Pleurodema bufoninum (Fig. 27a). En Engystomops y Eupemphix la fontanela no está expuesta según Nascimento et al. (2005), coincidentemente con mis observaciones.

En Leptodactylus latinasus asigné el estado 1 siguiendo a Ponssa (2008, carácter 46), dado en el material preparado no pude observar el tectum synoticum, con lo cual no pude establecer si la fenestra frontoparietal está total o parcialmente expuesta.

\section{(26) Borde posterior de los frontoparietales (Fig. 27)}

0: Cóncavo

1: Recto

3: Convexo

4: en V

Ponssa (2008, carácter 48) consideró que una de las sinapomorfía del género Leptodactylus es el borde posterior de los frontoparietales recto, lo cual fue observado en las especies del género incluidas en el presente análisis.

\section{(27) Superposición de los frontoparietales al margen anterior de los exoccipitales (Fig. 27)}

0 : Los frontoparietales se superponen al margen anterior de los exoccipitales.

1: Los frontoparietales no se superponen al margen anterior de los exoccipitales.

Nascimento et al. (2005) describieron que en Physalaemus y Engystomops los frontoparietales se superponen al margen anterior de los exoccipitales, mientras que en Eupemphix ocurre lo contrario. En el material examinado, observé que en los tres géneros hay superposición, y codifiqué de acuerdo con mis observaciones.

\section{(28) Relación entre exoccipitales y proóticos (Fig. 27)}

0 : Ambos huesos independientes

1: Ambos huesos fusionados en un complejo otoccipital 


\section{(29) Orientación de la columela respecto al eje axial}

0: La columela forma un ángulo de unos $90^{\circ}$ con el eje axial

1: La columela forma un ángulo de unos $45^{\circ}$ (o menos) con el eje axial

\section{Vista ventral del cráneo}

\section{(30) Desarrollo de la pars palatina del premaxilar (Fig. 29)}

0: Pars palatina del premaxilar con desarrollo moderado, con su eje mayor paralelo o subparalelo a la pars dentalis del premaxilar

1: Pars palatina expandida hacia la cavidad bucal, con su eje mayor perpendicular a la pars dentalis del premaxilar, separada del proceso palatino por un seno pronunciado

\section{(31) Dientes premaxilares (Fig. 29)}

0 : Presentes

\section{1: Ausentes}

Lynch (1970) y Cannatella \& Duellman (1984) describieron que Physalaemus pustulosus y E. nattereri carecen de dientes premaxilares (dentro del grupo de especies incluidas en el presente estudio).

\section{(32) Dientes maxilares (Fig. 29)}

0 : Presentes

1: Ausentes

Dentro del grupo de estudio, todas las especies poseen dientes maxilares, excepto Eupemphix nattereri y Engystomops pustulosus.

\section{(33) Lámina horizontalis del maxilar (Fig. 29)}

0 : Ausente

1: Presente

El maxilar puede poseer una delgada lámina desarrollada a lo largo de su extensión, dispuesta paralelamente al plano dorso-ventral del cráneo. Esta nomenclatura sigue a Sanchiz (1998).

(34) Proceso dentígero en el vómer (Fig. 29)

0: Presente 


\section{1: Ausente}

Cannatella \& Duellman (1984) propusieron que una de las sinapomorfías del grupo pustulosus del género Physalaemus (actualmente género Engystomops sensu Nascimento et al. 2005) es la presencia de un proceso dentígero del vómer delgado. Aquí sólo consideré la presencia del proceso y no la forma, dado que una sola especie de Engystompos fue incluida y sería un carácter no informativo.

\section{(35) Cantidad de dientes vomerinos (Fig. 29)}

$0:$ Ninguno

1: Hasta 7 dientes

2: Entre 8 y 13

La presencia o ausencia de dientes vomerinos es muy empleada en la identificación de anuros. Parker (1927) describe dientes vomerinos ausentes en Pseudopaludicola, usualmente ausentes en Physalaemus y presentes o ausentes en Pleurodema. De acuerdo con Nascimento et al. (2005), en Physalaemus, Engystomops y Eupemphix los dientes vomerinos están ausentes, característica que los diferencia de Pleurodema. Con respecto a Physalaemus biligonigerus, Parker (1927), Milstead (1963) y Barrio (1965) señalan que carece de dientes vomerinos; Lynch (1970) indica que la especie a veces los posee; y Cannatella \& Duellman (1984) describen que en 14 esqueletos examinados (incluido el material empelado por Lynch) nunca observaron dientes vomerinos. En el material examinado en el presente trabajo no observé dientes vomerinos en $\mathrm{P}$. biligonigerus (estado 0 ).

Por otro lado, algunas de especies de Pleurodema (no examinadas por Nascimento et al. [2005]) carecen de dientes vomerinos (e.g. P. bibroni, P. kriegi, P. cordobae [en espécimen no transparentado MACN 39911], $P$. guayapae, $P$. nebulosum y $P$. marmoratum), con lo cual este carácter no es útil para diferenciar ambos géneros.

La codificación aquí utilizada es similar a la de Ponssa (2008, carácter 63), quien consideró que una de las sinapomorfía del género Leptodactylus es la presencia de entre 8 y 13 dientes vomerinos, lo cual fue observado en las especies del género incluidas en el presente análisis.

\section{(36) Posición de los dientes vomerinos (Fig. 29)}

0 : Conforman dos series de posición irregular

1: Conforman dos series alineadas transversalmente al eje axial

2: Conforman dos series oblicuas

3: Conforman dos series arqueadas 


\section{(37) Proceso postcoanal del vómer}

0: Dirigido dorsalmente

1: En el mismo plano que el resto del hueso

(38) Proceso posterior del vómer (Fig. 29)

0 : Presente

1: Ausente

Heyer (1969a) propuso que uno de los caracteres diagnósticos de Leptodactylus era la ausencia de proceso posterior del vómer; confirmado en el presente trabajo en las tres especies de Leptodactylus incluidas.

\section{(39) Vómer con foramen para la salida de la rama palatina del nervio facial}

0 : Foramen ausente

1: Foramen presente

(40) Relación entre vómeres y palatinos (Fig. 29)

0 : No contactan

1: Vómeres superpuesto a los palatinos

Ponssa (2008, carácter 66) consideró que una de las sinapomorfía del género Leptodactylus es la superposición del vómer al palatino, lo cual fue observado en las especies del género incluidas en el presente análisis.

\section{(41) Relación entre palatinos y esfenoetmoides (Fig. 30)}

0 : Palatinos superpuestos al esfenoetmoides

1: Palatinos no superpuestos al esfenoetmoides

Lynch (1971) describe que estos huesos están en contacto en Pleurodema y Pseudopaludicola, levemente separados en Batrachyla, Eupsophus, Hylorina y Physalaemus y moderadamente separados en Edalorhina; sin embargo, no es uno de los caracteres empleados por el autor para diagnosticar taxones. En todo el material de Pleurodema examinado (excepto un ejemplar de P. kriegi, CENAI 5170) observé la condición descrita por el autor.

(42) Contacto entre la rama anterior de los pterigoides y los palatinos (Fig. 30)

0: Rama anterior del pterigoides contactando con los palatinos

1: Rama anterior del pterigoides sin contactar con los palatinos 
En acuerdo con Lynch (1971), observé que en Pleurodema la rama anterior de los pterigoides alcanza los palatinos.

(43) Contacto entre la rama media del pterigoides y las alas del paraesfenoides (Fig. 30)

0 : Presente

1: Ausente

En acuerdo con Lynch (1971), observé que ninguna especie de Pleurodema presenta la rama media del pterigoides en contacto con las alas del paraesfenoides.

\section{(44) Desarrollo anterior del esfenoetmoides en vista ventral (Fig. 30)}

0 : No alcanza el nivel de los palatinos

1: Alcanza el nivel de los palatinos

2: Supera el nivel de los palatinos, pero sin ingresar en el espacio entre los vómeres

3: Supera el nivel de los palatinos ingresando en el espacio entre los vómeres

(45) Extremo anterior del paraesfenoides (Fig. 30)

\section{0: Agudo}

1: Irregular o romo

\section{(46) Forma del proceso cultriforme del paraesfenoides (Fig. 30)}

0 : Proceso cuyo ancho se va adelgazando gradualmente hacia la región anterior

1: Proceso de ancho uniforme

2: Proceso más ancho en la región medial, y más adelgazado en las regiones anterior y posterior

Dentro del estado 0 observé cierta variabilidad, dado que en algunos individuos la base del proceso cultriforme también está relativamente adelgazada (e.g. Pleurodema kriegi) y en otros el proceso se afina regularmente (e.g. Physalaemus henselii). Sin embargo, a veces esa diferenciación no es del todo clara, por lo cual preferí incluirla dentro del gradiente de variaciones del estado 0 , el cual sí es claramente diferenciable del estado 1.

\section{(47) Exoccipitales (Fig. 30)}

0 : Fusionados ventralmente

1: Separados por cartílago 


\section{(48) Márgenes del foramen proótico (Fig. 31)}

0: Márgenes del foramen proótico cartilaginosos

1: Márgenes del foramen proótico rodeados parcialmente por el hueso proótico

2: Márgenes del foramen proótico rodeados completamente por el hueso proótico

Los huesos proóticos, ubicados en la pared posterior de la órbita, delimitan los forámenes por los cuales salen los nervios craneanos que inervan la musculatura extrínseca del ojo y la de la región orbitaria. Lobo (1996) describió tres variaciones en relación al modo en que el hueso proótico se extiende entre los forámenes proótico y óptico (= llamado oculomotor por el autor). Aquí seguí el criterio de Lobo (1996) pero con modificaciones que permiten una definición más apropiada de los estados de carácter.

\section{(49) Cuadradoyugal (Fig. 32)}

0: Cuadradoyugal desarrollado, en contacto con el maxilar (arcada maxilar completa)

1: Cuadradoyugal desarrollado, sin contactar el maxilar (arcada maxilar incompleta) con proceso maxilar desarrollado

2: Cuadradoyugal ausente, siendo visible sólo el cuadrado osificado

La ausencia de cuadradoyugal ha sido considerada como uno de los caracteres diagnósticos del género Pleurodema, utilizado por primera vez por Parker (1927) en su diferenciación de dicho género respecto de Physalaemus y Pseudopaludicola (véase Sección "Síntesis histórica del género Pleurodema") y luego repetido por otros autores (e.g. Vellard 1960; Lynch 1971; Cei 1980a). Frecuentemente el cuadradoyugal se encuentra reducido, ocurriendo este proceso en dirección anteroposterior (Trueb 1973), y es probable que su grado de reducción haya acarreado discrepancias y confusiones en la interpretación de la presencia y desarrollo de este hueso y del cuadrado.

Lobo (1994) en su revisión del género Pseudopaludicola determinó, de acuerdo a la observación de cortes histológicos de Pseudopaludicola boliviana (FML 4310), la presencia de cuadradoyugal en el género, aunque sin aclarar qué criterio utilizó para determinar que se trata de dicho hueso. Lobo (1994: 188) describió cuatro estados presentes en Pseudopaludicola en relación a este hueso y su proceso maxilar: a) Proceso maxilar del cuadradoyugal presente (e.g. P. falcipes); b) Proceso maxilar del cuadradoyugal reducido (e.g. P. mystacalis, pudiendo faltar en algunos ejemplares de esta especie); c) Proceso maxilar del cuadradoyugal ausente (e.g. P. boliviana); y 
d) Cuadradoyugal ausente. En conclusión, en las tres especies de Pseudopaludicola incluidas en el presente estudio, el cuadradoyugal está presente, aunque con diferentes grados de desarrollo de su proceso maxilar. Lobo (1994) asignó el estado ' $d$ ' a Pleurodema cinereum y el estado ' $a$ ' a las especies de Physalaemus estudiadas.

Por su parte, Nascimento et al. (2005) definen a los géneros Physalaemus, Eupemphix y Engystomops por una combinación de caracteres; uno de ellos es 'presencia de un proceso maxilar del cuadradoyugal desarrollado'. Los autores diferencian estos tres géneros de Pseudopaludicula y Pleurodema, indicando -entre otros caracteres- que Pseudopaludicula carece de proceso maxilar del cuadradoyugal y Pleurodema carece de cuadradoyugal.

Con respecto a su origen, el cuadradoyugal es uno de los huesos que aparecen más tardíamente, al final de la metamorfosis o incluso justo después de finalizada la misma (Roček 2003). De acuerdo con de Villiers (1936) y Stephenson (1961), el cuadradoyugal surge como una osificación que se fusiona con el cartílago quadratum, el cual más tarde se osifica. El desarrollo del condrocráneo de Heleophryne purcelli fue descripto por van der Westhuizen (1961) quien observó una osificación endocondral, aunque sin poder determinar si corresponde a un verdadero cuadrado 0 al cuadradoyugal. Esta osificación invade el cartílago cuadrado, lo cual ocurre en las mayoría de los anuros de acuerdo con van der Westhuizen (1961). Alcalde (2007) estudió secuencias de desarrollo de los géneros Hylorina y Batrachyla, no habiendo hallado un centro de osificación que corresponda al cuadradoyugal, aunque en ejemplares adultos de estos géneros observó una sutura (a veces no muy conspicua) entre el hueso cuadrado y la proyección anterior del mismo, lo cual podría corresponder al cuadradoyugal (véase página 50 y discusión del carácter 21 en Alcalde [2007] sobre la presencia de cuadradoyugal en Batrachyla). Sin embargo, hasta no contar con secuencias de desarrollo postmetamórficas, el autor prefirió considerar ausente el cuadradoyugal en las cinco especies de Batrachyla y en Hylorina sylvatica, Atelognathus patagonicus y Pleurodema borellii.

De acuerdo a lo anteriormente expuesto, debemos diferenciar dos situaciones. Por un lado, establecer fehacientemente la presencia de cuadradoyugal diferenciado de hueso cuadrado, y por otro lado, el grado de desarrollo del cuadradoyugal. Respecto a la primera cuestión, y siguiendo los criterio de Roček (2003) y Alcalde (2007), debemos contar con series completas de desarrollo post-metamórficas para poder determinar si existe un centro de osificación correspondiente al cuadradoyugal, especialmente en aquellos ejemplares con arcada maxilar incompleta, en los cuales surgen mayormente las discrepancias. Luego, una vez que 
podamos establecer con certeza la presencia de este hueso, podremos evaluar su grado de desarrollo.

En el presente trabajo se consideró presente al cuadradoyugal cuando se observó un elemento óseo ubicado lateralmente a la rama ventral del escamoso con un proceso maxilar diferenciado, contacte éste o no con el maxilar. No se hará referencia a cuadradoyugal 'reducido' o 'fuertemente reducido' (véase por ejemplo Lavilla \& Lobo 1992; Basso 1994), si no sólo a su presencia o ausencia.

Con respecto al grupo de estudio, para todas las especies de Pleurodema, tanto adultos como juveniles (aunque estos últimos no fueron utilizados en la codificación), siempre se observó un elemento óseo en la zona ventral del escamoso, interpretado como hueso cuadrado, considerándose ausente el cuadradoyugal.

En relación a los grupos externos, corresponde realizar algunas aclaraciones. En la única especie de Engystomops analizada en el presente trabajo (E. pustulosus), no observé cuadradoyugal con proceso maxilar como señalaron Nascimento et al. (2005), si no solamente un elemento óseo (sin suturas) interpretado como hueso cuadrado.

En el género Pseudopaludicola, sí fue observado cuadrado con proceso maxilar en P. falcipes, como señala Lobo $(1994 ; 1995)$, mientras que en P. boliviana observé un único elemento óseo interpretado aquí como cuadrado, aunque Lobo (1994: 155) describe “...rama posterior [del escamoso] apoyada sobre el cuadrado, el cual se conserva cartilaginoso. Cuadradoyugal muy reducido, sin proceso anterior dirigido al maxilar...". Sin embargo, de acuerdo a lo discutido precedentemente y hasta tanto contemos con un criterio preciso para establecer la presencia de este hueso, consideré cuadradoyugal ausente en $\mathrm{P}$. boliviana.

En Batrachyla leptopus observé un proceso maxilar corto, con lo cual considero que existe cuadradoyugal diferenciado (contra Alcalde 2007).

Por último, cabe considerar la clasificación de Lehr \& Trueb (2007), quienes diferenciaron la presencia/ausencia del cuadradoyugal respecto de su contacto o no con el maxilar, definiendo así una arcada maxilar completa o incompleta, respectivamente. Este carácter fue considerado aditivo.

\section{(50) Articulación cráneo-mandibular}

0: Posterior a un línea imaginaria transversal formada en la intersección de los procesos alares y el proceso cultriforme del paraesfenoides

1: Anterior (o al mismo nivel) a un línea imaginaria transversal formada en la intersección de los procesos alares y el proceso cultriforme del paraesfenoides 
Nascimento et al. (2005) describieron que en Physalaemus la articulación cráneomandibular nunca es anterior al plano transversal formado por la intersección entre los procesos alares y el proceso cultriforme del paraesfenoides, mientras que en Eupemphix y Engystomops, la articulación es anterior a dicho plano. En el material examinado, en todas los individuos de Pleurodema la articulación es posterior, al igual que en todas las Phyasalaemus. En Eupemphix nattereri la articulación es anterior, mientras que en Engystomops pustulosus es levemente anterior a dicho plano (en acuerdo con Nascimento et al. 2005). Se siguieron las observaciones propias al codificar.

\section{Vista lateral del cráneo}

(51) Orientación de los procesos alares del premaxilar

0 : Orientados verticalmente

1: Orientados postero-dorsalmente

2: Orientados hacia adelante

Lynch (1971), en la diagnosis de Pleurodema, indica que los procesos alares están dirigidos postero-dorsalmente. Dentro del género se observó que en algunas especies se dirige verticalmente sin inclinación posterior. El estado 2 lo observé en algunas especies de Physalaemus y en Engystomops pustulosus.

(52) Grado de desarrollo de la rama zigomática del escamoso (Fig. 33)

0 : Bien desarrolla

1: Reducida

2: Ausente

Lynch (1971), en la diagnosis de Pleurodema, describe la rama zigomática del escamoso relativamente corta. En el presente trabajo observé los estados 0 y 1 e las diferentes especies de Pleurodema, excepto en Pleurodema guayapae y P. nebulosum, únicas dos especies del grupo de estudio con estado 2.

\section{(53) Proceso timpánico de la rama zigomática del escamoso (Fig. 33)}

\section{0 : Ausente}

\section{1: Presente}

Este carácter, descripto por Lobo (1994), ha sido observado únicamente en las tres especies de Pseudopaludicola incluidas en el presente trabajo, pero no es una sinapomorfía de este género, dado que el proceso está ausente en varias especies no incluidas en el presente estudio (Lobo 1995, carácter 6). 
(54) Grado de desarrollo de la rama ótica del escamoso (Fig. 33)

0 : Bien desarrollada

1: Reducida

Lynch (1971), en la diagnosis de Pleurodema, describe rama ótica levemente más larga que la zigomática. En el presente trabajo observé que la rama zigomática es apenas más larga o subigual a la rama ótica, resultando muy difícil cuantificar estas diferencias, considerando además que la rama zigomática también sufre diferentes grados de reducción (véase carácter 57). Por lo tanto, se prefirió considerar sólo su grado de desarrollo. En la mayoría de las especies incluidas en este trabajo la rama ótica del escamoso está bien desarrollada, pero en P. guayapae, P. nebulosum y P. tucumanum está claramente reducida en tamaño.

(55) Ancho de la rama ótica del escamoso respecto a la rama zigomática, cuando la rama ótica está bien desarrollada (Fig. 33)

0: Rama ótica del escamoso más ancha que la rama zigomática

1: Rama ótica del escamoso del mismo ancho que la rama zigomática

2: Rama ótica del escamoso más angosta que la rama zigomática

Ponssa (2008, carácter 68 ) consideró que una de las sinapomorfía del género Leptodactylus es la rama ótica del escamoso del mismo ancho que la rama zigomática, lo cual fue observado en las especies del género incluidas en el presente análisis.

Para la especies con rama ótica del escamoso reducida (i.e. P. guayapae, P. nebulosum y $\mathrm{P}$. tucumanum, carácter 58:1) este carácter se consideró inaplicable.

(56) Relación entre la rama ótica del escamoso y la crista parótica (Fig. 33)

0: La rama ótica del escamoso no contacta con la crista parótica

1: La rama ótica del escamoso contacta la crista parótica

Faivovich (2002, carácter 4), en su análisis filogenético de Scinax (Hylidae), discute el grado de contacto entre la rama del escamoso y la región osificada de la crista parótica. Sin embargo, en la mayoría de las especies incluidas en el este trabajo la rama ótica del escamoso contacta con la porción cartilaginosa distal de la crista parótica, excepto en Leptodactylus ocellatus, Odontophrynus americanus y Eupsuphus calcaratus, donde se observó un contacto directo entre el escamoso y la porción ósea de la crista parótica. 
Los caracteres 58 y 60 han sido tratados independientemente dado que la reducción o no de la rama ótica del escamoso no afecta la posibilidad de que dicha región contacte con la crista parótica (véase codificación resultante para $P$. guayapae, P. nebulosum y P. tucumanum).

\section{(57) Ocurrencia de la Columela (Fig. 33)}

0 : Columela presente

1: Columela ausente

Dentro del grupo de estudio, Alsodes gargola no posee columela.

\section{(58) Desarrollo del anillo timpánico (Fig. 33)}

0 : Anillo timpánico presente

1: Anillo timpánico ausente

Dentro del grupo de estudio, Alsodes gargola no tiene desarrollado el anillo timpánico.

Los caracteres 56 y 57 han sido tratados independientemente dado que, en Anura, existen especies que carecen de anillo timpánico pero no de columela.

(59) Morfología del anillo timpánico, cuando está presente (Fig. 33)

0: Anillo timpánico completo

1: Anillo timpánico incompleto dorsalmente

(60) Forma de la porción distal de la extracolumela (Fig. 33)

0: Extracolumela no expandida distalmente

1: Extracolumela notablemente expandida distalmente

\section{Vista posterior del cráneo}

(61) Proceso caudal de la columela (Fig. 19)

0 : Ausente

1: Presente

En casi todas las especies del grupo interno y en varias del grupo externo observé que la columela, en su contacto con el opérculo, posee una expansión ventral de forma cuadrangular, distinguible claramente en una vista posterior del cráneo. Este proceso fue llamado proceso caudal siguiendo la nomenclatura de Mason (2006, véase fig. 6.3). 


\section{Esqueleto hiolaríngeo}

(62) Procesos anteromediales del hioides (Fig. 34)

0: Ausente

1: Presente

Este proceso se encuentra desarrollado en algunas de las especies en estudio. En Eupsophus calcaratus se observó que, además de estar desarrollado, entra en contacto con el proceso hial del hioides. Esta variación no la consideré como un estado más porque sólo la observé en $\mathrm{E}$. calcaratus, constituyéndose, para el grupo de estudio, en un estado de carácter no informativo.

\section{(63) Procesos anterolaterales del hioides (Fig. 34)}

0 : Unidos por un tallo a la placa hial

1: Dilatados en su unión con la placa hial

2: No se diferencia placa hial de los procesos anterolaterales

Lynch (1971), en la diagnosis de Pleurodema, describe procesos alares (= procesos anterolaterales) unidos por un tallo a la placa hial, lo cual fue corroborado en el material examinado, excepto en $\mathrm{P}$. bibroni y $\mathrm{P}$. nebulosum, donde algunos ejemplares presentan la base de los procesos dilatada. Lobo (1995) estableció que una de las sinapomorfías de Pseudopaludicola es el hioides y los procesos alares (= procesos anterolaterales) expandidos en una sola placa (aquí estado 2), lo cual fue corroborado en el presente trabajo. Este carácter fue considerado aditivo.

\section{(64) Procesos hiales del hiodes (Fig. 34)}

0 : Con la región medial ensanchada

1: Del mismo ancho en toda su extensión

\section{(65) Seno hiogloso del hioides (Fig. 34)}

0: Sobrepasa una línea imaginaria (transversal) que une los bordes anteriores de los procesos alares

1: No sobrepasa una línea imaginaria (transversal) que une los bordes anteriores de los procesos alares

Este carácter ha sido modificado de Scott (2005, carácter 88 ).

\section{(66) Forma del hioides (Fig. 34)}

0 : Ancho mayor o igual que el largo 
1: Angosto, ancho menor que el largo

Este carácter ha sido modificado de Scott (2005, carácter 91).

(67) Orientación del proceso bronquial del cricoides (Fig. 35)

0: Subparalelo a la placa hioidea

1: Dirigido ventralmente

2: Dirigido dorsalmente mediante una curvatura

(68) Extensión de los procesos bronquiales del cricoides (Fig. 34)

0: No alcanzan la línea imaginaria formada por el borde distal del aritenoides

1: Alcanzan la línea imaginaria formada por el borde distal del aritenoides

2: Alcanzan el proceso esofágico del cricoides

3: Sobrepasan el proceso esofágico del cricoides

(69) Expansión distal del proceso bronquial del cricoides (Fig. 34)

0: Distalmente no expandido

1: Distalmente expandido y ramificado, envolviendo los pulmones

\section{(70) Proceso esofágico del cricoides (Fig. 34)}

0 : Ausente

1: Presente

(71) Grado de desarrollo del proceso esofágico del cricoides (Fig. 34)

0: Desarrollo moderado, observable como una saliencia posterior

2: Desarrollo hipertrofiado

\section{(72) Forma del cricoides en vista dorsal en machos}

0: Ovalado

1: Ovalado, con una proyección dorsal y una constricción lateral

2: Ovalado, con una proyección dorsal y sin constricción lateral

3: Subtriangular

Dado que en algunas especies de Physalaemus (e.g. P. cuvieri, P. cuqui) se observó variación entre machos y hembras, este carácter se codificó sólo para machos.

(73) Desarrollo del cricoides en vista ventral en machos (Fig. 34) 
0: Desarrollo normal

1: Desarrollo hipertrofiado

Lobo (1996) describe que el cricoides en machos de Physalaemus cuvieri y Physalaemus cuqui (como Physalaemus albonotatus, véase Lobo 1993) se encuentra hipertrofiado y considerablemente expandido en sentido antero-posterior. Esta condición sólo fue observada en estas dos especies del grupo en estudio, además de Physalaemus albonotatus y Engystomops pustulosus.

\section{(74) Forma del proceso cardíaco del cricoides}

0 : En forma de $U$, con las dos proyecciones cefálicas muy próximas entre sí

1: En forma de $U$, con las dos proyecciones cefálicas separadas entre sí por un ancho seno

2: En forma de W

3: Laminar

Este carácter ha sido modificado de Faivovich (2002, carácter 13).

\section{Cintura pectoral}

\section{(75) Forma del extremo distal del omoesternón (Fig. 36)}

0 : En punta (o levemente ensanchado)

1: Redondeado

2: En forma de áncora

\section{(76) Superposición de los epicoracoides (Fig. 36)}

0: Epicoracoides desarrollados en amplio contacto medial

1: Epicoracoides delgados, apenas en contacto

Lobo (1995, carácter 1) estableció que una de las sinapomorfías de Pseudopaludicola es la presencia de epicoracoides delgados, apenas en contacto uno con el otro, lo cual fue observado en las especies del género incluidas en el presente análisis.

\section{(77) Estructura del mesosternón (Fig. 36)}

0: Óseo

1: Cartilaginoso

Parker (1927) describe esternón calcificado o cartilaginoso en Pseudopaludicola, mientras que señala esternón con estilo óseo en Physalaemus y Pleurodema. Noble (1931) definió la subfamilia Leptodactylinae (Bufonidae) por poseer un estilo esternal 
óseo (véase Sección “Síntesis histórica del género Pleurodema” de la Introducción); posteriormente Lynch (1971) concuerda con esta definición y además destaca que él considera el esternón de Pseudopaludicola óseo (p. 171). Dentro de los géneros considerados en ese momento pertenecientes a la subfamilia (e incluidos en el presente trabajo), en Pseudopaludicola falcipes observé un mesosternón cartilaginoso, como ya lo registrara Lobo (1995). En el resto de los Leptodactylinae sensu Lynch observé mesosternón óseo (=estilo óseo).

\section{(78) Forma del mesosternón (Fig. 36)}

0 : Del mismo ancho en toda su extensión

1: Adelgazado en su porción postero-medial

2: Extremadamente angosto en su porción postero-medial

\section{(79) Extremo distal del mesosternón (Fig. 36)}

0: Entero

1: Bifurcado

2: Doble

Lynch (1971), en la diagnosis de Pleurodema, indica que en hembras adultas de gran tamaño el esternón tiende a bifurcarse. En el presente trabajo observé que en algunas especies de Pleurodema es un carácter polimórfico, además de haber observado machos con esternón bifurcado.

\section{(80) Xifisternón (Fig. 36)}

0 : Ausente

1: Presente

\section{(81) Forma del xifisternón, cuando está presente (Fig. 36)}

0 : Entero, extremo distal redondeado o en punta

1: Entero, extremo distal escindido

2: Entero, extremo distal en forma de áncora

3: Doble

Ponssa (2008, carácter 80 ) consideró que una de las sinapomorfía del género Leptodactylus es el xifisternón trapezoidal o semi-circular (correspondiente con el estado 2 de la presente codificación), lo cual fue observado en las especies del género incluidas en el presente análisis. 


\section{Columna vertebral, cintura pélvica y miembros}

(82) Posición de las diapófisis sacras con respecto al eje axial (Fig. 37)

0: Perpendiculares

1: Dirigidas posteriormente

(83) Posición de los iliones en relación a las vértebras sacras (Fig. 37)

0 : Los iliones sobrepasan las vértebras sacras

1: Los iliones alcanzan las vértebras sacras

(84) Arcos neurales vertebrales I-Il (Fig. 37)

0 : No imbricados

1: Imbricados

(85) Arcos neurales vertebrales II-III (Fig. 37)

0 : No imbricados

1: Imbricados

(86) Zona preacetabular del ilion (Fig. 37)

0 : Proyectada

1: No proyectada

(87) Crista lateralis (sensu Gaupp, 1896) en la superficie dorsolateral externa del húmero de los machos

0 : Ausente

1: Presente

(88) Crista medialis (sensu Gaupp, 1896) en la superficie dorsolateral interna del húmero de los machos

0 : Ausente

1: Presente

(89) Crista ventralis (sensu Gaupp, 1896) en la superficie ventral del húmero de los machos

0 : Ausente

1: Presente 


\subsubsection{Caracteres reproductivos}

\section{(90) Amplexo}

0 : Amplexo axilar

1: Amplexo inguinal

\section{(91) Emisión de canto de anuncio}

0 : Los machos emiten canto de anuncio

1: Los machos no emiten canto de anuncio

(92) Sitio de vocalización

0: En el agua, flotando (Fig. 22 C)

1: En el agua, pero escondido/sujeto a vegetación

2: Sobre tierra, escondido entre vegetación

3: En cuevas

(93) Sitio de oviposición

$0:$ Huevos depositados en cuerpos de agua

1: Huevos depositados en tierra húmeda

2: Huevos depositados en grietas en la tierra o estructuras de barro construidas para tal fin

\section{(94) Modo oviposición}

0 : Huevos depositados en nidos de espuma

1: Huevos depositados en cordones

2: Huevos depositados en masas no batidas

3: Huevos depositados individualmente, sin ningún modo evidente de aglutinación o agrupamiento

(95) Si los huevos son puestos en cordones, pueden disponerse

0 : Flotando en la superficie del agua

1: Sumergidos en el cuerpo de agua

(96) Si los huevos son puestos en masas, pueden disponerse

0 : Asociados a vegetación sumergida

1: Asociados a vegetación emergente

2: Flotando en la superficie del agua 
Los caracteres 93-96 han sido codificados teniendo en cuenta las siguientes consideraciones.

Del grupo interno, no se conocen precisiones de las puestas de Pleurodema marmoratum, Duellman \& Veloso (1977) señalan que son puestas en masas en el agua, mientras que Sinsch (1990) no indica más precisiones. No se conoce ningún dato de la reproducción de Pleurodema fuscomaculatum. Con respecto a Pleurodema tucumanum, hay discordancias sobre su modo de oviposición en la bibliografía (véase Capítulo IV), pero aquí se ha seguido el criterio de Martori et al. (1994).

Con respecto a las especies incluidas en el grupo externo, Cei (1956c) y Fernández \& Fernández (1921) señalaron que Odontophrynus americanus pone huevos en los fondos de los charcos. Además, Barrio (1954) y Lavilla \& Rougès (1992) precisaron que los huevos son puestos individualmente en el fondo del cuerpo de agua.

Con respecto a Pseudopaludicola falcipes, Barrio $(1953 ; 1954)$ describe que deposita separadamente unos 300 huevos por vez en el fondo de los charcos o adheridos a vegetación, sólo si están varios muy cerca, sus envolturas están algo adheridas entre sí. Según Gallardo (1968b) las puestas son depositadas en el agua, mientras Basso (1990) detalla que las puestas están constituidas por masas gelatinosas adheridas a plantas de la orilla de pantanos o zanjas, sumergidas en el agua.

\subsubsection{Caracteres sexuales secundarios}

\section{(97) Saco vocal en machos}

0: simple y subgular

1: doble y lateral

2: ausente

Lynch (1971), en la diagnosis de Pleurodema, describe saco vocal medial y subgular para el género, lo cual fue comprobado en el material examinado, excepto para $P$. bufoninum que carece de saco vocal.

\section{(98) Callosidades nupciales en dedo Il en época reproductiva (Fig. 38)}

0 : ausentes

1: presentes conformando un solo parche

2: presentes conformando dos parches, uno sobre el dedo II y otro sobre el tubérculo metacarpal interno 


\section{(99) Callosidades nupciales en dedo III en época reproductiva}

0 : ausentes

1: presentes conformando espinas en la cara dorsal del dedo III

\subsubsection{Caracteres de anatomía interna de órganos blandos} (100) Pigmentación de los testículos en machos adultos (Fig. 38)

0: Ausencia total de células pigmentarias en la superficie de los testículos

1: Presencia de pocas células pigmentarias, generando una pigmentación discreta

2: Presencia de gran cantidad de células pigmentarias

3: Presencia masiva de células pigmentarias, generando una intensa pigmentación (testículos negros)

Franco-Belussi et al. (2009) han revisado el patrón de coloración en 17 especies de Leptodactílidos y Leiupéridos, describiendo los cuatro patrones de pigmentación utilizados en la presente codificación. Previamente, Barrio (1967) utilizó este carácter para diferenciar el par de especies crípticas Physalaemus biligonigerus (con testículos fuertemente pigmentados) y Physalaemus santafecinus (con testículos sin pigmentación o débilmente pigmentados). Este carácter fue considerado aditivo.

\subsubsection{Caracteres citogenéticos}

En el grupo en estudio existen variaciones en el complemento cromosómico, tanto en las especies de Pleurodema como en el grupo externo.

Dentro del grupo interno todas las especies de Pleurodema son diploides con excepción del par de especies crípticas tetraploides P. kriegi y P. bibroni (Veloso et al. 1973a; 1973b; Barrio 1977; Duellman \& Veloso 1977; Schmid et al. 1993; Lourenço et al. 2006) y de la especie octoploide recientemente descripta Pleurodema cordobae (Valetti et al. 2009). Con respecto al análisis citogenético presentado por Amaral et al. (2000) bajo el nombre Physalaemus fuscomaculatus, este taxón corresponde a Physalaemus marmoratus (véase Nascimento et al. 2006).

Por otro lado, dentro del grupo externo, Odontophrynus americanus constituye el primer registro de una especie bisexual de vertebrados naturalmente poliploide (Saez \& Brum 1959). Dado que se han registrado varios niveles de ploidía en poblaciones asignadas a 0 . americanus, en el presente trabajo se han empleado ejemplares de la provincia de Buenos Aires para evaluar todos los caracteres de la matriz de datos. Los ejemplares de 0 . americanus de Buenos Aires son tetraploides $(2 n=2 x=42$ cromosomas) y procederían de la localidad tipo de la especie (véanse comentarios 
para la especie en Frost [2009]). Para una revisión completa de los complejos de especies diploides y poliploides de 0. americanus véase Rosset et al. (2006).

Por su parte, para Pseudopaludicola falcipes se ha registrado $2 n=22$ en ejemplares de Montevideo, Uruguay (Saez \& Brum 1960; Brum-Zorilla \& Saez 1968) y $2 n=16,2 n=18$ y $2 n=20$ para ejemplares de São José do Rio Prêto, São Paulo, Brasil (Beçak 1968; Batistic et al. 1969). En consecuencia, y como se indicara en la sección Materiales y Métodos, sólo se utilizó la información de poblaciones de Uruguay, confirmada por D. Cardozo (com. pers.).

\section{(101) Nivel de ploidía}

$0:$ Diploides

1: Tetraploides que forman figuras tetravalentes durante la meiosis

2: Tetraploides que no forman figuras tetravalentes durante la meiosis

3: Octoploides

La poliploidía es un mecanismo de evolución genómica que ocurre cuando un organismo posee más de dos pares de un complemento de cromosomas homólogos. Este fenómeno ocurre de dos maneras: por autopoliplidía (más de una copia del mismo complemento cromosómico) o alopoliploidía (más de dos copias de complemento cromosómico surgidas por hibridación).

Dentro del grupo de estudio, la mayoría de las especies son diploides; aunque cuatro taxones son poliploides. Pleurodema bibroni, Pleurodema kriegi y Odontophrynus americanus son tetraploides, mientras que Pleurodema cordobae es octoploide (véase Introducción).

De acuerdo con Lanzone et al. (2009), las poblaciones de Buenos Aires de Odontophrynus americanus forman figuras tetravalentes durante la meiosis, lo cual podría sugerir un origen autopoliploide reciente. En cambio, en Pleurodema kriegi y P. bibroni, no fueron observadas figuras tetravalentes, con lo cual se ha sugerido un origen alopoliploide (Barrio 1977). Sin embargo, el hecho de que no se formen tetravalentes durante la meiosis tampoco es evidencia indiscutible de un origen alopoliploide (véase discusión y literatura citada en Lanzone et al. [2009]). En consecuencia, y hasta tanto se tenga más información sobre el origen de estas especies poliploides, se prefirió codificar como se descrbió previamente en base a la evidencia observada, dado que es posible que las dos formas de tetraplodía observadas sean no-homólogas.

\section{(102) Número básico (x)}


0: Número básico 11

1: Número básico 13

2: Número básico 15

El número básico se define como el menor número de cromosomas no homólogos de un organismo (White 1954).

\subsubsection{Caracteres larvales}

\section{Morfología externa de la larva}

(103) Posición de las narinas

0: Próximas a la punta del hocico

1: Próximas a los ojos

2: Entre hocico y ojos, a mitad de la distancia de ambos

\section{(104) Posición de los ojos}

0 : Dorsales

1: Dorsolaterales

2: Laterales

\section{(105) Posición del espiráculo}

0 : Izquierdo y lateral

1: Izquierdo y abdominal

En todas las especies del grupo en estudio para las cuales se ha descripto la larva, el espiráculo toma posición izquierda. En consecuencia, seguí el criterio de Alcalde (2007, carácter 97), quien diferencia la posición en la cual se ubica esta estructura.

Formas (1989) consideró que Eupsophus calcaratus carece de espiráculo pero presenta una pequeña fisura ventrolateral izquierda, en tanto Vera Candioti et al. (2005) describieron un espiráculo izquierdo y ventral, con abertura visible. Alcalde (2007, carácter 97) consideró que esta especie posee espiráculo izquierdo y lateral; seguí el criterio de estos dos últimos trabajos.

\section{(106) Posición de la abertura del tubo cloacal}

0 : Abertura izquierda

1: Abertura medial

2: Abertura dextral 
Altig \& McDiarmid (1999: 34) sugieren que se emplee la posición de la abertura del tubo cloacal y no la posición del tubo en sí mismo, dado que el tubo puede tener posición medial y tener una abertura izquierda o derecha.

\section{(107) Estructura sacular}

0 : Ausente

1: Presente

En las larvas de algunos anuros que se reproducen en arroyos rápidos, se ha descripto una estructura sacular que envuelve parcialmente los miembros durante el desarrollo y contiene el tubo cloacal (e.g. Lötters et al. 2005 y trabajos allí citados). Kolenc et al. (2009) describieron la misma estructura sacular para Pleurodema bibroni y Pleurodema kriegi, aunque es interesante resaltar que estas especies se reproducen en ambientes lénticos. En otras especies del grupo en estudio no se ha registrado esta estructura, aunque su presencia y grado de variación debieran ser explorados.

\section{(108) Aleta dorsal}

0: Originada en el cuerpo

1: Originada en la unión entre cuerpo y cola

\section{(109) Forma del extremo de la cola}

$0:$ Redondeado

1: En punta

\section{Disco oral}

\section{(110) Marginación lateral}

0 : Sin marginación lateral

1: Con marginación lateral

\section{(111) Papilas marginales}

\section{0 : Ausentes}

1: Presentes fila simple

2: Presentes fila doble

3: Presentes en múltiples filas 
Se considera la distribución de las papilas marginales en los laterales del disco oral, ya que se observaron variaciones en el perímetro del disco completo (e.g. Leptodactylus latinasus, Borteiro \& Kolenc 2007).

(112) Ocurrencia de claro dorsal en el patrón de configuración de las papilas marginales, cuando están presentes

0 : Ausente

1: Presente

(113) Ocurrencia de claro ventral en el patrón de configuración de las papilas marginales, cuando están presentes

0 : Ausente

1: Presente

(114) Ocurrencia de claro lateral en el patrón de configuración de las papilas marginales, cuando están presentes

0 : Ausente

1: Presente

(115) Ocurrencia de dos claros ventro-laterales en el patrón de configuración de las papilas marginales, cuando están presentes

0 : Ausente

1: Presente

Physalaemus albonotatus (Perotti 1997; Kehr et al. 2004) y Physalaemus cuqui (Perotti 1997), Physalaemus cuvieri (Heyer et al. 1999; Rossa-Feres \& Nomura 2006) y Pseudopaludicola falcipes (Laufer \& Barreneche 2008) poseen dos pequeños claros ventrolaterales, además del claro ventral.

(116) Segunda hilera de queratodontes superiores

0 : Interrumpida

1: No interrumpida

(117) Primera hilera de queratodontes inferiores

0 : Interrumpida

1: No interrumpida 


\title{
(118) Segunda hilera de queratodontes inferiores
}

\author{
0: Interrumpida \\ 1: No interrumpida
}

\section{(119) Tercera hilera de queratodontes inferiores}

\section{0 : Presente}

1: Ausente

El disco oral típico de las larvas de anuros posee un rostrodonte bordeado por hileras de queratododontes superiores e inferiores. Los caracteres 117-120 refieren a la cantidad de hileras de queratodontes y al desarrollo de las mismas. Dentro del grupo en estudio, se observó que los queratodontes superiores se distribuyen siempre en dos hileras, de las cuales la segunda puede estar interrumpida o no. Por su parte, los queratodontes inferiores se distribuyen en dos o tres hileras; de esta configuración, la última hilera inferior (segunda o tercera según la especie), puede estar interrumpida o no. La homología entre hileras se estableció siguiendo su numeración, i.e., la segunda de una especie con dos hileras inferiores se corresponde con la segunda de una especie que posee tres hileras. Esto implica pensar que, en especies con sólo dos hileras, se ha perdido la tercera, o al revés, que en especies con tres hileras, se ha ganado la última. Sin embargo, cabe destacar que no es sencillo establecer cuál hilera de ha perdido o ganado en cada especie con respecto a otra, por lo tanto en el presente trabajo se optó por seguir el criterio explicado.

Cei (1980a) y Fabrezi \& Vera (1997) describieron la fórmula dentaria 2(2)/3 para Pleurodema borellii, mientras que Alcalde (2007) observó 2(2)/3(1), destacando que la interrupción en la primer hilera ventral es ínfima; en el presente trabajo se siguió el criterio de Alcalde (2007) para el carácter 118.

Formas (1989) describe queratodontes ausentes para Eupsophus calcaratus, mientras que Vera Candioti et al. (2005) observaron que están reducidos (estado 5 de presente trabajo); en el presente trabajo se siguió el criterio de Vera Candioti et al. (2005) para los caracteres 117-119.

Fernández \& Fernández (1921) describieron la fórmula dentaria 2(2)/3 para Leptodactylus latinasus, Borteiro \& Kolenc (2007) y Vera Candioti et al. (2007) observaron 2(2)/3(1); en el presente trabajo se siguió el criterio de los últimos dos trabajos mencionados para el carácter 118.

\subsubsection{Caracteres musculares}




\section{(120) Rama lateral del m. lumbricalis longus digiti IV}

0 : Ausente

1: Presente

El estado 0 de la presente codificación se corresponde con Burton (1998, carácter 12:0,2,3) y Andersen (1978, carácter 15:2), mientras que el estado 1 se corresponde con Burton (1998, carácter 12:1) y Andersen (1978, carácter 15:0-1).

(121) Grado de desarrollo de la rama lateral del $\mathrm{m}$. Iumbricalis longus digiti IV en relación a su rama medial

0 : Rama lateral tan desarrollada como la rama medial

1: Rama lateral reducida

2: Rama lateral delgada

El estado 0 de la presente codificación se corresponde con Burton (1998, carácter 12:0), el estado 1 se corresponde con Burton (1998, carácter 12:2) y el estado 2 se corresponde con Burton (1998, carácter 12:3). Consideré que las descripciones de Burton (1998) sobre la rama lateral “reducida" y "delgada" no son equivalentes, porque interpreto que el autor refiere como reducción al acortamiento de la rama, mientras que por delgadez refiere a la menor cantidad de fibras. De todos modos, estas interpretaciones son personales y deben ser contrastadas con la observación de material.

(122) Origen de la rama lateral del $\mathrm{m}$. lumbricalis longus digiti IV

0 : Originada distalmente sobre el tendo superficialis

1: Originada en un tendón largo y angosto, originado a su vez en el tendo superficialis digiti IV

El estado 0 de la presente codificación se corresponde con Burton (1998, carácter 12:0-1), mientras que el estado 1 se corresponde con Burton (1998, carácter 12:3)

\section{(123) Origen del $\mathrm{m}$. extensor brevis superficialis digiti IV}

0: Originado del ulnar (y posiblemente de los carpales distales 5-4-3)

1: Originado solamente de los carpales distales 5-4-3

Burton (1998) y Andersen (1978) consideraron éste carácter con diferentes estados. A su vez, ambos estudiaron Engystomops pustulosus y hallaron estados de carácter diferentes: mientras Burton (1998) consideró que el m. extensor brevis superficialis digiti IV se origina del ulnar y carpales distales 5-4-3, Andersen (1978) observó que dicho músculo se origina solamente desde el ulnar. La discordancia entre 
las apreciaciones radica en determinar si el músculo se origina sólo del ulnar o también de los carpales distales 5-4-3, pero en lo que sí coinciden ambos autores es que (al menos) parte del origen ocurre en el ulnar. Como consecuencia, decidí incluir la codificación presentada, aunque posiblemente el estado 0 corresponda a más de un estado.

El estado 0 de la presente codificación se corresponde parcialmente con Burton (1998, carácter 30:0) y Andersen (1978, carácter 42:0), mientras que el estado 1 se corresponde con Burton (1998, carácter 30:1).

\section{(124) Musculatura mandibular superficial (vista ventral)}

0: Las fibras del $\mathrm{m}$. intermandibularis están generalmente dispuestas posteromedialmente formando una rama suplementaria apical, superponiéndose a las fibras del $m$. submentalis

1: Las fibras del $\mathrm{m}$. intermandibularis están dirigidas anteromedialmente y no se superponen a la superficie ventral del $\mathrm{m}$. submentalis, si no que se insertan en la fascia superpuesta a las porciones laterales del $\mathrm{m}$. submentalis

Este carácter fue tomado de Burton (1998).

En la tabla 3 se indican los caracteres tomados de la literatura para cada especie, mientras que en la tabla 4 se muestra la matriz de datos utilizada en el análisis filogenético de Pleurodema.

Tabla 3. Caracteres tomados de la literatura.

\begin{tabular}{lll} 
Especie & Caracteres & Bibliografía \\
\hline Pleurodema & $90-91 ; 93-96$ & Barrio (1977) \\
bibroni & $92 ; 103-119$ & Kolenc et al. (2009) \\
& $99-101$ & Barrio \& Rinaldi de Chieri (1970); Barrio (1977) \\
Pleurodema & 91 & Duellman \& Veloso (1977) \\
borellii & $92-93$ & Cei (1980a) \\
& $101-102$ & Barrio \& Rinaldi de Chieri (1970) \\
& $105-106 ; 103-110 ;$ & Fabrezi \& Vera (1997); Alcalde (2007, carácter 97) \\
Pleurodema & $112-119$ & Rivero (1961), Leon-Ochoa \& Donoso-Barros (1969) \\
brachyops & 15 & Leon-Ochoa \& Donoso-Barros (1969); Duellman \& Veloso (1977); \\
& $90-96$ & Ibáñez et al. (1999) \\
& $101-102$ & Schmid et al. (1973) \\
& $103-106 ; 109 ; 111-$ & Leon-Ochoa \& Donoso-Barros (1969) \\
& 119 & Andersen (1978); Burton (1998) \\
& $120 ; 123$ & Burton (1998) \\
Pleurodema & $121-122 ; 124$ & Duellman \& Veloso (1977) \\
bufoninum & $90-91$ & Barrio \& Rinaldi de Chieri (1970); Veloso et al. (1973a); Weigandt et \\
& $93-96$ & al. (2005) \\
& $101-102$ & Veloso et al. (1973a) \\
Pleurodema & $103-119$ & Weigandt et al. (2005) \\
cinereum & $90-92$ & Duellman \& Veloso (1977) \\
& $93-96$ & Cei (1980a)
\end{tabular}




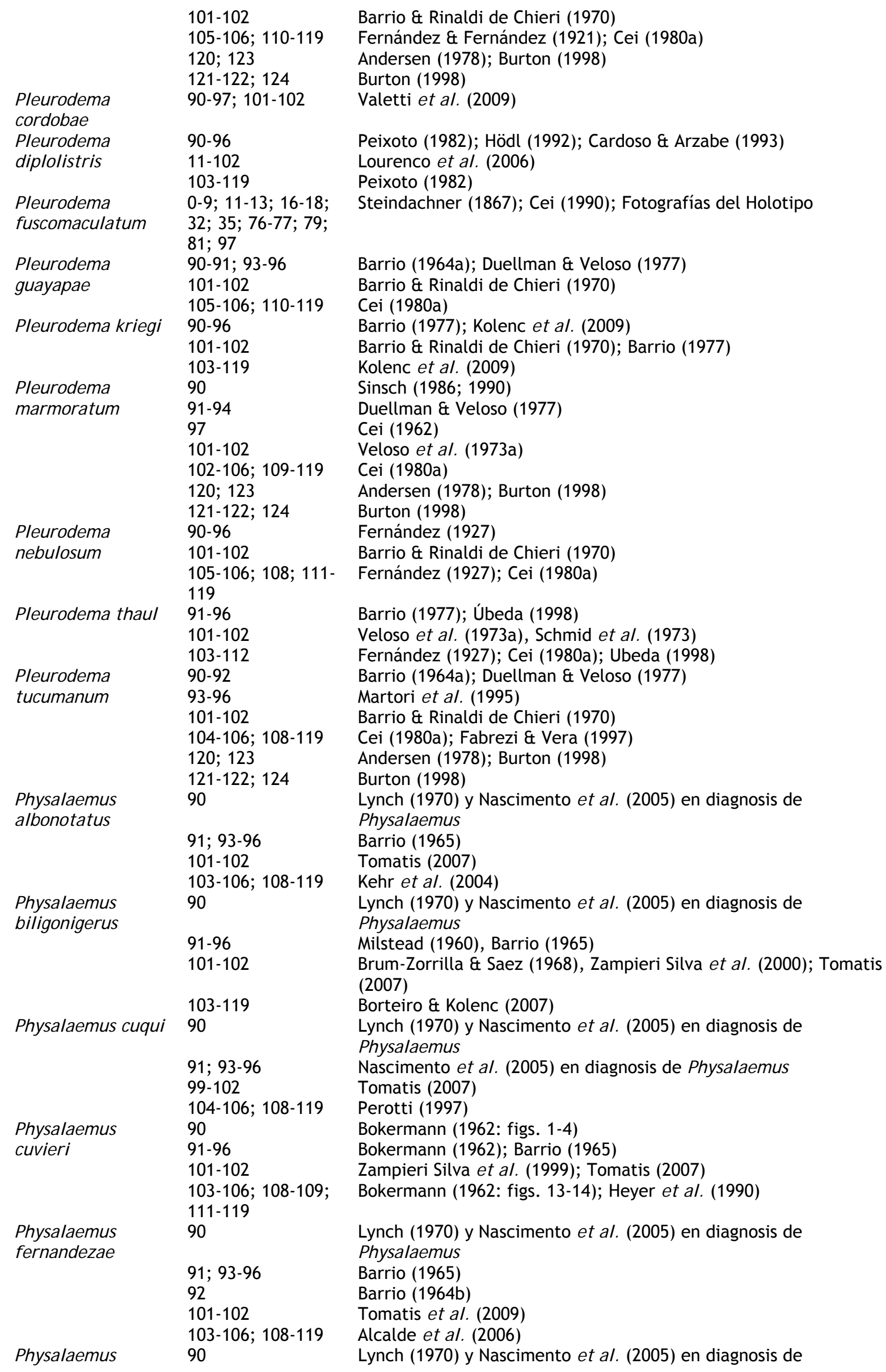




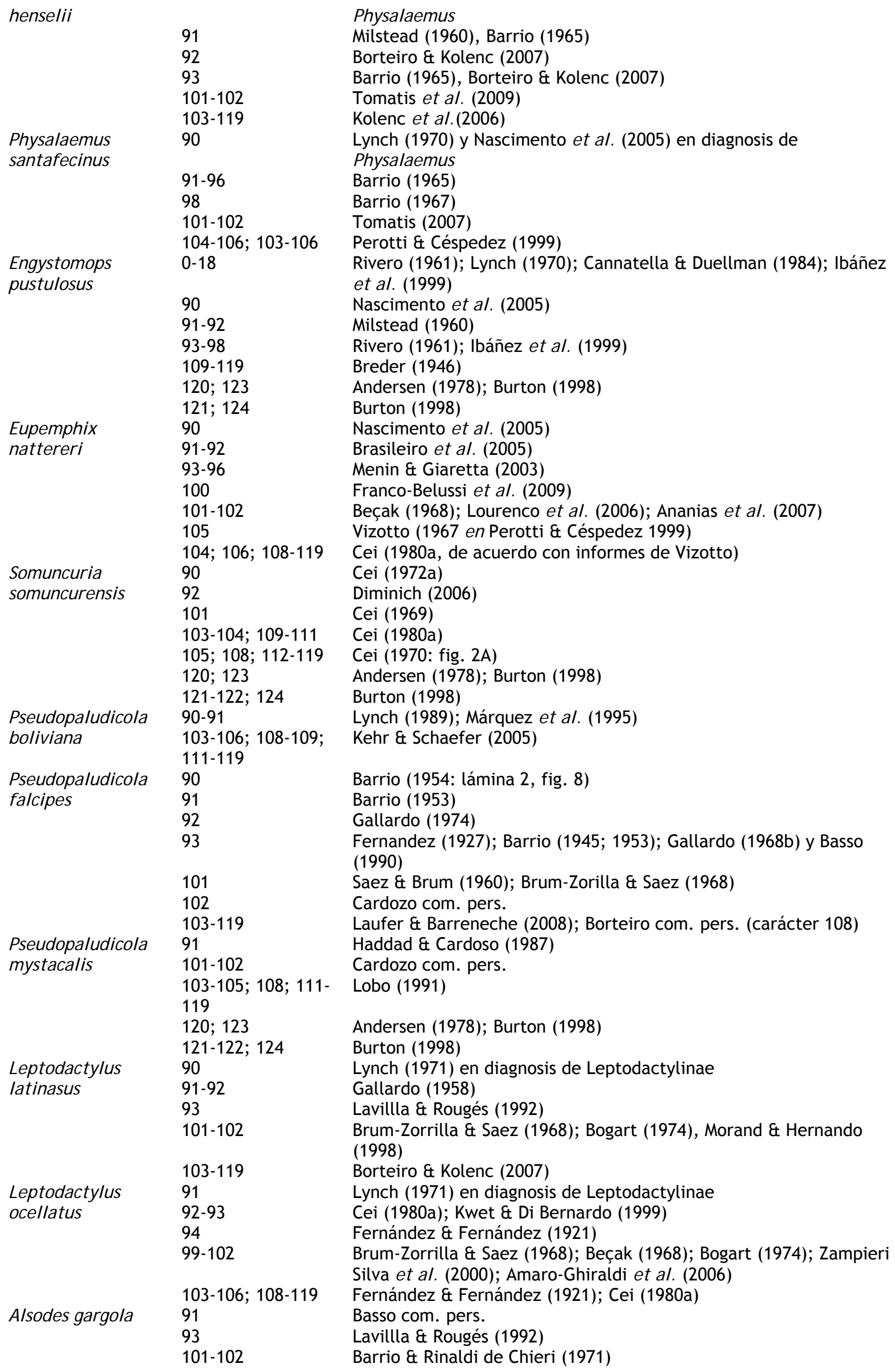




$\begin{array}{lll} & 102-105 ; 107-112 & \text { Ubeda (1998); Pillado et al. (2000) } \\ \text { Odontophrynus } & 91 & \text { Lynch (1971) } \\ \text { americanus } & 92-93 & \text { Barrio (1964c) } \\ & 94 & \text { Cei (1956); Fernández \& Fernández (1921); Lavilla \& Rougés (1992) } \\ & 99-102 & \text { Rosset et al. (2006) } \\ & 103-106 ; 108-119 & \text { Fernández \& Fernández (1921); Savage \& Cei (1965) } \\ \text { Eusophus } & 91-92 & \text { Formas (1989); Úbeda (1998) } \\ \text { calcaratus } & 93 & \text { Lavilla y Rougés (1992) } \\ & 101-102 & \text { Formas (1980) } \\ \text { Batrachyla } & 105-106 ; 108-119 & \text { Úbeda (1998); Vera Candioti et al. (2005) } \\ \text { leptopus } & 91-96 & \text { Cei \& Capurro (1958); Úbeda (1998) } \\ & 101-102 & \text { Barrio \& Rinaldi de Chieri (1971) } \\ & 103-119 & \text { Cei (1980, fig. 109 B); Lavilla (1988); Ubeda (1998); Alcalde (2007, } \\ & & \text { carácter 97) }\end{array}$


Tabla 4. Matriz de datos utilizada en el análisis filogenético de Pleurodema. Abreviaciones: Pl.: Pleurodema; Ph.: Physalaemus.

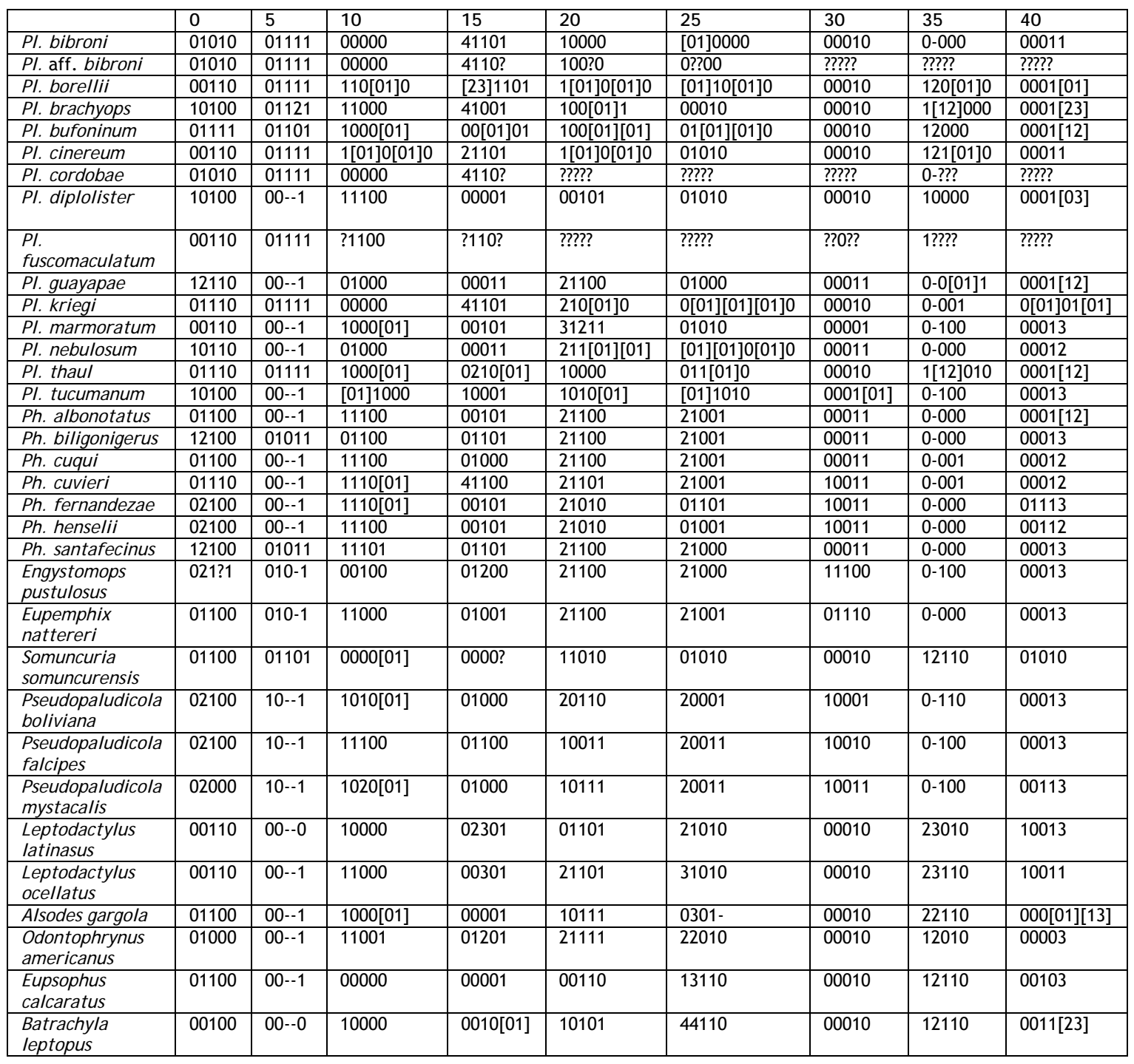




\begin{tabular}{|c|c|c|c|c|c|c|c|c|}
\hline & 45 & 50 & 55 & 60 & 65 & 70 & 75 & 80 \\
\hline PI. bibroni & 02112 & 00000 & 01001 & {$[01] 1101$} & $00[12] 2[01]$ & 10201 & {$[12] 00[12] 0$} & 11101 \\
\hline PI. aff. bibroni & ????? & $? ? 000$ & ????? & $1 ? ? ? ?$ & ????? & ????? & 20010 & 11111 \\
\hline PI. borellii & {$[01] 21[12] 2$} & $01[01] 00$ & 01001 & 01000 & 00031 & $0010 ?$ & {$[12] 0020$} & 11111 \\
\hline PI. brachyops & 02112 & 00100 & 01001 & $0[01] 001$ & $00[02][23] 1$ & 10001 & 10020 & 11110 \\
\hline PI. bufoninum & $1[02] 1[12] 2$ & 01000 & [01]1001 & $1100[01]$ & $000[23][01]$ & 10001 & 20010 & $111[01] 1$ \\
\hline PI. cinereum & {$[01] 2112$} & $0[01] 100$ & {$[01] 1001$} & $0100[01]$ & 00031 & 10100 & 20020 & $1[13] 1[01] 1$ \\
\hline PI. cordobae & ????? & ????? & $? ? 00 ?$ & ????? & ????? & ????? & ????? & ????? \\
\hline PI. diplolister & 12122 & 00100 & {$[01] 1001$} & $0[01]$ ??? & $0 ? 131$ & $0-00 ?$ & 10020 & 11111 \\
\hline $\begin{array}{l}\text { PI. } \\
\text { fuscomaculatum }\end{array}$ & ????? & ????? & ????? & ????? & ????? & ????? & $? 00 ? 1$ & ?3??? \\
\hline PI. guayapae & 12122 & 00201 & -1000 & 11001 & $000[23] 1$ & 10100 & 10021 & 13111 \\
\hline PI. kriegi & {$[01] 2112$} & $00[01] 00$ & 01001 & $11[01] 01$ & $001[23] 1$ & $0-20 ?$ & $200[12] 0$ & $111[01] 1$ \\
\hline PI. marmoratum & $101 ? 2$ & 00100 & 01001 & $0100 ?$ & ????? & ????? & 20010 & 12101 \\
\hline PI. nebulosum & 12112 & $00[12] 01$ & -1000 & $0[01] 00[01]$ & $10[02][23] 1$ & 10100 & [12]002[01] & 13111 \\
\hline PI. thaul & $1[012] 1[12] 2$ & 01000 & 01001 & $01[01] 01$ & $00[02] 31$ & $10[12] 01$ & {$[12] 00[12] 0$} & $111[01] 1$ \\
\hline PI. tucumanum & 12122 & 00101 & -1001 & $0100[01]$ & $00[01] 21$ & 10101 & 20010 & $1[13] 111$ \\
\hline Ph. albonotatus & 11110 & $0[02] 000$ & 11001 & 11111 & 01230 & 10310 & 10011 & $131[01] 1$ \\
\hline Ph. biligonigerus & 12110 & 00100 & 11001 & $11 ? ? ?$ & $? ? 020$ & 10310 & 20011 & 13101 \\
\hline Ph. cuqui & {$[01] 2120$} & 00000 & 11001 & 11111 & $01[02] 3[01]$ & 10312 & 10021 & $131[01] 1$ \\
\hline Ph. cuvieri & 12110 & $02[01] 00$ & {$[01] 1001$} & 01111 & {$[01] 1[02] 20$} & 10310 & 10021 & 13111 \\
\hline Ph. fernandezae & 00100 & 00000 & 01001 & 10101 & 01230 & $1030 ?$ & 10010 & 12011 \\
\hline Ph. henselii & 00120 & 02000 & 11001 & 01101 & 11230 & $1030 ?$ & 20010 & 11011 \\
\hline Ph. santafecinus & 12110 & 00000 & $1100 ?$ & ?1?1? & $0 ? ? ? ?$ & ?0??? & $0001[12]$ & $131 ? 0$ \\
\hline $\begin{array}{l}\text { Engystomops } \\
\text { pustulosus }\end{array}$ & 12112 & 12100 & 11001 & $11[01] 11$ & 11??? & 10310 & $0001[01]$ & $1[13] 001$ \\
\hline $\begin{array}{l}\text { Eupemphix } \\
\text { nattereri }\end{array}$ & {$[01] 2110$} & 10100 & $1100 ?$ & 11021 & 11031 & $10 ? ? 3$ & 10011 & 13111 \\
\hline $\begin{array}{l}\text { Somuncuria } \\
\text { somuncurensis }\end{array}$ & $121 ? 2$ & 01000 & 00001 & ????? & ????? & ???01 & 10011 & $0-010$ \\
\hline $\begin{array}{l}\text { Pseudopaludicola } \\
\text { boliviana }\end{array}$ & 11112 & $01[01] 10$ & {$[02] 0001$} & 10121 & 10231 & 10101 & {$[01] 1020$} & $1[02] 101$ \\
\hline $\begin{array}{l}\text { Pseudopaludicola } \\
\text { falcipes }\end{array}$ & 11121 & 00010 & 20001 & 10121 & 11231 & 10003 & 01100 & $0-011$ \\
\hline $\begin{array}{l}\text { Pseudopaludicola } \\
\text { mystacalis }\end{array}$ & 11121 & 01110 & 00001 & 01121 & $10 ? ? ?$ & $1020 ?$ & 01020 & 10001 \\
\hline $\begin{array}{l}\text { Leptodactylus } \\
\text { latinasus }\end{array}$ & $111 ? 0$ & 00000 & $1000 ?$ & 11000 & 00221 & 10200 & 20020 & 12011 \\
\hline $\begin{array}{l}\text { Leptodactylus } \\
\text { ocellatus }\end{array}$ & $121 ? 0$ & 01000 & 11001 & ??0?? & ??[02]31 & 10200 & 20020 & 12111 \\
\hline Alsodes gargola & $121 ? 0$ & 00000 & 0111- & --001 & $10[01] 21$ & $11 ? ? ?$ & 10100 & 11011 \\
\hline $\begin{array}{l}\text { Odontophrynus } \\
\text { americanus }\end{array}$ & 12010 & 01000 & 01001 & 01101 & 00221 & 10103 & $? 0130$ & $0-011$ \\
\hline $\begin{array}{l}\text { Eupsophus } \\
\text { calcaratus }\end{array}$ & 12110 & 01000 & 01001 & 00101 & 10020 & 11201 & 20000 & 10111 \\
\hline $\begin{array}{l}\text { Batrachyla } \\
\text { leptopus }\end{array}$ & $1[01] 0[12] 1$ & 00000 & 01001 & 01001 & 10120 & 21201 & 20000 & 10111 \\
\hline
\end{tabular}




\begin{tabular}{|c|c|c|c|c|c|c|c|c|}
\hline & 85 & 90 & 95 & 100 & 105 & 110 & 115 & 120 \\
\hline PI. bibroni & 01101 & 00102 & -1010 & 02010 & 01110 & $1[12] 100$ & 00011 & ????? \\
\hline PI. aff. bibroni & 0???? & ????? & $? ? 010$ & ????? & ????? & ????? & ????? & ????? \\
\hline PI. borellii & 01111 & 00000 & --020 & $000 ? 0$ & $1 ? ? 01$ & $1 ? 100$ & 000011 & ????? \\
\hline PI. brachyops & 11011 & 00000 & --020 & 00011 & $01 ? ? 0$ & $? 1100$ & $00[01] 11$ & 12111 \\
\hline Pl. bufoninum & 01111 & $11-01$ & $0-220$ & 00011 & $01 ? 10$ & $1[12] 100$ & $00[01] 11$ & ????? \\
\hline Pl. cinereum & 01011 & 00000 & --020 & $000 ? ?$ & $01 ? ? ?$ & 11100 & 00111 & 12111 \\
\hline PI. cordobae & ????? & 00101 & $-20 ? ?$ & ?30?? & ????? & ????? & ????? & ????? \\
\hline PI. diplolister & $00 ? ? ?$ & 00000 & --020 & ?0011 & $00 ? 10$ & 11100 & 00011 & ????? \\
\hline PI. fuscomaculatum & ????? & ????? & ?0??? & ????? & ????? & ????? & ????? & ????? \\
\hline PI. guayapae & 01111 & $00 ? 00$ & --020 & $000 ? ?$ & $01 ? ? ?$ & 11100 & 00110 & ????? \\
\hline Pl. kriegi & 00101 & 00102 & -1010 & 02010 & $0[02] 110$ & $1[12] 100$ & 00111 & ????? \\
\hline PI. marmoratum & $01 ? ? ?$ & 00202 & --110 & 20011 & $01 ? ? 1$ & 11100 & 00011 & 12111 \\
\hline PI. nebulosum & 01011 & 00100 & --020 & $100 ? ?$ & $01 ? 0 ?$ & $? 1100$ & 00110 & ????? \\
\hline PI. thaul & 01111 & ?0101 & $1-010$ & 00011 & $0[01] ? 0 ?$ & $1[123] 100$ & $00[01] 1[01]$ & ????? \\
\hline PI. tucumanum & 01001 & 00102 & -2020 & $000 ? 0$ & $01 ? 01$ & 13100 & 00110 & 12111 \\
\hline Ph. albonotatus & 01101 & $00 ? 00$ & --020 & 30011 & $02 ? 10$ & 11110 & 10011 & ????? \\
\hline Ph. biligonigerus & 01111 & 00000 & --020 & 30000 & 02010 & 11100 & 00010 & ????? \\
\hline Ph. cuqui & 01111 & $00 ? 00$ & --020 & $100 ? 1$ & $02 ? 11$ & 11110 & 10011 & ?????? \\
\hline Ph. cuvieri & 01111 & 00000 & --020 & 30021 & $0[12] ? 10$ & 11110 & $1[01] 111$ & ????? \\
\hline Ph. fernandezae & 11101 & 00000 & --010 & 30001 & 01010 & 12110 & 00011 & ????? \\
\hline Ph. henselii & 01100 & 00200 & $--0 ? 0$ & $? 0000$ & $0[012] 011$ & 11110 & 00011 & ????? \\
\hline Ph. santafecinus & $11 ? ? ?$ & 00000 & --020 & [01]00?1 & $02 ? 11$ & 11100 & 00010 & ????? \\
\hline Engystomops pustulosus & 01111 & 00000 & $--00 ?$ & ?0??? & ????1 & 11100 & 00111 & $10 ? 01$ \\
\hline Eupemphix nattereri & $01 ? ? ?$ & 00000 & $--0 ? 0$ & {$[123] 00 ? 0$} & $02 ? 01$ & 11100 & 00010 & ????? \\
\hline $\begin{array}{l}\text { Somuncuria } \\
\text { somuncurensis }\end{array}$ & $00 ? ? ?$ & $11-02$ & $1-21 ?$ & $? 0 ? 20$ & $1 ? ? 00$ & 12100 & 00011 & $10 ? 00$ \\
\hline $\begin{array}{l}\text { Pseudopaludicola } \\
\text { boliviana }\end{array}$ & 00001 & $002 ? ?$ & $? ? 010$ & $3 ? ? 11$ & $11 ? 11$ & 11111 & 00110 & ????? \\
\hline Pseudopaludicola falcipes & $00 ? ? ?$ & 00103 & --010 & 20120 & $01 ? 11$ & 11110 & 10111 & ????? \\
\hline $\begin{array}{l}\text { Pseudopaludicola } \\
\text { mystacalis }\end{array}$ & 01111 & ?0??? & $? ? 010$ & $? 0012$ & $0 ? ? 1 ?$ & $? 1100$ & 00110 & $10 ? 01$ \\
\hline Leptodactylus Iatinasus & 00111 & 00320 & --000 & 00001 & $0[01] 010$ & 01100 & 00011 & ????? \\
\hline Leptodactylus ocellatus & 00111 & 00100 & --000 & $000 ? 0$ & $01 ? 11$ & 03100 & 01111 & ????? \\
\hline Alsodes gargola & $01 ? ? ?$ & $? 1 ? 03$ & --211 & $? 0111$ & $02 ? 10$ & 01100 & 00011 & ????? \\
\hline $\begin{array}{l}\text { Odontophrynus } \\
\text { americanus }\end{array}$ & 01001 & 00203 & --010 & $010 ? 0$ & $02 ? 11$ & 11100 & 00111 & ?????? \\
\hline Eupsophus calcaratus & ?1111 & $? 0213$ & --011 & $102 ? ?$ & $01 ? 00$ & 11100 & 00100 & ????? \\
\hline Batrachyla leptopus & $01 ? ? ?$ & $? 0213$ & --011 & 00111 & $02 ? 10$ & 11100 & 00011 & ????? \\
\hline
\end{tabular}




\subsection{Análisis cladístico}

Los análisis bajo pesos implicados con valores de $\mathbf{k}$ entre 4 y 10 resultaron en tres árboles máximamente parsimonioso (496 pasos, IC=0,355, IR=0,565 para todos los casos), donde el género Pleurodema conforma un clado que incluye a Somuncuria somuncurensis como especie hermana de Pleurodema bufoninum, mientras que Pleurodema fuscomaculatum queda anidada dentro de (Physalaemus (Eupemphix + Engystomops)) (Figs. 39-40). Tres transformaciones homoplásicas dan soporte a este clado: glándulas en la zona sacra del cuerpo presentes (6:0), nasales no superpuestos al esfenoetmoides (22:0), bordes externos de los frontoparietales (24:0), esfenoetmoides cuyo desarrollo, en vista ventral, alcanza el nivel de los palatinos (44:1), cuadradoyugal ausente y hueso cuadrado presente $(49: 2)$ y huevos depositados en cordones (94:1).

De aquí en adelante, cada vez que se mencione Pleurodema* indicará que se refiere a Pleurodema conteniendo en su interior a Somuncuria somuncurensis y excluyendo a Pleurodema fuscomaculatum.

Dentro de Pleurodema* se recuperan dos sublcados. Uno lo constituyen (Somuncuria somuncurensis + Pleurodema bufoninum) sustentado por cuatro transformaciones, las dos primeras no homoplásicas: glándulas lumbares del mismo color que el resto del dorso (8:0), amplexo inguinal (90:1), machos que no emiten canto de anuncio (91:1) y saco vocal ausente en machos (97:2).

El otro subclado está formado por las restantes especies del género, y está soportado por dos sinapomorfías homoplásicas: patrón de coloración en el labio superior con varias barras verticales $(16: 1)$ y crista supraorbitalis del esfenoetmoides (23:0). Dentro de este sublclado se recuperan dos grupos: uno formado por las especies poliploides y el otro formado por las restantes especies del género.

El grupo de las especies poliploides contiene, en el consenso estricto, una politomía que incluye a P. kriegi, P. cordobae, P. aff. bibroni y P. bibroni. La relación entre estas especies es la única diferencia entre los tres árboles máximamente parsimoniosos. Este grupo está sustentado por dos sinapomorfías homoplásicas: ausencia de pliegue tarsal $(10: 0)$ y coloración flash como patrón de coloración en zona oculta de los fémures en animales vivos (15:4).

El otro grupo está formado por las restantes especies del género: ((P. thaul ( $P$. borellii + P.cinereum) (P. brachyops ( $P$. diplolister (P. marmoratum (P. tucumanum $(P$. nebulosum + P. guayapae)))))), soportado por tres transformaciones homoplásicas: extracolumela no expandida distalmente (60:0), procesos bronquiales del cricoides que sobrepasan el proceso esofágico del cricoides $(68: 3)$ y aleta dorsal 
de las larvas originada en el cuerpo (108:0). El par de especies (P. borellii + P.cinereum) resultan ser especies válidas y hermanas, sustentadas por una sinapomorfía: patrón de coloración en zona oculta de los fémures en animales vivos amarillo-anaranjada (15:2, aunque polimófico para P. borellii). Pleurodema cinereum se caracteriza por poseer el proceso postcoanal del vómer en el mismo plano que el resto del hueso (37:1) [proceso postcoanal del vómer dirigido dorsalmente en $\mathrm{P}$. borellii (37:0)] y primera hilera de queratodontes inferiores en el disco oral de las larvas no interrumpida (117:1) [primera hilera de queratodontes inferiores en el disco oral de las larvas interrumpida en P. borellii (117:0)], mientras que P. borellii se caracteriza por poseer el proceso esofágico del cricoides ausente (70:0) [proceso esofágico del cricoides presente en P. cinereum (70:1)] y espiráculo de la larva de posición izquierda y lateral (105:1)[espiráculo de la larva de posición izquierda y abdominal en $P$. cinereum (105:0)].

Otro aspecto para destacar dentro de este grupo, es que ( $P$. nebulosum $+P$. guayapae) también son especies hermanas, lo cual está soportado por cinco sinapomorfías (la primera y la anteúltima no homoplásicas): reborde cutáneo en la abertura de la cloaca presente (18:1), nasales de forma romboidal (20:2), Desarrollo anterior del esfenoetmoides en vista ventral superando el nivel de los palatinos (44:2), anillo timpánico completo( 59:0) y proceso cardíaco del cricoides en forma de $U$, con las dos proyecciones cefálicas muy próximas entre sí (74:0).

El clado Pleurodema* se constituye como grupo hermano de (Leptodactylus (Odontophrynus (Pseudopaludicola (Physalaemus (Pleurodema fuscomaculatum (Eupemphyx +Engystomops)))))), este último clado está sustentado por cuatro transformaciones homoplásicas, excepto la última: nasales de forma romboidal (20:2), márgenes mediales de los nasales alineados o contiguos (21:1), frontoparietales con sus bordes mediales paralelos y alineados en toda su extensión y fenestra frontoparietal subyacente expuesta a través de de una angosta fontanela frontoparietal $(27: 2)$ y procesos bronquiales del cricoides dirigidos dorsalmente por medio de una curvatura (69:2).

Dentro de este último clado, Leptodactylus y Pseudopaludicola se recuperan como monofiléticos con diez y doce sinapomorfías respectivamente. A su vez, Pseudopaludicola se constituye como el grupo hermano del clado (Physalaemus (Pleurodema fuscomaculatum (Eupemphyx + Engystomops))). El clado (Physalaemus (Pleurodema fuscomaculatum (Eupemphyx + Engystomops))) está sustentado por cinco sinapomorfías homoplásicas, excepto al anteúltima: bordes externos de los frontoparietales convergentes en su porción anterior (24:0), exoccipitales y proóticos 
independientes (28:0), proceso bronquial del cricoides distalmente no expandido (69:0), cricoides en subtriangular en vista dorsal en machos (72:3) y oviposición en nidos de espuma e (94:0).

Los valores de la medidas de soporte obtenidos por Symmetric Resampling se muestran en la Fig. 41. Los valores de soporte difieren dentro del clado Pleurodema*, de hecho este clado no está soportado en este análisis. Algunas ramas internas presentan muy buen nivel de soporte, i.e. ( $P$. kriegi ( $P$. cordobae ( $P$. aff. bibroni + P. bibroni $))$ ), (P. cinereum + P. borellii) y (P. nebulosum + P. guayapae), mientras que otras adoptan valores de 0.

El análisis bajo peso implicados se repitió, con los mismos parámetros de búsqueda, excluyendo a Pleurodema fuscomaculatum. Esta especie posee el $80,8 \%$ de entradas faltantes en la matriz de datos, incluyendo todos los caracteres diagnósticos de Pleurodema. Nascimento et al. (2006) habían transferido esta especie de Physalaemus a Pleurodema, argumentando que la misma posee dientes vomerinos, condición ausente en Physalaemus. Sin embargo, debido a que esta especie es conocida por la serie tipo y una muestra de fines del siglo XIX (Cei 1990), no ha sido posible codificar la mayoría de los caracteres incluidos en el presente trabajo. Los resultados obtenidos no se vieron afectados por la eliminación de esta especie, obteniéndose la misma topología que la ilustrada en el cladograma de las Figs. 3940.

EI análisis bajo pesos iguales se realizó excluyendo a Pleurodema fuscomaculatum. En primera instancia, se realizó un análisis filogenético incluyéndola, pero la posición de esta especie fluctuaba dentro de los árboles obtenidos, de modo tal que no se obtenía una topología estable. Finalmente, se decidió eliminar dicha especie del análisis bajo pesos iguales por las razones expuestas precedentemente.

El análisis bajo pesos iguales arrojó cuatro árboles máximamente parsimoniosos (482 pasos, IC=0,365, IR= 567). El consenso estricto se muestra en las Figuras 42-43. Del mismo modo que en análisis anterior, el conflicto entre los cladogramas surge entre las relaciones de las especies poliploides. El género Pleurodema y Somuncuria somuncurensis se recuperan como grupo monofilético soportado por tres sinapomorfías homoplásicas: nasales no superpuestos al esfenoetmoides (22:0), cuadradoyugal ausente y hueso cuadrado presente (49:2) y huevos depositados en cordones $(94: 2)$. 
Dentro del clado Pleurodema*, Somuncuria somuncurensis resulta ser la especie más basal, constituyéndose en la especie hermana de las restantes especies del género. Con respecto al análisis bajo pesos implicados, len el análisis bajo pesos iguales se obtuvieron los siguientes resultados: i) Pleurodema bufoninum no resulta la especie hermana de Somuncuria somuncurensis, si no del clado ( $P$. borellii + P.cinereum) ( $P$. brachyops (P. diplolister ( $P$. tucumanum (P. nebulosum $+P$. guayapae))))); ii) Pleurodema marmoratum no es la especie hermana del clado (P. tucumanum (P. nebulosum + P. guayapae)), si no del clado ((P. kriegi + P. cordobae + P. aff. bibroni + P. bibroni) (P. thaul (P. bufoninum (P. borellii + P. cinereum) $(P$. brachyops (P. diplolister (P. tucumanum (P. nebulosum + P. guayapae)))))))). Todas las sinapomorfías de cada rama pueden verse en las Figs. 42-43.

El clado Pleurodema* constituye, del mismo modo que en el análisis bajo pesos implicados, el grupo hermano de (Leptodactylus ((Odontophrynus (Pseudopaludicola (Physalaemus (Eupemphyx +Engystomops)))))). Las relaciones entre los grupos externos resultaron idénticas que las obtenidas con el análisis bajo pesos iguales.

Los valores de soporte obtenidos aplicando los re-muestreos Parsimony jackknifing y Bootstraping (Fig. 44) no ofrecen soporte al nodo Pleurodema*, sólo algunos nodos internos presentan buen soporte. Por su parte, los valores de Soporte de Bremer (Fig. 45) son bajos también para el clado Pleurodema*.

En los dos análisis realizados (con pesado de caracteres y sin pesado) Pleurodema spp. y Somuncuria somuncurensis conforman un grupo monofilético, aunque no presenta buenos niveles de soporte. Dos sinapomorfía son comunes a ambos análisis, nasales no superpuestos al esfenoetmoides (22:0), cuadradoyugal ausente y hueso cuadrado presente (49:2). Con respecto a los modos reproductivos, existe contradicción con el modo ancestral: mientras en el análisis bajo pesos implicados elmodo ancestral es huevos depositados en cordones (94:1), en el análisis bajo pesos iguales resulta ser huevos depositados en masas no batidas (94:2) (Figs. 39 y 42). En ambos análisis se recuperan los siguientes subclados: $(P$. kriegi $+P$. cordobae $+P$. aff. bibroni + P. bibroni); (P. borellii + P. cienreum); y (P. tucumanum (P. nebulosum + P. guayapae)).

El género Pleurodema resulta parafilético tal como se considera al día de hoy, dado que excluye a Somuncuria somuncurensis entre sus especies. En consecuencia, y para sugerir una clasificación basada en grupos naturales, se propone transferir de género a Somuncuria somuncurensis, con lo cual el nombre sugerido es Pleurodema somuncurensis nov. comb. 
Por último, no es posible establecer la posición filogenética de Pleurodema fuscomaculatum. Como se mencionó precedentemente, la gran cantidad de entradas faltantes, incluyendo los caracteres diagnósticos de Pleurodema*, no permiten definir a qué género pertenece dicha especie. En consecuencia, se sugiere mantener la asignación genérica actual hasta tanto nueva evidencia pueda ser incorporada a un análisis filogenético.

\subsection{Discusión de las relaciones filogenéticas de Pleurodema}

\section{Relaciones entre las especies de Pleurodema}

A pesar de la evidente variabilidad de las especies de Pleurodema (e.g. especies polimórficas, diferentes modos de oviposición, diferentes niveles de ploidía, etc), este género nunca fue objeto de análisis filogenéticos. El único estudio previo que considera a todas las especies conocidas (hasta ese momento) es el de Duellman \& Veloso (1977). Sin embargo, este estudio tiene serias falencias conceptuales y metodológicas. Por un lado, sólo está basado en cuatro caracteres (amplexo, modo de oviposición, glándulas lumbares y número básico de cromosomas, véase página 25), cuando los autores examinaron más caracteres (al menos hay nueve caracteres listados en la matriz de datos). Por otro lado, no incluye grupos externos, sólo se discute de manera sumamente especulativa las relaciones de Pleurodema con otros géneros, basándose en información bibliográfica (un detalle de la propuesta de Duellman \& Veloso se encuentra en la Introducción del presente trabajo, ver también Fig. 1A). Otra falla se encuentra en errores de codificación, e.g., al momento del trabajo se desconocía el modo reproductivo de P. bibroni y P. kriegi, y los autores asumieron que se reproducción por nidos de espuma (véase Capítulo IV). Por último, si se analiza la matriz de datos expuesta por los autores, no se obtiene la misma topología. Los autores proponen que el stock ancestral se divide durante el Oligoceno en dos grandes clados, con glándulas lumbares y sin ellas, mientras que en los resultados obtenidos en el presente análisis la presencia de glándulas lumbares es uno de los caracteres que arupan el género en el análisis bajo pesos implicados, perdiéndose una sola vez en el clado ( $P$. diplolister (Pleurodema marmoratum ( $P$. tucumanum (P. nebulosum + P. guayapae)))).

Pleurodema borellii y P. cinereum han sido consideradas, desde finales del siglo $X X$, especies crípticas que habitan las regiones orientales de la cordillera de los Andes (Cei 1980a; Lavilla et al. 2000; ver comentarios en de la Riva et al. 2000). Sin 
embargo, algunos autores consideraron a P. borellii como un sinónimo reciente de P. cinereum (Parker 1927; Barrio \& Rinaldi de Chieri 1970), siendo su estatus muy controvertido. Gallardo (1968) propuso algunas diferencias morfológicas sutiles entre estos dos taxones, en tanto que Duellman \& Veloso (1977) sugirieron una separación altitudinal entre ellos (tierras bajas, hasta los $3.000 \mathrm{~m}$ s.n.m. habitadas por P. borellii y tierras por encima de este nivel habitadas por P. cinereum) y una diferenciación en la coloración de las regiones ocultas de los fémures (rosa-lavanda para P. borellii y amarillo para P. cinereum). Sin embargo, ni análisis de bioacústica ni electroforéticos (McLister et al. 1991) ni morfología externa de larvas (Fernández \& Fernández 1921; Cei 1980a; Fabrezi \& Vera 1997) han aportado evidencia inequívoca sobre diferenciación de estos taxones. Una excepción sería el trabajo de Wassersug \& Heyer (1988), en el cual los autores describen diferencias en la papilación de las cavidades bucales de las larvas de las dos especies. En síntesis, los caracteres utilizados para diferenciar $P$. borellii y $P$. cinereum no parecen conclusivos, y en general, se sigue el criterio de la diferenciación de sus distribuciones para asignar los individuos a una o otra especie. Recientemente, Ferraro \& Casagranda (2009) han sugerido considerar a las poblaciones como un complejo de especies (P. cf. borellii y P. cf. cinereum) hasta tanto evidencia conclusiva sea publicada.

De acuerdo a los resultados aquí presentados, los análisis con pesos iguales y pesos implicados $P$. borellii y $P$. cinereum resultaron especies hermanas (véase optimización de sinapomorfías en Figs. 39 y 42 ).

En conclusión, considero que los resultados obtenidos sustentan la validez de las dos especies como tales, pero destaco la necesidad de estudios comparativos de morfología, osteología, bioacústica, citogenética, morfología larval y/o moleculares a fin de conocer el estatus de estas poblaciones que habitan desde Perú hasta el noroeste de Argentina. En el presente estudio no fuero incluidos representantes de todo el rango de distribución para todos los caracteres considerados; sin embargo, la hipótesis aquí presentada sugiere que se trata de dos especies que pueden diferenciarse, fundamentalmente, en base a caracteres osteológicos, para los cuales se incluyeron representantes de las respectivas localidades tipo. Sin embargo, sus límites de distribución aún no están bien establecidos; idealmente, debieran explorarse los caracteres que diferencian a P. borellii de P. cinereum en ejemplares de todo el rango y especialmente en especímenes de zonas de transición. 
Barrio (1964a) describió Pleurodema guayapae, especie que hasta entonces estaba confundida con P. nebulosum. El autor propuso que estas dos especies, diferenciables fundamentalmente por el canto y algunos pocos caracteres de morfología, están filogenéticamente relacionadas; incluso el autor describió el hallazgo de híbridos en zonas de simpatría (provincia de La Rioja). Además, estas dos especies mantienen estrecha relación con P. tucumanum. Por su parte, Cei (1980) destacó que Pleurodema nebulosum, P. guayapae y P. tucumanum conforman un especializado grupo dentro de Pleurodema que se diferenció de las restantes especies del género. El autor propone que estas tres especies habrían perdido las glándulas lumbares y los dientes vomerinos, su hocico se habría acortado y su fisiología les permitiría sobrevivir en ambientes desérticos y salinos. vomerinos presentes, dispuestos en dos grupos oblicuos entre las coanas..."; sin embargo, mis observaciones coinciden con Cei (1980), dado que no observé dientes vomerinos en ninguna de las tres especies (35:0), aunque en dos ejemplares de P. tucumanum observé proceso dentígero pero sin dientes (MLP A. 1960 y 4727). Con respecto a la morfología esternal, hallé un ejemplar con xifisternón doble (MLP A. 1961; 79:3) y dos con xifisternón escindido distalmente (MLP A. 1960, 4727), como el representado por Barrio (1964a, fig. 11 A). En consecuencia, este carácter es polimórfico para P. tucumanum y no constituye una diferencia con P. guayapae y P. nebulosum, especies en la cuales siempre observé xifisternón doble. Finalmente, mis observaciones sobre el oído de estas tres especies (caracteres 58-60) coinciden con las descripciones de Barrio (1964a).

\section{Relaciones de Pleurodema con otros géneros}

Lynch (1971; ver tabla 2 del presente trabajo) sugirió que Pleurodema es un Leptodactylinae primitivo, posiblemente relacionado con Eupsophus (incluyendo especies actualmente asignadas a Alsodes, Eupsophus y Phrynopus), aunque estos dos géneros difieren en su morfología esternal, biología reproductiva y pérdida de cuadradoyugal. Sin embargo, el autor propone que las similitudes entre los dos géneros son tan amplias que los Leptodactylinae pueden considerarse una tribu de los Telmatobiinae (Lynch 1971: 207). Estas conclusiones no están sustentadas por el presente análisis filogenético, dado que las especies incluidas de Eupsophus y Alsodes no están cercanamente emparentadas con el clado Pleurodema + Somuncuria.

El análisis que realizó Heyer (1975) entre los géneros de la familia Leptodactylidae (sensu Lynch 1971) arrojó dos hipótesis de relaciones para Pleurodema. En una de ellas, Pleurodema resulta relacionada con Batrachyla, 
Batrachophrynus, Eupsophus y Telmatobius y, en la otra hipótesis, con Physalaemus. El autor concluyó que no hay evidencias para preferir una u otra hipótesis. Finalmente, Heyer (1975) señaló que el género Pleurodema podría ser polifilético, debido a la distribución geográfica discontinua y a los diferentes modos reproductivos de sus especies. Los resultados de Heyer (1975) no son comparables con hipótesis filogenéticas, como bien indica Ponssa (2008), dado el tipo de metodología utilizado (i.e. agrupamientos por similitudes). Sin embargo, a modo de comentario, podemos citar las relaciones de Pleurodema con respecto a los géneros que propone Heyer (1975). De acuerdo al análisis filogenético de Alcalde (2007), Batrachyla no está cercanamente relacionado a Pleurodema (aunque el autor sólo incluyó Pleurodema borellii, especie con la cual enraizó el árbol). Con respecto a Eupsophus, los resultados aquí presentados no permiten sostener su afinidad. Finalmente, Barrionuevo (2009) recientemente presentó un análisis filogenético de Telmatobius, en el cual Batrachophrynus cae anidado dentro de Telmatobius, por ende, solo restaría evaluar la afinidad de Telmatobius con Pleurodema, aunque el análisis del autor obtiene a Pleurodema borellii lejanamente emparentada con Telmatobius.

Duellman \& Veloso (1977) sugirieron que Pleurodema es intermedio entre los Telmatobiinae (Alsodes, Batrachrohrynus, Eupsophus, Hylorina, Limnomedusa, y Telmatobius) y los Leptodactylinae. Además, proponen que los Leptodactylinae surgen de un stock de telmatobinos similar a Eupsophus y no de Pleurodema, dado que este último género carece de cuadradoyugal (que sí está presente en el resto de los Leptodactilinos excepto Pseudopaludicola). Los autores arriesgan una derivación aún más especulativa, sugiriendo que este stock de telmatobinos similar a Eupsophus dio origen por un lado a Pleurodema (sin cuadradoyugal) y por otro al resto de los Leptodactilinos, quienes se distribuyeron hacia los trópicos durante la paleoflora chaqueña del Terciario. Como ya indicáramos para las conclusiones de Lynch (1971), el análisis filogenético aquí presentado no permite sostener estas hipótesis, dado que la especie de Eupsophus incluida no resulta cercanamente emparentada con Pleurodema.

Cei (1969) describió Telmatobius somuncurensis (Fig. 10 B) y Telmatobius reberverii (actualmente Atelognathus reberverii) en base a material proveniente de la Meseta de Somuncurá (Río Negro, Argentina), un afloramiento basáltico del Terciario. El autor indica que las dos especies están indudablemente emparentadas con los telmatobinae mediante varios caracteres morfológicos $\mathrm{y}$, en el caso de $\mathrm{T}$. somuncurensis, por preferencias ecológicas y por su biología. Además, sugiere una posible relación entre $T$. somuncurensis y el género Cycloramphus (sudeste de 
Brasil), debido a la presencia de meniscos en los bordes superior e inferior de la pupila.

Posteriormente, Lynch (1978) describe el género Somuncuria y transfiere Telmatobius somucurensis, de modo tal que se constituye en un género monotípico debido a sus particularidades. Además, el autor sugiere que existe afinidad entre Somuncuria y Pleurodema debido a similitudes en su arquitectura craneana, columna vertebral, cintura pectoral y amplexo inguinal, si bien el autor consideró que Somuncuria era un Telmatobiinae. El autor destacó que los dos géneros difieren en el xifisternón (presente en Pleurodema y ausente en Somuncuria) y en el arreglo de los cótilos de la vértebra cervical. Este último carácter había sido definido previamente por Lynch (1971), quien identificó tres tipos: tipo I (cótilos ampliamente separados medialmente con dos superficies de articulación), tipo II (cótilos levemente separados medialmente con dos superficies de articulación) y tipo III (cótilos fusionados medialmente formando una superficie de articulación). Este carácter no fue incluido en el presente trabajo debido a que resultó ambiguo al momento de codificar, dado que el gradiente de proximidades de los cótilos no permitió asignar la variación observada a caracteres discretos; de hecho, el mismo Lynch (1971) es contradictorio, dado que señala que Limnomedusa, Odontophrynus y Pleurodema tienen un arreglo intermedio entre los tipo I y II (pág. 54), mientras que más adelante indica que Limnomedusa tiene arreglo tipo II (pág. 171) y Pleurodema tipo I (pág. 172).

El análisis filogenético aquí presentado no sustenta las relaciones de Somuncuria y los géneros de Telmatobiinae (sensu Lynch 1978) aquí incluidos, i.e., Eupsophus, Batrachyla y Alsodes. En cambio, Pleurodema somuncurensis nov. comb. resulta siempre anidada dentro de Pleurodema. Además de los caracteres en común entre ambas especies señalados precedentemente, Cei destaca la similitud en el gran tamaño de las gónadas de los machos; con una proporción promedio de longitud hocico-cloaca/largo de los testículos de 2.61 en P. somuncurensis (Cei 1970). Sin embargo, mientras que $P$. bufoninum tiene un ciclo anual discontinuo auto-regulado, P. somuncurensis posee un ciclo espermatogenético anual continuo, quizás relacionado con las condiciones ambientales estables de los ambientes de la Meseta de Somuncurá que ocupa la especie, i.e. arroyos termales de temperatura constante (Cei 1961; 1962b; 1970).

Relaciones entre los géneros de Leiuperidae (sensu Grant et al. 2006) 
Las más recientes propuestas filogenéticas, aunque con objetivos y muestreos de taxones muy diferentes, no coinciden en las relaciones de Pleurodema. Frost et al. (2006) obtiene a Pleurodema como grupo hermano de (Phyalaemus + Edalorhina). Por su parte, Grant et al. (2006) revalidan la familia Leiuperidae para incluir al clado (Pseudopaludicola (Pleurodema (Edalorhina + Physalaemus); además de estos cuatro géneros, incluyen a tres más de los cuales no poseen secuencias: Somuncuria, Engystomops y Eupemphix. Estos dos últimos géneros habían sido revalidados por Nascimento et al. (2005) separándolos de Physalaemus.

El análisis filogenético de Lourenço et al. (2008) recupera Scythrophrys + Paratelmatobius como un clado monofilético, el cual es a vez grupo hermano de Pseudopaludicola + Leptodactylus, aunque con bajo soporte. Estos cuatro géneros conforman un clado que forma parte de una tricotomía junto con ((((Edalorhina + Engystomops) (Euphemphix + Physalaemus)) Pleurodema) y Centronele + Cochranella. En conclusión, estos resultados no sustentan la monofilia de la familia Leiuperidae.

El análisis filogenético de Ponssa (2008) recupera a Leptodactylus monofilético en base a cinco sinapomorfías, tres no ambiguas. El grupo hermano de Leptodactylus está conformado por un clado constituido por los representantes de Leiuperidae (Pleurodema borellii (Engystomops pustulosus + Pseudopaludicola boliviana)) más los representantes de Ceratophryidae (Ceratophrys cranwelli (Telmatobius scrocchii + Telmatobius pisanoi) incluidos por la autora. Los resultados de Ponssa (2008) sugieren la monofilia de Leiuperidae, aunque muy pocas especies de la familia fueron incluidas.

En relación a los grupos externos, algunos comentarios sobre el nodo (Physalaemus (Pleurodema fuscomaculatum)(Eupemphyx + Engystomops))) pueden realizarse. Este grupo resultó siempre bien soportado en todos los análisis realizados (Figs. 41, 43-45). Sin bien no es el objetivo del presente trabajo analizar la filogenia de Physalaemus, el mismo puede aportar caracteres útiles al momento de realizar un análisis cladístico del género, el cual, obviamente, deberá incluir muchos más terminales.

Nuestros resultados no corroboran la propuesta de Nascimento et al. (2005), la cual sugiere revalidar Engystomops (para incluir las siete especies del grupo pustulosus de Physalaemus) y Eupemphix (para incluir Physalaemus nattereri). Si bien una sola especie del grupo pustulosus fue incluida (E. pustulosus), dicha especie resultó profundamente anidada dentro de Physalaemus junto con $\mathrm{E}$. nattereri en todos los análisis aquí presentados. 
Sin embargo, no considero conveniente sugerir ningún arreglo taxonómico (i.e. transferencia de estas dos especies al género Physalaemus). Si bien el trabajo de Nascimento et al. (2005) no emplea metodología cladística para sugerir los nuevos agrupamientos, el presente estudio carece de suficientes representantes para obtener una hipótesis sólida respecto a las relaciones de estos géneros. Por último, y como me mencionó previamente, la posición filogenética de Pleurodema fuscomaculatum debe ser re-evaluada a la luz de nueva evidencia; por el momento no se sugiere ningún cambio respecto a su estatus taxonómico.

En conclusión, al presente existe evidencia contradictoria sobre la monofilia de la familia Leiuperidae, recientemente revalidada por Grant et al. (2006). Son necesarios estudios diseñados especialmente para probar la monofilia de esta familia, incluyendo el mayor número de terminales posible.

\section{Origen de las glándulas lumbares}

La piel de los anfibios posee dos tipos de glándulas: las glándulas mucosas, usualmente asociadas a respiración y balance hídrico, y las glándulas granulosas (también llamadas venenosas o serosas), las cuales secretan sustancias relacionadas con mecanismos de defensa (Fox 1994). Ambos tipos glandulares están dispersos en toda la piel de los anuros, pero en algunas especies las glándulas granulosas conforman acúmulos de desarrollo excepcional, llamados macroglándulas (Toledo \& Jared 1995; Mattos et al. 2003). De los siete géneros de Leiuperidae reconocidos por Grant et al. (2006), cuatro de ellos poseen macroglándulas en la región sacra del cuerpo, llamadas, según su posición, glándulas lumbares (Pleurodema, Somuncuria, Edalorhina) o inguinales (Physal aemus).

De acuerdo al análisis bajo pesos implicados presentado, una de las sinapomorfías del clado Pleurodema* es la presencia de glándulas lumbares, condición que revierte una sola vez enel clado ( $P$. diplolister ( $P$. marmoratum (P. tucumanum ( $P$. nebulosum + P. guayapae)))). En el análisis bajo pesos iguales, si bien no surge como una sinapomorfía, su optimización indica que es la condición ancestral que revierte dos veces, $P$. marmoratum y en el clado ( $P$. diplolister ( $P$. tucumanum ( $P$. nebulosum + P. guayapae))). Mangione \& Lavilla (2004) estudiaron la piel de la región lumbar de estas cinco especies sin manifestación externa de glándula lumbar, con resultados muy interesantes. Los autores hallaron que, en la región lumbar, las glándulas ocupan un espesor no menor al 45\%. Además, encontraron que las glándulas granulosas, siempre alveolares, están en proporción 1:1 respecto a las mucosas, lo cual es superior a la proporción existente en la piel dorsal. Estos resultados indican 
que la región lumbar de estas cinco especies posee glándulas granulosas bien diferenciadas y en mayor proporción que el resto de la piel. Además, los autores hallaron las menores cantidades de tejido glandular en el par de especies hermanas $P$. nebulosum y P. guayapae; estos resultados son coincidentes con las relaciones sugeridas por el análisis filogenético aquí presentado.

En conclusión, estamos la condición ancestral para el género Pleurodema es la presencia de glándulas lumbares protuídas, las cuales resultan imperceptibles externamente pero evidentes a nivel microscópico en P. marmoratum, P. diplolister, P. tucumanum, P. nebulosum y P. guayapae.

Con respecto al género Physalaemus, podemos hacer algunos comentarios. A pesar de que en el presente estudio se incluyeron pocas especies, todas aquellas que sí poseen glándulas inguinales son las más derivadas ( $P$. santafecinus ( $P$. biligonigerus $(E$. nattereri $+E$. pustulosus))). Al día de hoy, existen estudios histológicos de las glándulas inguinales de Eupemphix nattereri (Mattos et al. 2003), Physalaemus albonotatus (Álvarez et al. 2005) y de larvas premetamórficas de Physalaemus biligonigerus (Delfino et al. 2001). Sería muy interesante encarar estudios filogenéticos de estos géneros, además de estudios histológicos comparativos de las especies que poseen manifestaciones externas de las glándulas inguinales como así también de las que no las poseen. Por último, si se incluyera Edalorhina al presente estudio sería interesante evaluar su posición en el árbol en relación a este carácter.

Las glándulas lumbares e inguinales han sido relacionadas con comportamientos defensivos llamados comportamientos aposemáticos o deimáticos, durante los cuales el animal, al sentirse amenazado, se da vuelta respecto al depredador, baja la cabeza y levanta la región sacra del cuerpo, aparentando ser un animal de mayor tamaño con un gran par de ojos (Mattos et al. 2003). Estas regiones del cuerpo posiblemente tengan baja palatabilidad, por lo cual su exhibición podría disuadir a potenciales depredadores. Este comportamiento fue registrado en varias especies con glándulas lumbares o inguinales protuberantes: Pleurodema brachyops (Martins 1989), P. bufoninum (Donoso-Barros 1969a; Cei 1962a; Kolenc et al. 2009), P. thaul (Cei 1958b; Kolenc et al. 2009), P. bibroni (Vaz-Ferreira 1984; Kolenc et al. 2009), P. borellii y P. kriegi (Kolenc et al. 2009), Eupemphix nattereri y Physalaemus deimaticus (Sazima \& Caramaschi 1986) y Physalaemus biligonigerus (Borteiro \& Kolenc 2007). Además, este comportamiento, a veces menos evidente, fue observado en otras especies carentes de glándulas lumbares o inguinales prominentes: Leptodactylus latinasus, Leptodactylus ocellatus, Physalaemus henselii (Borteiro \& Kolenc 2007) y Pleurodema tucumanum (Kolenc et al. 2009). Hasta donde sabemos, 
este comportamiento pareciera estar filogenéticamente conservado en al menos algunas especies de los géneros Physalaemus, Eupemphix, Pleurodema y Leptodactylus, además de ser independiente de la presencia de glándulas lumbares o inguinales.

En relación a la composición química de la piel de los anuros, interesantes resultados han sido hallados en la piel de varias especies de Pleurodema. Se han encontrado aminas biogénicas en la piel de Pleurodema borellii (como P. cinereum), P. tucumanum, P. guayapae, P. nebulosum, P. thaul (como P. bibroni) y Pleurodema bufoninum. En las primeras cuatro especies se halló fenil-alquilaminas (llamadas leptodactylinas); en poblaciones chilenas de $P$. thaul fenil-alquilaminas $e$ indolalquilaminas (sulfato 5-hidroxitriptamina creatinina), en poblaciones argentinas de P. thaul sólo fenil-alquilaminas, y en P. bufoninum sólo indolalquilaminas (sulfato 5-hidroxitriptamina creatinina). Otros compuestos peptídicos también han sido hallados en géneros relativamente afines a Pleurodema, e.g. Physalaemus, Leptodactylus (Cei \& Erspamer 1966; Cei et al. 1967; Cei 1985). Esta interesante línea de investigación podría ser profundizada y sus resultados aplicados a estudios filogenéticos.

\section{Modos reproductivos}

Como se indicara en el Capítulo IV, Pleurodema posee más de una modalidad reproductiva: (a) nidos de espuma, (b) cordones, (c) masas adheridas a vegetación emergente, y (d) masas gelatinosas que flota en la superficie del agua. De acuerdo a los resultados de la filogenia aquí presentada, las últimas tres modalidades descriptas sólo las desarrollan especies del género Pleurodema*. La modalidad en nidos de espuma esféricos puestos en el agua aparece en otros Leiupéridos (Physalaemus, Eupemphix y Engystomops) y Leptodacílidos (Leptodactylus latinasus y Leptodactylus ocelltatus).

De acuerdo a la topología obtenida en el presente análisis filogenético, sería esperable que la modalidad de reproducción de Pleurodema aff. bibroni sea la misma que la del clado que la contiene, i.e., huevos depositados en masas no batidas, asociados a vegetación emergente (Fig. 22 E).

Es interesante destacar que la modalidad en nidos de espuma aparece en un solo subgrupo del género, aquél que incluye P. cinereum, P. borellii, P. brachyops, P. diplolister, P. tucumanum, P. nebulosum y P. guayapae. Curiosamente, la información sobre la reproducción de P. tucumanum es contradictoria. De acuerdo con Martori et al. (1994), P. tucumanum ovipone mediante nidos ovoides, en forma 
de plato, mientras que Cei (1956c), Barrio (1964a; 1977) y Perotti (1994; 1997) sostienen que ovipone mediante nidos de espuma (en el presente trabajo se siguió a Martori et al. [1994] para codificar su modo de reproducción). En consecuencia, podemos interpretar que la condición nidos de espuma surge una sola e el género Pleurodema y sólo revierte en P. tucumanum (en la hipótesis bajo pesos iguales) o dos veces, sumando a P. marmoratum (en la hipótesis bajo peso simplicados).

\subsection{Análisis cladístico excluyendo especies poliploides}

La matriz de datos, excluyendo las especies poliploides, fue re-analizada bajo pesos implicados $(\mathrm{k}=6)$. Se obtuvo un único árbol máximamente parsimonioso (437 pasos, IC=0,387, IR=558), ilustrado en las Figuras 46-47. En este análisis el género Pleurodema resulta ser parafilético, y sus especies se agrupan en dos linajes: $(P$. thaul (S. somuncurensis + P. bufoninum); ((P. marmoratum (( $P$. tucumanum (P. nebulosum + P. guayapae) $)(P$. diplolister (P. brachyops $(P$. borellii + P. cinereum $)))$ ) La especie restante, Pleurodema fuscomaculatum, queda nuevamente anidada dentro de Physalaemus.

La poliploidía es un fenómeno que afecta tanto a plantas como a animales. En Anuros han sido reconocidos 16 géneros de diferentes familias (Arthroleptidae, Bufonidae, Hylidae, Leiuperidae, Leptodactylidae, Limnodynastidae, Microhylidae, Pipidae y Ranidae) donde se han registrado especies poliploides. Considerando la distribución taxonómica de este proceso, se ha postulado que no está restringido a ningún linaje particular de anuros (véase Rosset et al. 2006 y trabajos citados allí).

En el género Pleurodema tres niveles de ploidía han sido identificados: una especie octoploide ( $P$. cordobae, $2 n=8 x=88$ ), dos especies tetraploides ( $P$. bibroni y P. kriegi, $2 n=4 x=44$ ) y las restantes especies diploides (ver especies poliploides en Fig. 6). Además, cabe recordar que no se conoce el nivel de poliploidía de Pleurodema aff. bibroni, especie de Rio Grande do Sul, Brasil.

Previamente a la descripción de P. cordobae y a la distinción de las poblaciones de P. aff. bibroni como una potencial especie diferente de P. bibroni, ha sido discutido el posible origen de P. bibroni y P. kriegi. Varios autores coincidieron en considerar estas dos especies cercanamente emparentadas (Barrio \& Rinaldi de Chieri 1970; Barrio 1977; Duellman \& Veloso 1977).

En relación al origen de la poliploidía, Duellman \& Veloso (1977) y Barrio (1977) coinciden en proponer que la poliploidía se originó una sola vez, basándose en 
similitudes exomorfológicas, canto nupcial y de biología reproductiva. Además, coinciden en sugerir que el antecesor común de P. bibroni y P. kriegi habitó la zona centro-oeste de Argentina, dispersándose en dirección al este hacia la región central de Argentina, sur de Brasil y Uruguay. Sin embargo, los autores han propuesto mecanismos diferentes para el origen de este fenómeno. Duellman \& Veloso (1977) sugirieron que existió un evento de autopoliploidía con posterior conversión a complemento diploide, probablemente a partir de una especie con distribución cercana, como ser Pleurodema borellii. En cambio, Barrio \& Rinaldi de Chieri (1970) y Barrio (1977) propusieron que estas especies se originaron por un proceso de alopoliploidía a partir de un antecesor común tetraploide ampliamente distribuido, dado que no hay una correspondencia exacta entre los complementos mitóticos y que no se observan figuras tetravalentes en la meiosis.

Varios autores consideraron que P. bibroni y P. kriegi podrían estar emparentadas con el par de especies P. borellii-P. cinereum (Parker 1927; Lynch 1971; Duellman \& Veloso 1977). Por su parte, Barrio \& Rinaldi de Chieri (1970) y Barrio (1977) sugirieron que las dos especies parentales de P. bibroni y $P$. kriegi pueden no existir en la actualidad, pero que una de ellas podría ser Pleurodema thaul o Pleurodema bufoninum. Estas especies poseen glándulas lumbares, no producen nidos de espuma $y$ habitan zonas semidesérticas ( $P$. thaul, aunque se la encuentre preferentemente en bosques húmedos del sur de Argentina, vive en el ecotono con la estepa, y en Chile habita una amplia variedad de ambientes). Una detallada discusión de las dos hipótesis se encuentra en Barrio (1977). Más aún, Barrio (1977) propone un origen andino-patagónico de estas dos especies, sosteniéndose en las similitudes de cariotipos, reproducción a bajas temperaturas y no construcción de nidos de espuma en relación a $\mathrm{P}$. bufoninum y $\mathrm{P}$. thaul, además de las similitudes en el canto nupcial con esta última especie (Fig. 1 B).

Desde estos trabajos realizados en la década del '70, no contamos con nueva información referente al origen de la poliploidía en Pleurodema; la única evidencia indirecta de un posible origen alopolploide de P. kriegi y P. bibroni (i.e. no formación de figuras tetravalentes en la meiosis) fue sugerida por Barrio \& Rinaldi de Chieri (1970). Sin embargo, al presente contamos con nuevas herramientas a la luz de metodologías moleculares.

Para detectar el posible origen autopolploide o alopoliploide de especies poliploides, se han aplicado varias metodologías: técnicas citogenéticas (identificación de Regiones Organizadoras de Nucléolos) y técnicas moleculares (i.e. 
alozimas, Hibridación in situ fluorescente [FISH]) (e.g. Chenuil et al. 1999; Stöck et al. 2005; Holloway et al. 2006).

En los últimos años, han sido publicados varios trabajos que tratan esta problemática, especiamente en plantas, donde la poliploidía es un mecanismo evolutivo muy frecuentemente observado. Uno de los aspectos fundamentales respecto a la alopoliploidía es poder detectar patrones de evolución reticulada mediante marcadores moleculares adecuados. Sin embargo, Lott et al. (2009) destacaron que los estudios filogenéticos moleculares en plantas han sido dominados por el uso de secuencias de regiones incapaces de rastrear la historia evolutiva heredada biparental. Para poder diferenciar la poliploidización de otros procesos biológicos (e.g. hibridación homoploide, transferencia horizontal de genes, duplicación/pérdida de genes, recombinación, errores de muestreo) es necesario contar con un gran número de loci (Lott et al. 2009).

Además de la selección de los marcadores moleculares más apropiados, otro problema lo representa el hecho de que los eventos de alopoliploidía implican evolución reticulada. Esta condición dificulta los análisis filogenéticos basados en modelos dicotómicos de evolución de caracteres. Se ha sugerido que los procesos de poliploidía se representan mejor mediante redes (que reflejen la evolución reticulada) que mediante árboles dicotómicos (e.g. Posada \& Crandall 2001; Linder \& Rieseberg 2004; Huber \& Moulton 2006; Huber et al. 2006). Huber \& Moulton (2006) llamaron redes filogenéticas ("phylogenetic network”) a aquellos gráfico con raíz, ramas dirigidas y ciclos sin dirección, cuyas ramas son llamadas según los nombres de los taxones (siendo posible que varias ramas lleven el nombre del mismo taxón). Para una red filogenética determinada, es posible asociar un cladograma determinado, entendiendo por cladograma una red filogenética sin interacción entre los nodos (Huber et al. 2006).

En síntesis, al día de hoy contamos con metodologías moleculares que permitirían comprender los patrones de evolución en especies poliploides. Si bien al presente no ha sido publicada ninguna hipótesis filogenética de Pleurodema basada en evidencia molecular, sería sumamente interesante poder aplicar estas metodologías al género y en particular al clado de especies poliploides. 


\section{CAPITULO V}

Análisis biogeográfico

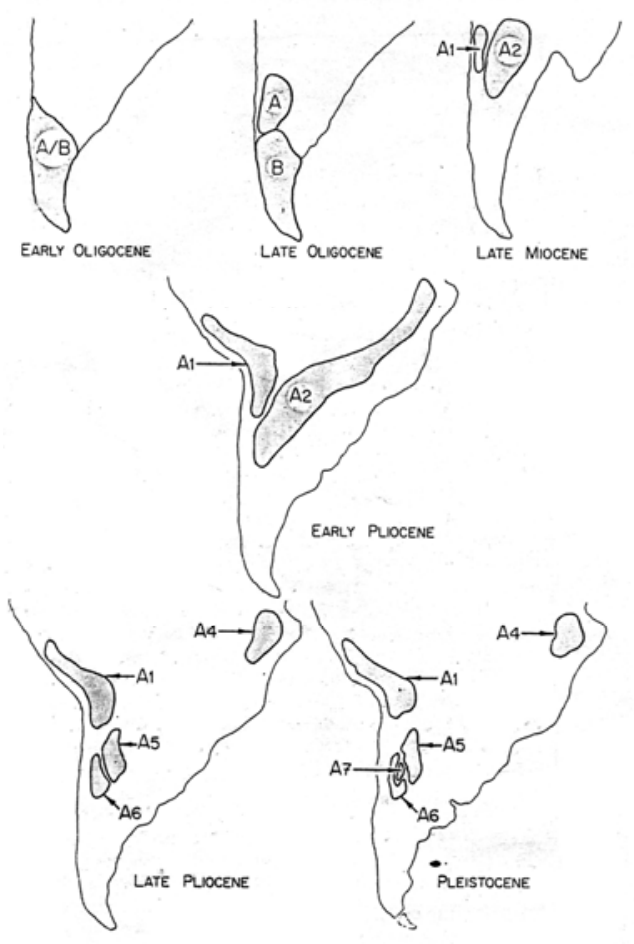

Tomado de Duellman \& Veloso (1977) 


\subsection{Distribución de las especies de Pleurodema}

A continuación se describen las áreas de distribución conocidas para cada especie y su correspondencia con el esquema biogeográfico de Morrone (2001). Para detalles de los rangos de distribución de las especies de Pleurodema en Argentina, ver Ferraro \& Casagranda (2009); para P. bibroni en Uruguay, ver Kolenc et al. (2009) y para P. aff. bibroni en Brasil ver Kolenc et al. (2009, como P. bibroni).

Pleurodema bibroni (Fig. 6 A-B) habita costas arenosas con pajonales y ciperáceas, y zonas serranas de Uruguay (Klappenbach \& Langone 1992; Maneyro et al. 1995; Núñez et al. 2004; Natale \& Maneyro 2008; Kolenc et al. 2009). Esta distribución corresponde a la REGIón NEOTROPICAL: Subregión Chaqueña: Provincia de la Pampa.

Pleurodema aff. bibroni (Fig. 6 E) fue hallada en los estados de Rio Grande do Sul y Santa Catarina, Brasil (J iménez de la Espada 1875; Braun 1973; Lema \& Braun 1993). Esta distribución corresponde a la REGIÓN NEOTROPICAL: Subregión Chaqueña: Provincia de la Pampa.

Pleurodema kriegi (Fig. 6 C-D) es un endemismo de Pampa de Achala y algunas otras altiplanicies de las Sierras de Grandes (Córdoba), habitando superficies rocosas graníticas, con vegetación herbácea (Barrio 1977). Esta distribución corresponde a la REGIÓN NEOTROPICAL: Subregión Chaqueña: Provincia del Chaco.

Pleurodema cordobae (Fig. 6 F) es una especie octoploide recientemente descripta, conocida por el momento sólo para su localidad tipo, Sierra de Comechingones, provincia de Córdoba (Argentina) (Valetti et al. 2009). Las referencias de Ávila \& Priotto (1995) y Ávila et al. (1999) posiblemente correspondan a este taxón, ya que están basadas en material de esa localidad. Esta distribución corresponde a la REGIÓN NEOTROPICAL: Subregión Chaqueña: Provincia del Chaco.

Pleurodema borellii y P. cinereum son un par de especies crípticas, distribuidas en las laderas orientales de la cordillera de los Andes. Los límites de sus distribuciones geográficas no están bien establecidos (Ferraro \& Casagranda 2009). Pleurodema cinereum (Fig. 7 A-B) habitaría las regiones altoandinas de Perú (Lago Titicaca y alrededores, Juliaca, Puno, llave), Bolivia (Departamentos de Cochabamba, Chuquisaca, La Paz, Oruro y Potosí) y Argentina (provincia de J ujuy), entre 2.500 y 4.500 m s.n.m (Cope 1877; Andersson 1906; Cei 1956c; 1959; 1980a; Duellman \& Veloso 1977; de la Riva 1990; de la Riva et al. 2000; Peracca 1897). Esta distribución corresponde a la REGIóN ANDINA: Subregión Páramo Puneña: Provincias de Puna y Prepuna. 
Por su parte, P. borellii (Fig. 7 C-D) fue hallada en ambientes subtropicales de montes deciduos, valles interandinos, matorrales xerófilos y selvas pedemontanas de Bolivia (Departamentos de Tarija y Chuquisaca) y Argentina (provincias de Jujuy, Tucumán, Salta, La Rioja y Catamarca), en áreas de 400 a 3.000 m s.n.m. (Peracca 1897; Gallardo 1968a; Laurent 1980; Cei 1980a; Lavilla et al. 2000). Esta distribución corresponde a la REGIÓN NEOTROPICAL: Subregión Chaqueña: Provincias del Monte y Chaco; Subregión Amazónica: Provincia de las Yungas.

Pleurodema brachyops (Fig. 7 E) habita savanas, llanos y regiones áridas de las Islas de Curazao, Aruba, Donaire, Klein Bonaire y Margarita; el norte de Colombia, Venezuela continental, Guayana, Panamá y norte de Brasil (Lutz 1927; Parker 1935; Rivero 1961; Cochran \& Goin 1970; Duellman \& Veloso 1977; Staton \& Dixon 1977; La Marca 1992). Esta distribución corresponde a la dos subregiones de la REGIóN NEOTROPICAL: Subregión Caribeña: Provincias de Antillas Menores, Chocó, Maracaibo, Trinidad y Tobago, Magdalena y Llanos Venezolanos; Subregión Amazónica: Provincias de Imerí, Guyana, Guyana Húmeda, Roraima, Amapá, Varzea y Madeira.

Pleurodema bufoninum (Fig. 8 A-C) habita toda la estepa patagónica argentina, incluyendo las provincias de Neuquén, Río Negro, Chubut y Santa Cruz (Cei 1980a); en Santa Cruz ingresa en bosques de lenga y guindo (Úbeda 1998). Su límite más septentrional lo alcanza ingresando hacia hasta Mendoza por la faja florística de la provincia patagónica, alcanzando una altitud de 1.900-2.000 m s.n.m. en el Valle del Pehuenche (Cei 1965; Cei \& Roig 1961). En Chile ha sido hallada desde Aysén hasta Magallanes, ocupando muy distintos biotopos desde el nivel del mar hasta los 2300 m.s.n.m. (Schmidt 1954; Capurro 1958; Cei 1962b; 1962a; 1972; Cei \& Roig 1961; Donoso-Barros 1969a; Duellman \& Veloso 1977; Rabanal Gatica \& Nuñez Navarro 2009). Esta distribución corresponde a la REGIÓN NEOTROPICAL: Subregión Chaqueña: Provincia de Monte; REGIón ANDINA: Subregión Patagónica: Provincias de Patagonia Central y Patagonia Subandina; Subregión Subantártica: Provincias de Maule, Bosque Valdiviano y Bosque Magallánico.

Pleurodema diplolister (Fig. 8 D) habita regiones áridas y semiáridas del noreste de Brasil (Caatinga y áreas abiertas adyacentes), donde predomina la vegetación xérica y la estacionalidad (Arzabe 1999; Santos et al. 2003), habiendo sido registrada para los estados de Bahia, Rio Grande do Norte, Ceará y Paraíba (véase Hödl 1992). Esta distribución corresponde a la REGIÓN NEOTROPICAL: Subregión Chaqueña: Provincia de Caatinga. 
Pleurodema fuscomaculatum (Fig. 8 E) se conoce sólo por su material tipo, proveniente de Caiçará, Estado de Mato Grosso, Brasil (Steindachner 1863) y por una muestra recolectada en la región del Río Apa (Paraguay) por el Dr. Borelli durante una expedición en 1893-1894 (Cei 1990). Esta distribución corresponde a la REGIóN NEOTROPICAL: Subregión Chaqueña: Provincia del Cerrado.

Pleurodema guayapae vive en salares y zonas semidesérticas en el área de confluencia de las provincias de Catamarca, Córdoba, La Rioja y Santiago del Estero, Argentina (Barrio 1964b; Gallardo 1968a; di Tada et al. 1976; 1996; Cei 1980a; Lavilla et al. 1992; 2000; Bridarolli \& di Tada 1994) (Fig. 8 F; ver ambiente en Fig. 9 D). Además, fue hallada en el Departamento de Santa Cruz (Bolivia), en una región chaqueña distante a unos $1000 \mathrm{~km}$ en línea recta de las poblaciones argentinas (Gonzales 1998; de la Riva \& Gonzales 1998). Esta especie podría estar presente en Paraguay, dado que las poblaciones bolivianas son próximas al Departamento Boquerón, pero resta su confirmación (Brusquetti \& Lavilla 2006). Esta distribución corresponde a la REGIÓN NEOTROPICAL: Subregión Chaqueña: Provincia del Chaco.

Pleurodema nebulosum (Fig. 9 A-B) habita la región del Monte y Chaco en Argentina, en La Rioja, Catamarca, Salta, San Juan, Mendoza, Neuquén, Río Negro y La Pampa, desplazándose hasta Córdoba y San Luis en su límite más oriental (Cei 1959; Cei \& Roig 1964; Cei 1980b; 1980a; Barrio 1964b; Gallardo 1965; Laurent 1969; di Tada et al. 1976; 1996; Hulse 1977; Martori \& Ávila 1988; Lavilla et al. 1992; Aún \& Martori 1999; Bridarolli \& di Tada 1994; 2000; Ferraro 2004; Cei 1956b). Prefiere ambientes áridos y relativamente salinos, encontrándose por debajo de los 2000 m.s.n.m (en San Juan, Cei 1956c; 1979). Esta distribución corresponde a la REGIóN NEOTROPICAL: Subregión Chaqueña: Provincias de Chaco, Monte y Pampa; REGIóN ANDINA: Subregión Páramo Puneña: Provincia de la Prepuna; Subregión Patagónica: Provincia de la Patagonia Central.

Pleurodema tucumanum (Fig. 9 C-D) habita regiones de monte y chaco en Salta, Tucumán, Catamarca, La Rioja, San Juan, Córdoba, San J uan y Santiago del Estero y selvas pedemontanas de Jujuy (Parker 1927; Cei 1956a; 1956c; Gallardo 1966; 1980a; Barrio 1964b; di Tada et al. 1976; 1996; Cruz et al. 1992; Lavilla et al. 1992; 2000; Haene 1994; Martori et al. 1994; Martori \& Aún 1995; Perotti 1994; 1997; Baldo \& Gutiérrez 1997; Vaira 1997). Esta distribución corresponde a la REGIóN NEOTROPICAL: Subregión Amazónica: Provincia de las Yungas; Subregión Chaqueña: Provincias de Chaco y Monte.

Pleurodema marmoratum (Fig. 7 F) habita las regiones de puna y altiplano del centro y sur de Perú, Bolivia (Departamentos de Cochabamba, La Paz, Oruro, Potosí, 
Tarija), norte de Argentina (Jujuy) y regiones montañosas del norte de Chile (Tarapacá, Montañas de Caquena), en altitudes que varían entre los 2.500-3.000 hasta los 5.000 m s.n.m. (Cei 1957; 1959; Cei 1962a; Vellard 1960; Fjeldså 1983; de la Riva 1990; 2000; Sinsch 1986; 1990; Sallaberry et al. 2007; Tarifa et al. 2007; Seimon et al. 2007). En Argentina habita en Abra Pampa, Santa Catalina, y Laguna de Ios Pozuelos, Jujuy (Cei 1959; Vaira 1998). Tarifa et al. (2007) consideraron que es una especie ampliamente distribuída en los Altos Andes de Bolivia. Esta distribución corresponde a la REGIón ANDINA: Subregión Páramo Puneña: Provincias de Puna y Atacama.

Pleurodema thaul (Fig. 9 E-F; 10 A) ocupa gran parte del territorio de Chile, desde la ciudad de Copiapó hasta la región de Aysén, desde el nivel hasta unos 2.700 m s.n.m. en la localidad de Vega Piuquenes (Schmidt 1954; Capurro 1957; Capurro 1958; Cei \& Capurro 1957; Cei 1962a; Correa et al. 2007; Rabanal Gatica \& Nuñez Navarro 2009). En Argentina vive en los bosques andino-patagónicos de Neuquén, Río Negro y Chubut, desde el nivel del mar hasta unos 1.500 m s.n.m. (Cei 1958b; 1960; 1980a; Úbeda 1998; 2001; Lavilla et al. 2000). Esta distribución corresponde a las cuatro subregiones de la REGIÓN ANDINA: Subregión Patagónica: Provincia de Patagonia Subandina; Subregión Antártica: Provincias de Maule, Bosque Valdiviano, Bosque Magallánico y Páramo Magallánico; Subregión Chilena Central: Provincias de Coquimbo y Santiago.

Pleurodema somuncurensis nov. comb. (Fig. 10 B) habita en la Meseta de Somuncurá, provincia de Río Negro, Argentina (Cei 1969b; Diminich 2006). Esta distribución corresponde a la REGIÓN ANDINA: Subregión Patagónica: Patagonia Central.

\subsection{Distribución de los grupos externos}

Las distribuciones de estas especies fueron reconstruidas de acuerdo a la página de Frost (2009) y la bibliografía indicada allí para cada especie. Además, se consideraron también los trabajos de síntesis existentes para algunos países: Bolivia (de la Riva et al. 2000), Paraguay (Brusquetti \& Lavilla 2006; Brusquetti et al. 2009), Uruguay (Núñez et al. 2004). De la misma forma que para las especies del grupo interno, se indica la correspondencia con la clasificación de Morrone (2001).

Batrachyla leptopus: REGIÓN ANDINA: Subregión Subantártica: Provincia del Bosque Valdiviano.

Physalaemus albonotatus: REGIÓN NEOTROPICAL: Subregión Amazónica: Provincia del Pantanal; Subregión Chaqueña: Provincias de Cerrado, Chaco y Pampa. 
Physalaemus biligonigerus: REGIÓN NEOTROPICAL: Subregión Chaqueña: Provincias de Chaco y Pampa.

Physalaemus fernandezae, Physalaemus henselii y Physalaemus santafecinus: REGIÓN NEOTROPICAL: Subregión Chaqueña: Provincia de la Pampa.

Physalaemus cuqui: REGIÓN NEOTROPICAL: Subregión Chaqueña: Provincia del Chaco. Presencia a confirmar en Paraguay, debido a su proximidad con los ambientes que ocupa en el Chaco Seco y Húmedo de Argentina (Brusquetti \& Lavilla 2006).

Physalaemus cuvieri. REGIÓN NEOTROPICAL: Subregión Chaqueña: Provincias de Cerrado, Chaco y Pampa; Subregión Amazónica: Provincias de Guyana, Guyana Húmeda, Amapá, Tapajós-Xingú, Pará y Pantanal; Subregión Paranaense: Provincias de Bosque Atlántico Brasileño, Bosque y Bosque de Araucaria angustifolia.

Engystomops pustulosus. REGIÓN NEOTROPICAL: Subregión Caribeña: Provincias de Costa Pacífica Mexicana, La Española, Puerto Rico, Antillas Menores, Chocó, Maracaibo, Trinidad y Tobago, Magdalena, Llanos Venezolanos y Cauca.

Eupemphix nattereri. REGIÓN NEOTROPICAL: Subregión Amazónica: Provincia del Pantanal; Subregión Chaqueña: Provincias de Cerrado y Chaco; Subregión Paranaense: Provincia del Bosque Paranaense.

Pseudopaludicola boliviana. REGIÓN NEOTROPICAL: Subregión Caribeña: Provincias de Llanos Venezolanos; Subregión Amazónica: Provincias de Imerí, Guyana, Roraima, Varzea, Madeira y Pantanal; Subregión Chaqueña: Provincias de Cerrado, Chaco y Pampa.

Pseudopaludicola falcipes. REGIÓN NEOTROPICAL: Subregión Chaqueña: Provincias de Chaco y Pampa; Subregión Paranaense: Provincias del Bosque Atlántico Brasileño, Bosque Paranaense y Bosque de Araucaria angustifolia.

Pseudopaludicola mystacalis. REGIÓN NEOTROPICAL: Subregión Chaqueña: Provincias de Cerrado, Chaco y Pampa; Subregión Paranaense: Provincias del Bosque Atlántico Brasileño, Bosque Paranaense y Bosque de Araucaria angustifolia.

Leptodactylus latinasus. REGIÓN NEOTROPICAL: Subregión Chaqueña: Provincias de Chaco y Pampa.

Leptodactylus ocellatus. REGIÓN NEOTROPICAL: Subregión Caribeña: Provincias de Maracaibo y Llanos Venezolanos; Subregión Amazónica: Provincias de Imerí, Guyana, Guyana Húmeda, Roraima, Amapá, Varzea, Madeira, Tapajós-Xingú, Pará y Pantanal; Subregión Chaqueña: Provincias de Caatinga, Cerrado, Chaco, Pampa y Monte; Subregión Paranaense: Provincias del Bosque Atlántico Brasileño, Bosque Paranaense y Bosque de Araucaria angustifolia.

Alsodes gargola. REGIón ANDINA: Subregión Patagónica: Patagonia Central. 
Odontophrynus americanus. REGIÓN NEOTROPICAL: Subregión Chaqueña: Provincia de la Pampa.

Eupsophus calcaratus. REGIÓN ANDINA: Subregión Subantártica: Provincia del Bosque Valdiviano.

\subsection{Reconstrucción del área ancestral de Pleurodema según Optimización} de Fitch (Ronquist 1994)

Se utilizó una de las resoluciones posible del análisis filogenético realizado bajo pesos implicados con valores de $\mathrm{k}$ entre 4 y 10. Los tres árboles obtenidos en dicho análisis difieren en las relaciones entre las especies poliploides de Pleurodema. En consecuencia, y considerando que para aplicar el DIVA es necesario emplear un árbol completamente dicotómico, se usó el mismo cladograma para aplicar la Optimización de Fitch y el DIVA.

La correspondencia entre las provincias biogeográficas y las letras y números empleados para construir la matriz se indica a continuación y en la Figura 49. Sólo se listan las áreas de Morrone (2001) en las cuales habitan representantes de los grupos interno y externo:

\section{REGIÓN Neotropical}

\section{SUBREGIÓN Caribeña}

P: Provincias de Costa Pacífica Mexicana, Española, Puerto Rico y Cauca

Q: Provincias de Antillas Menores, Chocó, Trinidad y Tobago y Magdalena

Y: Maracaibo

R: Llanos Venezolanos

\section{SUBREGIÓN Amazónica}

S: Provincias de Imerí, Varzea y Madeira

T: Provincia de Guyana

U: Provincias de Guyana Húmeda, Tapajós-Xingú y Pará

X: Provincia de Pantanal

Z: Provincia de Amapá

1: Provincia de Roraima

A: Provincia de Yungas

\section{SUBREGIÓN Chaqueña}
B: Provincia de Caatinga
C: Provincia de Cerrado
J: Provincia de Chaco
D: Provincia de Pampa
K: Provincia de Monte

\section{SUBREGIÓN Paranaense}

W: Provincias de Bosque Atlántico Brasileño y Bosque de Araucaria angustifolia

2: Provincia de Bosque Paranaense 


\section{REGIÓN Andina}

\section{SUBREGIÓN Páramo Puneña}

E: Provincia de Puna

F: Provincia de Atacama

G: Provincia de Prepuna

\section{SUBREGIÓN Chilena Central}

L: Provincias de Coquimbo y Santiago

\section{SUBREGIÓN Subantártica}

M: Provincias de Maule y Bosque Magallánico

H: Provincia de Bosque Valdiviano

$\mathbf{N}$ : Provincia de Páramo Magallánico

\section{SUBREGIÓN Patagónica}

I: Provincia de Patagonia Central

O: Provincia de Patagonia Subandina

El método de Optimización de Fitch asigna al área ancestral del género Pleurodema una única área, correspondiente a la Patagonia Central (Fig. 48).

\subsection{Reconstrucción de las distribuciones ancestrales de Pleurodema según} Análisis de Dispersión-Vicarianza (DIVA, Ronquist 1997)

Las áreas de distribución utilizadas para el DIVA siguen a Morrone (2001). Sin embargo, fueron necesarias algunas correcciones, dado que el DIVA no acepta más de 15 áreas de distribución (Ronquist 1996). En consecuencia, y considerando la optimización obtenida en el método de Optimización de Fitch para el nodo Leptodactylus + Odontophrynus + Pseudopaludicola + Physalaemus + Eupemphix + Engystomops (área D, Pampa), se resumió todo este clado al área de Pampa. Por otro lado, todas las provincias biogeográficas habitadas por Pleurodema brachyops fueron resumidas en una sola área $(\mathbf{N})$, dado que, considerando la modificación previamente descripta, no existe otro taxón del grupo de estudio que habite dichas áreas. Teniendo en cuenta estas dos simplificaciones, las áreas utilizadas se listan a continuación (las áreas A-K coinciden con la clasificación utilizada en la Optimización de Fitch):

$$
\begin{aligned}
& A=\text { Yungas } \\
& B=\text { Caatingas } \\
& C=\text { Cerrado } \\
& D=\text { Pampa } \\
& E=\text { Puna } \\
& F=\text { Atacama } \\
& G=\text { Prepuna } \\
& H=\text { Bosque Valdiviano }
\end{aligned}
$$




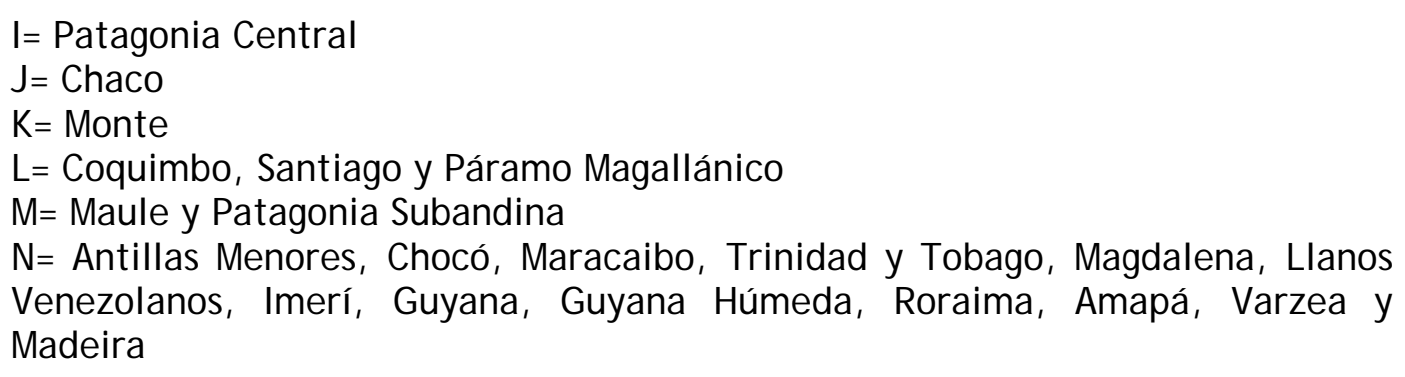

Una vez logrados los resultados, y cuando se obtiene más de una unidad de área por nodo ancestral, deben aplicarse las dos reglas establecidas por el método para seleccionar una de ellas (véase Materiales y Métodos). Estas áreas seleccionadas se indican en rojo en la Figura 49.

Sin embargo, cabe destacar que un problema del DIVA es que la optimización de las distribuciones ancestrales se vuelve menos confiable a medida que se acerca a los nodos basales, dado que el método tiende a incluir en el nodo raíz a todas las áreas de distribución incorporadas al análisis (Ronquist 1996). De hecho, en los resultados aquí presentados, el nodo basal de Pleurodema incluye 12 de las 14 áreas incorporadas al análisis (Nodo 1 en Fig. 49). De todos modos, los objetivos del método refieren a determinar la serie de eventos ocurridos en los nodos internos del género en estudio, los cuales influyen en la distribución actual de dicho taxón.

Una vez determinados los eventos ocurridos (i.e. dispersión, vicarianza, etc.), éstos son correlacionados con eventos geológicos ocurridos en las áreas involucradas. Para tal fin, es necesario contar con un registro fósil que se pueda referir, en el mejor de los casos, al grupo de estudio; o si no a algún taxón cercanamente emparentado. No habiendo ningún taxón fósil asignado a Pleurodema (ni a ningún otro Leiuperidae), es necesario buscar entre los grupos más afines. Sin embargo, las posiciones taxonómicas de varios fósiles que originariamente fueron asignados a alguna subfamilia de Leptodactylidae (al momento de sus descripciones), actualmente resultan contradictorias.

La aproximación más explícita con respecto al posible origen de Pleurodema fue sugerida por Duellman \& Veloso (1977: 32): “ ...La existencia de fósiles de Eupsophus del Oligoceno (telmatobino primitivo relacionado con Pleurodema) sugiere que Pleurodema pudo haber existido desde ese período..." (traducción propia). En consecuencia, los autores describen la historia biogeográfica de Pleurodema a partir del Oligoceno, basándose en el trabajo de Schaeffer (1949). Este autor, basándose en material recolectado en la localidad Deseadense de Scarritt Pocket (provincia de Chubut, Argentina), describió la especie Neoprocoela edentatus relacionándola con 
el género viviente Eupsohpus (Schaeffer 1949). Sin embargo, la asignación taxonómica de este fósil no está esclarecida; mientras el autor original lo relacionó con Batrachophrynus (Schaeffer, 1949), otros autores lo han relacionado con el antiguo género Bufo (Tihen 1962) o con los "Telmatobiinae" (Lynch 1978; Báez \& Fernicola 1999). En este punto en necesario recordar la siguiente información: i) Batrachophrynus resultó anidado dentro de Telmatobius en el análisis filogenético de Barrionuevo (2009); ii) Telmabiinae sensu Lynch resultó ser un taxón polifilético, con lo cual sus géneros pasaron a formar parte de las familias Cycloramphidae, Ceratophryidae, Batrachophrynidae y Calyptocephalellidae (véase Frost 2009). En síntesis, hasta tanto no se establezca la posición de Neoprocoela, no sería adecuado utilizarlo como referencia para la datación requerida por el Análisis de DispersiónVicarianza.

El fósil Baurubatrachus pricei, proveniente del Cretácico Superior de Minas Gerais (Brasil), fue asignado originariamente a Ceratophrynae (Báez \& Perí 1989), opinión compartida por Sanchíz (1998). Sin embargo, otros autores lo consideraron un posible representante de "Leptodactylidae" (Roçek \& Lamaud 1995; Candeiro 2007; Candeiro et al. 2008). Del mismo modo que en el caso anterior, tampoco será utilizado este fósil hasta tanto no se conozca su relación con anuros actuales.

El fósil Wawelia gerholdi, proveniente del Mioceno Medio de yacimientos cercanos a Ingeniero J acobacci (provincia de Río Negro, Argentina) fue relacionado originariamente con Ceratophrys (Casamiquela 1963). El único espécimen recolectado fue revisado posteriomente, confirmando que se trata de un juvenil con caracteres compartidos con Ceratophrys y Lepidobatrachus, por lo cual se considera apropiada su asignación original (Báez \& Perí 1990).

Otros métodos indirectos se han empleado para intentar conocer el origen del género Leptodactylus. De acuerdo con un análisis de distancias inmunológicas, Maxon \& Heyer (1982) propusieron que Leptodactylus pudo originarse en el Paleoceno, sufriendo una modesta especiación durante el Eoceno, Oligoceno y Mioceno; algunos pocos eventos más de especiación durante el Plioceno y prácticamente ausencia de especiación desde el Pleistoceno. Además, también fue sugerido que los eventos de especiación en Leptodactylus en los macizos brasileros ocurrieron fundamentalmente entre el Paleoceno y Mioceno (Heyer \& Maxon 1982).

De acuerdo a lo anteriormente expuesto, el único fósil cuya posición taxonómica no fue cuestionada es Wawelia gerholdi, relacionado con Ceratophrys. Este género pertenece a la familia Ceratophrynidae, de la cual fue utilizado uno de sus representantes en la filogenia aquí presentada, Batrachyla leptopus, especie 
utilizada para enraizar el árbol. Existen algunos otros fósiles asignados a "Leptodactylidae" sensu Lynch con afinidades no establecidas o que aún permanecen sin describir (Estes \& Reig 1973; Báez 2000). En conclusión, existen dos problemas: por un lado, los pocos fósiles para los cuales hay acuerdo en su asignación no están cercanamente emparentados a Pleurodema $y$, por otro lado, existe material aún no descripto que eventualmente podría estar vinculado a Pleurodema. En consecuencia, no se realizará una correlación de los eventos ocurridos en la historia biogeográfica de Pleurodema en relación a eventos geológicos, excepto para casos muy particulares referidos en la literatura.

El Análisis de Dispersión-Vicarianza asignó 12 de las 14 áreas empleadas en el análisis en el nodo basal de Pleurodema (Nodo 1 en Fig. 49). El linaje ancestral originaría dos linajes por un proceso de vicarianza seguido de duplicación; para estos dos linajes el método tampoco tiene gran poder explicativo dado que les asigna $4 \mathrm{y}$ 11 áreas de distribución a los Nodos 2 y 3, respectivamente.

El linaje del Nodo 2 habría sufrido nuevamente un proceso de vicarianza seguido de duplicación, originando por un lado a un linaje que habitaría Bosque Valdiviano, Patagonia Central y Maule + Patagonia Subandina (Pleurodema bufoninum) y otro restringido a la Patagonia central (Pleurodema somuncurensis nov. comb.).

El linaje del Nodo 3 habría sufrido nuevamente un proceso de vicarianza seguido de duplicación, originando al clado de especies poliploides (Nodo 4). Este ancestro originaría a P. cordobae por un lado, y por otro lado se dispersaría hacia la Pampa (nodo 5), ocurriendo luego un evento vicariante: Pleurodema kriegi queda restringida el Chaco, mientras que Pleurodema aff. bibroni y Pleurodema bibroni se limitarían a la Pampa. De todos modos, esta interpretación debe ser tomada con cautela, dado que el DIVA se aplicó sobre una de las tres resoluciones posibles para las relaciones de las especies poliploides en el análisis filogenético bajo pesos implicados.

El otro linaje surgido a partir del Nodo 3 corresponde al Nodo 6. Este linaje sufriría un proceso de vicarianza que origina a Pleurodema thaul por un lado (que actualmente habita Bosque Valdiviano, Patagonia Central y Coquimbo +Santiago + Páramo Magallánico) y al ancestro de las restantes especies del género por otro (Nodo 7).

El ancestro del Nodo 7 habría sufrido un proceso de vicarianza seguido de duplicación, originando por un lado al par de especies P. cinereum - P. borelli (Nodo 
8), y por otro lado a las restantes especies del género (Nodo 9). El ancestro del nodo 8 había un proceso de vicarianza mediante el cual $P$. cinereum queda restringida a la Prepuna y Puna, mientras que P. borellii habitaría Yungas, Chaco y Monte

El ancestro del Nodo 9 habría sufrido un proceso de vicarianza por el cual originaría por un lado a P. brachyops (quien habita Antillas Menores + Chocó, Maracaibo + Trinidad y Tobago + Magdalena + Llanos Venezolanos + Imerí + Guyana + Guyana Húmeda + Roraima + Amapá + Varzea + Madeira) y por otro lado a las restantes especies del género (Nodo 10).

El ancestro del Nodo 10 habría sufrido un proceso de vicarianza por el cual originaría por un lado a P. diplolister (actualmente restringida a las Caatingas) y por otro lado a las restantes especies del género (Nodo 11).

El ancestro del Nodo 11 habría sufrido un proceso de vicarianza por el cual originaría por un lado a P. marmoratum (quien habita Puna y Atacama) y por otro lado a un ancestro restringido al Chaco que originaría a (P. tucumanum ( $P$. nebulosum + P. guayapae)), incluyendo eventos de dispersión las dos últimas especies.

\subsection{Discusión de los análisis biogeográficos de Pleurodema}

Los alcances de los dos análisis empleados permiten dilucidar aspectos diferentes de la historia biogeográfica de Pleurodema. Por un lado, la Optimización de Fitch permitió identificar la posible área ancestral de Pleurodema, mientras que el DIVA sugirió cuál fue la serie de eventos, ocurridos en los nodos internos, que generaron la distribución actual de las especies que componen el género.

De acuerdo a la Optimización de Fitch. Pleurodema se originó en la Patagonia central. Lynch (1971: 214) sugirió que Pleurodema es un género de zonas templadas de América del Sur que invadió las zonas tropicales. Los resultados aquí presentados apoyan esta afirmación, dado que sólo dos especies habitan zonas tropicales (P. brachyops y P. diplolister).

Con respecto al origen del género, los resultados presentados difieren respecto a lo sugerido por Duellman \& Veloso (1977), quienes propusieron que el género se originó en los bosques australes, auque su figura 1 muestra un gran grupo ancestral distribuido tanto en bosques andino-patagónicos como en toda la estepa. Recordemos que en los bosques australes habita actualmente Eupsophus, género que los autores relacionaron con Pleurodema (véase Introducción). Una vez ocurrido el origen del género, Duellman \& Veloso (1977) sugirieron que éste da origen a dos linajes, uno 
incluyendo especies con glándulas lumbares y el otro con especies que carecen de dichas estructuras. La hipótesis aquí presentada no coincide con la aproximación realizada por Duellman \& Veloso (1977), por lo cual una discusión de los resultados obtenidos carece de sentido.

\section{Biogeografía histórica de P. bufoninum y P. somuncurensis (Nodo 2, Fig. 49)}

De acuerdo a la Optimización de Fitch, estas dos especies hermanas se originaron en la Patagonia Central. De acuerdo a los datos de distribución de ambas especies, es posible asumir que P. bufoninum se dispersó por toda la Estepa patagónica, incluyendo el ecotono con Bosques de Notophagus en el sur y la región del Monte hacia el norte. Por su parte, P. somuncurensis está restringida la Meseta de Somuncurá (provincia de Río Negro), un afloramiento basáltico del Terciario que se extiende por unos $15.000 \mathrm{~km}^{2}$ a unos 1.300-1.400 m s.n.m., y cuya historia geológica fue resumida por Cei (1969a; 1969b). No contamos con ninguna información para poder estimar cómo esta especie colonizó la Meseta, y sería interesante realizar investigaciones en tal sentido, considerando además, que existen otras especies endémicas (e.g. Atelognathus reverberii, el saurio Phymaturus somuncurensis).

\section{Biogeografía histórica de P. cordobae, P. kriegi, P. bibroni y P. aff. bibroni (Nodo 4, Fig. 49)}

Barrio (1977) sugirió una hipótesis sobre el origen del par de especies tetraploides P. kriegi y P. bibroni (recordemos que para ese entonces eran las únicas especies poliploides conocidas para el género). El autor propuso un origen andino-patagónico de estas dos especies, sugiriendo también que $P$. thaul (o quizás también $P$. bufoninum) podría haber intervenido en el proceso de alopoliploidía que les dio origen (véase también sección 5.4 del Capítulo V sobre el origen de la polipliodía). Barrio sugiere que, del mismo modo que el saurio Pristidactylus achalensis y que el bufónido Rhinella achalensis (endemismos de Pampa de Achala al igual que P. kriegi), el par de especies poliploides tuvo su origen en el oeste semidesértico de Argentina. Luego, este ancestro se habría dispersado hacia el este y habría colonizado las Pampas hasta la costa atlántica $y$, finalmente, por eventos del Pleistoceno, habrían quedado las poblaciones de las Sierras Grandes (P. kriegi) y las de Uruguay y sur de Brasil (P. bibroni) en alopatría.

Las Sierras Grandes (provincia de Córdoba) conforman un sistema serrano originado durante el Precámbrico que, a su vez, forma parte del sistema orográfico 
de las Sierras Pampeanas. Las Sierras Grandes se distribuyen unos $60 \mathrm{~km}$ de este a oeste y unos $300 \mathrm{~km}$ de norte a sur (Cei 1972b; Miró 1999). A pesar de que estas Sierras fueron consideradas por varios autores como pertenecientes a la ecoregión Chaco (Ab'Sáber 1977b; Cabrera \& Willink 1980; Morrone 2001), sus particularidades en relación al hábitat y sus particulares fauna y flora endémica inclinaron a algunos autores a considerarlas una unidad biogeográfica particular (Ringuelet 1961).

De acuerdo con Kolenc et al. (2009), el posible ancestro pudo haberse dispersado a través de las planicies del Río Paraná, las cuales se establecieron durante los últimos 10 Millones de años (Ma), bajo la influencia de las incursiones marinas del Océano Atlántico (Camacho 1967; Hubert \& Renno 2006). Los autores sugirieron que las fases áridas pudieron afectar este proceso (Kolenc et al. 2009). Durante el Pleistoceno tardío (unos 18.000 años atrás) y hasta el Holoceno temprano (unos 8.500 años atrás) ocurrió un período de aridez (van der Hammen 1974; Ab'Sáber 1977a), el cual fue seguido por una fase subtropical húmeda (Iriondo \& Garcia 1993). Luego, en el Holoceno tardío, otra fase árida (menos intensa) fue registrada, entre los últimos 3.500 a 1.000 años (Iriondo 1990; Iriondo \& Garcia 1993). Durante el Holoceno, los cambios proclives a climas más húmedos pudieron haber causado la retracción y fragmentación de especies neotropicales que habitaban previamente ambientes más xerófilos (Vanzolini 1992).

\section{Biogeografía histórica de P. thaul, P. cinereum, P. borellii, P. brachyops, P. diplolister, P. marmoratum, P. tucumanum, P. nebulosum y P. guayapae (Nodo 6,} Fig. 49)

La interpretación de la historia biogeográfica de este subclado de Pleurodema es mucho más compleja, dado que existe mucha ambigüedad respecto a las áreas de origen de varios de sus nodos.

De la información obtenida, podemos mencionar que en este clado se encuentran las especies del género que han colonizado las regiones más boreales (i.e. P. brachyops y P. diplolistris). Por otro lado, podemos destacar que el ancestro que origina P. tucumanum, P. nebulosum y P. guayapae habitaba el Chaco, área a donde quedó restringida P. guayapae hasta el presente. Pleurodema nebulosum se dispersó hacia el Monte y marginalmente hacia la Pampa, Prepuna y la Patagonia Central; mientras que $P$. tucumanum conquistó el Monte y marginalmente las Yungas.

Es interesante destacar que prácticamente todas las especies de este grupo habitan ambientes áridos, con la excepción de P. borellii y marginalmente P. 
tucumanum. Todas las especies originadas a partir del ancestro del nodo 7 (Fig. 49) se reproducen mediante nidos de espuma, con la excepción de P. tucumanum y $P$. marmoratum. Sería interesante estudiar más profundamente la historia biogeográfica de estas especies, asociada a sus modos de reproducción como elemento fundamental en la conquista de nuevo hábitats. 


\section{CONCLUSIONES GENERALES}

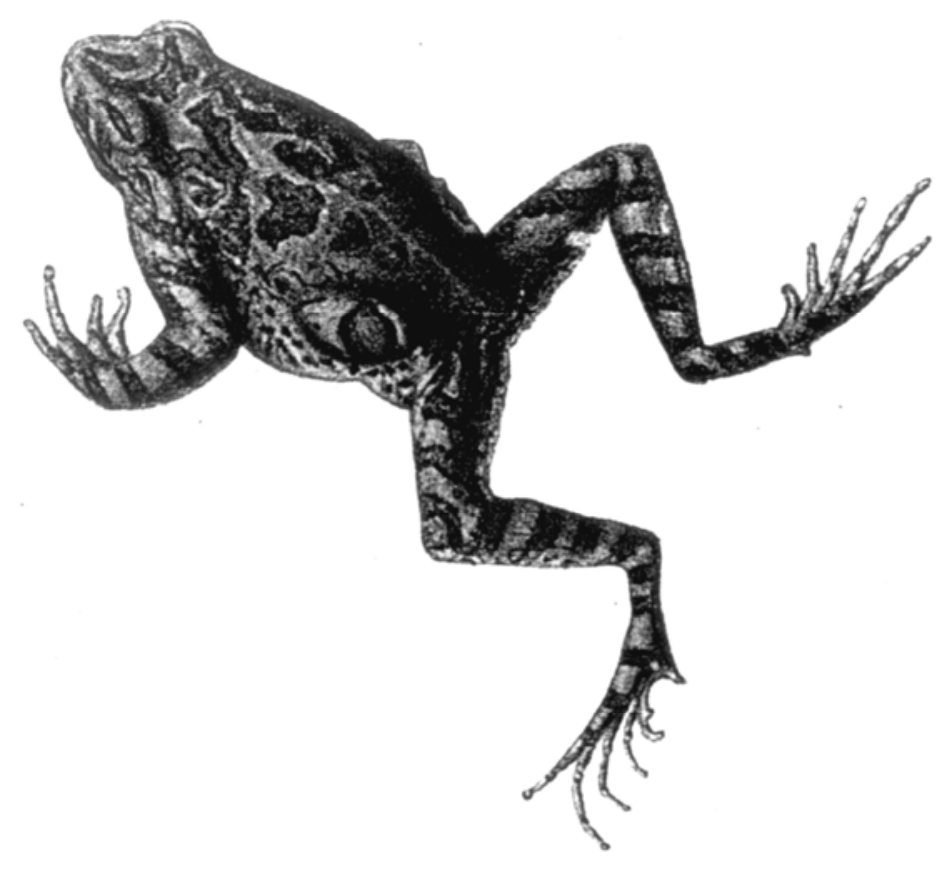

Tomado de Aderssen (1906) 
De acuerdo a la información presentada en los capítulos precedentes, podemos arribar a las siguientes conclusiones generales:

- El género Pleurodema es una unidad monofilética si consideramos a Somuncuria somuncurensis anidada dentro de él. En consecuencia, esta especie es transferida de género, siendo Pleurodema somuncurensis nov. comb. su nuevo nombre.

- La especie Pleurodema fuscomaculatum, conocida por la serie tipo y una muestra de fines del siglo XIX, no ha podido ser codificada más que para un $20 \%$ de la matriz de datos, excluyendo los caracteres diagnósticos. En consecuencia, su posición filogenética no ha podido ser corroborada. Si bien en los análisis bajo pesos implicados resulta anidad dentro de Physalaemus, no se sugiere ningún cambio taxonómico debido a la escasa evidencia incluida en el análisis.

El género Pleurodema así constituido está sostenido por al menos dos sinapomorfía en todos los análisis realizados: nasales no superpuestos al esfenoetmoides (22:0) y cuadradoyugal ausente y cuadrado presente (49:2).

- La osteología de las especies de Pleurodema es bastante conservada, sin embargo, la mayoría de las sinapomorfías para el clado surgen de esta fuente de información.

- Si bien la mayoría de los caracteres utilizados en el presente estudio provienen de los clásicos sets de caracteres de morfología y osteología, también se exploraron otras fuentes de información menos frecuentes (musculatura, coloración de las gónadas, etc). Sería interesante seguir explorando estas fuentes de información en busca de nuevos caracteres.

- Varios pares de especies crípticas del género Pleurodema presentan notables similitudes morfométricas ( $P$. borellii- P. cinereum, P. guayapae - P. nebulosum; P. bibroni - P. kriegi, de tal modo que no ha sido posible diferenciarlas con estudios de Análisis de Componentes Principales.

- Varias modalidades reproductivas han sido descriptas para el género Pleurodema, siendo los nidos de espuma la única compartida con otros Leiupéridos y Leptodactílidos.

- Dentro del género Pleurodema se conocen dos especies tetraploides y una octoploide. Estudios cariológicos de estas especies son necesarios para una mejor comprensión de sus relaciones de parentesco y posible origen. Además, estudios moleculares apropiados para la inclusión de especies poliploides en análisis filogenéticos mediante redes filogenéticas deberían desarrollarse para una comprensión más cabal de la evolución de estas especies. 
- Las glándulas lumbares externamente perceptibles, conformadas por acúmulos de glándulas granulosas, son la condición ancestral dentro del género Pleurodema. En las especies que carecen de manifestaciones externas de estas estructuras han sido descriptos acúmulos de glándulas granulosas, lo cual está sustentado por las relaciones filogenéticas sugeridas del análisis cladístico aquí presentado.

- Se reconoce a Pleurodema borellii y Pleurodema cinereum como dos especies válidas en base a los análisis filogenéticos aquí presentados.

- La historia biogeográfica de Pleurodema es compleja y difícil de reconstruir, debido a la ambigüedad en la asignación de las áreas ancestrales a varios nodos. Los análisis indicarían que el género se originó en la Patagonia de Argentina y luego se expandió hacia el norte por América del Sur. En el presente, la mayoría de las especies que constituyen el género se distribuyen en ambientes de relativa aridez. 


\section{APÉNDICE DE MATERIAL EXAMNADO}

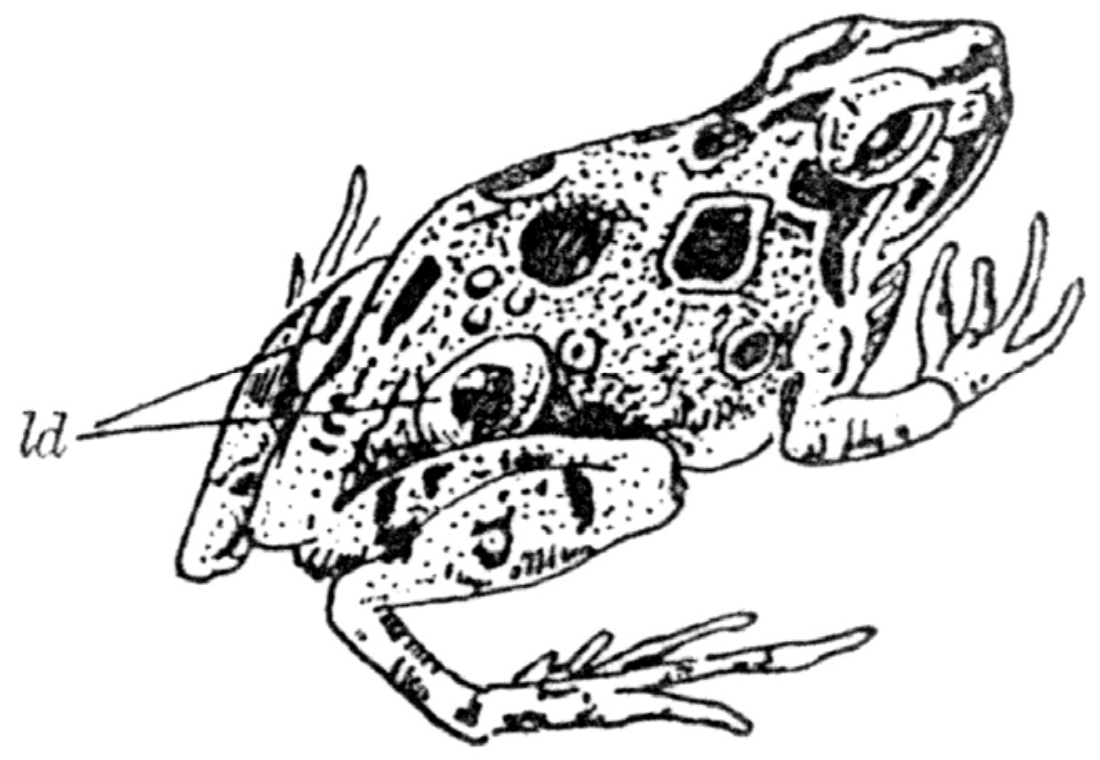

Tomado de Nieden (1923) 
El material estudiado se halla depositado en las siguientes colecciones herpetológicas:

MLP A: Museo de La Plata (Colección de Anfibios) (La Plata, Buenos Aires, Argentina).

MACN: Museo Argentino de Ciencias Naturales "Bernardino Rivadavia" (Buenos Aires, Argentina)

CENAI: Colección Herpetológica del Centro Nacional de Investigaciones lológicas, actualmente depositada en el MACN.

JF: Numeración de campo de Julián Faivovich, para ser ingresada en MACN.

BB: Numeración de campo de Boris Blotto, para ser ingresada en MACN.

FML: Fundación Miguel Lillo (Tucumán, Argentina).

ILPLA: Instituto de Limnología "Dr. Raúl A. Ringuelet" (Buenos Aires, Argentina).

MCM: Museu de Ciencias Naturais, Fundaçao Zoobotanica (Rio Grande do Sul, Brasil)

MNHN: Museo Nacional de Historia Natural (Montevideo, Uruguay).

MZUSP: Museo de Zoología de la Universidad de Sâo Paulo (San Pablo, Brasil).

NMW: Naturhistoriches Museum Wien (Viena, Austria)

UIS-A: Escuela de Biología, Universidad Industrial de Santander (Bucaramanga, Colombia).

Las abreviaciones usadas se explican a continuación:

(ठ) macho,

(ㅇ) hembra,

(D) ej emplar teñido y diafanizado para estudios osteológicos,

(ES) ej emplar preparado como esqueleto seco para estudios osteológicos,

(MM) ej emplar utilizado para estudios de morfometría,

(ME) ej emplar utilizado para estudios de morfología externa,

(T) ej emplar utilizado para evaluar la pigmentación de los testículos.

Todos los especímenes para los cuales no se indica el país, fueron recolectados en Argentina. Otras abreviaturas respecto a las localidades son: R. N. = Ruta Nacional; R.P. = Ruta Provincial.

\section{Fam. Leiuperidae}

Pleurodema bibroni. CENAI 6155 (ME), CENAI 6163 (ME), CENAI 6173 (ME), CENAI 6175 (ME), CENAI 6184 (ME), CENAI 6202 (ME), CENAI 6208 (ME), CENAI 6210 (ME), CENAI 6212 (ME), CENAI 6219 (ME) URUGUAY: Barra de Santa Lucía.

CENAI 4236 ( $\partial$, MM), CENAI 4968 (,+ MM), CENAI 4970 ( $ڤ$, MM) URUGUAY: Canelones; CENAI

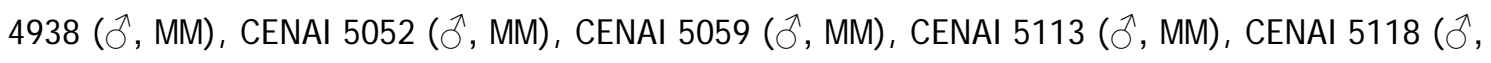

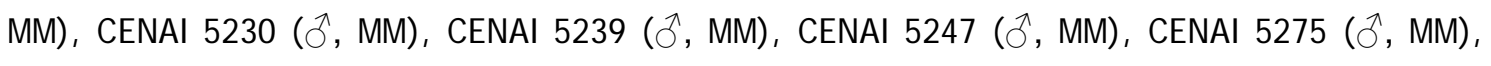

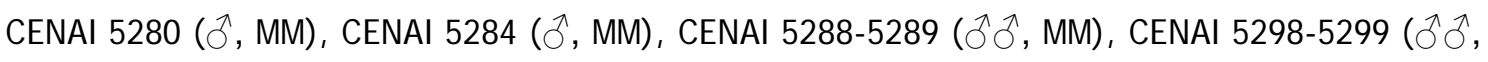

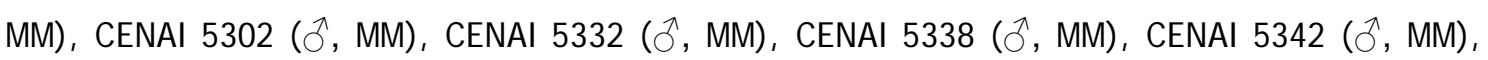


CENAI 5353-5354 (ô, MM), CENAI 5357 ( $\curvearrowright$, MM), CENAI 6205-6209 (ô, MM), CENAI 5048 ( + , MM), CENAI 5203 ( $q$, MM), CENAI 5205 ( + MM), CENAI 5207 ( $q$, MM), CENAI 5211 ( + MM), CENAI 5215 ( $q$, MM), CENAI 5227-5229 ( $q$, MM), CENAI 5234 ( $q$, MM), CENAI 5333 (,+ MM), CENAI 5335 ( $($, MM), CENAI 5339 (,+ MM), CENAI 5343-5345 ( $\odot$, MM), CENAI 5349 (, MM), CENAI 5358 ( + MM), CENAI 5362-5363 ( + , MM) URUGUAY: Barra de Santa Lucía.

CENAI 3491 ( $q$, MM) URUGUAY: Carrasco; CENAI 4934 (,+ MM), CENAI 5020 ( + , MM), CENAI 5024 ( $q$, MM), CENAI 5026 ( $q$, MM), CENAI 5029-5030 ( $q$, MM), CENAI ( $q$, MM) 5036 ( $q$, MM) URUGUAY: Santiago Vázquez; CENAI 4941 ( + MM) URUGUAY: La Pedrera.

CENAI 6205 (ô, D), CENAI 6204 ( ( , D) URUGUAY: Barra de Santa Lucía.

Pleurodema aff. bibroni. MCN 54 (ME) BRASIL: Estado de Rio Grande do Sul: São Francisco de Paula, Boca da Serra; MCN 55 (ME) BRASIL: São Francisco de Paula, Veraneio Hampe; MCN 1333 (ME) BRASIL: Río Tainhas, cerca del Río Cipó; MCN 2428 (ME) BRASIL: Cambará do Sul, Itaimbezinho; MCN 5533-4 (ME), MCN 55367 (ME) BRASIL: São Francisco de Paula, Cazuza Ferreira; MCN 7401 (ME) BRASIL: Nova Petrópolis, Linha Imperial; MCN 6616 (ME), MCN 66186619 (ME), MCN 6621-6122 (ME) BRASIL: Vacaria; MCN 9847-52 (ME) BRASIL: Bom J esus, Fazenda de Ari Velho (34 km de La ciudad); MCN 5574 (ME) BRASIL: Farroupilha.

Fotografías de los ejemplares MCN 6617 (つ, D) y MCN 6620 (क, D) cedidas por R. Maneyro. BRASIL: Vacaria.

Pleurodema borellii. MLP A.3814 (ME, T), MLP A. 3909-3911 (ME) TUCUMÁN: Dep. Yerba Buena: Yerba Buena; CENAI 8849-8856 (ME) TUCUMÁN: Floresta; FML 4084-1 (ME), FML 4084-2 (ME) SALTA: Dep. Anta: Parque Nacional El Rey: Sierra El Chañar; MLP A. 2013 (ME, T) CATAMARCA: Mutquín; MLP A. 4648-4650 (ME), MLP A. 4651 (ME) J UJ UY: Dep. El Carmen: R. N. 9, entre km 1664-1665, a unos 2 km de El Carmen.

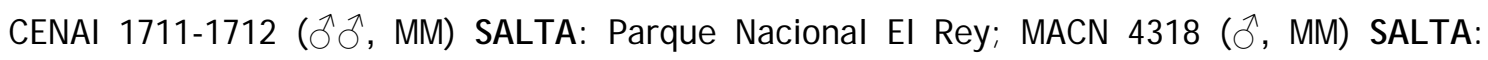
Quebrada del Río Blanco; MACN 32313 (ð̄, MM) SALTA: Dep. Orán: Río Pescado y Serranía Las Pavas, en el extremo SO del Parque Nacional Baritú; FML 2709 ( ${ }_{0}$, MM) SALTA: Dep. Orán: Angosto del Río Pescado; FML 2994-1 (૧. MM), FML 2994-2 (ठึ, MM), FML 2994-3 (ठึ, MM)

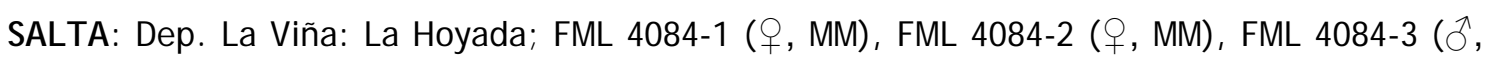
MM) SALTA: Dep. Anta: Parque Nacional El Rey - Sierra El Chañar; CENAI 1709-1710 ( $q$, MM)

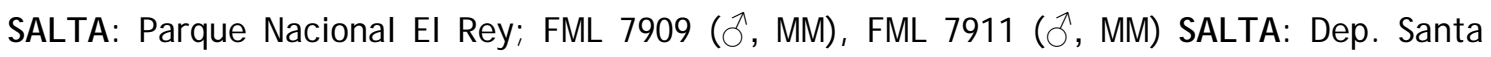
Victoria: Lipéo - Parque Nacional Baritú; MACN 15497 (q, MM) SALTA: General Ballivián; FML

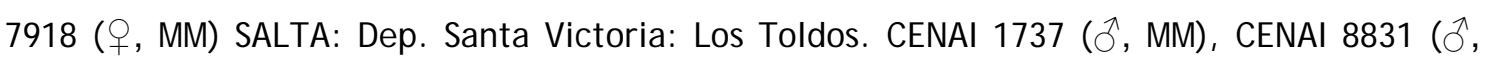

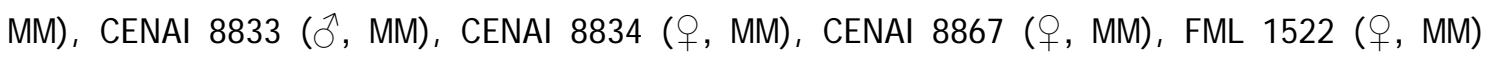

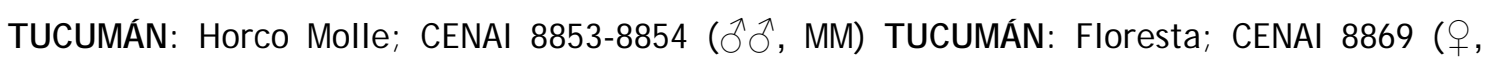

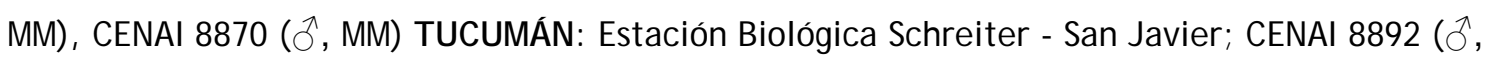

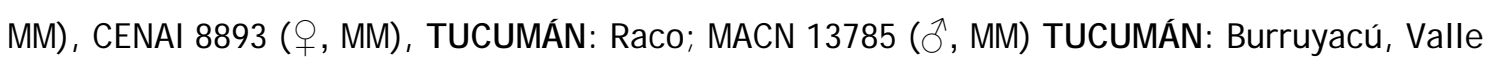


del Medio; MACN 25840 (§ิ, MM) TUCUMÁN: Tafí del Valle, Infiernillo; FML 1434-3 (†, MM),

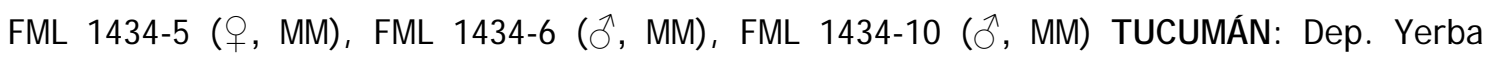
Buena: San Javier; FML 1432 ( $q$, MM) TUCUMAN: Dep. Capital: Río Salí; FML 1763 ( $q$, MM) TUCUMAN: Dep. Yerba Buena: Yerba Buena - Marcos Paz. CENAI 2665 ( $q$, MM), CENAI 2267

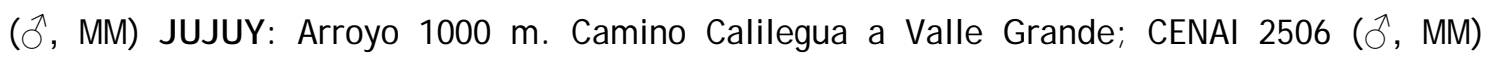
J UJ UY: Próximo a Huacanqui camino a Valle Grande; CENAI 3251-3256 (§, MM) JUJ UY:

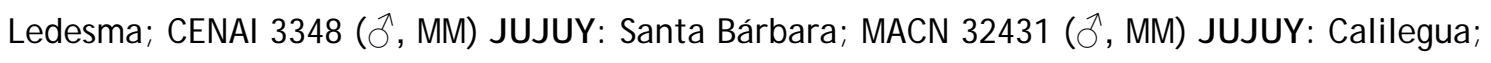
CENAI 3346-3347 ( $q$, MM) J UJ UY: Santa Bárbara; FML 2693-1 ( $q$, MM), FML 2693-2 ( $q$, MM), FML 2693-3 (ठึ, MM), FML 2693-4 (ð, MM) J UJ UY: Dep. Santa Bárbara: Cerro Pereira, Sierra De Santa Bárbara; FML 9009-9010 (ठ̋̂̉, MM) J UJ UY: Dep. Ledesma: Aguada Del Tigre - Parque Nacional Calilegua; CENAI 8871 ( $q$, MM) J UJ UY: Río de las Piedras, Yuto. MACN 12120 ( $\precsim$, MM), MACN 12121-12127 ( $\widehat{\partial} \hat{0}$, MM) CATAMARCA: Estancia "El Charro" - Sinquil; MLP A. 2010-

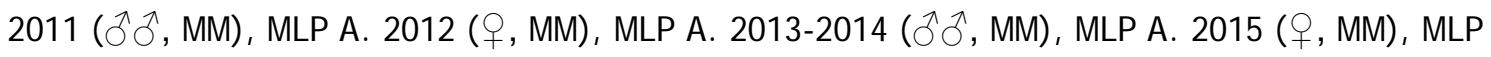

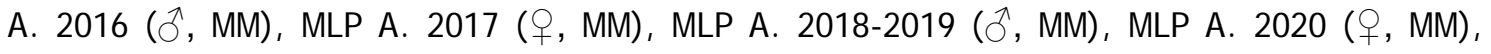
CENAI 380 ( $\hat{\sigma}$, MM), CENAI 1359-1360 ( $\%+$, MM) CATAMARCA: Mutquín; FML 633-1 ( $\hat{0}, \mathrm{MM})$,

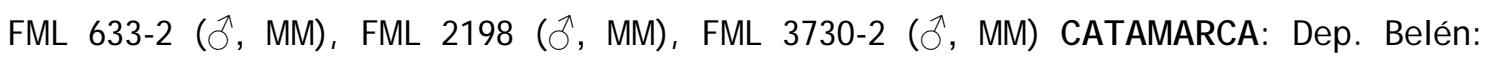
Hualfin; FML 320-1 (, MM), FML 320-2 (ठ, MM) CATAMARCA: Dep. Andalgalá: Campo Pucará; FML 3287-1 ( $\hat{\jmath}$, MM), FML 3287-2 ( $\widehat{\jmath}$, MM) CATAMARCA: Dep. Belén: Quebrada La Toma -

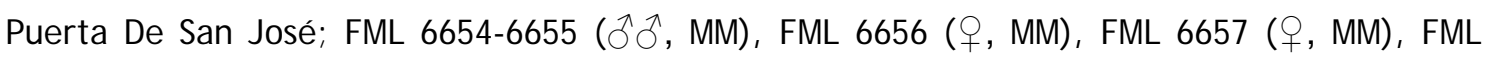

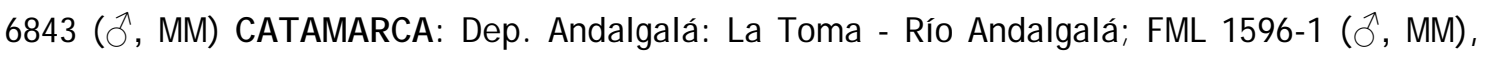
FML 1596-2 ( $\widehat{0}$, MM) CATAMARCA: Dep. Ambato: Cerro Manchao; MLP A. 3759 ( + , MM) CATAMARCA; FML 2635 ( $($, MM) CATAMARCA: Dep. El Alto: Paso De Alumbre; FML 2763-1 ( + , MM) CATAMARCA: Dep. Ambato: Campamento Las J untas - Finca del Dr. Figueroa; MACN 9987 ( + , MM), MACN 25000-25001 ( $\circ+$, MM) LA RIOJ A: Aimogasta, "Aschá". CENAI 3283 (ð, MM) BOLIVIA: Sucre.

MLP A. 2013 (ð̊, D) TUCUMAN: Dep. Yerba Buena: Yerba Buena; FML 4125 (sin dato de sexo, D) TUCUMÁN: Dep. Trancas: El Cadillal; MLP A. 4651 (ठ, D, T) J UJ UY: Dep. El Carmen: R.N. 9, entre km 1664-1665, a unos $2 \mathrm{~km}$ de El Carmen; ILPLA $400(\hat{O}$, D) SALTA: Parque Nacional El Rey; CATAMARCA: Mutquín; MLP A. $3814(\precsim, D)$.

Pleurodema brachyops. CENAI 2630-2631 (ME) VENEZUELA: Estado de Sucre: Hacienda La Rinconada: a 5 km de Cumanacoa; CENAI 3158 (ME, T), CENAI 3159 (ME) VenezUELA: Isla Margarita: Polamar; CENAI 8780-8785 (ME) PANAMÁ: Nueva Gorgona.

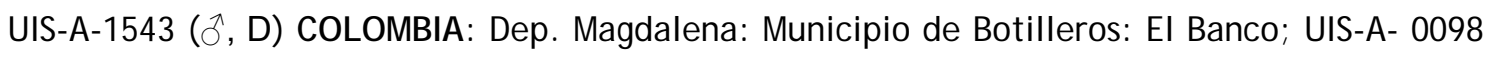
( + , D) COLOMBIA: Dep. Cesar: Municipio de Valledupar: Finca La Dorada.

Pleurodema bufoninum. MACN 17620 (T), MACN 17631 (T), MACN 17633 (T) NEUQUÉN: Laguna Blanca; MACN 38304 (ME) NEUQUÉN: Dep. Aluminé: Pampa de Lonco Luán sobre Ruta 
13; MLP A. 4054 (ME), MACN 38287 (ME), MACN 38290 (T), MACN 38306 (ME) Río NEGRO: Dep. Norquinco: Cruce de la R.N. 40 y Arroyo Las Bayas; MACN 38293 (ME) MACN 38273 (ME) Río NEGRO: Dep. Pilcaniyeu: Ruta 318 y Río Pichi Leufú; MACN 38294 (T) Río NEGRO: Dep. Pilcaniyeu: R.N. 40 y Arroyo El Porteño; MLP A. 4021 (ME) CHUBUT: Arroyo que cruza la R.N. 40 entre los km 1450 y 1451; MLP A. 1467 (ME) SANTA CRUZ: Puerto Deseado; MLP A. 15981599 (ME) SANTA CRUZ: Lago Viedma.

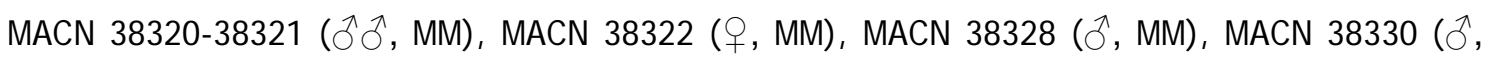
MM) MENDOZA: Dep. Malargüe: Próximo (Norte) de Calmuco, Ruta 221; MACN 38331 (†, MM), MACN 38332 (ð̊, MM), MACN 38333 (q, MM), MACN 38334 (ð, MM) MENDOZA: Dep. Malargüe:

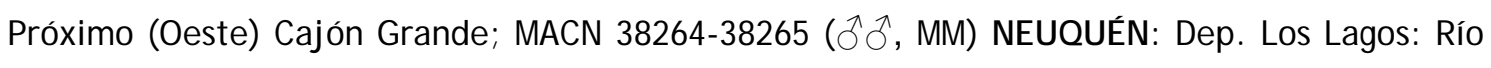
Traful, próximo a Confluencia; MACN 38292 ( ${ }_{0}$, MM) NEUQUÉN: Dep. Alumine: Arroyo $10 \mathrm{~km}$ aprox. Primeros Pinos; MACN 38299 (ô, MM), MACN 38300-38301 (우, MM), MACN 38304MACN 38305 ( + , MM), MACN 38343 ( ठ઼, MM) NEUQUÉN: Dep. Aluminé: Pampa de Lonco Luán sobre Ruta 13; CENAI 278-1 ( 9 , MM) NEUQUÉN: San Martín de los Andes; MACN 38313 ( 9, MM) NEUQUÉN: Alumine: Arroyo del Cerro La Atravezada; MACN 38335 ( + , MM) NEUQUÉN: Dep. Minas: Camalón; MACN 38337 ( 9 , MM) NEUQUÉN: Dep. Minas: Próximo Varvarco; MACN 38273 ( $\widehat{\jmath}$, MM), MACN 38278 (ô, MM) Río NEGRO: Dep. Pilcaniyeu: Ruta 318 y Río Pichi Leufú; MACN

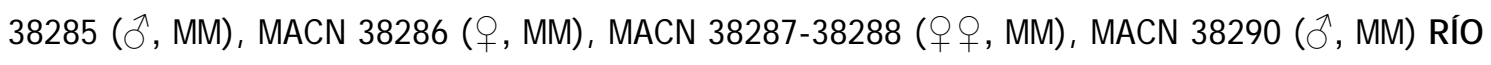
NEGRO: Dep. Pilcaniyeu: Ruta 80 y Arroyo Las Bayas; MACN 38294 ( $ぇ$, MM) Río NEGRO: Dep. Pilcaniyeu: R.N. 40 y Arroyo El Porteño; MACN 38306 (q, MM), MACN 38312 (ô, MM) Río NEGRO: Dep. Ñorquinco: Cruce de la R.N. 40 y Arroyo Las Bayas; MACN 28392-28393 (qq, MM) Río NEGRO: Meseta Somuncurá: Aguada, Pilquimán, Cañadón Corral Curá, Casco Cecchi; MACN 38293 ( + , MM) Río NEGRO: Dep. Bariloche: Próximo al Aeropuero Bariloche: Río Nirihuau; CENAI 3409-3411 ( + \%, MM), CENAI 3412 ( $\sigma^{\AA}$, MM) CHUBUT: Tehuelches; CENAI 8936

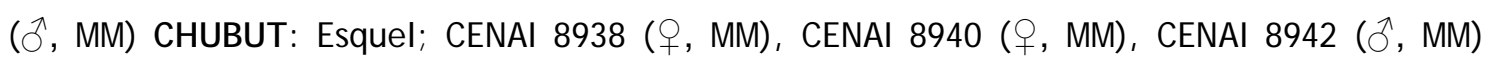
CHUBUT: Dep. Paso de Índio: Rinconada de López (SE de la Meseta Cauquel); CENAI 89718972 ( $q$ q, MM), CENAI 8977 ( $q$, MM) CHUBUT: Colonia Sarmiento; MACN 30300 ( $q$, MM)

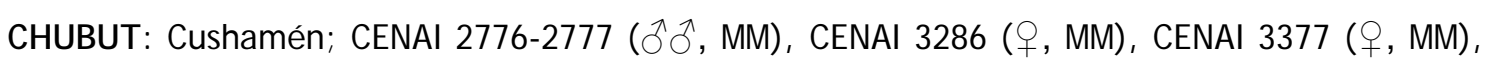
CENAI 3482 ( $\lesssim$, MM) SANTA CRUZ: Puerto Deseado; CENAI 4597 ( $ぇ$, MM) SANTA CRUZ: Puerto Deseado: Mariscanos; CENAI 8980-8981 ( $\widehat{\partial} \hat{\partial}$, MM), CENAI 8986 ( $\hat{\partial}$, MM) SANTA CRUZ: Dep. Magallanes: Est. Roca Blanca (250 km al S Colonia Las Heras); MACN 31483-31484 (ððત, MM) SANTA CRUZ: Río Bote; CENAI 4596 ( $($, MM) SANTA CRUZ.

MLP A. 2240 (q, D) NEUQUÉN: Cerro Policía; MLP A. 3991 ( $ð$ joven no utilizado en la codificación) Río NEGRO: Dep. Pilcaniyeu: Cruce de la R. N. 23 y Río Pichi Leufú; MLP A. 4054 (§, D), MLP A. 4061 (ㅇ, D) Río NEGRO: Dep. Norquinco: Cruce de la R.N. 40 y Arroyo Las

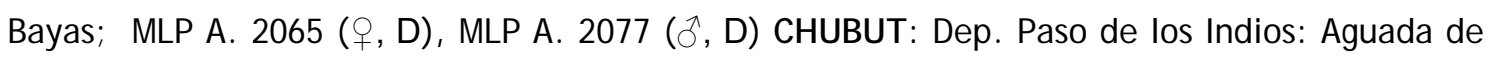
Batistín; MLP A. 1458 (ð̊, D), MLP A. 1459 (ㅇ, D) SANTA CRUZ: Puerto Deseado. 
Pleurodema cinereum. FML 14975-14980 (ME) PERÚ: Dep. Puno: Alrededores de Puno; FML 14981-14988 (ME) PERÚ: Provincia de Chucuito: Curmi; FML 14989-14992 (ME) PERÚ: Provincia de Chucuito: Desaguadero; CENAI 3240-3242 (ME), CENAI 3272-3275 (ME); CENAI 3282-3283 (ME) BOLIVIA: Sucre; MLP A. 4095-4098 (ME) J UJ UY: Dep. Yavi: La Intermedia; MLP A. 46934696 (ME) J UJ UY: Dep. Cochinoca: R. N. 11, camino a Casabindo; MLP A. 4699-4704 (ME) JUJ UY: Dep. Cochinoca: Casabindo; MLP A. 4707 (ME) JUJUY: Dep. Santa Catalina: Cieneguillas.

MACN 16745 ( $($, MM) PERÚ: Puno; FML 14975 (ð, MM), FML 14976-14977 (कㅇ, MM), FML

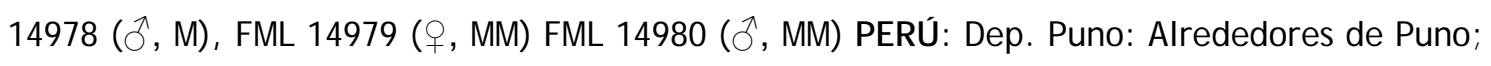

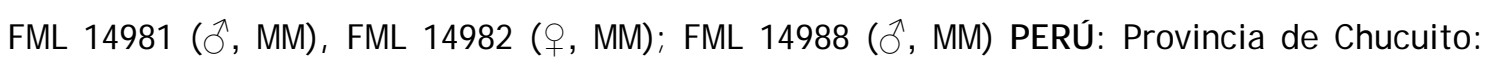

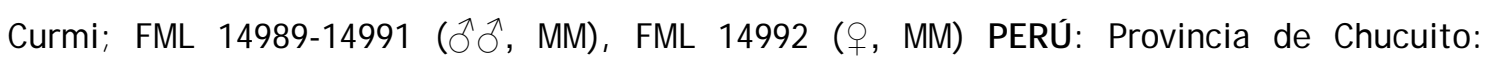

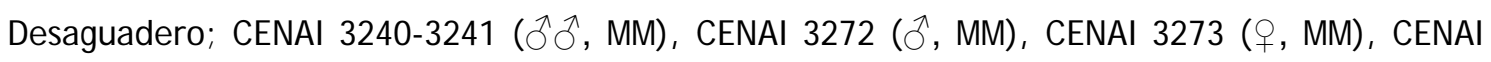

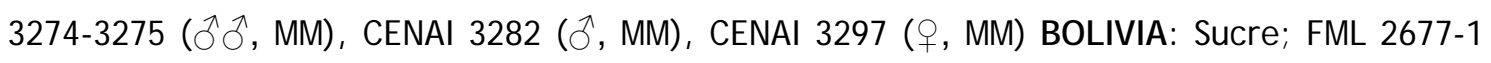
(§, MM) BOLIVIA: Dep. Cochabamba: Cochabamba; FML 2772-1 ( + MM), FML 2772-2 ( + MM) BOLIVIA: Ruinas de Tiahuanaco; CENAI 2313 ( $え$, MM), CENAI 2379 ( 0 , MM) JUJ UY: Abra

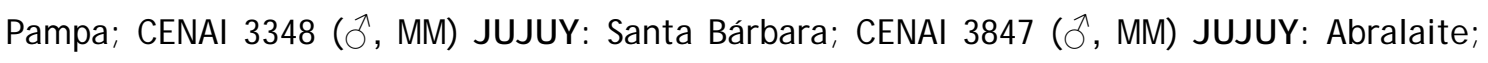

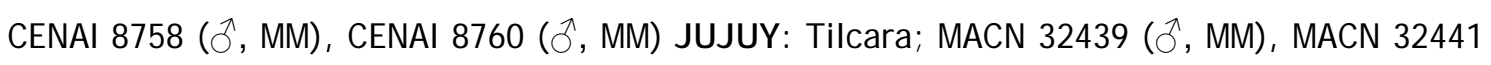
(ふ, MM) JUJ UY: Laguna de Yala; MACN 7773-7780 (ðえ, MM), MACN 7782-7793 (ðえ, MM),

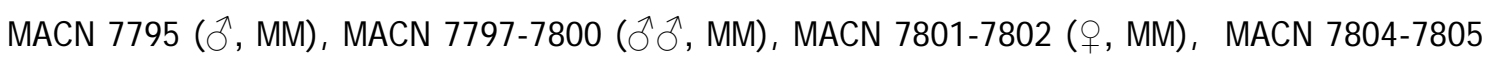
(우, MM) J UJ UY: La Quiaca; FML 2868 ( Catalina - Cerca De Piscuno; FML 4519-1 (q, MM), FML 4519-2 (§, MM), FML 4519-3 (q, MM) J UJ UY: Laguna Pozuelos; FML 5559 (ठ઼, MM) JUJ UY: Dep. Rinconada: Pampa Sur de Laguna Pozuelos; CENAI 2150 ( $q$, MM) JUJ UY: Humahuaca; FML 2731 ( + , MM) JUJ UY: Dep. Humahuaca: $3 \mathrm{Km}$ al Norte de entrada a Purmamarca; FML 2821-1 ( 9 , MM) J UJ UY: Dep. Yavi: en vega al Este (Camino de Quebrada al Pie del Totay) - Pozuelo.

FML 14975 (§ิ, D, T), FML 14976 (ㅇ, D) PERÚ: Dep. Puno: Alrededores de Puno; MLP A. 4689

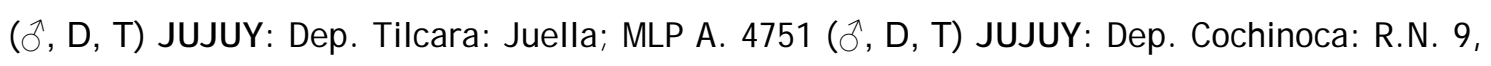
camino a Abra Pampa; MLP A. 4753 (q, D) JUJ UY: Dep. Cochinoca: R.N. 11, camino a Casabindo.

Pleurodema cordobae. MACN 39911-39912 (ME) CÓRDOBA: Dep. Calamuchita, aprox. 35 al este de Merlo (san Luis), Estancia Los Tabquillos.

Pleurodema diplolister. CENAI 8774-8775 (ME), CENAI 10003-1004 (ME) BRASIL: Ceará: Fortaleza.

MZUSP 38280 (\%, D), MZUSP 38291 (\%, D) BRASIL: Cocorobó, Bahia. 
Pleurodema fuscomaculatum. Fotografías del holotipo NMW 4316 cedidas por F. Tiedemann. BRASIL: Caiçara.

Pleurodema guayapae. CENAI 475-476 (ME) CENAI 477 (ME, T), CENAI 478 (ME), CENAI 493 (T), CENAI 495 (T) LA RIOJ A: Guayapa: próximo a Patquía: Establecimiento Santa Rosa; CENAI 4028-4040 (ME) LA RIOJ A: Patquía.

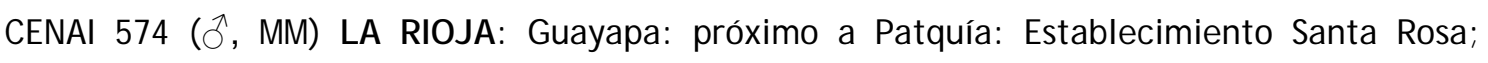
CENAI 4029 ( + , MM) LA RIOJ A: Patquía; CENAI 2591-1 ( $ð$, MM), CENAI 2591-3 ( + , MM), CENAI 2591-4 ( $q$, MM), CENAI 2591-14 ( + , MM), CENAI 2591-21 (ठ̊, MM), CENAI 2591-24(,+ MM), CENAI 2591-32 ( $\curvearrowright, M M)$, CENAI 2591-41 (,+ MM), CENAI 2591-44 ( $\odot$, MM), CENAI 2689 (,+ MM),

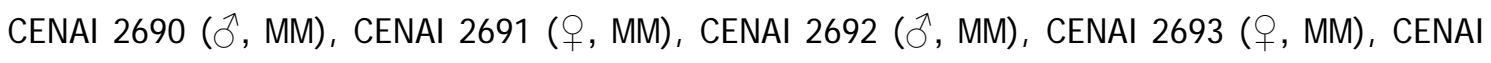
2694 ( $\curvearrowright$, MM), CENAI 2695 ( $($, MM) SANTIAGO ESTERO: Los Telares; FML 4368-2 ( $9, \mathrm{MM}), \mathrm{FML}$

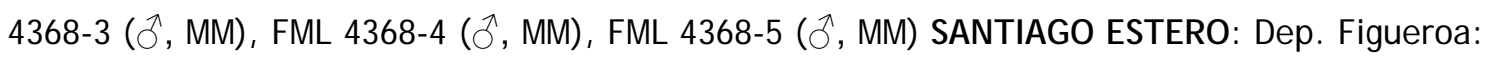
Caspi Corral; CENAI 2565 ( $q$, MM) SANTIAGO ESTERO: Saladillo. CENAI 2637 ( 0 , MM) CÓRDOBA: Totoralejos; FML 4898 ( $q$, MM) CORDOBA: Dep. Tulumba: Lucio V. Mansilla.

CENAI 574 ( $\widehat{\jmath}$, D) LA RIOJ A: Guayapa: próximo a Patquía: Establecimiento Santa Rosa; CENAI 2591-20 ( $\left.{ }^{\lambda}, \mathrm{D}\right)$ SANTIAGO ESTERO: Los Telares.

Pleurodema kriegi. MACN 38738 (ME), MACN 38740 (ME), CENAI 5079-510 (ME), CENAI 3278-8 (T).

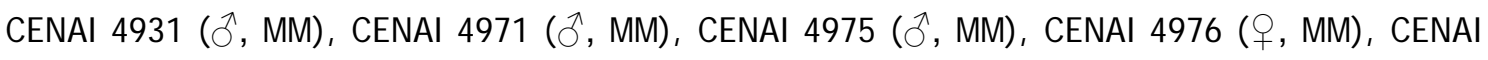

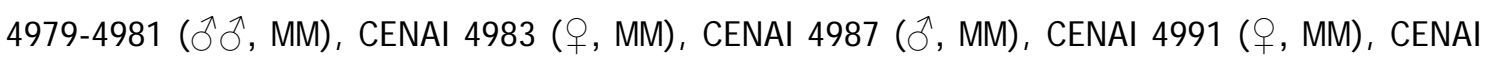

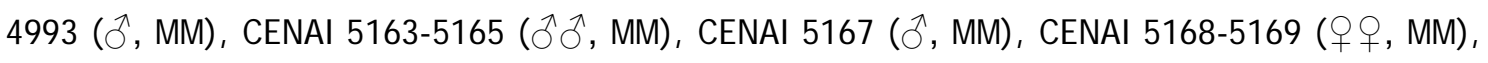

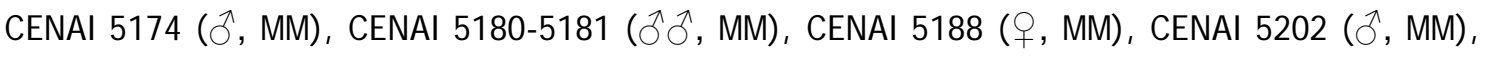

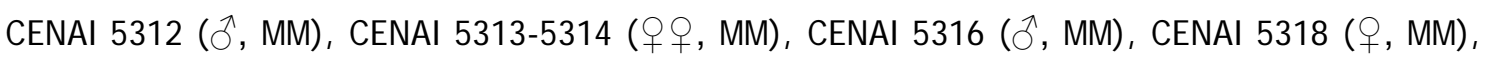
CENAI 5320 ( $q$, MM), CENAI 5324 ( $($, MM), CENAI 5327 ( $ð$, MM), CENAI 6224-6226 ( $q$,, MM), CENAI 6233 ( $q$, MM), CENAI 6275-6276 ( $q$, MM), CENAI 6278-6279 ( $q$, MM), CENAI 6280 ( $\precsim$, MM), CENAI 6281 ( $($, MM), CENAI 6283 (,+ MM), CENAI 6285 ( $q$, MM), CENAI 6287 (,+ MM),

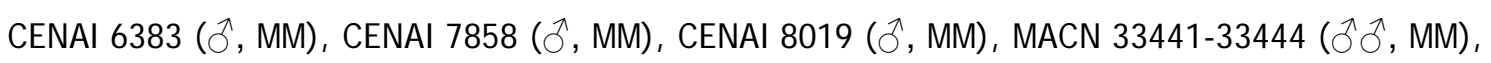
CENAI 6311 ( $(, M M)$, CENAI 6401 ( $($, MM), CENAI 6407 ( $($, MM), CENAI 6418 ( $($, MM), CENAI 8926 ( $($, MM), MACN 32407 (,+ MM), MACN 32410 ( + , MM) CÓRDOBA: Pampa de Achala;

CENAI 4948-4950 (ふَ̋, MM) CóRDoBA: Pampa de Achala, La Posta.

CENAI 5169 ( $q, D)$, CENAI 5170 ( $\delta$, D) CÓRDOBA: Pampa de Achala; MLP A. 4728 ( $q, D$ ) CÓRDOBA: Parque Nacional Quebrada del Condorito, sendero peatonal entre postas 4 y 5.

Pleurodema marmoratum. CENAI 9007-9008 (ME), CENAI 9014 (ME), CENAI 9019 (ME), CENAI 9025-9026 (ME), CENAI 9030 (ME); CENAI 10751-10752 (ME), CENAI 10755 (ME), CENAI 10761 
(ME), CENAI 10763 (ME), CENAI 10766-10767 (ME) BOLIVIA: Tiahuanacu, $65 \mathrm{~km}$ al Norte de La Paz; FML 3757-2 (ME) J UJ UY: Dep. Tumbaya: El Quemado - Abra de Pives.

CENAI 10769 ( $q$, D) BOLIVIA: Tiahuanacu, $65 \mathrm{~km}$ al Norte de La Paz.

Pleurodema nebulosum. MACN 38748-38754 (ME) MENDOZA: Dep. Santa Rosa: $50 \mathrm{~km}$ de Ñacuñán, Arroyo en Ruta 153; MACN 38993-38996 (ME) MENDOZA: Dep. Lavalle: Reserva Provincial Telteca, próximo a Estación de Guardaparque; 39800-39801 (ME) CATAMARCA: Tinogasta; FML 5560 (ME) CATAMARCA: Dep. Tinogasta: R.P. 45 próximo a Guanchin.

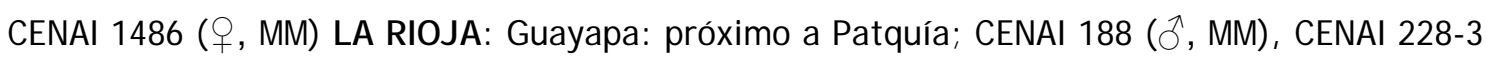
( + , MM), CENAI 228-4 (,+ MM), CENAI 228-5 ( $\curvearrowright, M M)$, CENAI 228-6 (,+ MM), CENAI 228-8 ( MM), CENAI 228-9 (,+ MM), CENAI 228-10 (,+ MM), CENAI 228-11 (,+ MM), CENAI 228-14 ( + , MM), CENAI 228-16 (ð, MM), CENAI 228-17 (ð, MM), LA RIOJ A: Patquía; CENAI 7203 (ð, MM),

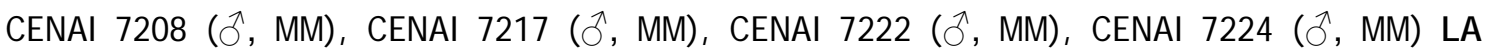
RIOJ A: alrededores de La Rioja; MACN 38766 ( $\widehat{~}$, MM) LA RIOJ A: General Lavalle: Ruta 40, 5 km al Sur de Chilca, 20 km del límite con San Juan; MACN 38769 (ふ, MM), MACN 38770 ( MM), MACN 38771 ( entre 5 y 25 km del límite con San J uan; FML 3689-1 (ð, MM), FML 3689-2 (ふ, MM), FML 4704-

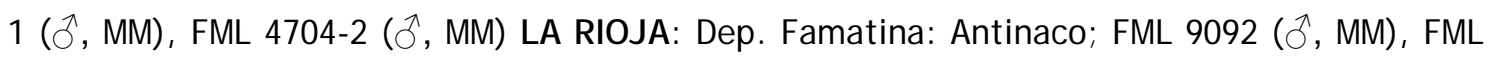
9093 ( $q$, MM) LA RIOJ A: Dep. Castro Barros: Anillaco; MLP A. 2420 ( $\%$, MM) LA RIOJ A; CENAI 428 ( $\odot$, MM) LA RIOJ A: Chamical; FML 5560 ( + , MM) CATAMARCA: Dep. Tinogasta: R.P. 45

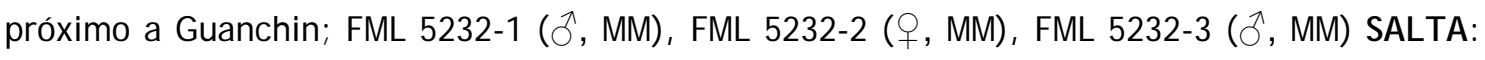
Dep. Cafayate: Los Médanos - Cafayate; FML 5245 ( $\widehat{\partial}$, MM) SALTA: Dep. Cafayate: Cafayate;

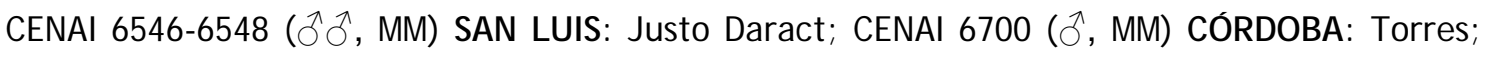
CENAI 7081 ( $\widehat{0}$, MM) NEUQUÉN: Dep. Catan-Lil: Charahuilla;MACN 38993 ( + , MM), MACN 38995

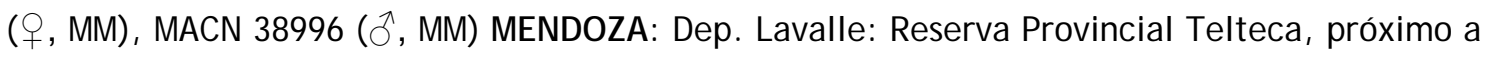
Estación de Guardaparque; MLP A. 3440 ( $\%$, MM) MENDOZA: Dep. Valle Grande, San Rafael; CENAI 9037 ( $($, MM), CENAI 9038 (ð̊, MM) LA PAMPA: Dep. Chalileo: Río Salado o Chapileufú, sobre Ruta 143; MACN 22042 (ठ̊, MM) LA PAMPA: Dep. Utracán: $26 \mathrm{~km}$ al Este de Chacharramendi; MACN 36678 ( $\sigma^{\AA}$, MM) LA PAMPA: Las Vertientes, $35 \mathrm{~km}$ al Sudoeste de Carro

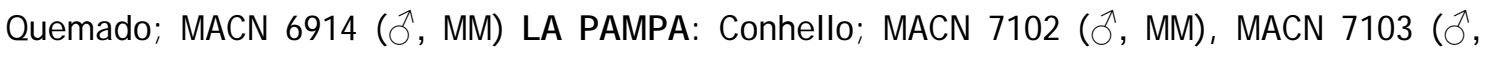
MM), MACN 7104-7105 ( $q$, MM), MACN 20996 ( + , MM) LA PAMPA: General PiCo; MACN 26002

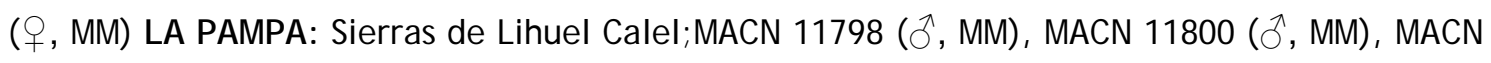
11801-11802 ( $q$, MM), Río NEGRO: Dep. Avellaneda: Lamarque; MACN 14032 ( + , MM) Río

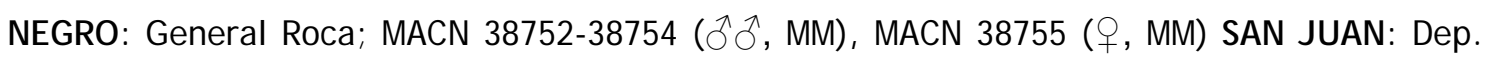
25 de Mayo: Ruta 20, km 450; CENAI 9045 ( $q$, MM) SAN J UAN: Baldecitos; FML 2428 (ð̊, MM) CATAMARCA: Dep. Santa María: $5 \mathrm{Km}$ De Santa María - Ruta Santa María -Amaicha Del Valle; FML 3268 (ô, MM) MENDOZA: Dep. Santa Rosa: Santa Rosa - Reserva Ñacuñan. 
CENAI 228-5 ( $ぇ, D)$ LA RIOJ A: Patquía; CENAI 6546 (ð, D) SAN LUIS: J usto Daract; MLP A. $5061(\widehat{\jmath}, \mathrm{D}, \mathrm{T}) \mathrm{MLP}$ A. $5062(\%, \mathrm{D})$ Río NEGRO: 25 de Mayo.

Pleurodema thaul. BB 2189 (ME) NEUQUÉN: RN 231 y Río Totoral; MACN 28701-28702 (T) NEUQUÉN: J unín de los Andes; MACN 38028 (ME) NEUQUÉN: Los Lagos: Laguna Pire; BB 2210 (T), BB 2212 (ME) Río NEGRO: próximo a Pampa Linda; BB 2203 (ME), BB 2206 (ME), BB 2217 (T), BB 2229-2230 (ME), BB 2234 (ME) CHUBUT: próximo a Desemboque.

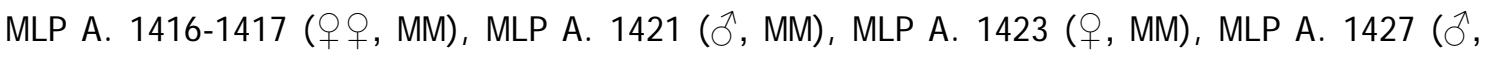

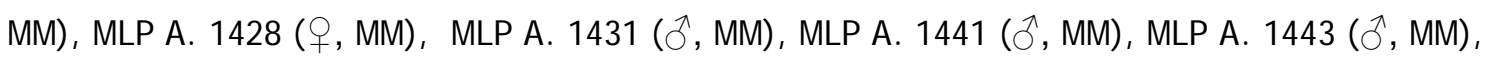

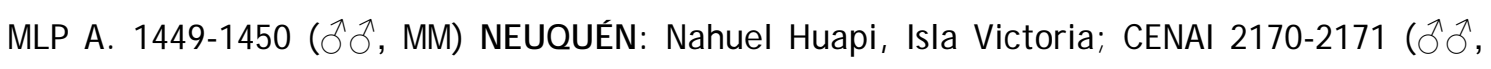
MM) NEUQUÉN: Lago Curruhé; MACN 11739 ( 9, MM), MACN 11867 (ठ, MM), MACN 11869-11870

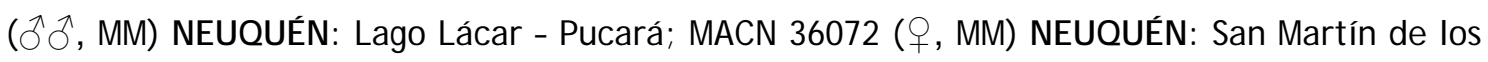
Andes, Lago Lácar; MACN 28705 ( 9, MM), MACN 28706 ( 0 , MM) NEUQUÉN: J unín de los Andes; MLP A. 1589-1590 ( $q$, MM), MLP A. 1592 (,+ MM) NEUQUÉN: Dep. Aluminé: Laguna Cari-

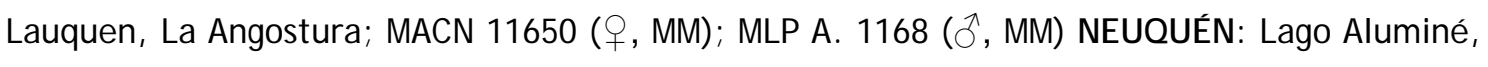
La Angostura; NEUQUÉN: Aluminé; MACN 38028-38030 ( + , MM) NEUQUÉN: LoS Lagos: Laguna Pire; FML 3663-11 (क, MM) NEUQUÉN: Dep. Lácar: Lago Queñi - Parque Nacional Lanín; FML 3695-3 (†, MM) NEUQUÉN: Dep. Los Lagos: Laguna Piré - Cerca De Paso Puyehue Parque Nacional Nahuel Huapi; MLP A. 1276 (ð, MM), MLP A. 1277 (ठ, MM) Río NEGRO: Tronador, Nahuel Huapi; MLP A. 2754 ( $え, M M)$, MACN 14816-14818 (qq, MM) Río NEGRO: El

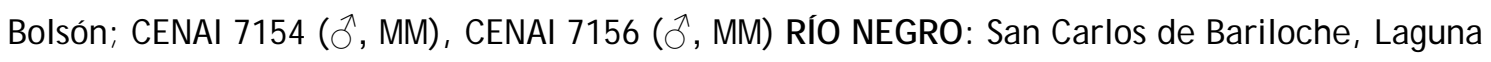

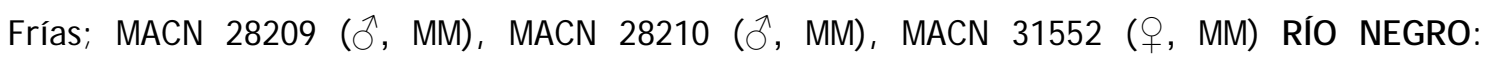
Bariloche; MACN 11180 ( $($, MM) Río NEGRO: Cerro Otto; MLP A. 2654 (ठึ, MM), MACN 15320

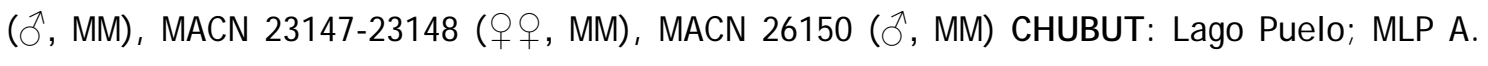
2275 ( $ᄋ$, MM) CHUBUT: Dep. Río Senguer: Turberas entre Lagos La Plata y La Plata chico;

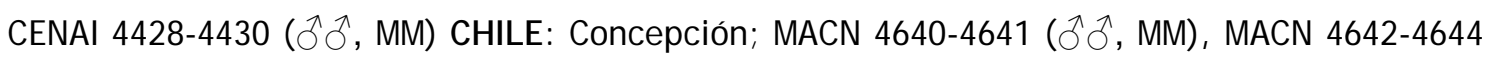
(우, MM), MACN 4645 ( $\hat{\jmath}$, MM), MACN 4646 (,+ MM), MACN 4648 (,+ MM), CHILE: Valdivia,

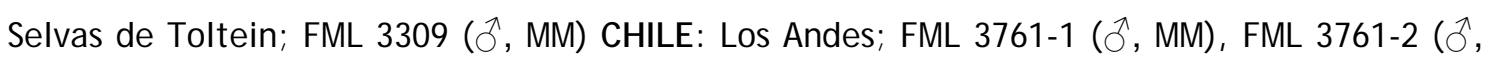
MM) CHILE: Pirehueico; MLP A. 1170 ( $q$, MM) CHILE: Mallín de Icalma; MLP A. 3530 ( + , MM) CHILE: Lago Todos los Santos; FML 3310 ( 9 , MM) CHILE: Quebrada El Teniente. MACN 28701 (sin dato de sexo, D), MACN 28702 (sin dato de sexo, D), MACN 28703 (q, D), MACN 29214 (sin dato de sexo, D), MACN 32114 (sin dato de sexo, D), MACN 32118 (q, D), NEUQUÉN: J unín de los Andes; MACN 11648 (q, D), MACN 11649 (क, D) NEUQUÉN: Aluminé;

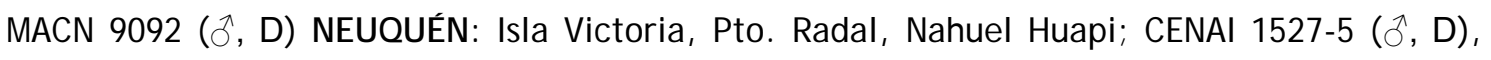
CENAI 1527-8 ( $($, D) Río NEGRO: Alrededores de Puerto Blest, Costa del Lago; CENAI 3617 ( $ð$,

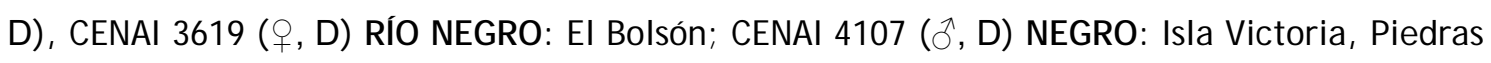
Blancas; CENAI 8826 ( $\hat{O}$, D) CHUBUT: Esquel - Orillas del Lago Verde - Mermut, Parque 
Nacional Los Alerces; CENAI 1952 (, D) CHILE: El Correntoso (Chamiza) próximo a Puerto Montt.

Pleurodema tucumanum. MLP A. 3852-3856 (ME), MLP A. 3858 (ME), 3862-3863 (ME), MLP A. 3897-3906 (ME), MLP A. 4721-4724 (ME), MLP A. 4726 (ME), MLP A. 4727 (ME) LA RIOJ A: Dep. Independencia: Establecimiento Santa Rosa, RN 150, km 11, próximo a Patquía.

FML 11156-11157 (ð̊, MM) SALTA: Dep. Anta: J oaquín V. González; FML 2734-1 (ð̊, MM), FML

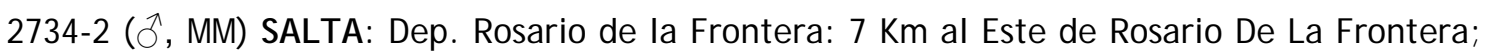

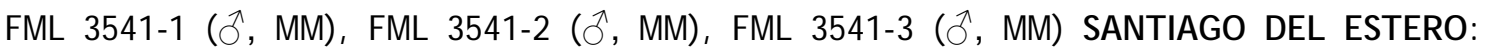
Choya, Villa De La Punta; FML 5484-1 ( + , MM), FML 5484-2 (क, MM), FML 5484-3 (ठ․ MM), FML

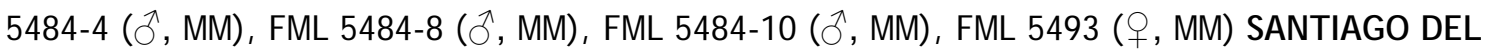
ESTERO: Dep. Figueroa: $2 \mathrm{Km}$ al oeste del cruce entre R.P. 2 y 5, sobre R.P. 5; FML 4746-1

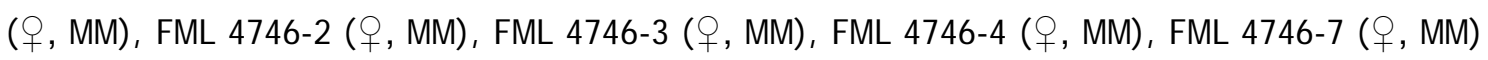
SANTIAGO DEL ESTERO: Dep. Figueroa: Caspi Corral; FML 3549-1 (q, MM), FML 3549-2 ( $q$, MM) SANTIAGO DEL ESTERO: Dep. Choya: Villa De La Punta; FML 7687 (ð, MM), FML 7688 (ð, MM), FML 7689 (ð, MM), FML 7690-7694 (ðð, MM) TUCUMAN: Dep. Lules: El Ceibal - Cerca De San Pablo; FML 7725 (ô, MM) TUCUMÁN: Dep. Cruz Alta: Ranchillos - Cerca De Canal Dp2; FML 9747-9750 (ふふふ, MM) TUCUMÁN: Dep. Burruyacú: Río Loro - Frente A La Usina; FML 8479 (Ō, MM) CóRDOBA: Dep. Río Cuarto: R.N. 36 - Km 624 - Río Cuarto.

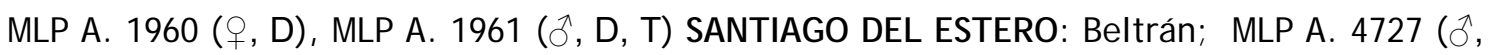
D, T) LA RIOJ A: Dep. Independencia: Establecimiento Santa Rosa, RN 150, km 11, próximo a Patquía;

Engystomops pustulosus. FML 12080 (ㅇ, D), FML 12083 ( $\delta$, D) PANAMÁ: 2,6 km al W de Gamboa.

Eupemphix nattereri. CENAI 11006-10007 (ME) BRASIL: Mato Grosso: Miranda; MACN 3195931960 (ME), MACN 32721 (ME) BOLIVIA: Santa Cruz de la Sierra.

FML 1450 ( + , D), FML 1819 (,+ D) PARAGUAY: Dep. San Pedro, Carumbé.

Physalaemus albonotatus. MLP A. 2809-2810 (ME), MLP A. 2811 (ME, T), MLPA. 2812-2822 (ME) CORRIENTES: Bella Vista; MLP A. 3421 (ME), MLP A. 3764-3765 (ME) BUENOS AIRES: Ramallo; MLP A. 3802 (ME) BUENOS AIRES: Pergamino. MLP A. 4972 (ME) BUENOS AIRES: Arrecifes; MLP A. 4742 (ME) BUENOS AIRES: San Nicolás: Parque Rafael Aguilar.

FML 4837 (dos $\hat{o} \hat{o}$, D) SANTA Fé: Dep. Gral. Obligado: Entre Reconquista y Puerto Reconquista; FML 3598 (dos,+ D) CHACO: Dep. Gral. Güemes, J uan J osé Castelli. 
Physalaemus biligonigerus. MLP A. 4645-3647 (ME) J UJ UY: Dep. El Carmen: R. N. 9, próximo al Dique La Ciénaga; MLP A. 4282-4310 (ME) FORMOSA: Ingeniero J uárez; MLP A. 4311-4313 (ME) FORMOSA: Comunidad María Cristina; CENAI 2491 (ME): SALTA: Embarcación.

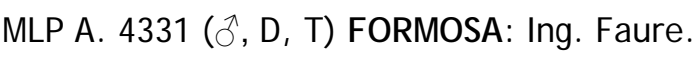

Physalaemus cuqui. MLP A. 4939 (ME), MLP A. 4640 (ME, T), MLP A. 4641 (ME) J UJ UY: Dep. El Carmen: R. N. 9, próximo al Dique La Ciénaga; MACN 32316 a 32320 (ME) SALTA: Dep. Orán: Río Pescado y Serranía Las Pavas, extremo So del Parque Nacional Baritú; MACN 34031 (ME), MACN 34709 (ME) SALTA: Río Pescado: Finca J akuika, "Bañado 1".

FML 1281 (un $\widehat{O}$ y una + , D). J UJ UY: Dep. Ledesma: Yuto.

Physalaemus cuvieri. MLP A. 1301-1307 (ME), MLP A. 1308 (ME, T), MLP À. 1309-1313 (ME) MISIONES : Aristóbulo del Valle: Cuña Pirú; J F 161 (ME), J F 200 (ME), JF 202 (ME), J J 235 (ME), J F 236 (ME), J F 238 (ME), J F 601 (ME), JF 734 (ME) MISIONES: Cuartel Río Victoria.

FML 2353 (un ô y una $q$, D). MISIONES: Dep. Cainguas: Dos de Mayo; JF 1134 ( $\widehat{\partial}$, D) MISIONES: Cuartel Río Victoria: km 1272.

Physalaemus fernandezae. MLP A. 1809-1812 (ME) BUENOS AIRES: Punta Indio; MLP 22642266 (ME) BUENOS AIRES: Pila: Estancia La Postrera; MACN 11004-11010 (ME) BUENOS AIRES: Libres del Sur; MACN 29780 (ME) BUENOS AIRES: Escobar.

BB 2025 ( $§, T, D)$ BUENOS AIRES: próximo Balneario La Balandra.

Physalaemus henselii. MLP A. 1095 (ME) ENTRE RIOS: Salto Grande; MLP A. 3009-3010 (ME) ENTRE RIOS: Dep. Colón: Parque Nacional El Palmar: La Glorieta; CENAI 147 (ME) BUENOS AIRES: La Brava; CENAI 3261-3262 (ME) URUGUAY: Barra de Santa Lucía; CENAI 3486 (ME) URUGUAY ; CENAI 9553 (ME) : BUENOS AIRES: Parque Pereyra Iraola; MACN 34743 (ME) ENTRE RíoS: Palmar de Colón, MACN 14101 (ME) Corrientes: San Cosme.

MLP A. 3010 (§̂, D). ENTRE RIOS: Dep. Colón: Parque Nacional El Palmar: La Glorieta.

Physalaemus santafecinus. CENAI 1044-1046 (ME), CENAI 1243 (ME), CENAI 1336-1337 (ME) SANTA FÉ: Helvecia.

FML 937 (dos $\widehat{\text { ô }} \widehat{\text { y }}$ dos 우, D). CORRIENTES: Dep. Manantiales: Mburucuyá.

Pseudopaludicola boliviana. MLP A. 2953-2954 (ME) CORRIENTES: Bella Vista. MLP A. 43864387 (ME) FORMOSA: Clorinda. MLP A. $4372-3378$ (ME), MLP A. 4379 (क, ME, D), MLP A. 4380 ( ${ }^{2}$, ME, T, D), MLP A. 4381 (ME) CHACO: Resistencia: Peaje General Belgrano. MACN 38522 (ME).

CENAI 9354 (sin dato de sexo, D), CENAI 9356 (sin dato de sexo, D) BOLIVIA: Santa Cruz de la Sierra: Nueva Moka. MACN 31453 (sin dato de sexo, D) SANTA FÉ: Ruta 11, norte de Reconquista. 
Pseudopaludicola falcipes. MACN 36611-36615: URUGUAY Artigas: San Gregorio, A. Conti. CENAI 806-807 (sin dato de sexo, D). URUGUAY, Pueblo Santiago Vázquez.

Pseudopaludicola mystacalis. MLP A. 1550 (ME) SANTA FE: Guadalupe. MLP A. 3003-3004 (ME) ENTRE RIOS: Dep. Colón: Parque Nacional El Palmar: La Glorieta. MLP A. 3032 (ME), MLP A. 3047 (ME) ENTRE RIOS: Villa Elisa : Arroyo San Pascual.

$$
\text { MACN 10934-10935 (dos đ̋ D) CORRIENTES: Ituzaingó. }
$$

Somuncuria somuncurensis. CENAI 7399 (ME) : Río NEGRO: próximo a Valcheta, MACN 3392833929 (ME) Río NEGRO: Meseta de Somuncurá: Valcheta: Estancia El Rincón.

MLP A. 5109 (sin dato de sexo, D) Río NEGRO: Meseta de Somuncurá: Estancia El Rincón.

\section{Fam. Leptodactylidae}

Leptodactylus latinasus. MLP A. 5043-5044 (ME) BUENOS AIRES: Ramallo: San Miguel, Campo de Mayo ; MLP A. 3768 (ME, T), MLP A. 3769-3779 (ME) BUENOS AIRES: La Plata ; MLP A. 3968-3972 (ME) BUENOS AIRES: Partido Magdalena: aprox. $20 \mathrm{~km}$ al Sur de Magdalena. MLP A. 3968 ( $\hat{\text { }}$, D). BUENOS AIRES: Partido de Magdalena, aprox. $20 \mathrm{~km}$ al sur de Magdalena.

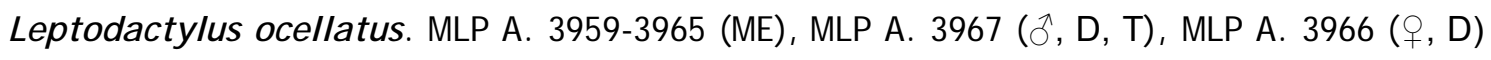
BUENOS AIRES: Partido Magdalena: aprox. $20 \mathrm{~km}$ al Sur de Magdalena. MLP A. 4949 (ठิ, ES) BUENOS AIRES: La Plata.

\section{Fam. Cycloramphidae}

Alsodes gargola. MLP A. 2872-2873 (ME), MLP A. 2875-2890 (ME), MLP A. 2892-2894 (ME) NEUQUEN: Primeros Pinos: Lag. Atravesada; MACN 37848-37852 (ME); MACN 37854(ME); MACN 37856 (ME) NEUQUEN: Dep. Picunches: Lag. Cerro La Atravesada; MACN 37860 (ME) NEUQUEN: Dep. Picunches: arroyo en Cerro La Atravesada.

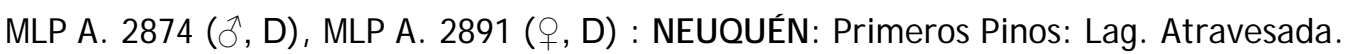

Eupsophus calcaratus. MLP A. 4012-4013 (ME) MLP A. 4015 (ME) : CHUBUT: Dep. Cushamén: Parque Nacional Lago Puelo : próximo a Los Hitos.

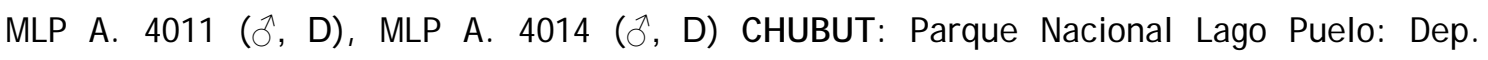
Cushamén: próximo a Los Hitos.

Odontophrynus americanus. MLP A. 3980 (ME) BUENOS AIRES: Partido Magdalena: aprox. 20 km al Sur de Magdalena; CENAI 1636-1637 (ME) BUENOS AIRES: Monte.

CENAI 3939 ( $\widehat{\jmath}$, D) BUENOS AIRES: Ezpeleta. 


\section{Fam. Ceratophryidae}

Batrachyla leptopus. MLP A. 3999 (ME) CHUBUT: Dep. Cushamén: Parque Nacional Lago Puelo: alrededores del sendero Pitranto Grande; MLP A. 4016-4017 (ME) CHUBUT: Dep. Cushamén: Parque Nacional Lago Puelo, próximo a Los Hitos; MACN 38006-38008 (ME) CHUBUT: Dep. Cushamén: Lago Puelo; BB 2202 (T), BB 2236 (T) CHUBUT: Desemboque: Lago Puelo CENAI 1807 (ME) CHILE: El Correntoso (Chamiza), próximo a Puerto Montt ; CENAI 38483849 (ME) CHILE: Puyehué; CENAI 4682-4685(ME), CENAl 470 (ME) Río NEGRO: Puerto Blest; BB 2224 (T), BB 2228 (T) Río NEGRO: próximo a Pampa Linda; BB 2242 (T) CHUBUT: próximo a Desemboque.

CENAI 1309 ( sin dato de sexo, D) Río NEGRO: Parque Nacional Nahuel Huapi: Lago Felipe; CENAI 1828 (sin dato de sexo, D), CENAI 1830 (,+ D) : Río NEGRO: Puerto Blest. 


\section{BIBLIOGRAFÍA}

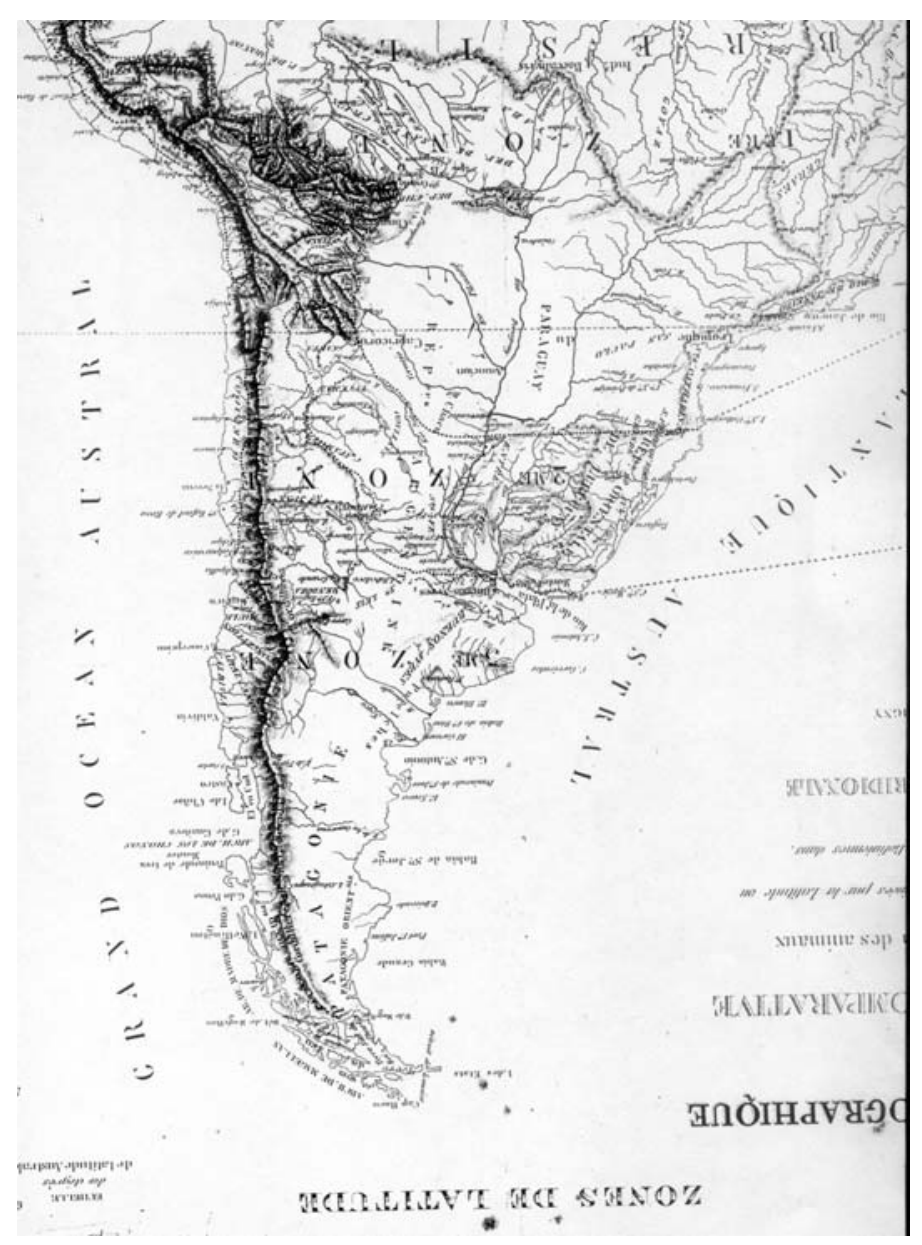

Tomado de Dorbingyi (1847) 
Ab'Sáber, A. N. (1977a). Espaços ocupados pela expansão dos climas secos na América do Sul, por ocasião dos períodos glaciais quaternários. Paleoclimas (São Paulo), 3, 1-20.

Ab'Sáber, A. N. (1977b). Os domínios morfoclimáticos na América do Sul. Primeira aproximação. Geomorfologia (SãoPaulo), 52, 1-21.

Agostini, M. G., Cajade, R. \& Roesler, I. (2007). Comunal oviposition. Pleurodema cinereum. Herpetological Review, 38, 441.

Alberch, P. \& Gale, E. A. (1985). A developmental analysis of an evolutionary trend: digital reduction in Amphibians. Evolution, 39, 8-23.

Alcalde, L. (2007). Desarrollo del esqueleto larvario y musculatura asociada en el género Batrachyla Bell 1843 (Anura: Neobatrachia) y sus relaciones filogenéticas interespecíficas. Tesis de Doctorado, Universidad Nacional de La Plata. 314 pp.

Alcalde, L., Natale, G. S. \& Cajade, R. (2006). The tadpole of Physalaemus fernandezae (Anura: Leptodactylidae). Herpetological J ournal, 16, 203-211.

Altig, R. \& McDiarmid, M. W. (1999). Body Plan. Development and Morphology. In M. W. McDiarmid \& R. Altig (Eds) Tadpoles: The Biology of Anuran Larvae (pp. 24-51). Chicago: University of Chicago Press.

Álvarez, B. B., Delfino, G., Nosi, D. \& Terreni, A. (2005). Ultrastructure of poison glands of South American frogs: a comparison between Physalaemus albonotatus and Leptodactylus chaquensis (Anura: Leptodactylidae). J ournal of Morphology, 263, 247-258.

Amaral, M. J. L. V., Cardoso, A. J. \& Recco-Pimentel, S. M. (2000). Cytogenetic analysis of three Physalaemus species (Amphibia, Anura). Caryologia, 53, 283-288.

Amaro-Ghilardi, R. C., Skuk, G. O., de Sá, R. O., Rodrigues, M. T. \& Yonenaga-Yassuda, Y. (2006). Karyotypes of eight species of Leptodactylus (Anura, Leptodactylidae) with a description of a new karyotype for the genus. Phyllomedusa, 5, 119-133.

Ananias, F., Bombeiro, A. L., Silva, C. D. B., Zampieri Silva, A. P., Haddad, C. F. B. \& Kasahara, S. (2007). Cytogenetics of Eupemphix nattereri Steindachner, 1863 (Anura: Leiuperidae) and karyotypic similarity with species of related genera: taxonomic implications. Acta Zoologica Sinica, 53, 285-293.

Andersen, M. L. (1978). The comparative myology and osteology of the carpus and tarsus of selected anurans. Kansas: Ph.D., University of Kansas.

Andersson, L. G. (1906). On Batrachians from Bolivia, Argentina and Peru, collected by Erland Nordenskiöld 1901-1902 and Nils Holmgren 1904-1905. Arkiv för Zoologi, 3, 1-20.

Andersson, L. G. (1938). Batrachians from Burma collected by Dr. R. Malaise, and from Bolivia and Ecuador collected by Dr. C. Hammerlund. Arkiv för Zoologi, 30A, 1-24.

Arzabe, C. (1999). Reproductive activity patterns of anurans in two different altitudinal sites within the Brazilian Caatinga. Revista Brasileira de Zoologia, 16, 851-864.

Aún, L. \& Martori, R. (1999). Pleurodema nebulosa. Geographic distribution. Herpetological Review, 30, 231.

Ávila, L. J., Morando, M. \& Priotto, J. W. (1999). Amphibia and Reptilia of the high grasslands of the Sierra de Comechingones, Córdoba, Argentina. Bulletin of the Maryland Herpetological Society, 35, 97-114.

Ávila, L. J. \& Priotto, J. W. (1995). Geographic Distribution. Pleurodema kriegi. 
Herpetological Review, 26, 106.

Báez, A. M. (2000). Tertiary anurans from South America. In H. Heatwole \& R. L. Carroll (Eds) Amphibian Biology. Vol. 4. Palaeontology. The evolutionary history of Amphibians (pp. 1388-1391). New South Wales: Surrey Beatty and Sons Pty. Limited.

Báez, A. M. \& Fernicola, J. C. (1999). Nuevo material de anuros en estratos deseadenses de Scarritt Pocket, provincia del Chubut, y la supuesta presencia de bufónidos paleárticos en el Oligoceno de Patagonia. Ameghiniana, 36, 23-35.

Báez, A. M. \& Perí, S. I. (1989). Baurubatrachus pricei, nov. gen. et sp., un anuro del Cretacico Superior de Minas Gerais, Brazil. Anais da Academia Brasileira de Ciências, 61, 447-458.

Báez, A. M. \& Perí, S. I. (1990). Revisión de Wawelia gerholdi, un anuro del Mioceno de Patagonia. Ameghiniana, 27, 83-94.

Baldo, J. \& Gutiérrez, M. (1997). Sobre la presencia del género Pleurodema (Anura: Leptodactylidae) en el noroeste de la provincia de Córdoba, con especial referencia a Pleurodema nebulosa. Cuadernos de Herpetología, 11, 69-85.

Barrio, A. (1945). Contribución al estudio de la etología y reproducción del batracio Pseudopaludicola falcipes. Revista Argentina de Zoogeografía, 5, 37-43.

Barrio, A. (1953). Sistemática, morfología y reproducción de Physalaemus henselii (Peters) y Pseudopaludicola falcipes (Hensel) (Anura, Leptodactylidae). Physis, 20, 379-389.

Barrio, A. (1954). Contribución a la etología y reproducción del batracio Pseudopaludicola falcipes. Revista Argentina de Zoogeografía, 5, 37-43.

Barrio, A. (1964a). Especies crípticas del género Pleurodema que conviven en una misma área, identificadas por el canto nupcial (Anura, Leptodactylidae). Physis, 24, 471-489.

Barrio, A. (1964b). Relaciones morfológicas, eto-ecológicas y zoogeográficas entre Physalaemus henseli (Peters) y P. fernandezae (Müller) (Anura, Leptodactylidae). Acta zoológica Lilloana, 20, 285-305.

Barrio, A. (1964c). Caracteres eto-ecológicos diferenciales entre Odontophrynus americanus (Dum. et Bibron) y O. occidentalis (Berg) (Anura, Leptodactylidae). Physis, 24, 385-390.

Barrio, A. (1967). Notas complementarias sobre el género Physalaemus Fitzinger (Anura, Leptodactylidae). Physis, 27, 5-8.

Barrio, A. (1977). Aportes para la elucidación del "status" taxonómico de Pleurodema bibroni Tschudi y Pleurodema kriegi (Müller) (Amphibia, Anura, Leptodactylidae). Physis, Sección C, 37, 311-331.

Barrio, A. \& Rinaldi de Chieri, P. (1970). Estudios citogenéticos sobre el género Pleurodema y sus consecuencias evolutivas (Amphibia, Anura, Leptodactylidae). Physis, 30, 309-319.

Barrionuevo, J. S. (2009). Análisis filogenético de las especies del grupo meridional del género Telmatobius (Anura: Ceratophryidae). Tesis de Doctorado, Universidad Nacional de Tucumán. 228 pp.

Basso, N. G. (1990). Estrategias adaptativas en una comunidad subtropical de anuros. Serie de Monografías. Asociación Herpetológica Argentina, 1, 1-70.

Basso, N. G. (1994). Una nueva especie de Batrachyla (Anura, Leptodactylidae, 
Telmatobiinae) de Argentina. Relaciones filogenéticas interespecíficas. Cuadernos de Herpetología, 8, 51-56.

Batistic, R. F., Beçak.M.L. \& Vizoto, L. D. (1969). Variacão cromossômica no gênero Pseudopaludicola (Anura). Ciencia e Cultura, 21, 260.

Bauer, A. M., Günther, R. \& Klipfel, M. (1995). The herpetological contributions of Wilhelm C.H.Peters (1815-1883). Ithaca, New York: Society for the Study of Amphibians and Reptiles.

Beçak, M. L. (1968). Chromosomal analysis of eighteen species of Anura. Caryologica, 21, 191-208.

Bell, T. (1843). Reptiles, part. V. In C. Darwin (Ed) The zoology of the voyage of H.M.S. Beagle, under the command of Captain Fitzroy, R. N., during the years 1832 to 1836. (pp. 1-51). London: Smith, Elder and Co.

Berg, C. (1896). Batracios Argentinos. Enumeración sistemática, sinonímica y bibliográfica de los batracios de la República Argentina. Anales del Museo Historia Natural de Buenos Aires, $5,147-226$.

Bogart, J. P. (1974). A karyosystematic study of frogs in the genus Leptodactylus (Anura: Leptodactylidae). Copeia, 1974, 728-737.

Borteiro, C. \& Kolenc, F. (2007). Redescription of the tadpoles of three species of frogs from Uruguay (Amphibia: Anura: Leiuperidae and Leptodactylidae), with notes on natural history. Zootaxa, 1638, 1-20.

Boulenger, G. A. (1882). Catalogue of the Batrachia Gradientia s. Caudata and Batrachia Apoda in the collection of the British Museum. London: British Museum.

Boulenger, G. A. (1887). Descriptions of new or little-known South-American frogs of the genera Paludicola and Hyla. Annal and Magazine of Natural History, 5, 295-300.

Boulenger, G. A. (1888). Description of new brazilian batrachians. Annal and Magazine of Natural History, 6, 187-189.

Brasileiro, C. A., Sawaya, R. J., Kiefer, M. C. \& Martins, M. (2005). Amphibians of an open cerrado fragment in Southeastern Brazil. Biota Neotropica, 5, 1-17.

Braun, C. A. S. (1973). Sobre a ocorrêmcia de Pleurodema bibronii Tschudi, 1838 no estado de Rio Grando so Sul, Brasil (Anura, Leptodactylidae). Iheringia (Zool gia), 44, 28-31.

Breder, C. M. (1946). Amphibians and reptiles of the rio Chucunaque drainage, Darien, Panama, with notes on their life histories and habits. Bulletin of the American Museum of Natural History, 86, 375-346.

Bremer, K. (1988). The limits of amino acid sequence data in angiosperm phylogenetic reconstruction. Evolution, 42, 795-803.

Bremer, K. (1992). Ancestral Areas: a cladistic reinterpretation of the center of origin concept. Cladistics, 41, 436-445.

Bremer, K. (1994). Branch support and tree stability. Cladistics, 10, 295-304.

Bridarolli, M. E. \& di Tada, I. E. (1994). Biogeografía de los anfibios anuros de la región central de la República Argentina. Cuadernos de Herpetología, 8, 63-82.

Brum-Zorilla, N. \& Saez, F. A. (1968). Chromosomes of Leptodactylidae (Amphibia, Anura). 
Experimenta, 24, 969.

Brusquetti, F. \& Lavilla, E. O. (2006). Lista comentada de los anfibios de Paraguay. Cuadernos de Herpetología, 2, 1-79.

Brusquetti, F., Netto, F. \& Scott, N. (2009). Physalaemus santafecinus Barrio, 1965 (Anura, Leiuperidae) en la República del Paraguay. Cuadernos de Herpetología, 23, 63-65.

Burmeister, H. (1861). Reise durch die La Plata-Staaten, mit besonderer rücksicht auf die physische beschaffenheit und den culturzustand der Argentinischen republik. Halle.

Burton, T. C. (1998). Variation in the hand and superficial throat musculature of Neotropical Leptodactylid frogs. Herpetologica, 54, 53-72.

Cabrera, A. L. \& Willink, A. (1980). Biogeografía de América Latina. Washington: OEA, Serie Biología, Monografía 13.

Camacho, H. H. (1967). Las transgresiones del Cretácico Superior y Terciario de la Argentina. Revista de la Asociación Geológica Argentina, 22, 253-280.

Camargo, A., Maneyro, R. \& Langone, J. A. (2005). Análisis morfológico de las poblaciones uruguayas y brasileñas de Pleurodema bibroni Tschudi, 1838 (Anura, Leptodactylidae). Actas de las VII J ornadas de Zoología de Uruguay, 16.

Candeiro, C. R. A. (2007). Cretaceous biota of the Triângulo Mineiro region (Brazil): A review of recent finds. Estudios Geológicos, 63, 65-73.

Candeiro, C. R. A., Santos, A. R., Bergqvist, L. P., Ribeiro, L. C. B. \& Apesteguía, S. (2008). The Late Cretaceous fauna and flora of the Uberaba area (Minas Gerais State, Brazil). J ournal of South American Earth Sciences, 25, 203-216.

Cannatella, D. C. \& Duellman, W. E. (1984). Leptodactylid frogs of the Physalaemus pustulosus group. Copeia, 1984, 902-921.

Capurro, L. F. (1953). Dos casos de semialbinismo en Pleurodema bibronii (D. et B.). Investigaciones Zoológicas Chilenas, 2, 14-15.

Capurro, L. F. (1957). Anfibios de la Región de los Lagos Valdivianos. Investigaciones Zoológicas Chilenas, 3, 22-28.

Capurro, L. F. (1958). Lista preliminar de los anfibios de Chile, y breves apuntes sobre su distribución y biología. Investigaciones Zoológicas Chilenas, 2, 289-299.

Cardoso, A. J. \& Arzabe, C. (1993). Corte e desenvolvimento larvário de Pleurodema diplolistris (Anura: Leptodactylidae). Revista Brasileira de Biologia, 53, 561-570.

Carvalho, A. L. \& Bailey, J. B. (1948). Sõbre os hábitos e ecologia de Pleurodema diplolistris (Peters) (Amphibia, Anura). Revista Brasileira de Biologia, 8, 261-264.

Casamiquela, R. M. (1963). Sobre un par de anuros del Mioceno de Río Negro Patagonia) Wawelia gerholdi $\mathrm{n}$. gen. et sp. (Ceratophrydidae) y Gigantobatrachus parodi (Leptodactylidae). Ameghiniana, 3, 141-157.

Cei, J. M. (1956a). Nueva lista sistemática de los batracios de Argentina y breves notas sobre su biología y ecología. Investigaciones Zoológicas Chilenas, 3, 35-68.

Cei, J. M. (1956b). Nueva lista sistemática de los batracios de Argentina y breves notas sobre su biología y ecología. Investigaciones Zoológicas Chilenas, 3, 35-68. 
Cei, J. M. (1956c). Nueva lista sistemática de los batracios de Argentina y breves notas sobre su biología y ecología. Investigaciones Zoológicas Chilenas, 3, 35-68.

Cei, J. M. (1957). Sobre la presencia de Pleurodema marmorata en territorio chileno. Investigaciones Zoológicas Chilenas, 4, 32.

Cei, J. M. (1958a). Las láminas originales del suplemento a los batracios chilenos de Philippi: primera impresión y comentarios. Investigaciones Zoológicas Chilenas, 4, 265-288.

Cei, J. M. (1958b). Polimorfismo y distribución geográfica en poblaciones chilenas de Pleurodema bibroni Tschudi. Investigaciones Zoológicas Chilenas, 4, 30-327.

Cei, J. M. (1959). Hallazgos herpetológicos y ampliación de la distribución geográfica de las especies argentinas. Actas y Trabajos del Primer Congreso Sudamericano de Zoología, La Plata, Argentina, Tomo I, 209-210.

Cei, J. M. (1960). Geographic variation of Bufo spinulosus in Chile. Herpetologica, 16, 243250.

Cei, J. M. (1961). Bipolaridad del ciclo espermatogenetico discontinuo autoregulado en los Anfibios. Revista Argentina de Biología, 37, 48-51.

Cei, J. M. (1962a). Batracios de Chile. Santiago: Ediciones Universidad de Chile.

Cei, J. M. (1962b). Pleurodema bufonina Bell, anfibio australe con ciclo spermatogenetico discontinuo autoregolato. Archivio Zoologico Italiano, 4, 180.

Cei, J. M. (1965). Comentarios sobre el hallazgo de Telmatobius montanus Lataste (in Philippi) en la Cordillera al Sur de Mendoza. Acta III Congreso ALtinoamericano de Zoología.Santiago, Chile, 1-4.

Cei, J. M. (1969a). La meseta basáltica de Somuncurá, Río Negro. Herpetofauna endémica y sus peculiares equilibrios biocenóticos. Physis, 28, 257-271.

Cei, J. M. (1969b). The Patagonian Telmatobiid fauna of the Volcanic Somuncurá plateau of Argentina. J ournal of Herpetology, 3, 1-18.

Cei, J. M. (1970). Further observations on endemic Telmatobiid frogs from the Patagonian Somuncurá plateau (Río Negro, Argentina). J ournal of Herpetology, 4, 57-61.

Cei, J. M. (1972a). Herpetología patagónica. IV. Distribución geográfica y diferenciación serológica poblacional de Pleurodema bufonina Bell. Physis, 31, 423-430.

Cei, J. M. (1972b). Segregación corológica y procesos de especiación por aislamiento en Anfibios de la Pampa de Achala, Córdoba. Acta zoológica Lilloana, 29, 233-246.

Cei, J. M. (1979). Albinismo y canibalismo en larvas de Pleurodema nebulosa de la región precordillerana de la provincia de San Juan, Argentina (Anura, Leptodactylidae). Publicaciones ocasionales del Instituto de Biología Animal, 11, 1-3.

Cei, J. M. (1980a). Amphibians of Argentina. Monitore zoologico italiano, N.S., Monografia, 2: $1-609$.

Cei, J. M. (1980b). New endemic Iguanid Lizard from the Famatina Mountains of Western Argentina. J ournal of Herpetology, 14, 57-64.

Cei, J. M. (1985). Taxonomic and evolutionary significance of peptides in Amphibian skin. Peptides, 6 (Suppl. 3), 13-16. 
Cei, J. M. (1990). On a Paraguayan sample of a long time confused species: Physalaemus fuscomaculatus (Steindachner, 1864) (Anura, Leptodactylidae). Bolletino del Museo Museo regionale di Scienze naturali, 8, 215-231.

Cei, J. M. \& Capurro, L. F. (1957). La distribución de los patrones de coloración en Pleurodema bibroni en relación con la distribución geográfica y el habitat. Investigaciones Zoológicas Chilenas, 3, 156-161.

Cei, J. M. \& Capurro, L. F. (1958). Biología y desarrollo de Eupsophus taeniatus Girard. Investigaciones Zoológicas Chilenas, 4, 159-182.

Cei, J. M. \& Codoceo, M. (1957). Probable discontinuidad del ciclo espermatogenético de Pleurodema bufonina. Investigaciones Zoológicas Chilenas, 4, 77-82.

Cei, J. M. \& Erspamer, V. (1966). Biochemical taxonomy of South American Amphibians by means of skin amines and polypeptides. Copeia, 1966, 74-78.

Cei, J. M., Erspamer, V. \& Roseghini, M. (1967). Taxonomic and evolutionary significance of biogenic amines and polypeptides occuring in amphibian skin. I. Neotropical Leptodactylid frogs. Systematic Zoology, 16, 328-342.

Cei, J. M. \& Espina Aguilera, S. (1957). La vibración sexual preventiva "warning vibration" en Pleurodema chilenas. Investigaciones Zoológicas Chilenas, 4, 15-21.

Cei, J. M. \& Roig, V. G. (1961). Sobre la presencia de un batracio característico de la fauna patagónica en territorio Mendocino. Boletín de Estudios Geográficos, 8, 129-134.

Cei, J. M. \& Roig, V. G. (1964). Apuntes batracológicos de un itinerario de observaciones biológicas en las llanuras pampeanas y en el litoral. Notas Biológicas de la Facultad de Ciencias Exactas, Físicas y Naturales de Corrientes.Zoología, 4, 1-14.

Cochran, D. \& Goin, C. J. (1970). Frogs of Colombia. U.S. National Museum Bulletin, 288, 1 655.

Cope, E. D. (1862). Catalogue of the Reptiles obtained during the exploration of the Parana, Paraguay, Vermejo and Uraguay Rivers by Capt. Thos. J. Page. U. S. N.; and those procured by Lieut. N. Michler, U. S. Top. Eng., Commander of the Expedition conducting the Survey of the Atrato River. Proceedings of the Academy of Natural Sciences of Philadelphia, 1862, 346-359.

Cope, E. D. (1865). Sketch of the primary groups of Batrachia Salientia. The Natural History Review (n.s. ), 5, 97-120.

Cope, E. D. (1868). Sixth contributions to the herpetology of tropical America. Proceedings of the Academy of Natural Sciences of Philadelphia, 20, 305-315.

Cope, E. D. (1877). Synopsis of the cold blooded Vertebrata, procured by Prof. James Orton during his exploration of Peru in 1876-77. Proceedings of the American Philosophical Society, 17, 33-49.

Cope, E. D. (1890). Scientific results of explorations by the U. S. Fish comission steamer albatross. III. Report on Batrachians and Reptiles collected in 1887-'88. Proceedings National Museum, 12, 141-147.

Correa, C. L., Sallaberry, M., González, B. A., Soto, E. R. \& Méndez, M. A. (2007). Amphibia, Anura, Leiuperidae, Pleurodema thaul: Latitudinal and altitudinal distribution extension in Chile. Check List, 3, 267-270.

Correa, C. L., Veloso, A. M., Iturra, P. C. \& Méndez, M. A. (2006). Phylogenetic relationships 
of Chilean leptodactylids: a molecular approach based on mitochondrial genes $12 \mathrm{~S}$ and $16 \mathrm{~S}$. Revista Chilena de Historia Natural, 79, 435-450.

Crisci, J. V., Katinas, L. \& Posadas, P. (2000). Introducción a la teoría y práctica de la biogeografía histórica. Buenos Aires: Sociedad Argentina de Botánica.

Crump, M. L. (1983). Opportunistic cannibalism by amphibian larvae in temporary aquatic environments. American Naturalist, 121, 281-287.

Crump, M. L. \& Vaira, M. (1991). Vulnerability of Pleurodema borelli tadpoles to an avian predator: effect of body size and density. Herpetologica, 47, 316-321.

Cruz, F. B., Perotti, G. \& Fitzgerald, L. A. (1992). Lista de Anfibios y Reptiles colectados en una localidad del Chaco Salteño. Acta zoológica Lilloana, 62, 101-107.

D'orbigny, A. (1847). Voyage dans I'Amérique Méridionale 1826-1833. 1er. Partie: Reptiles. Paris.

Chenuil, A., Galtier, N. \& Berrebi, P. (1999). A test of the hypothesis of an autopolyploid vs. allopolyploid origin for a tetraploid lineage: application to the genus Barbus (Cyprinidae). Heredity, 82, 373-380.

Darst, C. R. \& Cannatella, D. C. (2004). Novel relationships among hyloid frogs inferred from $12 \mathrm{~S}$ and $16 \mathrm{~S}$ mitochondrial DNA sequences. Molecular Phylogenetics and Evolution, 31, 462475 .

Daudin, F. M. (1802). Histoire naturelle des rainettes, des grenouilles et des crapauds. Paris: Bertrandet.

Daudin, F. M. (1803). Histoire Naturelle, générale et particulière des Reptiles. Paris: Dufart.

de la Riva, I. (1990). Lista preliminar comentada de los anfibios de Bolivia con datos sobre su distribución. Bolletino del Museo regionale di Scienze naturali, 8, 261-319.

de la Riva, I. \& Gonzales, L. (1998). Sobre la presencia de Pleurodema guayapae Barrio, 1964 (Anura, Leptodactylidae) en Bolivia. Alytes, 16, 68-76.

de la Riva, I., Köhler, J., Lötters, S. \& Reichle, S. (2000). Ten years of research on Bolivian amphibians: updated checklist, distribution, taxonomic problems, literature, and iconography. Revista Española de Herpetología, 14, 19-164.

De Pinna, M. C. C. (1991). Concepts and tests of homology in the cladistic paradigm. Cladistics, 7, 367-394.

de Villiers, C. G. S. (1936). Some aspects of the amphibian suspensorium with special reference to the paraquadrate and quadratomaxillary. Anatomischer Anzeiger, 81, 225-247.

Delfino, G., Nosi, D., Brizzi, R. \& Alvarez, B. B. (2001). Serous cutaneous glands in the paludicoline frog Physalaemus biligonigerus (Anura, Leptodactylidae): pattern of cytodifferentiation and secretory activity in premetamorphic specimes. Acta Zoologica, 82, 149-158.

di Tada, I. E., Saluso, M. M. \& Martori, R. (1976). Lista de los Batracios de Córdoba. Boletín de la Academia Nacional en Ciencias en Córdoba, 51, 324-362.

di Tada, I. E., Zavattieri, M. V., Bridarolli, M. E., Salas, N. E. \& Martino, A. L. (1996). Anfibios Anuros de la provincia de Córdoba. In I. E. di Tada \& E. H. Bucher (Eds) Biodiversidad de la Provincia de Córdoba. Fauna. Vol. I (pp. 191-213). Córdoba: Univ. Nac. Río Cuarto y Centro de Zoología Aplicada. 
Díaz, N. F., Sallaberry, M. \& Valencia, J. (1987). Microhabitat and reproductive traits in populations of the frog, Batrachyla taeniata. J ournal of Herpetology, 21, 317-323.

Díaz-Páez, H. \& Ortiz, J. C. (2001). The reproductive cycle of Pleurodema thaul (Anura, Leptodactylidae) in central Chile. Amphibia-Reptilia, 22, 431-445.

Diminich, M. C. (2006) Historia natural y características de hábitat de Somuncuria somuncurensis (Anura, Leiuperidae), un anfibio amenazado de extinción. Tesis de Licenciatura, Facultad de Ciencias Exactas y Naturales, Universidad Nacional de Buenos Aires. $46 \mathrm{pp}$.

Dobkin, D. S. \& Gettinger, R. D. (1985). Thermal aspects of anuran foam nests. J ournal of Herpetology, 19, 271-275.

Donoso-Barros, R. (1969a). Nota distribucional sobre Pleurodema bufonina Bell. Boletín de la Sociedad de Biología de Concepción, 41, 155-156.

Donoso-Barros, R. (1969b). Posición nomenclatural de un leptodactylido Uruguayo (AmphibiaAnura). Boletín de la Sociedad de Biología de Concepción, 41, 161-162.

Downie, J. R. (1988). Functions of the foam in the foam-nesting leptodactylid Physalaemus pustulosus. Herpetological J ournal, 1, 302-307.

Downie, J. R. (1990). Functions of the foam in foam-nesting leptodactylids: antipredator effects of Physalaemus pustulosus foam. Herpetological J ournal, 1, 501-503.

Downie, J. R. (1993). Functions of the foam in foam-nesting leptodactylids: the nest as a post-hatching refuge in Physalaemus pustulosus. Herpetological J ournal, 3, 35-42.

Duellman, W. E. (1970). The hylid frogs of Middle America. Monographs, Museum of Natural History, University of Kansas, 1, 1-753.

Duellman, W. E. (1993). Amphibian species of the world: Additions and corrections. The University of Kansas, Museum of Natural History. Special Publication.

Duellman, W. E. \& Morales, V. R. (1990). Variation, distribution, and life history of Edalorhina perezi (Amphibia, Anura: Leptodactylidae). Studies on Neotropical Fauna and Environment, 25, 19-30.

Duellman, W. E. \& Trueb, L. (1994). Biology of Amphibians. New York: Mc Graw Hill Book Co.

Duellman, W. E. \& Veloso, A. M. (1977). Phylogeny of Pleurodema (Anura: Leptodactylidae): a biogeographic model. Occasional Papers of the Museum of Natural History, 64, 1-46.

Duméril, A. M. C. \& Bibron, G. (1841). Erpétologie générale ou histoire naturelle complète des reptiles. Paris: Librairie Encyclopédique de Roret.

Dunn, E. R. (1944). Los géneros de anfibios y reptiles de Colombia, Primera parte: anfibios. Caldasia, 2, 497-529.

Estes, R. \& Reig, O. (1973). The early fossil record of frogs: a review of the evidence. In J. L. Vial (Ed) Evolutionary Biology of the Anurans (pp. 11-63). Columbia: University of Missouri Press.

Evans, B. J., Kelley, D. B., Tinsley, R. C., Melnick, D. J. \& Cannatella, D. C. (2004). A mitochondrial DNA phylogeny of African clawed frogs: phylogeography and implications for polyploid evolution. Molecular Phylogenetics and Evolution, 33, 197-213.

Fabrezi, M. (1992). El carpo de los anuros. Alytes, 10, 1-29. 
Fabrezi, M. (1993). The anuran tarsus. Alytes, 11, 47-63.

Fabrezi, M. \& Alberch, P. (1996). The carpal elements of anurans. Herpetologica, 52, 188204.

Fabrezi, M. \& Barg, M. (2001). Patterns of carpal development among anuran amphibians. J ournal of Morphology, 249, 210-220.

Fabrezi, M. \& Vera, R. (1997). Caracterización morfológica de larvas de anuros del Noroeste Argentino. Cuadernos de Herpetología, 11, 37-49.

Faivovich, J. (2002). A cladistic analysis of Scinax (Anura: Hylidae). Cladistics, 18, 367-393.

Faivovich, J., Garcia, P. C. A., Ananias, F., Lanari, L., Basso, N. G. \& Wheeler, W. C. (2004). A molecular perspective on the phylogeny of the Hyla pulchella species group (Anura, Hylidae). Molecular Phylogenetics and Evolution, 32, 938-950.

Faivovich, J., Haddad, C. F. B., Garcia, P. C. A., Campbell, J. A. \& Wheeler, W. C. (2005). Systematic review of the frog family Hylidae, with special reference to Hylinae: phylogenetic analysis and taxonomic revision. Bulletin of the American Museum of Natural History, 294, 1-240.

Farris, J. S. (1969). A successive aproximations approach to character weighting. Systematic Zoology, 18, 374-385.

Farris, J. S. (1983). The logical basis of phylogenetic analysis. In N. I. Platnick \& V. A. Funk (Eds) Advances in cladistics 2. Proceedings of the Third Meeting of the Willi Hennig Society (pp. 7-36). New York: Columbia University.

Farris, J. S. (1989). The retention index and the rescaled consistency index. Cladistics, 5, 417-419.

Farris, J. S. (1990). The retention index and homoplasy excess. Systematic Zoology, 38, 406407.

Farris, J. S., Albert, V. A., Källersjo, M., Lipscomb, D. \& Kluge, A. G. (1996). Parsimony jackknifing outperforms neighbour-joining. Cladistics, 12, 99-124.

Felsenstein, J. (1985). Limits on phylogenies: an approach using the Bootstrap. Evolution, 39, 783-791.

Fernández, K. (1927). Sobre la biología y reproducción de batracios argentinos. Segunda Parte. Boletín de la Academia Nacional en Ciencias en Córdoba, 29, 271-328.

Fernández, K. \& Fernández, M. (1921). Sobre la biología y reproducción de algunos batracios argentinos. I. Cystignathidae. Boletín de la Academia Nacional en Ciencias en Córdoba, 91, 97-140.

Ferrari, L. (1992). Morfometría y osteología de dos especies del género Pleurodema (Anura: Leptodactylidae). Seminario de Licenciatura, Facultad de Ciencias Naturales, Universidad de Tucumán. 50 pp.

Ferraro, D. P. (2004). Geographic distribution. Pleurodema nebulosum. Herpetological Review, 35, 405-406.

Ferraro, D. P. \& Casagranda, M. D. (2009). Geographic distribution of the genus Pleurodema in Argentina (Anura: Leiuperidae). Zootaxa, 2024, 33-55.

Fjeldså, J. (1983). Vertebrates of the Junín Area, Central Peru. Steenstrupia, 8, 285-298. 
Ford, L. \& Cannatella, D. C. (1993). The major clades of frogs. Herpetological Monographs, 7, 94-117.

Formas, F. (1980). The chormosomes of E. calcaratus an the karyological evolution of the genus Eupsophus (Anua, Leptodactylidae). Experientia, 36, 1163-1164.

Formas, J. R. (1989). The tadpole of Eupsophus calcaratus in Southern Chile. J ournal of Herpetology, 23, 195-197.

Fortune, P. M., Pourtau, N., Viron, N. \& Ainouche, M. L. (2008). Molecular phylogeny and reticulate origins of the polyploid Bromus species from section Genea (Poaceae). American J ournal of Botany, 95, 454-464.

Fox, H. (1994). The structure of the integument. In H. Heatwole (Ed) Amphibian Biology (pp. 1-32). Australia: Surrey, Beaty \& Sons.

Franco-Belussi, L., Zieri, R., Santos, L. R. d. S., Moresco, R. M. \& de Oliveira, C. (2009). Pigmentation in Anuran testes: anatomical pattern and variation. The Anatomical Record, 292, 178-182.

Freiberg, M. A. (1942). Enumeración sistemática y distribución geográfica de los batracios argentinos. Physis, 19, 219-240.

Frost, D. R. (1985). Amphibian species of the world. A taxonomic and geographical reference. Lawrence, Kansas: Joint Venture of Allen Press.

Frost, D. R. (2009). Amphibian Species of the World: an Online Reference. Version 5.3 (12 de febrero de 2009). Database electrónica accesible en http://research.amnh.org/herpetology/amphibia/. American Museum of Natural History, New York.

Frost, D. R., Grant, T., Faivovich, J., Bain, R., Haas, A., Haddad, C. F. B., de Sá, R. O., Donnellas, S. C., Raxworthy, C. J., Wilkinson, M., Channing, A., Campbell, J. A., Blotto, B. L., Moler, P., Drewes, R. C., Nussbaum, R. A., Lynch, J., Green, D. M. \& Wheeler, W. C. (2006). The amphibian tree of life. Bulletin of the American Museum of Natural History, 297, 1-370.

Gallardo, J. M. (1958). Observaciones biológicas sobre Leptodactylus prognathus Boulenger. Ciencia e Investigación, 14, 460-465.

Gallardo, J. M. (1965). Consideraciones zoogeográficas y ecológicas sobre los anfibios de la Provincia de La Pampa, Argentina. Revista del Museo Argentino de Ciencias Naturales "Bernardino Rivadavia" (Ecología), 1, 57-77.

Gallardo, J. M. (1966). Zoogeografía de los anfibios chaqueños. Physis, 26, 67-81.

Gallardo, J. M. (1968a). Sobre la validez de algunas especies argentinas de Pleurodema (Anura, Leptodactylidae). Physis, 28, 135-144.

Gallardo, J. M. (1968b). Observaciones biológicas sobre Pseudopaludicola falcipes (Hensel), (Anura, Leptodactylidae). Ciencia e Investigación, 24, 411-419.

Gallardo, J. M. (1974). Anfibios de los alrededores de Buenos Aires. Buenos Aires: EUDEBA.

Gallardo, J. M. (1987). Anfibios Argentinos. Guía para su identificación. Buenos Aires: Biblioteca Mosaico.

Gassó Miracle, M. E., van den Hoek Ostende, L. W. \& Arntzen, J. W. (2007). Type specimens of amphibians in the National Museum of Natural History, Leiden, The Netherlands. 
Zootaxa, 1482, 25-68.

Gavetti, E. \& Andreone, F. (1993). Revised catalogue of the herpetological collection in Torino University. I. Amphibia. Torino: Museo Regionale di Scienze Naturali di Torino.

Gay, C. (1848). Historia física y política de Chile según documentos adquiridos en esta República durante doce años de residencia en ella. Paris: Imprenta de Maulde y Renou.

Giaretta, A. \& Menin, M. (2004). Reproduction, phenology and mortality sources of a species of Physalaemus (Anura: Leptodactylidae). J ournal of Natural History, 38, 1711-1722.

Girard, C. (1853). Descriptions of new species of Reptiles, collected by the U.S. Exploring Expedition, under the command of Capt. Charles Wilkes, U. S. N. Second Part. Including the species of Batrachians, exotic to North America. Proceedings of the Academy of Natural Sciences of Philadel phia, 6, 424.

Girard, C. (1858). United States Exploring Expedition during the years 1838, 1839, 1840, 1841, 1842, under the command of Charles Wilkes, U.S.N., Volume 20, Herpetology. Philadelphia: J. B. Lippincott and Co.

Glaw, F. \& Franzen, M. (2006). Type catalogue of amphibians in the Zoologische Staatssammlung München. Spixiana, 29, 153-192.

Gmelin, J. F. (1789). Caroli a Linné Systema Naturae. Tom I, Pars III. Classis III, Amphibia. pp. 1033-1125.

Goloboff, P. A. (1993). Estimating character weights during tree search. Cladistics, 9, 83-91.

Goloboff, P. A. (1998). Principios Básicos de Cladística. Buenos Aires: Sociedad Argentina de Botánica.

Goloboff, P. A. \& Farris, J. S. (2001). Methods for quick consensus estimation. Cladistics, 17, 26-34.

Goloboff, P. A., Farris, J. S., Källersjö, M., Oxelman, B., Ramírez, M. \& Szumik, C. A. (2003a). Improvements to resampling measures of group support. Cladistics, 19, 324-332.

Goloboff, P. A., Farris, J. S. \& Nixon, K. C. (2003b). T.N.T.: Tree analysis using new technology, version 1.0. Program and documentation available from the authors and at www.zmuc.dk/public/phylogeny.

Gonzales, L. (1998). La herpetofauna del Izozog. Ecología en Bolivia, 31, 45-52.

Gorham, S. W. (1966). Liste der rezenten Amphibien und Reptilien. Ascaphidae, Leiopelmatidae, Pipidae, Discoglossidae, Pelobatidae, Leptodactylidae, Rhinophrynidae. Tierreich, 85, 1-222.

Grant, T., Frost, D. R., Caldwell, J. P., Gagliardo, R., Haddad, C. F. B., Kok, P. J. R., Means, B. D., Noonan, B. P. S. W. \& Wheeler, W. C. (2006). Phylogenetic systematics of dartpoison frogs and their relatives (Anura: Athesphatanura: Dendrobatidae). Bulletin of the American Museum of Natural History, 299, 1-262.

Guibé, J. (1950). Catalogue des types d'Amphibiens du Muséum National d'Histoire Naturelle. Paris: Imprimerie nationale.

Günther, A. (1858). Catalogue of the Batrachia Salientia in the collection of the British Museum. London: Taylor \& Francis.

Haas, A. (2003). Phylogeny of frogs as inferred from primarily larval characters (Amphibia: 
Anura). Cladistics, 19, 23-89.

Haddad, C. F. B. \& Cardoso, A. J. (1987). Taxonomia de três espécies de Pseudopaludicola (Anura, Leptodactylidae). Papéis Avulsos de Zoologia, 36, 287-300.

Haene, E. H. (1994). Pleurodema tucumana (Anura, Leptodactylidae) en la provincia de San Juan, República Argentina. Cuadernos de Herpetología, 8, 229-233.

Halloy, M. (2006). Choice of oviposition site in Pleurodema borellii (Leptodactylidae): importance of conspecific tadpole size. South American J ournal of Herpetology, 1, 72-78.

Halloy, M. \& Fiaño, J. M. (2000). Oviposition site selection in female Pleurodema borelli (Anura: Leptodactylidae) may be influenced by tadpole density. Copeia, 2000, 606-609.

Hamilton, W. D. (1971). Geometry for the selfish herd. J ournal or Theoretical Biology, 31, 295-311.

Häupl, M. \& Tiedemann, F. (1978). Typenkatalog der Herpetologischen Sammlung. Amphibia. Vertebrata 1. Kataloge der wissenschaftlichen Sammlungen des Naturhistorischen Museums, 34, 1-36.

Hawkins, J. A., Colin, E. H. \& Scotland, R. W. (1997). Primary homology assessment, characters and character states. Cladistics, -275 .

Hay, J. M., Ruvinsky, I., Hedges, S. B. \& Maxson, L. R. (1995). Phylogenetic relationships of Amphibian families inferred from DNA sequences of mitochondrial $12 \mathrm{~s}$ and $16 \mathrm{~s}$ ribosomal RNA genes. Molecular Biology and Evolution, 12, 928-937.

Hennig, W. (1968). Elementos de una sistemática filogenética. Buenos Aires: EUDEBA.

Hensel, R. (1867). Beiträge zur Kenntnis der Wirbelthiere Südbrasiliensis. Wiegmann's Arch. Naturgesch. , 33, 120-162.

Heyer, W. R. (1969a). Studies on the genus Leptodactylus (Amphibia, Leptodactylidae) III. A redefinition of the genus Leptodactylus and a description of a new genus of Leptodactylid frogs. Contributions in Science, 155, 1-14.

Heyer, W. R. (1969b). The adaptative ecology of the species groups of the genus Leptodactylus (Amphibia, Leptodactylidae). Evolution, 23, 421-428.

Heyer, W. R. (1975). A preliminary analysis of the intergeneric relationship of the frog family Leptodactylidae. Smithsonian Contributions to Zoology, 199, 1-55.

Heyer, W. R. \& Maxon, L. R. (1982). Neotropical frog biogeography: Paradigms and problems. American Zoologist, 22, 397-410.

Heyer, W. R., McDiarmid, M. W. \& Weigemann, D. L. (1975). Tadpoles, predation and pond habitats in the tropics. Biotropica, 7, 100-111.

Heyer, W. R. \& Rand, A. S. (1977). Foam nest construction in the Leptodactylid frog Leptodactylus pentadactylus and Physalaemus pustulosus (Amphibia: Anura: Leptodactylidae). J ournal of Herpetology, 11, 225-228.

Hödl, W. (1986). Foam nest construction in South American leptodactylid frogs. In Z. Roèek (Ed) Studies in Herpetology (pp. 565-570). Prague, Czechoslovakia: Charles University Press.

Hödl, W. (1990). An analysis of foam nest construction on the neotropical frog Physalaemus ephippifer. Copeia, 547-554. 
Hödl, W. (1992). Reproductive behavior in the neotropical foam-nesting frog Pleurodema diplolistris (Leptodactylidae). Amphibia-Reptilia, 13, 263-274.

Holloway, A. K., Cannatella, D. C., Gerhardt, H. C. \& Hillis, D. M. (2006). Polyploids with different origins and ancestors form a single sexual polyploid species. The american naturalist, 167, 88-101.

Howell, W. N. \& Black, D. A. (1980). Controlled silver staining of nucleolus organizer regions with a protective colloidal developer: a one step method. Experientia, 36, 1014-1015.

Huber, K. T., Oxelman, B., Lott, M. \& Moulton, V. (2006). Reconstructing the evolutionary history of polyploids from multilabeled trees. Molecular Biology and Evolution, 23, 17841791.

Hubert, N. \& Renno, J. F. (2006). Historical biogeography of South American freshwater fishes. J ournal of Biogeography, 33, 1414-1436.

Hulse, A. C. (1977). New distributional records for amphibians and reptiles from the provinces of Catamarca, La Rioja and Córdoba, Argentina. Herpetological Review, 8, 40.

Ibáñez, R. D., Rand, A. S. \& Jaramillo, C. A. (1999). Los anfibios del Monumento Natural de Barro Colorado, Parque Nacional Soberanía y áreas adyacentes. The amphibians of Barro Colorado Nature Monument, Soberania National Park and adjacent areas. Santa Fé de Bogotá: D'Vinni Editorial Ltda. Panama: Editorial Mizrachi \& Pujol, S.A.: Fundación Natura, Círculo Herpetológico de Panamá, Smithsonian Tropical Research Institute.

ICZN Internacional Comission on Zoological Nomenclature (1999). International Code of Zoological Nomenclature adopted by the International Union of Biological Science. International Trust for Zoological Nomenclature.

Iriondo, M. (1990). A Late Holocene dry period in the Argentine plains. Quaternary of South America and Antarctic Peninsula, 7, 197-218.

Iriondo, M. \& Garcia, N. (1993). Climatic variations in the Argentine plains during the last 18,000 years. Paleogeography, Paleoclimatology, Palaecology, 101, 209-220.

Jiménez de la Espada, M. (1875). Vertebrados del Viaje al Pacifico: Batracios. Madrid: Imprenta de M. Ginesta.

Jurgens, J. D. (1971). The morphology of the nasal region of Amphibia and its bearing on the phylogeny of the group. Annale Universiteit van Stellenbosch, 46 A, 1-146.

Kehr, A. I., Schaefer, E. F. \& Duré, M. (2004). The tadpole of Physalaemus albonotatus (Anura: Leptodactylidae). J ournal of Herpetology, 38, 145-148.

King, M . (1990). Amphibia. En: Animal Cytogenetics. John B. \& C. Gwent (ed). Gebrüder Borntraeger, Berlin, 4(2): $241 \mathrm{pp}$.

Kitching, I., Forey, P. L., Humphries, C. \& Williams, D. (1998). Cladistics. Theory and practice of parsimony analysis. New York: Oxford University Press.

Klappenbach, M. A. (1968). Notas herpetológicas III. Identificación delas especies uruguayas descriptas por Philippi en el "Suplemento a los Batraquios chilenos". Investigaciones Zoológicas Chilenas, 13, 147-151.

Klappenbach, M. A. \& Langone, J. A. (1992). Lista sistemática y sinonímica de los anfibios del Uruguay, con comentarios y notas sobre su distribución. Anales del Museo Nacional de Historia Natural de Montevideo, 2o serie, 8, 163-222. 
Kluge, A. G. \& Farris, J. S. (1969). Quantitative phyletics and the evolution of anurans. Systematic Zoology, 18, 1-32.

Kolenc, F., Borteiro, C., Baldo, D., Ferraro, D. P. \& Prigioni, C. M. (2009). The tadpoles and advertisement calls of Pleurodema bibroni Tschudi and Pleurodema kriegi (Müller), with notes on their geographic distribution and conservation status (Amphibia, Anura, Leiuperidae). Zootaxa, 1969, 1-35.

Kwet, A. \& di-Bernardo, M. (1999). Pró.Mata - Anfíbios. Amphibien. Amphibians. Porto Alegre, Brasil: EDIPUCRS.

La Marca, E. (1992). Catálogo taxonómico, biogeográfico y bibliográfico de las ranas de Venezuela. Mérida, 197 pp: Cuadernos Geográficos 9, Universidad de Los Andes.

Lanzone, C., Baldo, D. \& Rosset, S. D. (2009). Meiotic differentiation in two allopatric population groups of the tetraploid frog Odontophrynus americanus from Argentina. Herpetological J ournal, 18, 213-223.

Laufer, G. \& Barreneche, J. M. (2008). Re-description of the tadpole of Pseudopaludicola falcipes (Anura: Leiuperidae), with comments on larval diversity of the genus. Zootaxa, 1760, 50-58.

Laurent, R. F. (1969). Diferencias morfológicas entre especies crípticas de los géneros Pleurodema y Physalaemus. Acta zoológica Lilloana, 25, 83-94.

Laurent, R. F. (1975). Diferencias biométricas entre dos poblaciones similares de Pleurodema. Acta zoológica Lilloana, 31, 99-106.

Laurent, R. F. (1980). Herpetofauna of the forest remnants of northwestern Argentina. National Geographic Society Research. 1977 Report, 417-425.

Lavilla, E. O. (1988). Lower Telmatobinae (Anura: Leptodactylidae): generic diagnoses based on larval characters. Occasional Papers of the Museum of Natural History, 124, 1-19.

Lavilla, E. O. (1992). Tipos portadores de nombre y localidades tipo de anfibios de Argentina. Acta zoológica Lilloana, 42, 61-101.

Lavilla, E. O. \& Lobo, F. (1992). Osteological notes on Hylorina sylvatica (Anura: Leptodactylidae). Bolletino del Museo Museo regionale di Scienze naturali, 10, 209-216.

Lavilla, E. O., Richard, E. \& Scrocchi, G. J. (2000). Categorización de los Anfibios y Reptiles de la República Argentina. S. M. de Tucumán: Edición Especial Asociación Herpetológica Argentina.

Lavilla, E. O. \& Rougès, M. (1992). Reproducción y desarrollo de anuros argentinos. Asociación Herpetológica Argentina, Serie Divulgación Nº 5, 1-66.

Lavilla, E. O., Scrocchi, G. J. \& Ávila, L. J. (1992). Clave para la identificación de los anfibios de la Provincia de Córdoba (Argentina). Serie de divulgación de la Asociación Herpetológica Argentina, 7, 1-18.

Lehr, E. \& Trueb, L. (2007). Diversity among New World microhylid frogs (Anura: Microhylidae): morphological and osteological comparisons between Nelsonophryne (Günther 1901) and a new genus from Peru. Zoological Journal of the Linnean Society, 149, 583-609.

Lema, T. \& Braun, P. C. (1993). Contribuição à herpetologia da Argentina e do Rio Grande do Sul, Brasil por William Wright Milstead (Amphibia, Reptilia). Revista Brasileira de Biologia, 
$10,261-287$.

Leon-Ochoa, J. \& Donoso-Barros, R. (1969). Desarrollo embrionario y metamorfosis de Pleurodema brachyops (Cope) (Salientia, Leptodactylidae). Boletín de la Sociedad de Biología de Concepción, 42, 355-379.

Lesson, R. P. (1826). Voyage autour du monde pendant les annés 1822, 1823, 1824 et 1825. Zoologie. In R. P. Lesson \& R. P. Garnot (Eds) Voyage autour du monde, executé par ordre du Roi, sur la Corvette de La Majesté, La Coquille, pendant les anneés 1822, 1823, 1824 et 1825 (pp. 1-65). París.

Linder, C. R. \& Rieseberg, L. H. (2004). Reconstructing patterns of reticulate evolution in plants. American J ournal of Botany, 91, 1700-1708.

Lobo, F. (1992). Osteología de dos especies crípticas de Physalaemus (Anura: Letodactylidae). Acta zoológica Lilloana, 42, 171-175.

Lobo, F. (1995). Análisis filogenético del género Pseudopaludicola (Anura: Leptodactylidae). Cuadernos de Herpetología, 9, 21-43.

Lobo, F. (1996). Nuevas observaciones sobre la osteología del género Physalaemus (Anura: Leptodactylidae). Acta zoológica Lilloana, 43, 317-326.

Lobo, F. (1994) Revisión del género Pseudopaludicola (Anura: Leptodactylidae). Tesis de Doctorado, Universidad Nacional de Tucumán. 318 pp.

Lott, M., Spillner, A., Huber, K. T., Petri, A., Oxelman, B. \& Moulton, V. (2009). Inferring polyploid phylogenies from multiply-labeled gene trees. BMC Evolutionary Biology, 209, 111.

Lötters, S., Reichle, S., Faivovich, J. \& Bain, R. (2005). The stream-dwelling tadpole of Hyloscirtus charazani (Anura: Hylidae) from Andean Bolivia. Studies on Neotropical Fauna and Environment, 40, 181-185.

Lourenço, L. B., Bacci-Júnior, M., Martins, V. G., Recco-Pimentel, S. M. \& Haddad, C. F. B. (2008). Molecular phylogeny and karyotype differentiation in Paratelmatobius and Scythrophrys (Anura, Leptodactylidae). Genetica, 132: 255-266., 13, 255-266.

Lourenço, L. B., Nascimento, J. A. A., Andrade, G. V., Rossa-Feres, D. C. \& Recco-Pimentel, S. M. (2006). Chromosomal analysis of the leptodactylids Pleurodema diplolistris and Physalaemus nattereri (Amphibia, Anura). Amphibia-Reptilia, 27, 482-489.

Lutz, A. (1927). Notas sobre batrachios da Venezuela e da Ihla de Trinidad. Memórias do Instituto Oswaldo Cruz, 20, 35-65.

Lynch, J. (1970). Systematic status of the American leptodactylid frog genera Engystomops, Eupemphix, and Physalaemus. Copeia, 1970, 48-496.

Lynch, J. D. (1971). Evolutionary relationships, osteology, and zoogeography of leptodactyloid frogs. Miscellaneous Publication, Museum of Natural History, University of Kansas, 53, 1-238.

Lynch, J. (1978). A re-assessment of the telmatobiine leptodactyloid frogs of Patagónia. Occasional Papers of the Museum of Natural History, 72, 1-57.

Lynch, J. (1989). A review of the Leptodactylid frogs of the genus Pseudopaludicola in Northern South America. Copeia, 1989, 577-588.

Lynch, J. D. \& Duellman, W. E. (1997). Frogs of the genus Eleutherodactylus 
(Leptodactylidae) in western Ecuador: systematics, ecology, and biogeography. University of Kansas, Natural History Museum, Special Publication, 23, 1-236.

Maddison, W. P. (1991). Squared-change parsimony reconstructions of ancestral states for continuous-valued characters on a phylogenetic tree. Systematic Zoology, 40, 304-314.

Malnate, E. V. (1971). A catalog of primary types in the herpetological collections of the Academy of Natural Sciences, Philadelphia (ANSP). Proceedings of the Academy of Natural Sciences of Philadel phia, 123, 345-375.

Maneyro, R., Forni, F. \& Santos, M. (1995). Los anfibios del departamento de Rocha. Serie Divulgación Técnica. PROBIDES, 1, 1-24.

Mangione, S. \& Lavilla, E. O. (2004). Histología de la piel de la región lumbar de las especies sin glándula lumbar del género Pleurodema (Anura: Leptodactylidae). Acta zoológica Lilloana, 48, 37-56.

Marble, B. K. (2004) 'Why polyploidy is rarer in animals than in plants': myths and mechanisms. Biological J ournal of the Linnean Society, 82, 453-466.

Márquez, R., de la Riva, I. \& Bosch, J. (1995). Advertisement calls of Bolivian Leptodactylidae (Amphibia, Anura). J ournal of Zoology, 237, 313-336.

Martin, A. A. (1970). Parallel evolution in the adaptive ecology of leptodactylid frogs of South America and Australia. Evolution, 24, 643-644.

Martins, M. (1989). Deimatic behavior in Pleurodema brachyops. J ournal of Herpetology, 23, 305-307.

Martori, R. \& Aún, L. (1995). Relevamiento de la Herpetofauna de las Sierras Pampeanas del este de la provincia de Córdoba (Argentina) (registro de taxa y comentarios taxonómicos). Acta zoológica Lilloana, 43, 87-97.

Martori, R., Aún, L. \& Vignolo, P. E. (1994). Aporte al conocimiento de la biología y distribución de Pleurodema tucumana (Anura, Leptodactylidae). Boletín de la Asociación Herpetológica Argentina, 10, 18-19.

Martori, R. \& Ávila, L. J. (1988). Nueva localidad para Pleurodema nebul osa Burmeister, 1861 (Amphibia, Anura). Boletín de la Asociación Herpetológica Argentina, 4, 12.

Mason, M. J. (2006). Pathways for sound transmission to inner ear in amphibians. In P. M. Narins, A. S. Feng, R. R. Fay \& A. N. Popper (Eds) Hearing and Sound Communication in Amphibians (pp. 146-182). New York: Springer.

Mattos, R. L., Antoniazzi, M. M., Haddad, C. F. B. \& Jared, C. (2003). Structure of venom glands in the frog Physalaemus nattereri (Anura, Leptodactylidae). XIX Congress of the Brazilian Society for Microscopy and Microanalysis, 12, 563-564.

Maxon, L. R. \& Heyer, W. R. (1982). Leptodactylid frogs and the Brasilian shield: an old and continuing adaptive relationship. Biotropica, 14, 10-15.

McLister, J. D., Lougheed, S. C. \& Bogart, J. P. (1991). Electrophoretic and vocalization comparisons among three leptodactylid frogs (Pleurodema spp.) from northwestern Argentina. Canadian J ournal of Zoology, 69, 2397-2403.

Méhelÿ, L. v. (1904). Investigations on Paraguayan batrachians. Annales Musei Nationalis Hungarici, 2, 207-233.

Menin, M. \& Giaretta, A. (2003). Predation on foam nests of leptodactyline frogs (Anura: 
Leptodactylidae) by larvae of Beckeriella niger (Diptera: Ephydridae). J ournal of Zoology, 261, 239-243.

Merrem, B. (1820). Tentamen Systematis Amphibiorum. Marburg: J.C. Krieger.

Milstead, W. W. (1960). Frogs of the genus Physalaemus in the Southern Brazil with the description of a new species. Copeia, 1960, 83-89.

Milstead, W. W. (1963). Notes on Brazilian frogs of the genera Physalaemus and Pseudopaludicola. Copeia, 1963, 565-566.

Miranda-Ribeiro, A. d. (1926). Notas para servirem ao estudo dos Gymnobatrachios (Anura) brasileiros. Tomo primeiro. Arquivos do Museu Nacional, 27, 1-227.

Miró, R. C. (1999). El basamento Precámbrico-Paleozoico Inferior de las Sierras Pampeanas, Famatina, Cordillera Oriental y Puna. In R. Caminos (Ed) Geología Argentina (pp. 133-167). Buenos Aires, Instituto de Geología y Recursos Minerales. Anales 29.

Molina, J. I. (1782). Saggio sulla storia naturale del Chili. Bologna, Stamperia di S. Tommaso d'Aquino. 349 pp.

Molina, J. I. (1788). Compendio de la historia geográfica, natural y civil del Reyno de Chile. Primera parte, que abraza la historia geográfica y natural. Madrid: Antonio de Sancha.

Morand, M. \& Hernando, A. (1998). Análisis citogenético comparado en cinco especies de Leptodactylus (Anura: Amphibia). Comunicaciones Científicas y Tecnológicas, 6, 127-130.

Morrone, J. J. (2001). Biogeografía de America Latina y el Caribe. Zaragoza: Manuales \& Tesis Sociedad Entomológica Aragonesa, Vol. 3.

Müller, L. (1926). Neue Reptilien und Batrachier der Zoologischen Sammlung des bayrischen Staates. Zoologischer Anzeiger, 65, 193-200.

Myers, C. W. \& Duellman, W. E. (1982). A new species of Hyla from Cerro Colorado, andother tree frog records and geographical notes from western Panama. American Museum Novitates, 2752, 1-32.

Nascimento, L. B., Caramaschi, U. \& Cruz, C. A. G. (2005). Taxonomic review of the species groups of the genus Physalaemus Fitzinger, 1826 with revalidation of the genera Engystomops Jiménez-de-la-Espada, 1872 and Eupemphix Steindachner, 1863 (Amphibia, Anura, Leptodactylidae). Arquivos do Museu Nacional, 63, 297-320.

Nascimento, L. B., Silva Pimenta, B. V., Gonçalvez Cruz, C.A. \& Caramaschi, U. (2006). Taxonomic status of Gomphobates marmoratus Reinhardt and Lütken, 1862 "1861" and Eupemphix fuscomaculatus Steindachner, 1864 (Amphibia, Anura, Leptodactylidae). South American J ournal of Herpetology, 1, 166-174.

Natale, G. S. \& Maneyro, R. (2008). Amphibia, Anura, Leiuperidae, Pleurodema bibroni: Rediscovery. Check List, 4, 47-49.

Nieden, F. (1923). Anura. I. Subordo Aglossa und Phaneroglossa. Sectio 1. Arcifera. Das Tierreich, 46, 1-584.

Nixon, K. C. (1999). WINCLADA. Distribute by the author. Nueva York: Ithaca.

Noble, G. K. (1922). The phylogeny of the Salientia. I. The osteology and the thigh musculature; their bearing on classfication and phylogeny. Bulletin of the American Museum of Natural History, 46, 1-87. 
Noble, G. K. (1931). The biology of the Amphibia. New York: McGraw-Hill Book Company.

Núñez, D., Maneyro, R., Langone, J. A. \& de Sá, R. O. (2004). Distribución geográfica de la fauna de anfibios del Uruguay. Smithsonian Herpetological Information Service, 134, 1-34.

Ortiz, J. C. \& Hermosilla, I. (1991). Albinismo en Pleurodema thaul (Lesson, 1826). Comunicaciones del Museo Regional de Concepción, 5, 59-60.

Ortiz, J. C. \& Lescure, J. (1989). Les types d' Amphibiens Anoures du Chili dans les collections du Muséum National d'Histoire Naturelle de Paris. Bulletin du Muséum National d'Histoire Naturelle de Paris, 4éme Série, Section A 11 (3) (supplément), 113-122.

Parker, H. W. (1927). A revision of the frogs of the genera Pseudopaludicola, Physalaemus and Pleurodema. Annal and Magazine of Natural History, 9, 450-478.

Parker, H. W. (1935). The frogs, lizards, and snakes of British Guiana. Proceedings of the Zoological Society of London, 3, 505-530.

Peixoto, O. L. (1982). Observações sobre a larva de Pleurodema diplolistris (Peters, 1870) (Amphibia, Anura, Leptodactylidae). Revista Brasileira de Biologia, 42, 631-633.

Penna, M. \& Veloso, A. M. (1982). The warninig vibration of Pleurodema thaul. J ournal of Herpetology, 16, 408-410.

Peracca, M. G. (1895). Viaggio del Dr. Borelli nella Repubblica Argentina e nel Paraguay. Bolletino del Musei di Zoologia ed anatomia comparata, 10, 1-32.

Peracca, M. G. (1897). Viaggio del Dr. Borelli nella Repubblica Argentina e nel Paraguay. Bolletino del Musei di Zoologia ed anatomia comparata, 12, 1-32.

Perotti, M. G. (1994). Aportes preliminares sobre la reproducción en una comunidad de anuros chaqueños en Argentina. Cuadernos de Herpetología, 8, 39-50.

Perotti, M. G. (1997). Modos reproductivos y variables reproductivas cuantitativas de un ensamble de anuros del Chaco semiárido, Salta, Argentina. Revista Chilena de Historia Natural, 70, 277-288.

Peters, W. C. H. (1870). Über neue Amphibien (Hemidactylus, Urosaura, Tropidolepisma, Geophis, Uriechis, Scaphiophis, Hoplocephalus, Rana, Entomoglossus, Cystignathus, Hylodes, Arthroleptis, Phyllobates, Cophomantis) des Königlich zoologischen Museums. Monatsberichte der königlich Akademie der Wissenschaften zu Berlin, 641-652.

Peters, W. C. H. (1877). Über die von Hrn. Prof. Dr. K. Möbius 1874 auf den Maskarenen und Seychellen, sowie über die von Hrn. Dr. Sachs im vorigen Jahr in Venezuela gesammelten Amphibien. Monatsberichte der königlich Akademie der Wissenschaften zu Berlin, 455-460.

Philippi, R. A. (1902). Suplemento a los Batraquis chilenos descritos en la historia física i política de Chile de don Claudio Gay. Santiago: Librería Alemana de José Ivens.

Pillado, M. S., Alonso, C. A. \& Úbeda, C. A. (2000). La larva de Alsodes gargola Gallardo, 1970 (Leptodactylidae, Telmatobiinae). Alytes, 18, 67-72.

Ponssa, M. L. (2008). Cladistic analysis and osteological descriptions of the frog species in the Leptodactylus fuscus species group (Anura, Leptodactylidae). Journal of Zoological Systematics \& Evolutionary Research, 46, 249-266.

Posada, D. \& Crandall, K. A. (2001). Intraspecific gene genealogies: trees grafting into networks. Trends in Ecology and Evolution, 16, 37-45. 
Pramuk, J. B., Hass, C. A. \& Blair Hedges, S. (2001). Molecular phylogeny and biogeography of West Indian toads (Anura: Bufonidae). Molecular Phylogenetics and Evolution, 20, 294301.

Rabanal Gatica, F. E. \& J. J. Nuñez Navarro. 2009. Anfibios de los Bosques Templados de Chile. Chile: Universidad Austral de Chile.

Ramírez, M. J. 2003. A cladistic generic revision of the spider subfamily Amaurobioidinae (Araneae, Anyphaenidae). Bulletin of the American Museum of Natural History, 277,1-262.

Ramírez, M. J. (2005). Resampling measures of group support: A reply to Grant and Kluge. Cladistics, 21, 83-89.

Ringuelet, R. A. (1961). Rasgos fundamentales de la Zoogeografía argentina. Physis, 22, 151 170.

Rivero, J. A. (1961). Salientia of Venezuela. Bulletin of Museum of Comparative Zoology, 126, 207.

Roček, Z. (1980). A contribution to the systematics of European ranid frogs (Amphibia, Ranidae) on the basis of the incrassatio frontoparietalis. Vestník Ceskoslovenské spolecnosti zoologické, 44, 219-229.

Roček, Z. (1989). Developmental patterns of the ethmoidal region of the anuran skull. In Splechtna/Hilgers (Ed) Trends in Vertebrate Morphology - Fortschritte in Zoologie (pp. 412415). New York.

Roček, Z. (2003). Larval development and evolutionary origin of the anuran skull. In $\mathrm{H}$. Heatwole (Ed) Amphibian Biology - Osteology (pp. 1878-1995). Australia: Surrey Beatty \& Sons, Chipping Norton.

Roček, Z. \& Lamaud, P. (1995). Thaumastosaurus bottii de Stefano, 1903, an anuran with Gondwanan affinities from the Eocene of Europe. Journal of Vertebrate Paleontology, 15, 506-515.

Ronquist, F. (1994). Ancestral areas and parsimony. Systematic Biology, 43, 237-274.

Ronquist, F. (1996). DIVA versión 1.1. Computer program and manual available by anonymous FTP from Uppsala University (http://www.ebc.uu.se).

Ronquist, F. (1997). Dispersal-vicariance analysis: a new approach to the quantification of historical biogeography. Systematic Biology, 46, 195-203.

Rosset, S. D., Baldo, D., Lanzone, C. \& Basso, G. (2006). Review of the geographic distribution of diploid and tetraploid populations of the Odontophrynus americanus species complex (Anura: Leptodactylidae). J ournal of Herpetology, 40, 465-477.

Rossa-Feres, D. \& Nomura, F. (2006). Characterization and taxonomic key for tadpoles (Amphibia: Anura) from the northwestern region of São Paulo State, Brazil. Biota Neotropical, $6 . \quad$ Accesible en: http: / / www.biotaneotropica.org.br/v6n1/pt/abstract?identification-key+bn00706012006.

Rosset, S. D., Basso, G. \& Lombardo, R. J. (2001). Análisis morfométrico de Pleurodema thaul (Lesson, 1926) (Anura, Leptodactylidae) y algunas consideraciones acerca de su morfología esternal. Alytes, 19, 154-172.

Ruthven, A. G. (1922). The amphibians and reptiles of the Sierra Nevada de Santa Marta, Colombia. Miscellaneous Publication, Museum of Zoology, University of Michigan, 8, 1-69. 
Ruvinsky, I. \& Maxson, L. R. (1996). Phylogenetic relationships among Bufonoid frogs (Anura: Neobatrachia) inferred from mitochondrial DNA sequences. Molecular Phylogenetics and Evolution, 5, 533-547.

Ryan, M. J. (1985). The Túngara Frog: a study in sexual selection and communication. Chicago: The University of Chicago Press.

Saez, F. A. \& Brum, N. (1959). Citogenética de anfibios anuros de América del Sur. Los cromosomas de Odontophrynus americanus y Ceratophrys ornata. Anales de la Facultad de Medicina, Montevideo, 44, 414-423.

Saez, F. A. \& Brum, N. (1960). Chromosomes of South America Amphibians. Nature, 185, 945946.

Sallaberry, M. A., Pastenes, L. O., Correa, C. Q. \& Méndez, M. T. (2007). Geographic distribution. Pleurodema marmorata. Herpetological Review, 38, 349.

Salthe, S. N. \& Duellman, W. E. (1977). Quantitative constraints associated with reproductive mode in anurans. In J. L. Vial (Ed) Evolutionary biology of the Anurans: contemporary research on major problems (pp. 229-249). Columbia: University of Missouri Press.

Sanchíz, B. (1998). Salientia. In P. Wellnhofer (Ed) Encyclopedia of Paleoherpetology, 4 (pp. 1-276). Munchen: Dr. Friedrich Pfeil Verlag.

Santos, J. W. A., Damasceno, R. P. \& Rocha, P. L. B. (2003). Feeding habits of the frog Pleurodema diplolistris (Anura, Leptodactylidae) in Quaternary sand dunes of the Middle Rio São Francisco, Bahia, Brazil. Phyllomedusa, 2, 83-92.

Savage, J. M. \& Cei, J. M. (1965). A review of the Leptodactylid frog genus, Odontophrynus. Herpetologica, 21, 178-195.

Savage, J. M. \& Heyer, W. R. (1967). Variation and distribution in the tree-frog genus Phyllomedusa in Costa Rica, Central America. Beiträge für Neotropischen Fauna Band, 5, 111-131.

Sazima, I. \& Caramaschi, U. (1986). Descrição de Physalaemus deimaticus sp. n., e observações sobre comportamiento deimatico em P. nattereri (Steindn.) - Anura, Letodactylidae. Revista de Biologia, 13, 91-101.

Schaeffer, B. H. (1949). Anurans from the early Tertiary of Patagonia. Bulletin of the American Museum of Natural History, 93, 45-68.

Schlüter, A. (1990). Reproduction and Tadpole of Edalorhina perezi (Amphibia, Leptodactylidae). Studies on Neotropical Fauna and Environment, 25, 49-56.

Schmid, M. (1982). Chromosome banding in Amphibia. VII. Analysis of the structure and variability of NORs in Anura. Chromosoma, 87, 327-344.

Schmid, M., Steinlen, C., Feichtinger, W. \& Poot, M. (1993). Chromosome banding in Amphibia. XVIII. Karyotype evolution and genomic size variation in Pleurodema (Anura: Leptodactylidae). Cytogenctics and Cell Genetics, 62, 42-48.

Schmidt, K. P. (1954). Reports of the Lund Universitiy Chile Expedition 1948-1949. 13. Amphibia Salientia. Lunds Universitets Arsskrift, 3-6.

Schneider, J. G. (1799). Historiae Amphibiorum naturalis et literariae. Fasciculus Primus continens Ranas, Calamitas, Bufones, Salamandras et Hydros in genera et species descriptos notisque suis distinctos. Jena: Frederici Frommanni. 
Scott, E. (2005). A phylogeny of ranid frogs (Anura: Ranoidea: Ranidae), based on a simultaneous analysis of morphological and molecular data. Cladistics, 21, 507-574.

Seale, D. B. (1982). Physical factors influencing oviposition by the woodfrog, Rana sylvatica, in Pennsylvannia. Copeia, 1982, 627-635.

Seimon, T. A., Seimon, A., Daszak, P., Halloy, S., Schloegel, L. M., Aguilar, C. A., Sowell, P., Hyatt, A., Konecky, B. \& Simmons, J. E. (2007). Upward range extension of Andean anurans and chytridiomycosis to extreme elevations in response to tropical deglaciation. Global Change Biology, 13, 288-299.

Silva, A. P. Z., Baldissera Júnior, F. A., Haddad, C. F. B. \& Kasahara, S. (2000). Karyotypes and nucleolus organizer regions in four species of the genus Physalaemus (Anura, Leptodactylidae). Iheringia (Zoolgia), 88, 159-164.

Sinsch, U. (1986). Anfibios de la Sierra Central del Perú - Una clave para identificación de adultos y larvas. Bol etín de Lima, 45, 23-33.

Sinsch, U. (1990). Froschlurche (Anura) der zentral-perunischen Andes: Artdiagnose, Taxonomie, Habitat, Verhaltensokologie. Salamandra, 26, 177-214.

Staton, M. A. \& Dixon, J. R. (1977). The Herpetofauna of the Central Llanos of Venezuela: noteworthy records, a tentative checklist and ecological notes. J ournal of Herpetology, 11, 17-24.

Stebbins, G. L. (1950). Variation and evolution in plants. New York: Columbia University Press.

Steindachner, F. (1863). Über einige neue Batrachier aus den Sammlungen des Wiener Museums. Sitzungaberichte O.der Akademie der Wissenschaften, 48, 186-192.

Steindachner, F. (1864). Batrachologische Mitteilungen. Verhandelugen ZoologischBotanischen Gesellschaft in Wien, 14, 239-288.

Steindachner, F. (1867). Amphibien. Reise der Österreichischen Fregatte Novara um die Erde in den Jahren 1857, 1858, 1859 unter den Befehlen des Commodore B.von WüllerstorffUrbair (pp. 1-70). Zoologischer Theil.

Stephenson, E. M. (1961). The anatomy of the head of the New Zealand frog, Leiopelma. Transactions of the Zoological Society of London, 27, 255-305.

Stöck, M., Steinlein, C., Lamatsch, D. K., Schartl, M. \& Schmid, M. (2005). Multiple origins of tetraploid taxa in the Eurasian Bufo viridis subgroup. Genetica, 124, 255-272.

Straneck, R., de Olmedo, E. V. \& Carrizo, G. R. (1993). Catálogo de voces de anfibios argentinos. Parte 1. Buenos Aires: Ediciones L.O.L.A.

Strong, E. E. \& Lipscomb, D. (1999). Character coding and inapplicable data. Cladistics, 15, 363-371.

Stuardo, J. R. (2007). Trascendencia del primer Saggio sulla storia naturale del Chili de J.I. Molina, su traducción, el Compendio Anónimo y el Bicentenario. Atenea (Concepc.), 495, 83-107.

Tarifa, T., Aparicio, J. \& Yensen, E. (2007). Mammals, amphibians, and reptiles of the bolivian high Andes: an initial comparison of diversity patterns in Polylepis woodlands. University of California Publications in Zoology, 134, 241-274. 
Tihen, J. A. (1962). A review of New World fossil bufonids. The American Midland Naturalist, $68,50$.

Toledo, R. C. d. \& Jared, C. (1995). Cutaneous granular glands and amphibian venoms. Comparative Biochemistry and Physiology, Part A, 111, 1-29.

Toledo, R. C. d., Jared, C. \& Brunner, Jr. (1996). The lumbar glands of the frog Pleurodema thaul (Amphibia, Anura, Leptodactylidae): an ultrastructural study. Revista Brasileira de Biologia, 56, 451-457.

Tomatis, C. (2007). Estudios cromosómicos en las especies Argentinas-Uruguayas del género Physalaemus Fitzinger, 1826 (Amphibia, Anura, Leiuperidae). Tesis de Licenciatura, Facultad de Ciencias Exactas Químicas y Naturales, Universidad Nacional de Misiones.

Tomatis, C., Baldo, D., Kolenc, F. \& Borteiro, C. (2009). Chromosomal variation in the species of the Physalaemus henselii group. J ournal of Herpetology, 43, 555-560.

Trewavas, E. (1933). The hyoid and larynx of Anura. Philosophical Transactions of the Royal Society of London (Series B), 222, 401-527.

Trueb, L. (1973). Bones, frogs, and evolution. In J. L. Vial (Ed) Evolutionary biology of the Anurans: contemporary research on major problems (pp. 65-132). Columbia: University of Missouri Press.

Trueb, L. (1993). Patterns of cranial diversity among the Lissamphibia. In J. Hanken \& B. Hall (Eds) The Vertebrate Skull (pp. 255-343). Chicago: University of Chicago Press.

Tschudi, J. J. (1838). Classification der Batrachier, mit Berücksichtigung der fossilen Thiere dieser Abtheilung der Reptilien. Mémoires de la Société des Sciences Naturelles de Neuchâtel, 2, 1-99, 1-6 pl.

Tschudi, J. J. (1845). Reptilium Conspectum quae in Republica Peruana reperiuntur et pleraque observata vel collecta sunt in itinere. Archiv für Naturgeschichte, 11, 150-170.

Úbeda, C. A. (1998) Batracofauna de los bosques templados patagónicos: un enfoque ecobiogeográfico. Tesis de Doctorado, Universidad de Buenos Aires.

Úbeda, C. A. (2001). Geographic distribution. Pleurodema thaul. Herpetological Review, 32, 272.

Vaira, M. (1997). Geographic distribution. Pleurodema tucumana. Herpetological Review, 28, 156.

Vaira, M. (1998). Herpetofauna. Anfibios de la Reserva de la Biósfera Laguna de Pozuelos: Lista comentada y claves para su identificación. In J. Cajal, R. Tecchi \& J. García Fernandez (Eds) Bases para el Manejo de la Puna y Cordillera Frontal. El Rol de las Reservas de Biósfera (pp. 1-7). FUCEMA.

Valetti, J. A., Salas, N. E. \& Martino, A. L. (2009). A new polyploid species of Pleurodema (Anura: Leiuperidae) from Sierra de Comechingones, Córdoba, Argentina and redescription of Pleurodema kriegi (Müller, 1926). Zootaxa, 2073, 1-21.

van der Hammen, T. (1974). The Pleistocene changes of vegetation and climate in tropical South America. J ournal of Biogeography, 1, 3-26.

van der Westhuizen, C. M. (1961). The development of the chondrocranium of Heleophryne purcelli Sclater with with special reference to the palatoquadrate and the sound-conducting apparatus. Acta Zoologica (Stockholm), 42, 1-72. 
Vanzolini, P. E. (1992). Paleoclimas e especiação em animais da América do Sul tropical. Estudos Avançados (São Paulo), 6, 41-65.

Vaz-Ferreira, R. (1984). Etología: el estudio biológico del comportamiento animal. Washington: OEA, Serie Biología, Monografía 29.

Vellard, J. (1960). Estudios sobre batracios andinos. VII. El género Pleurodema en los Andes peruanos. Memorias del Museo de Historia Natural "J avier Prado", 10, 1-14, 5 pls.

Veloso, A. M., Díaz, N. \& Galleguillos, R. (1973a). Revisión cariosistemática de las especies del género Pleurodema en Chile. Anales del Museo de Historia Natural de Valparaíso, 6, 4955.

Veloso, A. M., Galleguillos, R. \& Díaz, N. (1973b). Karyotipic analysis of allopatric populations of Pleurodema thaul (Lesson), Amphibia, Leptodactylidae. Caryologica, 26, 6976.

Vera Candioti, M. F., Brusquetti, F. \& Netto, F. (2007). Morphological characterization of Leptodactylus elenae tadpoles (Anura: Leptodactylidae: L. fuscus group), from central Paraguay. Zootaxa, 1435, 1-17., 1435, 1-17.

Vera Candioti, M. F., Úbeda, C. A. \& Lavilla, E. O. (2005). Morphology and metamorphosis of Eupsophus calcaratus tadpoles (Anura: Leptodactylidae). Journal of Morphology, 264, 167177.

Villa, J., McDiarmid, M. W. \& Gallardo, J. M. (1982). Arthropod predators of leptodactylid frog foam nests. Brenesia, 19/20, 577-589.

Wagler, J. G. (1830). Natürliches System der Amphibien, mit vorangehender Classification der Säugethiere und Vögel. München: Cotta'schen.

Wassersug, R. J. (1976). A procedure for differential staining of cartilage and bone in whole, formalin fixed vertebrates. Stain Technology, 51, 131-134.

Wassersug, R. J. \& Heyer, W. R. (1988). A survey of internal oral features of Leptodactyloid larvae (Amphibia: Anura). Smithsonian Contributions to Zoology, 457, 1-99.

Weigandt, M., Úbeda, C. A. \& Díaz, M. (2004). The larva of Pleurodema bufoninum Bell, 1843 , with comments on its biology and on the egg strings (Anura, Leptodactylidae). Amphibia-Reptilia, 25, 429-437.

Weyenberg, H. (1876). VIII .The Argentine Fauna [III - Amphibia]. In R. Napp (Ed) The Argentine Republic, written in german by Richard Napp assisted by several fellow writers for the Central Argentine Commission of the Centenary Exhibition at Philadelphia (pp. 149152). Buenos Aires: printed by the Sociedad Anónima, calle de Belgrano.

Wheeler, W. C. (1995). Sequence alignment, parameter sensitivity, and the phylogenetic analysis of molecular data. Systematic Biology, 44, 321-331.

White, M. J. D. 1954. Animal Cytology and Evolution. Cambridge University Press, Cambridge.

Wiley, E. O. (1981). Phylogenetics: The Theory and Practice of Phylogenetics Systematics. New York: Wiley Intersci.

Wilkinson, M. (1995). A comparison of two methods of character construction. Cladistics, 11, 297-308.

Zampieri Silva, A. P., Haddad, C. F. B. \& Kasahara, S. (2000). Chromosomal studies on five species of the genus Leptodactylus Fitzinger, 1826 (Amphibia, Anura) using differential 
staining. Cytobios, 103, 38.

Zina, J. (2006). Communal nests in Physalaemus pustulosus (Amphibia: Leptodactylidae): experimental evidence for female oviposition preferences and protection against desiccation. Amphibia-Reptilia, 27, 148-150. 